\title{
EFFECTS OF LOW VELOCITY IMPACT ON THE FLEXURAL STRENGTH OF COMPOSITE SANDWICH STRUCTURES
}

\author{
A Thesis Presented to \\ The Faculty of California Poytechnic State University, \\ San Luis Obispo
}

\author{
In Partial Fulfillment \\ Of the Requirements for the Degree of \\ Masters of Science in Aerospace Engineering
}

By
Jeffrey S. Carter

October 2014 
(c) 2015

Jeffrey S. Carter

ALL RIGHTS RESERVED 
TITLE:

AUTHOR:

DATE SUBMITTED:

COMMITTEE CHAIR:

COMMITTEE MEMBER:

COMMITTEE MEMBER:

COMMITTEE MEMBER:

COMMITTEE MEMBER:
Effects of Low Velocity Impact on the Flexural Strength of Composite Sandwich Structures

Jeffrey S. Carter

February 11, 2015

Faysal Kolkailah, Ph.D, P.E

Professor of Aerospace Engineering

Eltahry Elghandour, Ph.D

Lecturer of Aerospace Engineering

Eric Kasper, Ph.D., P.E.

Professor of Civil Engineering

Kira Abercromby, Ph.D

Assistant Professor of Aerospace Engineering

Kenneth Gamble

Composite Materials Industry Expert 


\begin{abstract}
Effects of Low Velocity Impact on the Flexural Strength of Composite Sandwich Structures

Jeffrey S. Carter
\end{abstract}

The use of composite sandwich structures is rapidly increasing in the aerospace industry because of their increased strength-to-weight and stiffness-to-weight characteristics. The effects of low velocity impacts on these structures, however, are the main weakness that hinders further use of them in the industry because the damages from these loadings can often be catastrophic. Impact behavior of composite materials in general is a crucial consideration for a designer but can be difficult to describe theoretically. Because of this, experimental analysis is typically used to attempt to describe the behavior of composite sandwiches under impact loads. Experimental testing can still be unpredictable, however, because low velocity impacts can cause undetectable damage within the composites that weaken their structural integrity. This is an important issue with composite sandwich structures because interlaminar damage within the composite facesheets is typical with composites but the addition of a core material results in added failure modes. Because the core is typically a weaker material than the surrounding facesheet material, the core is easily damaged by the impact loads. The adhesion between the composite facesheets and the core material can also be a major region of concern for sandwich structures. Delamination of the facesheet from the core is a major issue when these structures are subjected to impact loads.

This study investigated, through experimental and numerical analysis, how varying the core and facesheet material combination affected the flexural strength of a composite sandwich subjected to low velocity impact. Carbon, hemp, aramid, and glass fiber materials as facesheets combined with honeycomb and foam as core materials were considered. Three layers of the same composite material were laid on the top and bottom of the core material to form each sandwich structure. This resulted in eight different sandwich designs. The 
carbon fiber/honeycomb sandwiches were then combined with the aramid fiber facesheets, keeping the same three layer facesheet design, to form two hybrid sandwich designs. This was done to attempt to improve the impact resistance and post-impact strength characteristics of the carbon fiber sandwiches. The two and one layer aramid fiber laminates on these hybrid sandwiches were always laid up on the outside of the structure. The sandwiches were cured using a composite press set to the recommended curing cycle for the composite facesheet material. The hybrid sandwiches were cured twice for the two different facesheet materials. The cured specimens were then cut into 3 inch by 10 inch sandwiches and 2/3 of them were subjected to an impact from a $7.56 \mathrm{lbf}$ crosshead which was dropped from a height of 38.15 inches above the bottom of the specimen using a Dynatup 8250 drop weight machine.

The impacted specimen and the control specimen (1/3 of the specimens not subjected to an impact) were loaded in a four-point bend test per ASTM D7250 to determine the nonimpacted and post-impact flexural strengths of these structures. Each sandwich was tested under two four-point bend loading conditions which resulted in two different extension values at the same $100 \mathrm{lbf}$ loading value. The span between the two supports on the bottom of the sandwich was always 8 inches but the span between the two loading pins on the top of the sandwich changed between the two loading conditions. The $2 / 3$ of the sandwiches that were tested after being impacted were subjected to bending loads in two different ways. Half of the specimens were subjected to four-point bending loads with the impact damage on the top facesheet (compressive surface) in between the loading pins; the other half were subjected to bending loads with the damage on the bottom facesheet (tensile surface).

Theoretical failure mode analysis was done for each sandwich to understand the comparisons between predicted and experimental failures. A numerical investigation was, also, completed using Abaqus to verify the results of the experimental tests. Non-impacted and impacted four-point bending models were constructed and mid-span deflection values were collected for comparison with the experimental testing results. Experimental and numeri- 
cal results showed that carbon fiber sandwiches were the best sandwich design for overall composite sandwich bending strength; however, post-impact strengths could greatly improve. The hybrid sandwich designs improved post-impact behavior but more than three facesheet layers are necessary for significant improvement. Hemp facesheet sandwiches showed the best post-impact bending characteristics of any sandwich despite having the largest impact damage sizes. Glass and aramid fiber facesheet sandwiches resisted impact the best but this resulted in premature delamination failures that limited the potential of these structures. Honeycomb core materials outperformed foam in terms of ultimate bending loads but post-impact strengths were better for foam cores. Decent agreement between numerical and experimental results was found but poor material quality and high error in material properties testing results brought about larger disagreements for some sandwich designs.

Keywords: Aerospace Engineering, Composite Materials, Composite Sandwich Structures, Impact Testing, Four-Point Bend Testing 


\section{ACKNOWLEDGMENTS}

I would like to begin by thanking my thesis advisor, Dr. Faysal Kolkailah, and my lab professor, Dr. Eltahry Elghandour. I would not have been able to complete this study without their continual support and assistance throughout the past couple years. Everything that I have achieved as a graduate student has been because of their guidance and I appreciate everything they have done for me. I would also like to thank Dr. Kira Abercromby for all of her support throughout my time at Cal Poly. She has been a helpful professor and good friend to me throughout my college career. I also appreciate all of the numerical analysis help that Dr. Eric Kasper provided me. I would also like to thank Ken Gamble for all of his donations to our lab and for being apart of my thesis committee.

Thank you to all of the Cal Poly Lacrosse teammates and coaches that I have played with and played for throughout my college career. They have taught me the meaning of hard work and dedication and have given me lifelong friendships that I will cherish forever. I would especially like to thank my teammate and roommate, Nick Czapla, for being such a great friend to me and giving me a partner in crime for everything I ever did in college. I would also like to thank all of the other friends that I have met during my time at $\mathrm{Cal}$ Poly and throughout my life for their endless support and dedication to making me a better person. Along with them, thank you to my structures labmates and fellow Aerospace Engineering friends for all of their help with every aspect of my schooling. I wouldn't have been able to make it through college without them.

Lastly, I would like to give a huge thank you to my family. Thank you to my mom and dad for their endless support and for teaching me everything that I have needed to be successful in this world. Thank you to my older brother, Tim, for always being there to help me in any life situation that I have faced and being the best big brother that I could ask for. And thank you to my little brother, Greg, for being a great friend growing up and being the best little brother I could ask for. I wouldn't be here if it wasn't for you guys. 


\section{TABLE OF CONTENTS}

LIST OF TABLES X xiii

LIST OF FIGURES $\quad$ XV

LIST OF EQUATIONS $\quad$ xx

NOMENCLATURE $\quad$ xxi

1 INTRODUCTION 1

1.1 Overview of Composites . . . . . . . . . . . . . 1

1.1.1 Introduction to Composites . . . . . . . . . . . . . . 1

1.1.2 Types of Composites . . . . . . . . . . . . 3

1.1.2.1 Bio-Composites ............. 6

1.1.3 Advantages and Disadvantages of Composites . . . . . . . . 7

1.1.4 Manufacturing Techniques ............... 8

1.1.4.1 "Wet" Layup Techniques . . . . . . . . . . . . . . . . 9

1.1.4.2 Open Molding . . . . . . . . . . . . . . . 10

1.1.4.3 Resin Infusion Processes . . . . . . . . . . . 11

1.1.4.4 High-Volume Molding Methods . . . . . . . . . . . . 13

1.1.5 Composite Structures . . . . . . . . . . . . . . . 15

1.2 Overview of Composite Sandwich Structures _ . . . . . . . . . . 15

1.2.1 Sandwich Composite Facesheets . . . . . . . . . . . . . . 16

1.2.2 Sandwich Composite Cores . . . . . . . . . . . . . . 16

1.2.3 Advantages and Disadvantages of Composite Sandwiches _ . . . . 17 
1.2.3.1 Core Advantage on Structure's Flexural Characteristics 18

1.2.4 Impact Behavior of Composite Sandwiches . . . . . . . . . . . 19

1.2.5 Applications of Composite Sandwiches _ . . . . . . . . . 20

1.3 Previous Research on Impact and Flexural Behavior of Composite Sandwich Structures $\ldots \ldots \ldots \ldots \ldots \ldots$

1.4 Main Objective and Scope of Study _ . . . . . . . . . . . . . . . . 24

2 SPECIMENS MANUFACTURING AND TESTING PROCEDURES 26

2.1 Composite Sandwich Structure Design and Materials Used . . . . . . . 26

2.1 .1 Facesheets . . . . . . . . . . . . . . . 27

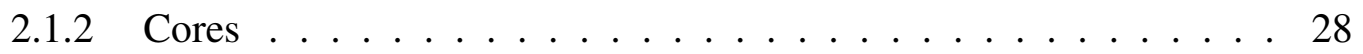

2.1 .3 Adhesives . . . . . . . . . . . . . . . . . . . . . 29

2.1.3.1 Adhesive Comparison . . . . . . . . . . . . 30

2.2 Specimens Manufacturing $\ldots \ldots \ldots \ldots \ldots \ldots$

2.2 .1 Layup Methods . . . . . . . . . . . . . . . . . . . . 32

2.2.1.1 Non-automated Tape Layup for Prepreg Facesheet Materials ................ . 32

2.2.1.2 "Wet" Layup . . . . . . . . . . . . . . . . . . . . . 34

2.2.2 Curing and Test Setup Process _ . . . . . . . . . . . . 35

2.2.2.1 Manufacturing and Testing of Hybrid Carbon and Aramid Fiber Facesheet Sandwiches with Honeycomb Cores . . . 38

2.2.2.2 Preparing Specimens for Mechanical Properties Testing . 40

2.3 Mechanical Properties Testing of Facesheet and Core Materials . . . . . . 40

2.3.1 Preparing Facesheet Specimens for Material Properties Testing . . . 40

2.3.2 Compressive Testing Procedure (ASTM D3410) . . . . . . . . 42

2.3.3 Tensile Testing Procedure (ASTM D3039) _ . . . . . . . . . 43

2.3.4 Strain Gage Setup for Poisson's Ratio Test Specimens . . . . . . 44

2.3.5 Poisson's Ratio Testing Procedure (ASTM E132) . . . . . . . . 45 
2.3.6 Poisson's Ratio Testing of Honeycomb Core (ASTM D6790) . . . . 47

2.3.6.1 Tensile Testing of Honeycomb Core . . . . . . . . . 49

2.3.7 Fiber Volume Fraction Calculations for Facesheet Materials _ . . . 50

2.4 Composite Sandwich Experimental Impact and Four-Point Bend Testing . 51

2.4.1 Mechanical and LabView Rework on Dynatup 8250 Impact Machine 52

2.4.2 Impact Machine and Testing Procedure . . . . . . . . . . . . 54

2.4.3 Four-Point Bend Testing Procedure (ASTM D7250) . . . . . . . . 56

3 EXPERIMENTAL TESTING RESULTS AND DISCUSSION 59

3.1 Facesheet and Core Material Properties Testing . . . . . . . . . . . . 59

3.1.1 Compressive Properties of Facesheet Materials from Testing . . . . 60

3.1.2 Tensile Properties of Facesheet Materials from Testing . . . . . . . 62

3.1.3 Poisson's Ratio Values from Testing of Facesheet Materials . . . . 64

3.1.4 Honeycomb Poisson's Ratio Testing Method and Core Material

Datasheet Properties ................. 65

3.1.5 Calculation of Shear Moduli of Facesheet Materials . . . . . . . . . 68

3.1.6 Comparison of Experimental and Datasheet Material Properties . . 69

3.1.7 Summary of Constituent Material Properties Testing . . . . . . . . 70

3.1.8 Fiber Volume Fractions for Facesheet Materials . . . . . . . . . . . 70

3.2 Impact Testing Results and Discussion . . . . . . . . . . . . . . 72

3.2.1 Carbon Fiber Facesheet Sandwiches . . . . . . . . . . . . . . 74

3.2.2 Hemp Fiber Facesheet Sandwiches . . . . . . . . . . . . . 75

3.2.3 Aramid Fiber (Twaron) Facesheet Sandwiches . . . . . . . . . 75

3.2.4 Glass Fiber (Texalium) Facesheet Sandwiches . . . . . . . . . . . . 77

3.2.5 Hybrid Carbon and Aramid Fiber Facesheet Sandwiches . . . . . . 78

3.2.6 Summary and Comparison of Impact Test Results . . . . . . . . . . 79

3.3 Four-Point Bend Testing Results and Discussion . . . . . . . . . . . . . 80

3.3.1 Toe Correction of Experimental Data . . . . . . . . . . . . 80 
3.3.2 Experimental Results Calculations . . . . . . . . . . . . . 81

3.3.3 Carbon Fiber Facesheet Sandwiches . . . . . . . . . . . . . . . 84

3.3.4 Hemp Fiber Facesheet Sandwiches _. . . . . . . . . . . . 85

3.3.5 Aramid Fiber (Twaron) Facesheet Sandwiches _ . . . . . . . . 89

3.3.6 Glass Fiber (Texalium) Facesheet Sandwiches . . . . . . . . . . . . 92

3.3.7 Hybrid Carbon and Aramid Fiber Facesheet Sandwiches . . . . . 94

3.3.8 Summary and Comparison of Four-Point Bending Test Results . . . 98

3.4 Experimental Failure Mode Analysis . . . . . . . . . . . . . . . . . 99

3.4.1 Carbon Fiber Facesheet Sandwiches . . . . . . . . . . . . . 100

3.4.2 Hemp Fiber Facesheet Sandwiches ． . . . . . . . . . . 101

3.4.3 Aramid Fiber (Twaron) Facesheet Sandwiches . . . . . . . . 102

3.4.4 Glass Fiber (Texalium) Facesheet Sandwiches . . . . . . . . . . 104

3.4.5 Hybrid Carbon and Aramid Fiber Facesheet Sandwiches . . . . 105

3.4.6 Summary and Comparison of Experimental Failure Modes . . . . 106

3.5 Summary and Comparison of Experimental Test Results _ . . . . . . 110

4 COMPARISON OF EXPERIMENTAL RESULTS TO THEORETICAL AND NUMERICAL ANALYSIS 115

4.1 Theoretical Failure Mode Analysis . . . . . . . . . . . . . . . . 115

4.1 .1 Methodology . . . . . . . . . . . . . . . . 116

4.1.2 Failure Mode Comparison for Carbon Fiber Facesheet Sandwiches . 118

4.1.3 Failure Mode Comparison for Hemp Fiber Facesheet Sandwiches . 120

4.1.4 Failure Mode Comparison for Aramid Fiber (Twaron) Facesheet Sandwiches . . . . . . . . . . . . . . . . 121

4.1.5 Failure Mode Comparison for Glass Fiber (Texalium) Facesheet Sandwiches . . . . . . . . . . . . . . . . 122

4.2 Numerical Four-Point Bending Model . . . . . . . . . . . . . . . 124

4.2.1 Geometric Definitions and Partitions . . . . . . . . . . . . 124 
4.2.2 Material Creation and Section Assignments . . . . . . . . . . . 126

4.2.3 Assembly and Steps . . . . . . . . . . . . . . . . 127

4.2.4 Constraints, Boundary Conditions, and Loads . . . . . . . . . . . . 128

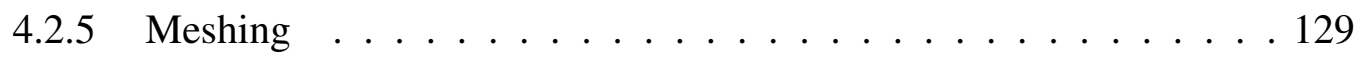

4.3 Additions to Four-Point Bend Numerical Model to Implement Impact Load-

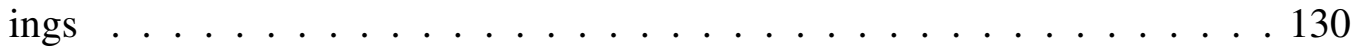

4.3.1 Impact Tup Part Creation, Assembly, and Steps . . . . . . . . . 130

4.3.2 Interactions, Loads, Boundary Conditions, and Predefined Fields . . 131

4.4 Comparison of Experimental and Numerical Mid-Span Deflection Results . 133

5 DISCUSSION OF RESULTS

6 CONCLUSION

6.1 Future Considerations . . . . . . . . . . . . . . . . . . . 142

BIBLIOGRAPHY

APPENDIX

A.1 Impact Testing Figures $\ldots \ldots \ldots$. . . . . . . . . . . . . . . . . . . . . . .

A.2 Four-Point Bending . . . . . . . . . . . . . . . . . 148

A.3 Hybrid Sandwich Experimental Results Plots . . . . . . . . . . . . . . . 149

A.4 Failure Mode Plots using Experimental Honeycomb Material Properties . 151

A.5 Numerical Model Mesh Convergence Plot . . . . . . . . . . . . . 153 


\section{LIST OF TABLES}

3.1 Comparison of facesheet material compressive moduli and strengths . . . . . . 61

3.2 Comparison of facesheet material tensile moduli and strengths . . . . . . . 63

3.3 Comparison of core material properties . . . . . . . . . . . . 66

3.4 Honeycomb experimental material properties found from tensile test on hon-

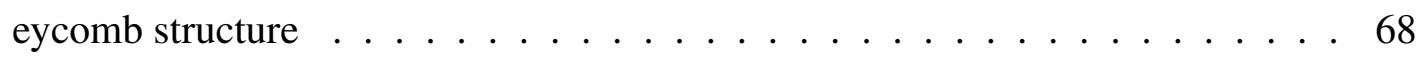

3.5 Comparison of facesheet material shear moduli . . . . . . . . . . . . . . 69

3.6 Comparison of experimental and datasheet carbon fiber material properties . . . 70

3.7 Comparison of fiber volume percentages from ignition loss calculations to theoretical values for facesheet materials . . . . . . . . . . . . . 72

3.8 Impact testing results for composite sandwiches with carbon fiber facesheets . . 74

3.9 Impact testing results for composite sandwiches with hemp fiber facesheets . . 76

3.10 Impact testing results for composite sandwiches with aramid fiber facesheets . . 77

3.11 Impact testing results for composite sandwiches with glass fiber facesheets . . . 78

3.12 Impact testing results for composite sandwiches with hybrid carbon and aramid fiber facesheets . . . . . . . . . . . . . . . . . . 79

3.13 Four-point bend test results for carbon fiber facesheet sandwiches . . . . . . 86

3.14 Four-point bend test results for hemp fiber facesheet sandwiches . . . . . . . 88

3.15 Useful four-point bend test results for aramid fiber facesheet sandwiches . . . . 91

3.16 Useful four-point bend test results for glass fiber facesheet sandwiches . . . . 9 93

3.17 Four-point bend test results for carbon and aramid fiber hybrid facesheet sand-

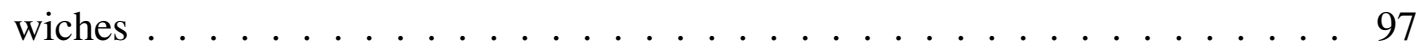


3.18 Failure Modes (FF: Face Fracture), (FFI: Face Fracture at Impact Damage), (CS: Core Shear), (D: Delamination), (CC: Core Compression), (DIL: Interlaminar Delamination), (DI: Delamination from Impact) $\ldots \ldots \ldots \ldots$

4.1 Experimental and numerical comparison of mid-span deflections for carbon fiber facesheet sandwiches $\ldots \ldots \ldots \ldots \ldots$

4.2 Experimental and numerical comparison of mid-span deflections for hemp fiber facesheet sandwiches . . . . . . . . . . . . . . . . . . . . 134

4.3 Experimental and numerical comparison of mid-span deflections for aramid fiber facesheet sandwiches . . . . . . . . . . . . . . . 135

4.4 Experimental and numerical comparison of mid-span deflections for glass fiber facesheet sandwiches . . . . . . . . . . . . . . . . 135

4.5 Experimental and numerical comparison of mid-span deflections for carbon and aramid fiber hybrid facesheet sandwiches $\ldots \ldots \ldots \ldots$ 


\section{LIST OF FIGURES}

1.1 Unidirectional fiber-reinforced polymer composite . . . . . . . . . . . . 4

1.2 Composite sandwich structure (with honeycomb core) [12] . . . . . . . . . 16

1.3 Increase in bending stiffness and strength with an increase in honeycomb core height $[16] \ldots \ldots \ldots \ldots \ldots \ldots \ldots$

2.1 Honeycomb (left) and foam (right) core materials used in this study (shown in

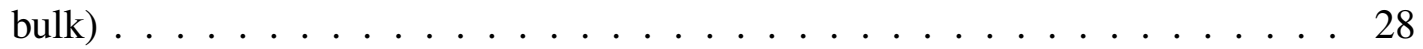

2.2 Comparison of bending strength and stiffness of carbon fiber/honeycomb composite sandwiches manufactured with the two different adhesive materials . . . 30

2.3 Overview of groups of manufactured specimens . . . . . . . . . . 31

2.4 Rolls of bulk composite sandwich facesheet and adhesive materials . . . . . . . 33

2.5 Preassembly three ply carbon fiber laminates (top left), 3M adhesive (bottom), and 12 inch by 12 inch foam cores (top right) $\ldots \ldots 33$

2.6 Roll of dry hemp fabric in bulk . . . . . . . . . . . . . . . . . . 34

2.7 Aeropoxy resin and hardener (top), hemp dry sheet with epoxy spreader (left), honeycomb core $($ right $) \ldots \ldots \ldots \ldots$. . . . . . . . . . . . . . . . . .

2.8 Uncured glass fiber composite sandwich plates with protective films on the

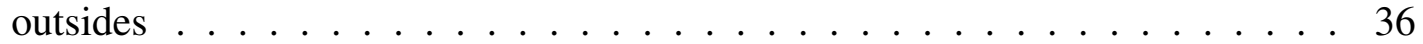

2.9 Cal Poly Aerospace structures lab heat press . . . . . . . . . . . . . . 36

2.10 Cure cycles of every composite sandwich facesheet material . . . . . . . . 37

2.11 Post-cure composite sandwiches . . . . . . . . . . . . . . 38

2.12 Instron 8801 tensile/compression test fixtures with clamped test specimen . . . 41 
2.13 Compressive properties test strip with bonded aluminum tabs . . . . . . . . . 41

2.14 Compressive test specimens with dimensions . . . . . . . . . . . . . 42

2.15 Tensile test specimens with dimensions . . . . . . . . . . . . 43

2.16 Poisson's ratio test specimens with strain gages and wiring attached . . . . . . 44

2.17 Strain indicator used with a quarter bridge circuit to collect strain data . . . . 45

2.18 LabView code used to collect transverse strain gage data . . . . . . . . . . 46

2.19 Example of anticlastic curvature with a honeycomb core . . . . . . . . . . . 47

2.20 Visual of how to calculate Poisson's ratio of honeycomb using anticlastic cur-

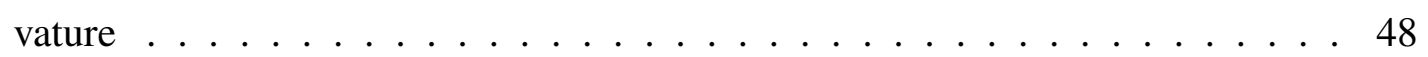

2.21 Honeycomb core tensile test . . . . . . . . . . . . . . . 49

2.22 Furnace used to burn the epoxy out of fiber volume percentage specimens . . . 50

2.23 Red laser used to calculate veloctiy of impacts . . . . . . . . . . . 52

2.24 Signal conditioner with wires connecting to laser (left), accelerometer (middle), and load cell (right) modules . . . . . . . . . . . . . . 53

2.25 Dynatup 8250 impact machine LabView code created for data collection . . . . 53

2.26 Dynatup 8250 impact machine . . . . . . . . . . . . . . . . . 54

2.27 Cylindrical silver load cell with black impact tup below it and small accelerom-

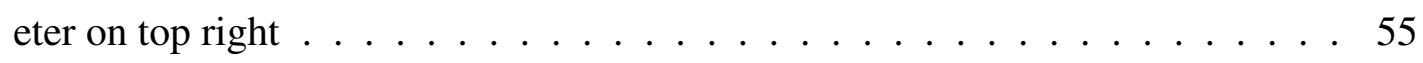

2.28 Metal sheet crossing the path of the red laser and disrupting Si detector data

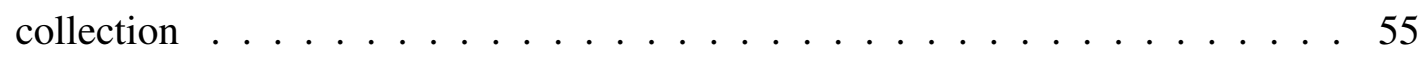

2.29 Accelerometer (bottom left), Si detector (bottom right), and load cell (top) raw

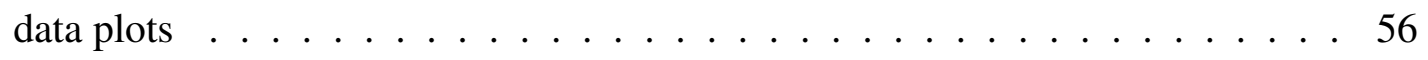

2.30 Matlab GUI prompt window for plotting LabView data . . . . . . . . . . . 56

2.31 Quarter-point (top) and standard (bottom) four-point bend configurations for

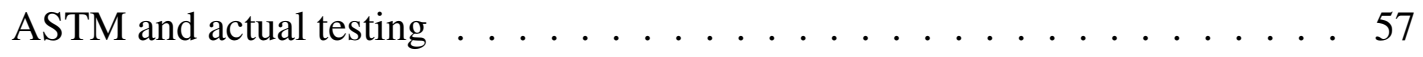

2.32 Carbon fiber/honeycomb composite sandwich under a standard four-point bend

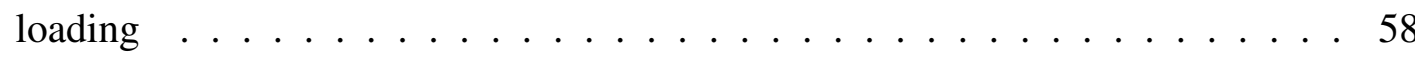


3.1 Raw data plots from compressive material properties testing . . . . . . . . 60

3.2 Compressive mechanical properties testing failure modes of facesheet materials 62

3.3 Raw data plots from tensile material properties testing . . . . . . . . . . 62

3.4 Tensile mechanical properties testing failure modes of facesheet materials . . . 64

3.5 Longitudinal and transverse strain versus load plots for facesheet Poisson's ratio calculations . . . . . . . . . . . . . . . 65

3.6 Example of impact testing results outputted on the Matlab GUI window . . . . 72

3.7 Comparison of foam and honeycomb core impact damages in carbon fiber facesheet sandwiches . . . . . . . . . . . . . . . . . . 74

3.8 Comparison of foam and honeycomb core impact damages in hemp fiber facesheet

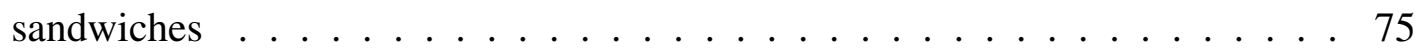

3.9 Comparison of foam and honeycomb core impact damages in aramid fiber facesheet sandwiches . . . . . . . . . . . . . 76

3.10 Comparison of foam and honeycomb core impact damages in glass fiber facesheet

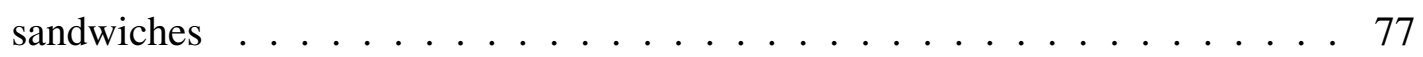

3.11 Example of load vs. extension plot being toe corrected . . . . . . . . . . 80

3.12 Raw data plots for carbon fiber sandwich structures under four-point bend load-

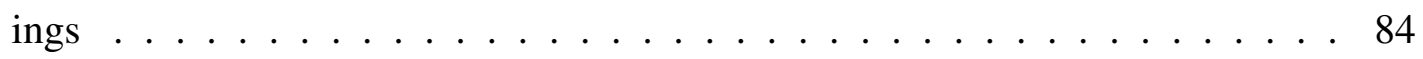

3.13 Raw data plots for hemp fiber sandwich structures under four-point bend loadings 87

3.14 Raw data plots for aramid fiber sandwich structures under four-point bend load-

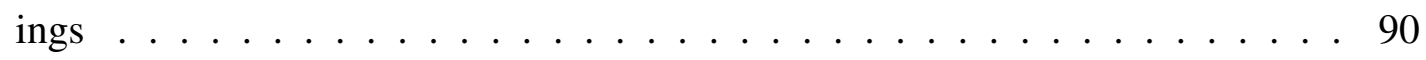

3.15 Raw data plots for glass fiber sandwich structures under four-point bend loadings 92

3.16 Raw data plots for hybrid carbon and aramid fiber sandwich structures under four-point bend loadings . . . . . . . . . . . . . . . . 95

3.17 Core shear failure of carbon fiber/foam sandwich . . . . . . . . . . 100

3.18 Face fracture at impact damage of carbon fiber facesheet sandwich . . . . . . 101

3.19 Hemp fiber composite sandwich failures . . . . . . . . . . . . . . 102 
3.20 Aramid fiber composite sandwich failures . . . . . . . . . . . . . 103

3.21 Glass fiber composite sandwich failures . . . . . . . . . . . . . . 104

3.22 Hybrid carbon and aramid fiber composite sandwich failures $\ldots . . . . .105$

3.23 All carbon fiber facesheet sandwich design failure modes . . . . . . . . . 108

3.24 All hemp fiber facesheet sandwich design failure modes . . . . . . . . . 108

3.25 All aramid fiber facesheet sandwich design failure modes . . . . . . . . . 109

3.26 All glass fiber facesheet sandwich design failure modes . . . . . . . . . . . 109

3.27 All hybrid carbon and aramid fiber facesheet sandwich design failure modes . . 109

3.28 Impact force versus maximum bending load for all composite sandwich structures 110

3.29 Plots of impact damage depth sizes versus bending test results for all composite

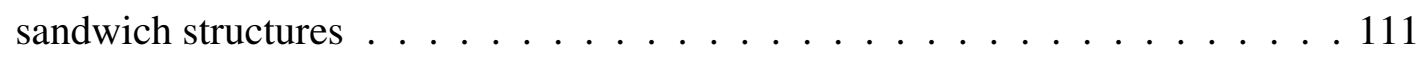

3.30 Plots of the reduction in maxium bending load after impact versus other bending test results for all sandwich structures $\ldots \ldots \ldots \ldots \ldots$

4.1 Theoretical failure mode analysis plots for carbon fiber facesheet sandwiches . 119

4.2 Theoretical failure mode analysis plots for hemp fiber facesheet sandwiches . . 121

4.3 Theoretical failure mode analysis plots for aramid fiber facesheet sandwiches . 122

4.4 Theoretical failure mode analysis plots for glass fiber facesheet sandwiches . . 123

4.5 Top facesheet, core, and bottom facesheet numerical model part with red par-

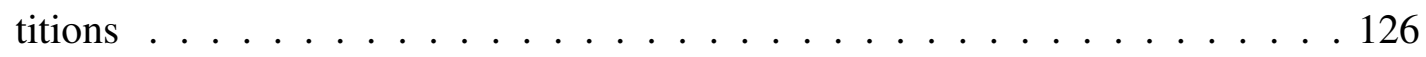

4.6 Fully assembled numerical composite sandwich model . . . . . . . . . . . 127

4.7 Constraints, boundary conditions, and bending load on composite sandwich . 129

4.8 Top facesheet, core, and bottom facesheet meshes . . . . . . . . . . . 130

4.9 Fully assembled numerical composite sandwich model with impact tup . . . . 131

A.1 Signal conditioner wiring for laser module (left), accelerometer module (center), and load cell module (right) $\ldots \ldots \ldots \ldots \ldots$. . . . . . . . 147 
A.2 Impact machine setup with signal conditioning box (bottom), power and control box (left), and testing area (center) . . . . . . . . . . . . . 148

A.3 Four-point bending test setup with control panel (left), computer control (center), and testing machine and fixtures (right) . . . . . . . . . . . . . 148

A.4 Stack of composite sandwich test specimens before testing . . . . . . . . . . 149

A.5 Hybrid carbon and aramid fiber sandwich impact damage size vs. flexural strength-to-weight . . . . . . . . . . . . . . . . . . . . . . . 149

A.6 Hybrid carbon and aramid fiber sandwich post impact flexural strength reduction percentage vs. flexural strength-to-weight . . . . . . . . . . . . 150

A.7 Hybrid carbon and aramid fiber sandwich impact damage size vs. post impact flexural strength reduction percentage . . . . . . . . . . . . . . 150

A.8 Carbon fiber/honeycomb sandwich failure mode plots with datasheet and experimental honeycomb material properties . . . . . . . . . . . . . 151

A.9 Hemp fiber/honeycomb sandwich failure mode plots with datasheet and experimental honeycomb material properties . . . . . . . . . . . . . 151

A.10 Aramid fiber/honeycomb sandwich failure mode plots with datasheet and experimental honeycomb material properties . . . . . . . . . . . . 152

A.11 Glass fiber/honeycomb sandwich failure mode plots with datasheet and experimental honeycomb material properties . . . . . . . . . . . . . 152

A.12 Mesh convergence plot . . . . . . . . . . . . . . . 153

A.13 Numerical results for deflection in the z-axis . . . . . . . . . . . . 153 


\section{LIST OF EQUATIONS}

2.1 Experimental Poisson's Ratio of composite facesheet materials . . . . . . . . . 47

2.2 Radius of anticlastic curvature of honeycomb core . . . . . . . . . . . 48

2.3 Poisson's ratio of honeycomb core . . . . . . . . . . . . . . 48

2.4 Percentage matrix mass loss from burning of facesheet materials . . . . . . . 51

3.1 Cross sectional area of honeycomb material used for experimental elastic mod-

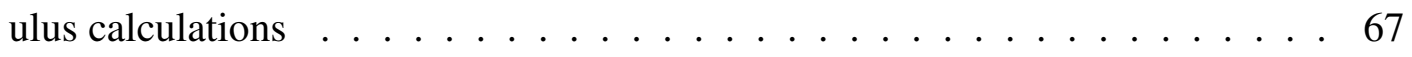

3.2 Shear modulus relationship with Young's modulus and Poisson's . . . . . . . . 68

3.3 Kinetic impact energy equation ..................... 73

3.4 Experimental flexural stiffness (ASTM D7250) . . . . . . . . . . . 82

3.5 Experimental transverse shear rigidity (ASTM D7250) . . . . . . . . . 82

3.6 Experimental mid-span deflection $($ ASTM D7250) . . . . . . . . . . 82

3.7 Experimental core shear modulus (ASTM D7250) . . . . . . . . . . . 82

3.8 Experimental ultimate facesheet stress (ASTM D7249) . . . . . . . . . . 83

3.9 Experimental ultimate core shear stress (ASTM D7249) . . . . . . . . . 83

3.10 Experimental facesheet bending stress (ASTM D7249) . . . . . . . . . 83

4.1 Face and core shear failure transition equation . . . . . . . . . . 116

4.2 Face and core compressive failure transition equation . . . . . . . . 116

4.3 Core shear and core compressive failure transition equation $\ldots \ldots$. . . . 116 


\section{NOMENCLATURE}

$$
\begin{aligned}
& \varepsilon=\text { strain from strain gage }[\text { in } / \text { in }] \\
& v \quad=\text { Poisson's ratio } \\
& \Delta \quad=\quad \text { extension of four-point bend loading machine at load } P[\mathrm{in}] \\
& \delta \quad=\quad \text { mid-span deflection }[i n] \\
& \sigma \quad=\operatorname{stress}[p s i] \\
& A_{h c} \quad=\text { cross sectional area of honeycomb core }\left[i n^{2}\right] \\
& A F \quad=\text { aramid fiber facesheet } \\
& b \quad=\quad \text { sandwich width }[i n] \\
& c=\text { distance between anticlastic curved honeycomb raised edges for Poisson's ratio tests [in] } \\
& C F \quad=\text { carbon fiber facesheet } \\
& d \quad=\text { honeycomb anticlastic curvature height for Poisson's ratio tests [in] } \\
& D \quad=\quad \text { flexural stiffnes }\left[l b f-i n^{2}\right] \\
& E \quad=\text { elastic modulus }[p s i] \\
& F \quad=\text { foam core } \\
& F^{\text {ult }} \quad=\text { ultimate stress } \\
& G \quad=\text { shear modulus }[p s i] \\
& G F \quad=\text { glass fiber facesheet } \\
& H=\text { honeycomb core } \\
& H F \quad=\text { hemp fiber facesheet } \\
& K E \quad=\text { kinetic energy }\left[l b m-f t^{2} / \sec ^{2}\right] \\
& L=\text { four-point bending loading span length [in] } \\
& L^{*} \quad=\text { dimensional ratio of length and thickness for theoretical failure mode analysis } \\
& m=\operatorname{mass}[\mathrm{lbm}] \\
& N=\text { number of honeycomb cells in the transverse direction of tensile test specimen } \\
& P \quad=\text { four-point bending load }[l b f] \\
& R_{a} \quad=\text { radius of anticlastic curvature of honeycomb for honeycomb Poisson's ratio tests [in] }
\end{aligned}
$$




$$
\begin{array}{ll}
R_{c} & =\text { radius of cylinder that honeycomb was bent around for honeycomb Poisson's ratio tests }[\mathrm{in}] \\
S & =\text { four-point bending support span length }[\mathrm{in}] \\
s^{*} & =\text { core strength ratio for theoretical failure mode analysis } \\
S_{1} & =\text { four-point bend loading configuration dimensional values for } 1^{s t} \text { loading condition [in] } \\
S_{2} & =\text { four-point bend loading configuration dimensional values for } 2^{\text {nd }} \text { loading condition }[\mathrm{in}] \\
t & =\text { thickness }[\mathrm{in}] \\
U & =\text { transverse shear rigidity }[\mathrm{lbf}] \\
V & =\text { velocity }[\mathrm{ft} / \mathrm{sec}] \\
W_{1} & =\text { mass of fiber volume specimen before burning }[\mathrm{lbm}] \\
W_{2} & =\text { mass of dry fibers after burning for fiber volume measurements }[\mathrm{lbm}] \\
X & =\text { strength }[\mathrm{psi}]
\end{array}
$$

\section{Subscripts \& Superscripts}

$$
\begin{array}{ll}
* & =\text { non-dimensionalized ratio } \\
12 & =\text { longitudinal } \\
\text { bend } & =\text { relating to four-point bend loading } \\
c & =\text { core } \\
\text { cell } & =\text { cell of honeycomb core structure } \\
f & =\text { facesheet } \\
l & =\text { longitudinal } \\
\text { max } & =\text { maximum } \\
s & =\text { shear } \\
\text { sand } & =\text { sandwich as a whole } \\
t & =\text { transverse } \\
\text { ult } & =\text { ultimate }
\end{array}
$$




\section{Chapter 1 \\ INTRODUCTION}

The following sections will delve into discussions on composite materials, composite sandwich structures, and impact effects on composite structures to familiarize the reader on the subjects that will be covered throughout this study. Composite variations, manufacturing techniques and characteristics will be defined in the initial sections. Descriptions of the design and characteristics of composite sandwich structures will be discussed as well as reasons why impact on composite sandwiches must be investigated. Lastly, previous works and the reason for this study will be described at the end of the chapter.

\subsection{Overview of Composites}

Composite materials are rapidly becoming a norm in numerous fields of engineering due to the increase in demand for lighter materials with increased performance characteristics. These materials have high strength-to-weight characteristics, are able to be formed to any part as one continuous material, and can be manufactured to fit the structural needs of any design.

\subsubsection{Introduction to Composites}

Composite materials have been around for many centuries in many different forms. The earliest uses of composite materials were with the Egyptians who combined mud and straw to form bricks that were used to build buildings throughout their cities. The walls of the 
temples inside of the Egyptian pyramids were usually built using these mud bricks. After years of building with these mud bricks, they found that adding plywood to these mud bricks would form a material with higher strength and thermal characteristics. Egyptians also made containers from coarse fibers that were drawn from heat-softened glass.[1] The next advancement in composite materials was with the Mongols who built bows for archery out of wood, bone, and animal glue. In medieval times, different types of metals were combined to improve the strength of their armor and weapons.[2] The most recent example of composite materials is concrete, which is just a combination of aggregate, cement, sand and water.

These examples of composite materials may not seem like the typical composite materials used in engineering industries today but the definition of a composite may clear that up. A composite material is defined as two or more materials combined to form a new material. The individual materials that are combined to form the composite material are called constituents. Typically, the composite material brings together the best structural characteristics of its constituents to form a material that has properties unachievable by any individual constituent material. The new composite material shows improved properties in strength, stiffness, corrosion resistance, formability, weight, fatigue life, and thermal characteristics. Materials can't gain advantages in all of these structural characteristics, however. Composite materials are built to meet specifications for certain structures and it is up to the designer of that structure to find the most optimal combination of constituents to produce a material that has the necessary mechanical and thermal properties. In some cases, composites can develop structural properties that neither constituent has which adds another dimension of design considerations.

The constituent materials that make up a composite are described as being either reinforcements or matrices of that composite. Both components must be present to classify the material as a composite. The matrix is introduced as a support for the reinforcements. Matrices surround and protect the reinforcements as well as contain them in their relative 
positions.[3] Typical matrices have high shear strength characteristics, are low density, and can be fabricated easily. They are mainly made of thermoplastics, such as polycarbonates or polyester, or of thermoset polymers like epoxy or polyurethane. Composites can be classified as metal, ceramic, or polymer matrix composites. The most popular of these is the polymer matrix composite (PMC), which contains reinforcements of boron, glass, carbon, and metals.[4] These reinforcements are typically in a fibrous form and are brittle compared to the ductile matrix materials. These fibers are the structural backbone of the composite material and are the main line of defense against any tensile loads. They also define the stiffness of the composite material and have low densities like the matrix that surrounds them, creating an overall material that has great strength-to-weight and stiffnessto-weight characteristics. This property is extremely important in the aerospace industry where a pound of weight saved on an aircraft can result in major reductions in fuel usage and with composite materials, there can be no penalty to structural integrity.

\subsubsection{Types of Composites}

The majority of modern composites are classified as either thermosetting or thermoplastic materials. These designations describe the matrix material used for that composite. A thermoset matrix is a plastic that contains polymers which form cross-links when heat is applied to the material to cure it.[5] This curing cycle forms an irreversible chemical bond within the plastic that results in a rigid structure. The irreversibility of this material means that it cannot be cured again and will never be able to be remolded or reshaped. Because the material cannot be cured a second time and is highly rigid, it provides high chemical resistance, heat resistance, and structural integrity material properties.[5] This matrix is typically more cost-effective as well. The thermoplastic material, on the other hand, soft-

ens when heated and becomes more fluid when additional heat is applied.[5] This allows it to be injected into molds and manipulated in any way necessary to create a composite material. Cooling the material hardens it into the shape of the mold with no chemical 
cross-links being formed.[6] Because of this, the material is reversible which means that it can be reprocessed whenever necessary by adding heat to it. Thermoplastics have high recyclability and reshaping capabilities, as well has high impact and chemical resistance characteristics. They can be formed to have hard crystalline structures or ductile surfaces depending on the type of resin used.[5] This matrix, however, is typically more expensive than thermosets and is not beneficial in composite materials that need to have high heat resistance characteristics.

The reinforcements that provide the strength for these composites combine with the matrices to create three main composite categories: fibrous, particulate, and laminate with a fourth category being a combination of the three of these.[2] All of these fall into the definition of a composite with a matrix and reinforcements. The difference between the three is the type of reinforcements and the way that the constituents are combined.

Fibrous composites are, pretty obviously, composite materials with fiber reinforcements embedded into the matrix as shown in Figure 1.1. These fibers are defined as having very small cross sections and are high strength and stiffness. The geometry of the fibers is important for the strength of the composite. Fibers have higher strength than that same material in a larger form because the alignment of the molecules along the axial direction of the fibers give much better tensile strength and smaller forms of the material minimize the defects.[2] The matrix of these composites transfers the stresses along the fibers evenly allowing for the fibers to perform optimally. The fibers carrying these loads can be made of glass, carbon, graphite, aramid, ceramic, and boron materials. E-glass ("electrical") fibers account for $90 \%$ of the glass fibers used in industry because of their high ten-

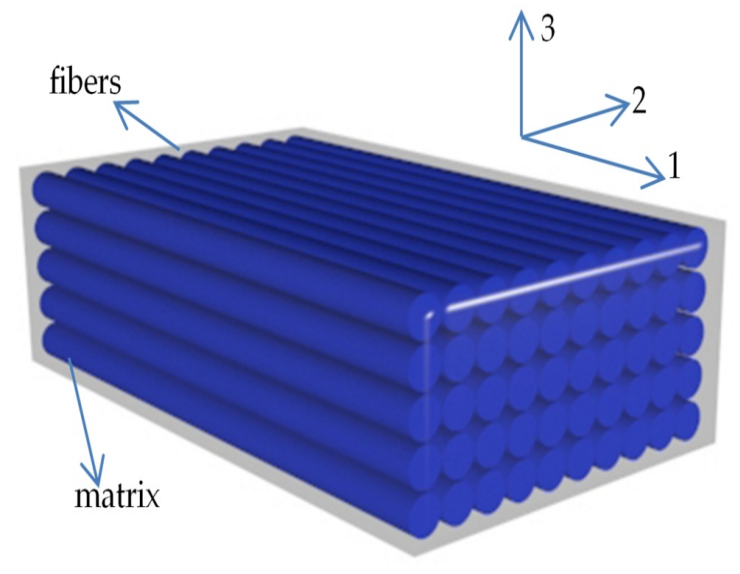

Figure 1.1: Unidirectional fiber-reinforced polymer composite 
sile strength and modulus as well as relatively low costs. S-glass fibers are 10-15\% stronger than E-glass and have improved heat resistance but they are more expensive.[7] Carbon and graphite fibers have high strength and modulus but can be expensive. For example, graphite reinforced epoxy matrix composites can be up to five times stronger than steel on a weightfor-weight basis.[2] Aramid fibers have poor fiber elongation properties but are used a lot under impact loads. Boron fibers have very high strengths and moduli but are extremely expensive so their use in industry applications is minimal.[7] Lastly, ceramic fibers are great for high temperature uses but don't have strengths comparable to the other fiber options. Depending on the type of fibrous composite, it could contain long or short fibers. Longer fibers are stronger but shorter fibers are much easier and less costly to manufacture making them useful in situations where high strength and stiffness aren't crucial.

Particulate composites are similar to short fiber composites but much more extreme. They are made of particles scattered throughout a matrix. The particles have short dimensions in every axis and can be made of a number of different metallic and non-metallic materials. A good example of particulate composites is the one mentioned earlier, concrete. The rocks in concrete are particles within a matrix. These particles create a stiffer material that performs better than fibrous composites in general with structures that witness higher temperature loadings. Use in electrical wiring is a common place for these types of composites because of the ability to use conductive particles and the ease and low cost of manufacturing.[8] The strength of the particles, like the fibers, defines the strength of the overall composite.

Laminate composites are a combination of multiple layers of fibrous or particulate layers. Each layer can be the same or a different composite material but typically materials of the same fibers and matrix will be combined at different fiber orientations to create an overall "laminate" with characteristics that optimize the overall characteristics of the structure. This layering can be done with any type of material. Bimetals are produced by combining two metals with significantly different thermal properties to create a new laminate that 
has improved deflection characteristics under high temperature loads, which makes them useful for high temperature measuring instruments.[9] Laminate glass is glass coated in a protective material to create a safe and transparent laminate that is used in places like car windshields. The most common type of laminate, however, is laminated fibrous composites, which are layers of fibrous composite materials that are combined to allow for fibers to be oriented in the directions of the predicted loads on a structure. This laminate is used throughout this study for each test structure.

These composite materials can all be combined in different ways to create a completely different composite material as well. Rebar reinforced concrete is an example of particulate composite materials reinforced with fibers. The composite materials described are all formed to improve mechanical and thermal properties of a structure and have different uses but this study will focus mainly on the performance of fibrous composite materials.

\subsubsection{Bio-Composites}

All of these composite materials mentioned above are the mainstream materials that are used in numerous engineering fields. They have improved mechanical and thermal properties over their metallic counterparts but are not the most optimal materials in terms of the environment and the use of the raw materials that they are made of. These materials are produced using fossil fuels, which are non-renewable resources that release harmful pollutants into the atmosphere during production and are disposed of by burning or high energy recycling methods. Fossil fuels are quickly diminishing, which means that these materials will diminish with them unless a legitimate alternative is found. Bio-composites may be that alternative. They are fibrous composites that use natural fibers from plants and matrices that are made of biopolymers. The reason for the use of these types of materials is that they, theoretically, will be sustainable forever and they are beneficial to the environment. When these materials are ready to be disposed of, they can be fully biodegraded or can be burned with zero harmful emissions. They have the same low density as mainstream 
composite materials but at a much lower cost due to the availability and ease of production. The overall strength of these materials still lacks compared to typical composite materials but research is being done to improve the mechanical characteristics of these materials. This study investigates the post-impact flexural strengths of these materials and compares the results to those of typical composites to understand areas of improvement for future bio-composite production.

\subsubsection{Advantages and Disadvantages of Composites}

Composite materials are manufactured to provide superior mechanical and thermal properties over their metal counterparts in all areas of engineering. This doesn't mean that they are more improved in every mechanical and thermal characteristic, however. As mentioned earlier, the structural designer has to design a material with the necessary constituents to get the properties required for certain situations. This gives materials with increased structural properties but also with decreased properties that must be accounted for as well in the design process.

The advantages of composite materials can definitely outweigh the negatives if manufactured correctly and for the proper applications. The most well known benefit of composite materials is the improved strength-to-weight and stiffness-to-weight characteristics that it possesses over metallic materials. The low-density fibers and matrix combined with the high tensile strength and stiffness of the fibers in their axial direction result in these superior properties. Composites are typically easy to tailor allowing entire structures to be produced with one consistent material and no bolts or rivets to connect parts. Fewer parts during production mean a reduction in production costs and overall structure weight. The properties of the composite are based very strongly on the constituent materials and the interactions between the constituent materials so not all composites have these advantages. For example, with the correct reinforcements and matrices used, composite materials can have improved corrosion resistance, low thermal conductivity and low coefficient of thermal ex- 
pansion, and increased fatigue resistance, allowing for radio frequency transparency.[10] Some composites can have improved impact properties but the majority of these materials have issues with impact absorption.

The main setback that composite materials have is their increased raw material costs. Creating composite material structures is much more expensive than creating structures using their metal counterparts. The initial costs for the molds, autoclaves, and layup machinery necessary for the production of composite structures can be much more than the machinery necessary to create metal structures as well. Another major issue with composites is the difficulty of repairs. Failures within composites can be non-visible and detection requires expensive machinery. Once fibers within the composite are compromised, the strength of the composite is degraded and if too much damage is present, large parts may need to be replaced because composite structures are usually produced as one consistent part. Exposure to moisture can also severely damage the structure if the composite is not manufactured with the correct protection. Another major issue with most composites is the ability to resist impact loads. Because of the low toughness of the matrix and the brittleness of the fibers, composites in general are damaged easily by small impacts, which lead to major repairs.[10] As mentioned earlier, composites are also hazardous to dispose of and use a lot of energy to recycle.

Composite materials have a very promising future which is why more research is being done to minimize these disadvantages and improve composite structures. Since the impact behavior of composite materials is a major area of concern, this research will attempt to improve the knowledge of impact effects to assist the improvement of these structures through continued research.

\subsubsection{Manufacturing Techniques}

Combining the constituent materials of a composite material can be done using many different methods. The manufacturing technique and the quality of production of the com- 
posite material determine the properties of the material. Combining two constituents does not guarantee an improved material unless the manufacturing is performed correctly. The quality of the part depends on the moisture content, temperature, duration of the cure cycle, temperature rates during the cure cycle, vacuum pressures, surface preparation, and the condition of the material. A lack of consideration in any of these areas of the manufacturing process can result in major decreases in material properties. The main manufacturing methods used are "wet" layups, open moldings, resin infusion processes, and high-volume molding methods.[11] The manufacturing technique used to create a structure depends on the part size, shape, cure cycle, cost limitation, and the experience of the manufacturer or machine operator. The more advanced (and costly) manufacturing techniques improve the quality of the finished material by minimizing the effects of negative production factors.

\subsubsection{1 "Wet" Layup Techniques}

Hand layup techniques (or "wet" layups) are the simplest and least costly manufacturing technique. Typically, layers of dry fibers are laid together and resin is applied to the dry fibers. When the resin is applied to each layer before layers are combined, it is considered a "wet" layup.[11] The "wet" layup method usually is compressed after the layup or put into a vacuum to extract excess resin from the laminate, pull air out of the resin, and allow for even curing throughout. "Wet" layup techniques are typically used with composites that cure at room temperatures but the curing method can be accelerated by adding pressure and heat with an oven or autoclave.[11] When heat is added to the system, it is per the resin data sheets and for the time required to cure the resin. After curing, the temperature must be brought back down to room temperature slowly to keep the part from warping from uneven expansion. When the cost of using an autoclave for curing is too much, out-of-autoclave (OOA) curing can be used which uses heat from an oven only or room temperature to cure the part. 
Overall, "wet" layups are great for low cost and easy production of a part that require little setup; however, air pockets left in the resin due to poor resin application and curing can lead to large decreases in structural properties of the material. Also, the work time can be limited due to the resin, fiber-to-resin ratios can be severely off of the optimal ratio, and the fibers can be damaged during the resin application process if care isn't taken. This all leads to lower quality material. Parts that require higher quality should be produced using different curing methods.

\subsubsection{Open Molding}

The next step up in the manufacturing of composite materials is open molding, which uses a one-sided mold to create a part or structure out of composite materials. This method is commonly used with hand layups on the mold but is also used with sprayup manufacturing to create fiberglass composite structures. For either case, the mold has to be treated with a mold release to allow the composite to separate from the mold after curing. Once the mold release is applied, either the hand layup of the composite onto the mold or the sprayup is used to form the uncured composite material to the mold.

The sprayup method is slightly more difficult than the "wet" layup technique mentioned earlier. This technique uses a tool called a chopper gun to spray catalyzed resin onto the mold while simultaneously chopping continuous glass fibers into short (or "chopped") fibers that are sprayed onto the mold in the same stream as the resin.[11] Once the entire mold is covered in the sprayed fiberglass composite, a hand roller is used to press the material into the mold and create a laminate structure throughout the mold. Once the fiberglass is cured, the solid structure in the shape of the mold can be used for production and the mold can be reused for the next sprayup process. This method can be used for more than just single material laminate layups. If a core material is necessary to create a structure, the fiberglass can be sprayed on the mold first, the core can be placed on top of that sprayed layer, and then another laminate of fiberglass can be sprayed on top of that core to enclose 
it. This creates a sandwich structure which will be described in more detail later in this report. A hand layup and sprayup technique can be used together as well. A fabric that has been laid up on the mold using the "wet" layup technique can be covered with the sprayed fiberglass to create a multi-material laminate structure.

The sprayup method is another low-cost, quick composite layup method but its use has been slowly declining throughout the engineering industry for safety reasons. The chemicals used during the sprayup are harmful to the workers laying up the composite material and controlling the emission of these harmful chemicals is difficult and expensive so manufacturers have moved away from this method in recent decades.[11] Robotic sprayups have begun to be more common but it is still not the preferred method in industry. Hand layups in open molds are being replaced by automated layups of pre-impregnated ("pre-preg") composite materials, which are fabrics that contain the optimal amount of resin evenly distributed throughout them already. Pre-preg materials can be expensive, though, and need to be kept at very low temperatures before use. In general, open mold techniques are still widely used throughout the engineering industries but much more commonly with automated layup techniques.

\subsubsection{Resin Infusion Processes}

Some of the most common automated layup techniques used today are resin transfer molding (RTM), reaction injection molding (RIM), vacuum-assisted resin transfer molding (VARTM), and resin film infusion (RFI). These are significantly faster layup processes that increase productivity and finished part quality.

Resin transfer molding (or liquid molding) uses a male and female mold made of metal or composite materials that combine to create a closed mold system. A dry reinforcement fabric is placed inside the closed mold and moderated amounts of resin and catalyst are combined just before being injected into the mold through designated ports at low pressures.[11] The resin system has low viscosity to allow it to flow evenly throughout the dry 
fabric and quickly so that it covers all of the dry fabric in the mold before it cures. RTM methods can be beneficial for multiple reasons. They eliminate the need for an autoclave to create composite parts which minimizes costs and the dry fibers and resin systems are less expensive than pre-preg materials. The constituents of the composite material also don't need to be stored at low temperatures like the pre-preg materials which means that they don't expire as quickly. The finished parts created using RTM are precise and have near-perfect finishes, eliminating the need for post-fabrication work. Also, it was mentioned earlier that hand layup techniques leave large voids or air pockets in the composite that weaken the structural integrity; RTM techniques decrease the amount of voids in the composite down to, at most, $2 \%$. RTM also reduces the time from preparation to cured part drastically over the open mold and hand layup techniques, which results in high production rates and decreased costs. Light RTM is a slight alternative to RTM that can be used to reduce costs even more. It uses a vacuum to pull the resin throughout the mold, allowing for the use of less-expensive, lightweight molds to be used.[11] The major issue with RTM overall is the fact that the molds used can be extremely expensive and the initial costs for all of the resin infusion equipment can be very high.

RIM, VARTM, and RFI are slight variants of RTM. RIM varies slightly from RTM in that the resin and catalyst do not mix until they are in the mold. Both are injected separately and when they are distributed throughout the mold, they combine and result in the curing chemical reaction. Issues with curing happening in the injection ports are minimized and low voids result from this method. A main difference between VARTM and RTM is that resin is pulled into a preform through a vacuum; unlike RTM which pushes the resin into the mold using pressure.[11] This process does not require heat or pressure so it reduces the tooling costs and allows for larger production of inexpensive, intricate parts. Another difference between the two methods is that VARTM is an open mold method that uses a vacuum sealing cover on top of the mold. The resin is pulled into the mold through ports called "manifolds".[11] This method creates high fiber volume composites with low void 
content at a lower cost. Lastly, RFI is a combination of all of these methods. RFI uses the same method of placing a dry fabric in a mold but it differs from the other methods by laying a film of resin over the dry fibers. When the film is heated and pressure is applied, it mixes with the dry fibers evenly and creates perfectly uniform resin distribution.[11]

\subsubsection{High-Volume Molding Methods}

The last general manufacturing method of composite materials is high-volume molding which contains compression molding, injection molding, filament winding, pultrusion, automated fiber placement (AFP), and automated tape laying (ATL). These methods all have different purposes but they are all used for mass production throughout the engineering industries.

Compression molding is a very popular manufacturing method for outputting tens of thousands of parts rapidly. It is incredibly expensive though due to the fact that it uses very durable, forged metal dies. Sheets of composite materials are made first by chopping glass fibers and laying them on top of a sheet of resin. Another sheet of resin is then poured on top of that and a roller is used to compact the sheet, saturating the glass with the resin and releasing trapped air pockets.[11] Over time this sheet molding compound (SMC) becomes very viscous but is moldable. After a couple days, this sheet is then cut and placed in the heated mold, which is clamped and pressurized. The heat and pressure lower the viscosity of the sheet and it fills the mold. This method is used with thermoset resin systems that can cure in as long as 150 seconds and as short as 30 second.[11] This is incredibly faster than the hours it takes to cure for the previous manufacturing methods mentioned. Research is being done to use this method with carbon fibers to improve SMC strength and stiffness characteristics.

Another good high-volume manufacturing method is injection molding. It is a fast, low-pressure, closed manufacturing process that typically uses nylon thermoplastics with chopped glass fibers. This method has advanced over the decades to use bulk molding 
compounds (BMC) which are ready-to-mold glass fiber reinforced thermoset materials. This material is forced through a headed barrel and injected into a closed, heated mold.[11] Injection speeds are a few seconds and thousands of parts can be made in an hour by continually forcing BMC through this process.

Filament winding is another high-volume manufacturing method that is easily repeatable and has low material costs. This method does not use dry fiber fabrics but, instead, creates the fabric by winding the fibers around a rotating cylindrical tool called a mandrel. This winding is usually automated to ensure the fibers are placed in their precise locations. There are two types of this method when used with thermoset resin systems: dry winding and wet winding. Wet winding runs the fibers through resin before winding them and dry winding winds the fibers without resin and then uses the wound mandrel as a preform for another molding process like RTM.[11] If thermoplastics are used, pre-preg materials are wound around the mandrel and are cured with heat while they are winding, eliminating the need for autoclave curing. Multiple methods for removing the mandrel from the cured composite are used and in some cases, the mandrel remains part of the structure. Filament winding produces high circumferential strength structures for a lower cost than other methods.[11]

Pultrusion, AFP, and ATL are all modifications of the methods mentioned earlier. Pultrusion is a simple, low-cost method that pulls fibers through heated resin and forming guides and eventually ends up in a heated die where it takes its final form.[11] AFP is similar to the filament winding process but is a process that automatically places prepreg tows onto a mandrel at high speeds and accuracies, limiting material waste.[11] Lastly, ATL is beginning to be used more widely in the aerospace industry for larger structures like the wings and fuselage of the Boeing 787 and Airbus A380 XWB. Instead of just laying down individual prepreg fibers onto a part like AFP, ATL wraps prepreg tape around the part, creating one continuous structure. This process is automated and can create composite structures at any orientation necessary with as many layers necessary. 


\subsubsection{Composite Structures}

Overall, composite materials have many improved material characteristics over their metal counterparts; however, there are disadvantages as well. Fiber-reinforced composites are typically poor in compression, most are brittle and easily susceptible to impact damage, and they can have a low buckling tolerance. These disadvantages can be countered to a certain extend by creating composite structures. A composite structure typically brings a composite laminate together with another material structure to create an improved overall structure. The best example of this is a composite sandwich structure which layers composite laminates on the top and bottom of a core. These structures show improved structural characteristics over composite plates with minimal weight penalties. The next section will describe these structures in detail.

\subsection{Overview of Composite Sandwich Structures}

The need for lower weight, higher strength structures is incredibly important in the aerospace industry and composite materials have begun to fill this need; however, composite sandwiches allow for structures to have even more improved flexural characteristics over composites alone. These structures use the high strength of composite materials combined with the low weight of another material to create a structure that has greatly improved strength-to-weight and stiffness-to-weight characteristics over composite laminates. Typically, a thick, low density core is "sandwiched" between two thin, high strength and stiffness composite laminates ("facesheets" or "skins") with the possible addition of an adhesive layer between the facesheets and core to minimize delamination effects between the two. A common sandwich structure can be seen in Figure 1.2. A composite sandwich can be compared to a structure like a wing that has stringers, ribs and skins because it incorporates the idea of separation of tasks to create an improved overall structure. 


\subsubsection{Sandwich Composite Facesheets}

The facesheet of a composite sandwich is the same as all of the composite materials mentioned in the previous section. Typically, the facesheet will be a composite laminate but it can just be a single layer of material as well. The main reason for having the facesheet on a composite sandwich is so that it can withstand the main in-plane stresses caused by bending forces on the structure. The top facesheet of the sandwich has to withstand compressive loads and the bottom skin has to withstand tensile loads in the fibers' axial direction. Because of this, the facesheets have to be the highest strength and stiffness parts of the composite structure. This is why typically high strength metals or com-

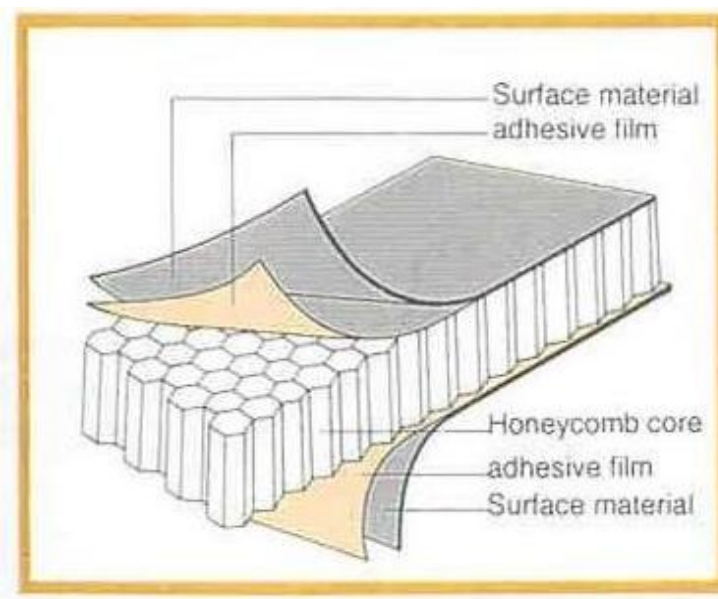

Figure 1.2: Composite sandwich structure (with honeycomb core) [12]

posite materials are used for the facesheets. Typical composite materials used are thermoset and thermoplastic matrix composites with carbon, glass, and aramid fibers. These materials are typically anisotropic, which means that their material properties are different along each axis so certain directions of loadings on the facesheet will yield different results. Research will be done in this study on natural fibers as well. Along with strength, the facesheets usually contribute most of the stiffness to the sandwich and they carry the local pressures from point loads on the structure.[13]

\subsubsection{Sandwich Composite Cores}

The core material is a support mechanism for the sandwich that holds everything together. The main reasons for the core is to resist the shear loads as the facesheets try to slide past it under loading and increase the stiffness of the structure by separating the 
facesheets, all while keeping a low weight structure.[14] While keeping the facesheets separated, the core supports the them by uniformly distributing the external load throughout the facesheet, which creates an overall stiffened sandwich structure. By doing this, the core keeps the facesheets from buckling or deforming and keeps the top and bottom facesheets fixed relative to each other under any loading. Fixing the facesheets allows the entire load to be focused there other than on the weaker core material. This shearing resistance that the core provides to the structure, as well as the thickness of the core, adds extra stiffness to the overall structure. Stiffer core materials have higher shear moduli and more flexible cores have a lower shear modulus. Another important characteristic of core materials is that they are good in compression which supports the prevention of face wrinkling. Typical core materials are polyurethane foams and honeycomb structures due to their high shear moduli and low density but wood, bamboo, and other lightweight materials have been used as well.

\subsubsection{Advantages and Disadvantages of Composite Sandwiches}

When these sandwiches are manufactured correctly and allow the facesheets and cores to work together, the overall structure can have many advantages over composite laminates and metals. The most important advantage that composite sandwiches have is their superior strength-to-weight and stiffness-to-weight properties. These properties are most prevalent when the structure is subjected to bending loads. The core is the main reason for that flexural improvement. Because of the increase in moment of inertia with the thick core, buckling resistance is increased along with flexural rigidity. The core also has good fatigue and damping resistance, which creates good acoustic insulation, and has increased thermal properties for aircraft exterior structure uses.[15] Construction and maintenance costs can also be decreased due to the inexpensive cores compared to expensive composite laminate alternatives. 
These structures have a lot of benefits over their composite laminate and metal counterparts but they are still far from perfect. One of the major issues with composite sandwiches is the construction. The face-to-core connection is very weak and even with assistance from adhesive materials, it is still an area of focus because if that is not strong enough, it doesn't matter how strong the core and facesheet materials are; failure will occur there. If delamination does happen, any compressive load on the structure will be concentrated at that delamination area. This creates buckling in the facesheets which propagates the delamination along the structure. Because these structures are complexly constructed, they can also be difficult to join to other structures. Joining two composite structures together with fasteners or rivets weakens the soft, weak core creating failures in those areas. The core also absorbs moisture easily which leads to corrosion within the core if moisture prevention isn't considered during manufacturing. The facesheets can also cause problems because of the minimal thickness compared to the overall structure. The facesheets can wrinkle easily under concentrated loading and the fibers and matrix within composite facesheets can fracture easily under impact loadings. Composite facesheets can also be weak in shear so in-plane shear failure can occur.

\subsubsection{Core Advantage on Structure's Flexural Characteristics}

As mentioned earlier, composite sandwich structures have improved flexural properties over composite laminates and metals. The improvement in flexural characteristics can be compared to the flexural strengths of I-beam structures. An Ibeam is a structure that has a top and bottom flange (facesheet) and a tall skinny web (core). The I-beam separates tasks within

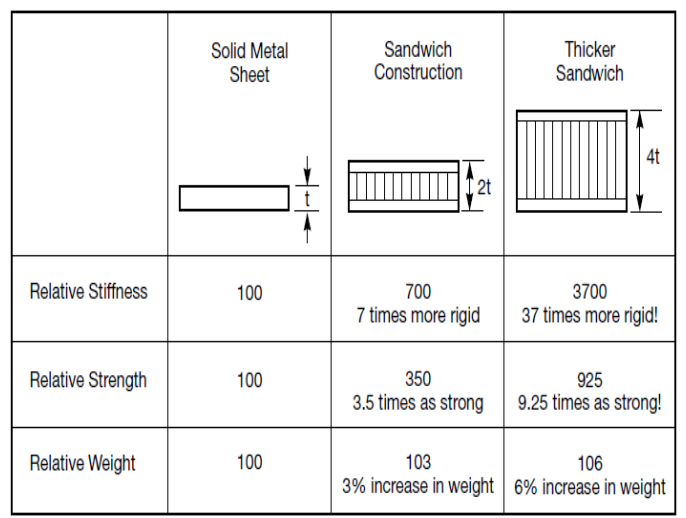

Figure 1.3: Increase in bending stiffness and strength with an increase in honeycomb core height [16] 
the structure like a composite sandwich does. The flexural strength and stiffness of a composite sandwich or an I-beam depends on the moment of inertia of the beam. This can be changed by increasing or decreasing the height of the web (core). Figure 1.3 shows how a slight increase in the height of the core of a composite sandwich can drastically increase the stiffness and strength of the structure. The difference between the I-beam and the composite sandwich is that because of the low density of the core, when the height is increased, there is a very minimal weight penalty. Because of this, composite sandwiches are able to greatly improve the flexural strength-to-weight and stiffness-to-weight characteristics mentioned earlier.

\subsubsection{Impact Behavior of Composite Sandwiches}

Composite materials and composite structures have greatly improved characteristics over their metal counterparts in aerospace applications but as they become more widely used in the industry, the focus on impact and energy absorption properties of these structures will become crucial. Overall strength and stiffness has improved using sandwich structures but with a significant reduction in resistance to impact loadings. One of the main issues with impacts on composite structures is the micro-damage done to the fibers and matrix within the composite. These small, undetectable damages can cause major reductions in overall strength of the structure and can be caused by small impacts, such as tools dropping on the part or hail strikes on an aircraft. Because these damages are so small, they are not noticeable with the naked eye so expensive machinery and repair techniques are required to find and repair them. The low-velocity, low-mass impacts produce undetectable, but repairable, damages. Higher-velocity and higher-mass impacts can cause much greater damage that leads to catastrophic structural failures. Larger impacts, such as bird strikes on an aircraft, require full replacement of an entire composite structure which can be something as large as major sections of the wing of an aircraft. This is why the 
ability to understand, predict, and prevent impacts on composite structures is a crucial area of focus for engineers.

The ability for a material to absorb energy describes the toughness of that material and can be predicted with many different techniques for isotropic materials, like metals, that have the same structural properties along every axis. There are fracture mechanics theories and equations that describe the fracture behaviors of brittle materials.[17] The fracture behavior of brittle composite materials is drastically different than homogeneous, isotropic materials, however, and can't be predicted using these simple methods. Because of this, drop weight tests have been implemented to understand the low-velocity impact behavior of these composite sandwich structures and allow us to better predict how they behave and prevent catastrophic failures from happening. High velocity impact tests have also been used to understand how to prevent the larger impact damages from happening. This understanding of composite sandwich impact behavior is crucial for the future use of these structures in aerospace applications and is the reason that this study is focused on it.

\subsubsection{Applications of Composite Sandwiches}

Composite sandwich structures have been used extensively in recent years for all engineering industries from aerospace to naval to automotive and even the train industry as well. Aircraft interiors are made primarily of composite sandwich structures for the lowweight structural properties. The flooring in a lot of aircraft is being made of composite sandwiches because of the great flexural strength-to-weight and stiffness-to-weight characteristics, which is the primary loading seen by aircraft flooring. Using composite sandwich structures on the exterior of aircraft is still not as common as the interior because of the high moisture content and large impacts experienced by exterior aircraft structures. For aircraft that have implemented composite sandwich structures on the exterior, they are usually in the secondary structures like the rudders, flaps, elevators, and ailerons. More testing and improvement in design of composite sandwiches is necessary before a full scale implemen- 
tation will happen on aircraft but the technology is out there and the aerospace industry is always in need of low-weight, high-strength structures. Along with the aerospace industry, high performance machines in the train, automotive, and marine industries have begun to use composite sandwiches for the light-weight benefits. Structures used for the collection of wind energy and in general transportation have also been made of composite sandwiches. Overall, composite sandwich structures are useful for a wide variety of applications and the number of structures that implement this technology will only grow in the near future.

\subsection{Previous Research on Impact and Flexural Behavior of Composite Sandwich Struc- tures}

The impact resistance characteristics of composite sandwich materials is one of the main reasons that these structures are not more widely used throughout the aerospace industry so a lot of experimental research has been done to gain a better understanding of how to improve this characteristic. One of the most important focuses in these publications is the improvement of compression after impact (CAI) strengths. This compression can be edgewise compression, three-point or four-point bending, or a shearing compression test. The most common type of research is done on edgewise CAI strengths. Leijten, Bersee, Bergsma, and Beukers[18] investigated the damage tolerance of composite sandwich structures for primary aircraft structures. The sandwiches were constructed to represent those used on the fuselages of Boeing 787 and Airbus A350 aircraft. The study used a drop-weight impact test followed by ultrasonic C-scans and edgewise compression tests to determine that variations in facesheet thickness have minimal influences on the damage behavior compared to variations in core size; however, both variations followed similar trends. They were also able to conclude that the residual compressive strength only depends on the damage inflicted on the facesheets and that the damage is governed by the thickness of the core (rigidity of the sandwich). Depending on the way the test is setup, however, 
these results can be less accurate than a shearing compression method. Schubel, Luo, and Daniel[19] researched the damage tolerance of composite sandwich structures composed of carbon fiber/epoxy facesheets and PVC foam cores using three different CAI testing methods and developed a better understanding for impact-initiated delaminations. They found that the four-point bend and end-loading tests were not as successful as compression through shearing column compression. A drop-weight impact combined with column compression tests resulted in a pre-delaminated compressive strength that was half of the nonimpacted sandwich at high impact energies; lower impact energies showed minimal damage but still reduced the compressive strength. The edgewise compression tests, however, can require precision machining, potting at loading ends, and specimen modification to have a successful test so Nettles, Jackson, and Gates[20] examined the effectiveness of using four-point bend tests instead of edgewise tests to understand CAI strengths in composite sandwiches. Their investigation found that end-loaded generally gave higher compression strengths and stresses than the four-point bend loading and that the stress-state throughout the facesheets was not uniform. Because of this, longer four-point bending specimen will probably be needed to get results similar to the end-loading method. Since both methods are still legitimate representations of the CAI strength of composite sandwich, Klaus and Reimerdes[21] used finite element modeling techniques to verify that models can be used for first prediction of the behavior of pre-damaged sandwich structures under both loading types without the need of sandwich construction. They found similar results to Nettles, Jackson, and Gates[20] in that it took more force to cause the same compression stress in the damaged facesheets for end-loading than it did for four-point bending; about 5 times more. The results of the finite element simulation in this study agreed with the experimental results enough to use that model as a preliminary tool for predicting the CAI strengths of composite sandwiches under both loadings.

Since this study focuses on the four-point bending CAI strength, research on this type of post-impact testing is more pertinent. Gottner, Klaus, and Reimerdes[22] investigated the 
post-impact behavior under this loading of composite sandwiches with varying core structures. In their study, post-impact and non-impacted carbon fiber sandwiches with three types of honeycomb cores (classic Nomex honeycomb, X-core, and K-core) tested under four-point bending showed that the area of delamination affected by the impact increases with the stiffness of the core. Two impact energies were tested with each sandwich type and it was found that the higher impact energies caused reductions in residual flexural strengths of about 50\%; whereas, the smaller impact energies saw a reduction of $40 \%$ but with an $80 \%$ drop in indentation depths from the higher impact. Klaus and Reimerdes[23] also did a study to create a finite element model that accurately simulates the CAI strength of composite sandwiches but this study focused on the variation of honeycomb core direction over a range of impact energies. Their model outputted comparable results to the experimental tests which showed significant drops in flexural strength as the impact energies increased. Composite sandwiches with the core's W-direction oriented parallel to the long edge of the beam, however, showed less of a drop in flexural strength at each impact energy but with a smaller non-impacted flexural strength compared to the L-direction orientation. All of these composite sandwich studies are not strictly focused on composite materials and four-point or edgewise compression, though. Yu, Wang, Li, and Zheng[24] examined how varying the core and facesheet thicknesses affected the failure modes of aluminum alloy facesheet and aluminum foam core composite structures that were subjected to post-impact three-point bending tests. The experimental failure mode results were compared to analytical failure modes calculated using Gibson's model. Upon completion of their study, it was determined that the three main failure modes (face yielding, core shear, and indentation) assumed at the beginning of the study were the main failures observed during testing with one exception; beams with thin facesheets and thick cores initially failed in indentation mode but then collapsed due to face yielding. Overall, the Gibson's model and theoretical failure mode maps could predict experimental failure modes and maximum loads for 
face yield and core shear failing beams but overestimated the ability of beams failing in an indentation mode.

There has been a lot of research done and have been a lot of experiments performed in recent decades to understand the effects that low-velocity impacts have on the CAI strengths of many different types of composite sandwiches. Composite sandwich designs have made significant strides in the near future thanks to studies like these but these structures still have a long way to go in terms of their impact resistance characteristics before they become the primary structures in aerospace and other engineering applications. Continual research is being performed, and will continue to be performed, because of this and the study described in this report will add another piece of information to the ongoing improvements.

\subsection{Main Objective and Scope of Study}

The main objective of this study was to determine the effects of low velocity impacts on the flexural strength of varying composite sandwich structures subjected to four-point bending loads. Low velocity drop weight impacts were introduced to $2 / 3$ of these sandwiches to compare the damage resistance abilities of each design. The four-point bending tests were performed to understand which facesheet and core material combination performed the best with and without an initial impact damage. The impact was applied to the compressive bending facesheet of the sandwich for $1 / 3$ of the designs and the tensile facesheet surface for another $1 / 3$ to see if the location of the impact damage affected the flexural strength of a sandwich design. Carbon and aramid fiber facesheet materials were then combined to create a hybrid sandwich design with a honeycomb core and aramid fiber layers on the exterior of the sandwich to determine if the post-impact load carrying ability could be improved for the carbon fiber sandwich designs. Overall, this study compared the ultimate load carrying ability and percent reduction in load carrying ability after impact of 
each sandwich design to find the best overall structure for applications on aircraft where impact and bending loads are prevalent.

The remainder of this study will delve into the manufacturing and testing processes performed for each sandwich design, the experimental results of each test, and the comparisons of experimental and numerical analyses. Chapter 2 explains the manufacturing methods used to construct each composite sandwich and to construct the testing strips used for material properties testing. The impact and four-point bending procedures used for all testing will be described as well. Chapter 3 will present the experimental results for all material properties, impact, and four-point bending tests. The experimental impact and bending failure modes will also be examined and discussed for each sandwich design. Chapter 4 will compare the experimental failure modes and mid-span deflections of each sandwich design to theoretical failure mode analysis results and numerical mid-span deflection values. At the end, Chapter 5 will discuss the derived conclusions of this study based on the experimental and numerical results obtained. 


\section{Chapter 2 \\ SPECIMENS MANUFACTURING AND TESTING PROCEDURES}

This chapter will delve into the manufacturing methods of each test specimen, including layup processes, material curing cycles, and post-cure specimen preparation. The latter half of the chapter will describe all of the testing procedures used for impact and four-point bending tests, as well as the compressive, tensile, and strain gage tensile testing methods used to find composite sandwich constituent material properties.

\subsection{Composite Sandwich Structure Design and Materials Used}

As mentioned earlier, a composite sandwich structure is composed of two composite facesheet materials and a core material that is "sandwiched" in between them. The composite sandwich design is utilized throughout this study in the form of 3 inch by 10 inch specimens. These specimens were dimensioned as such to conform to the constraints of the Dynatup 8250 impact machine fixtures used for testing. Every sandwich tested had the same length and width dimensions and the same half-inch core dimension, regardless of core material, to minimize dimensional variables throughout testing. As mentioned earlier, the height of the core material can greatly improve the flexural characteristics of a composite sandwich and research has been done on the benefits of this increase; however, this study focuses more on the material design of a composite sandwich than the dimensional design. To keep consistent with sandwich design, each specimen was constructed with three layers (or "plies") of composite material on the top facesheet and three plies on

the bottom facesheet as well. A slight variation in facesheet thickness occurred between 
each sandwich due to the difference in post-cure thickness of each composite material. The variation in facesheet thickness between two different materials was about 0.06 inches at its largest.

\subsubsection{Facesheets}

Depending on the application, the facesheet materials can be a metal or any type of composite material. In this study, only fibrous composite materials were used to create the facesheets of the sandwiches. Each fibrous composite material weaved the fibers throughout the material in a different way, creating a variation in weave patterns as well as in material. The four materials used for the facesheets were carbon fiber, hemp fiber, aramid fiber (Kevlar), and glass fiber composites. The carbon fiber facesheet was a bi-weave prepreg material designed and manufactured by Hexply with AGP 280-5H fibers and an 8552 epoxy matrix. The bi-weave description means that the fibers were woven in both the 0 degree orientation and in the 90 degree orientation. The $280-5 \mathrm{H}$ designation is Hexcel's method of describing the type of carbon fibers used and the weave pattern. The 8552 epoxy is Hexcel's designation of an epoxy with a certain type and amount of resin and hardener used to create it. Since this material is a prepreg, it was stored in the Cal Poly Aerospace structures freezer on campus at a temperature of $0^{\circ} \mathrm{F}$ to prolong the time it takes for the material to structurally degrade. The hemp fiber used was a dry, B601 plain weave natural fabric manufactured by EnviroTextiles and it was combined with an Aeropoxy epoxy composed of PR2032 resin and PH3660 hardener. The PR and PH stand for resin and hardener, respectively, and the numbers are Aeropoxy's description of the type of resin and hardener. The aramid fiber composite was actually a Twaron fiber which is a man-made high-performance aramid fiber material created by Teijin. It is a unidirectional fiber oriented composite material (as opposed to the bi-weave composites used for the other three materials), described by Teijin as XF9810/Twaron-90-38-40\%. The 40\% designation describes the fiber-to-epoxy volume ratio (or fiber volume) of the material. The last material 
used was the fiberglass which was a slight variation of a typical fiberglass composite material. This material is called Texalium and it is a $2 / 2$ twill weave (two fibers woven in one direction for every two fibers woven in the perpendicular direction) fiberglass that has a proprietary finish and a thin coating of $99.99 \%$ pure aluminum, which is approximately 200 angstroms thick.[25] Its designation is NB308T 7725 Texalium. The ability of these four materials, used as composite sandwich facesheets, to withstand post-impact bending loads will be compared throughout this study.

\subsubsection{Cores}

The core material is the reason for the increase in flexural strength and stiffness in the composite sandwich and is the lowest density material in the sandwich design. The two most common materials used as cores in aerospace sandwich structures are foam and honeycomb cores. Because of this, these are the two cores that will be analyzed throughout this study. The foam core is a Last-a-Foam product with a designation of FR-6710. This material is a rigid polyurethane foam that was cut from half-inch thick sheets into the specimen dimensions necessary. The honeycomb material is drastically different from the foam in terms of the design of the structure. Figure 2.1 shows the difference between the two types of material structures. Foam is a homogeneous, isotropic material which means that it is one solid material throughout the whole structure and it has the same material characteristics in every axis direction; whereas, the honeycomb is a nonhomogeneous, anisotropic material which means it is not one solid structure and its material characteristics are different in each axis direction. This happens because the fibers

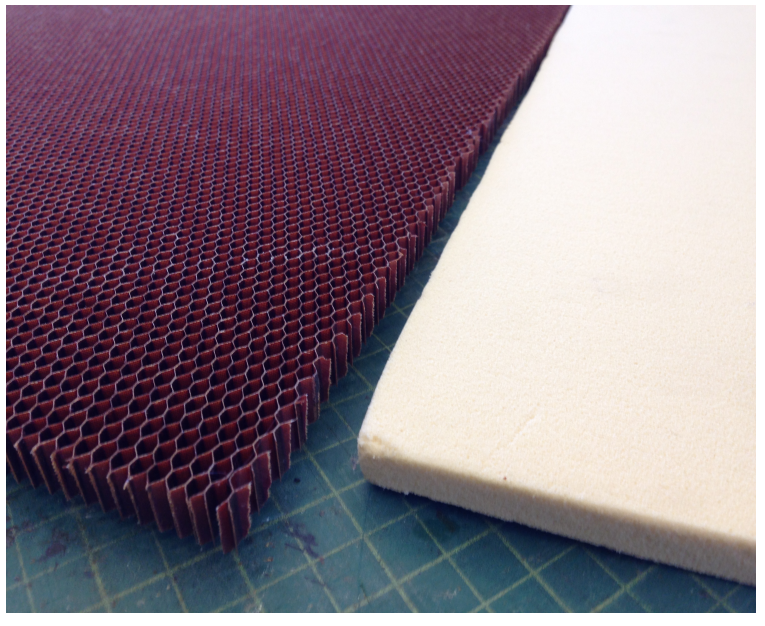

Figure 2.1: Honeycomb (left) and foam (right) core materials used in this study (shown in bulk) 
that make up the cell walls of honeycomb run in one direction along the honeycomb structure (the longitudinal direction). The other axis direction of the honeycomb is called the transverse direction and it runs perpendicular to the fiber orientation. The honeycomb used for this study was a Hexcel HRP-3/16-8.0 material. Hexcel's HRP honeycombs are composed of hexagonal cells that are made of glass fiber cell walls coated in a heat-resistant phenolic resin.[26] 3/16 describes the cell size in inches and 8.0 is the nominal density of the material in pounds per cubic foot. These two core materials combined with the four facesheet materials mentioned earlier resulted in eight different composite sandwich structure designs that were investigated throughout this study. Two hybrid sandwich designs were also analyzed using two of the facesheet materials, carbon and aramid fiber.

\subsubsection{Adhesives}

One of the major reasons for failure in a composite sandwich is the delamination of the facesheets from the core so an adhesive material is usually added to reinforce the adhesion of the facesheets to the core. In this study, two different adhesive materials were used to improve facesheet-to-core bonding characteristics. The first adhesive was manufactured by $3 \mathrm{M}$ and was designated as AF 163-2OST WT 0.03 . This was a thermosetting modified epoxy structural adhesive that comes in film form.[27] The OST designation means that the adhesive is a one-sided tacky material with a non-woven carrier on the low-tack surface.[27] This all means that it has a structural reinforcement within a thermosetting epoxy; the epoxy is more prevalent on the tacky side of the film. The weight of the material is 0.03 pounds per square foot. This material was replaced with another adhesive during the manufacturing of the test specimen due to reasons that will be mentioned in the next subsection. The adhesive that was used for the latter half of the specimen was an epoxy film made by Hexcel that was designated as 8552 RFI A1030/B430. It is made of the same epoxy used in the carbon fiber prepreg facesheet material but comes as a non-reinforced epoxy film. Both materials had 
to be stored in the same freezer as the prepreg facesheet materials to lengthen the useable life of the material.

\subsubsection{Adhesive Comparison}

The reason for the change in adhesive materials in the middle of specimen manufacturing was that the first $3 \mathrm{M}$ adhesive ran out. Since all of the materials used in the Cal Poly Aerospace structures lab are generously donated, more of the $3 \mathrm{M}$ adhesive could not be obtained. So the next best option, the Hexcel 8552 resin film, was used as an alternative. To make sure this material would be a legitimate alternative to the first adhesive, a comparative experiment was done. Carbon fiber/honeycomb composite sandwich structures were manufactured with the Hexcel 8552 adhesive and the four-point bending strength and stiffness of that sandwich was compared to the already manufactured and tested $3 \mathrm{M}$ adhesive, carbon fiber/honeycomb sandwiches. The results of this side experiment are shown in Figure

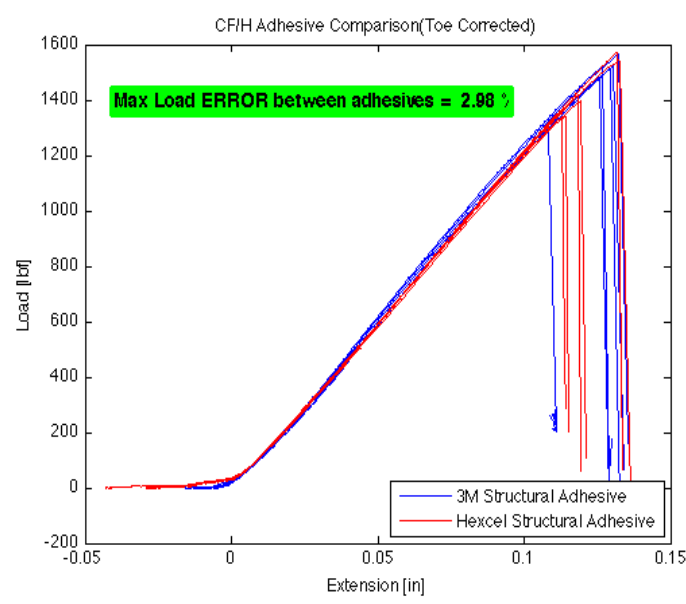

Figure 2.2: Comparison of bending strength and stiffness of carbon fiber/honeycomb composite sandwiches manufactured with the two different adhesive materials

2.2 and show a $2.98 \%$ difference in maximum loading between the two adhesives. The stiffness (slope of each curve) of each sandwich is the same regardless of adhesive used. Because of these results, it was decided that the Hexcel 8552 adhesive was a legitimate alternative to the $3 \mathrm{M}$ adhesive. 


\subsection{Specimens Manufacturing}

Each specimen was laid up using raw materials to form 12 inch by 12 inch composite sandwich plates. These plates were then cured using pressure and heat and cut into individual 3 inch by 10 inch sandwiches. The individual sandwiches are organized and shown in Figure 2.3. Each 12 inch by 12 inch plate produced three sandwich specimens and two plates were made for each variation in composite sandwich testing per ASTM; the testing standards will be described in a later section in this chapter. The sandwiches were constructed with three layers of the same facesheet material on the top and bottom faces of the core material. The facesheet materials were never combined for the initial sandwich designs. This resulted in eight variations in composite sandwiches;

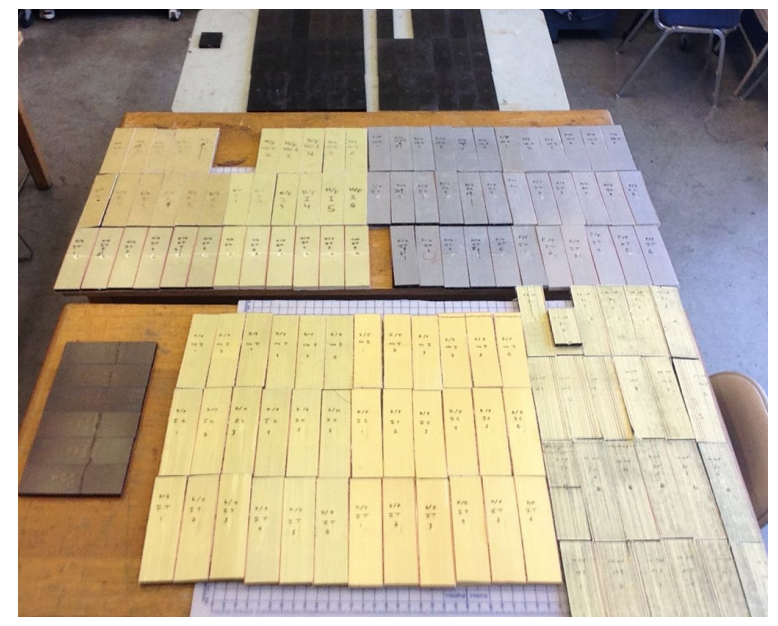
four facesheet materials combined with two

Figure 2.3: Overview of groups of manufactured specimens

core materials in eight different constructions. Once these sandwiches were created, aramid and carbon fiber materials were combined in two different ways with the aramid fiber always on the outside of the sandwich. The same three layer structure on the top and bottom of the core was kept and this created two more composite sandwich variations. Two plates were constructed for all ten of these sandwich variations and for each testing configuration to get the test specimens necessary. For example, six carbon fiber/honeycomb sandwich specimens were made to be a control sandwich that was bent under a four-point bending load without being impacted, six were made to be impacted and then bent with the impact damage on the tensile facesheet (bottom surface), and six were made to be impacted and then bent with the impact damage on the compressive facesheet (top surface). This meant that two identical 12 inch by 12 inch plates had to be manufactured out of carbon fiber 
facesheets and honeycomb cores for each testing case (six plates in total) and then cut after curing to get all of the specimens necessary. These plates underwent different layup methods and curing methods depending on the facesheet materials and the epoxy matrix used for each composite.

\subsubsection{Layup Methods}

Because the carbon fiber, aramid fiber, and glass fiber facesheets were prepreg materials and the hemp was a dry fabric, different layup methods had to be used to create the composite sandwich plates described above. The three prepreg materials were laid up using the tape layup method and the hemp was laid up using the "wet" layup method mentioned in Chapter 1.

\subsubsection{Non-automated Tape Layup for Prepreg Facesheet Materials}

The carbon fiber, aramid fiber, and glass fiber prepreg materials came straight from the manufacturer as a roll of material. So the first step in the layup process was to unroll the material, measure 12 inch by 12 inch squares of material, and cut those squares of prepreg out. The carbon fiber and glass fiber rolls came as five foot wide rolls so 5 of those squares were able to be cut out for every 12 inches that were cut down the length of the roll. The aramid fiber roll was one foot wide so only one square of prepreg was able to be cut for every 12 inches that were cut down the length of the roll. Six squares of prepreg material were cut for each composite sandwich plate manufactured to represent the three plies of prepreg that make up the top and the three plies that make up the bottom facesheet. Along with cutting the facesheets, the core had to be cut in 12 inch by 12 inch sections from the bulk material in Figure 2.1 and two adhesive sections had to be cut into the same size squares for each plate from its roll. The rolls of carbon fiber, aramid fiber, and Hexcel adhesive material are shown in Figure 2.4a, 2.4b, 2.4c, respectively. The $3 \mathrm{M}$ adhesive was three feet wide so three squares could be cut out for every 12 inches cut down the 


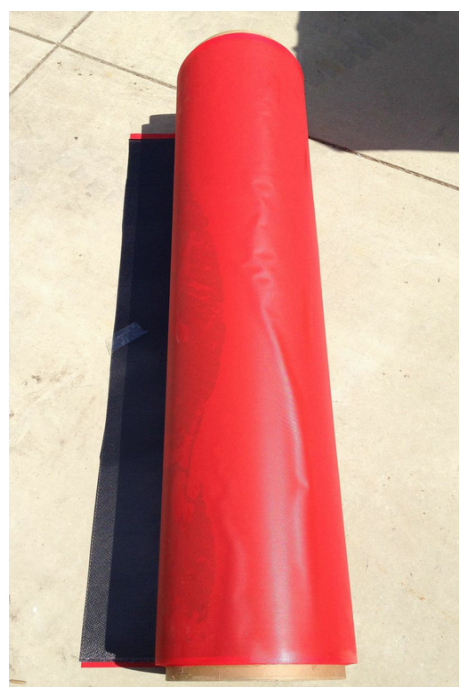

(a) Carbon fiber prepreg material

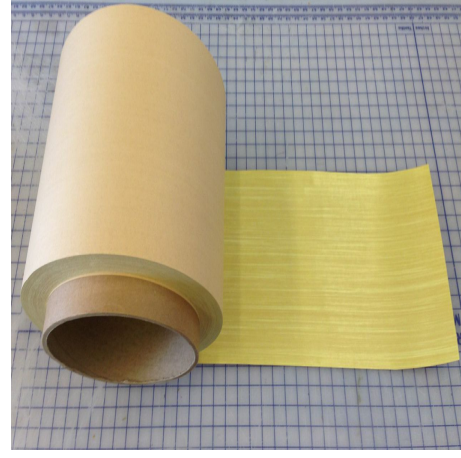

(b) Aramid fiber prepreg material

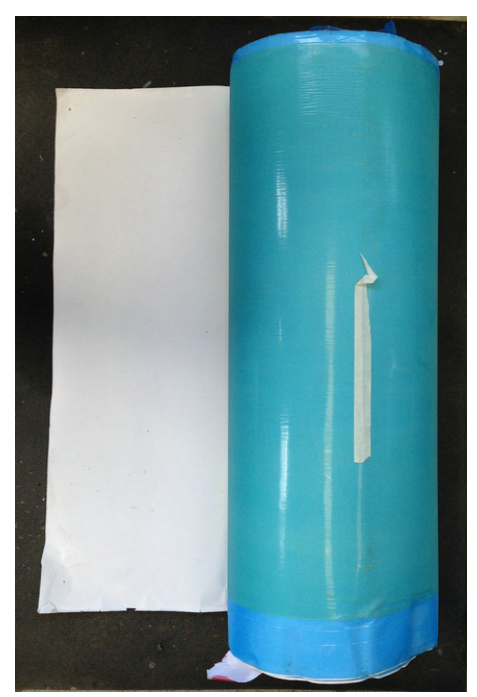

(c) Hexcel adhesive material

Figure 2.4: Rolls of bulk composite sandwich facesheet and adhesive materials

length of that roll. The Hexcel adhesive roll, on the other hand, was 25 inches wide so two squares of adhesive were cut for every 12 inches cut down the length of the roll. The

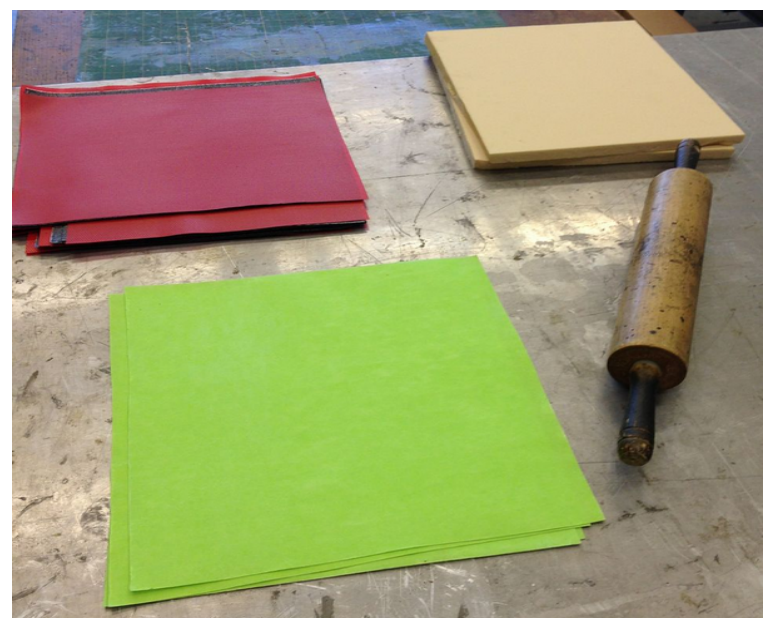

Figure 2.5: Preassembly three ply carbon fiber laminates (top left), 3M adhesive (bottom), and 12 inch by 12 inch foam cores (top right) protective blue and white sheets around the

Hexcel adhesive were tough to peel off of the adhesive, however, so a one inch strip was cut 12 inches down the length of the roll in the middle of the width of the roll. This allowed for each 12 inch by 12 inch square of Hexcel adhesive to have a little overhang of protective layers for easy peeling.

Once each facesheet, core, and adhesive material was cut out, the assembly of each

piece began. The preassembly parts are shown in Figure 2.5 for a carbon fiber/foam sandwich design. Three plies of the same prepreg composite material were laid up together to create a composite laminate and then the adhesive layer was laid on top of these laminates. 
After this process was done for both the top and bottom facesheets, the two composite laminates with adhesive layers were placed on the top and bottom of the honeycomb or foam core material, making sure that the adhesive layer of the laminate was contacting the core for both the top and bottom facesheets.

\subsubsection{2 "Wet" Layup}

The composite sandwiches constructed with hemp fiber facesheets were constructed exactly the same as the sandwiches with the other three facesheet materials but since the hemp came from the manufacturer as a roll of dry fabric with no

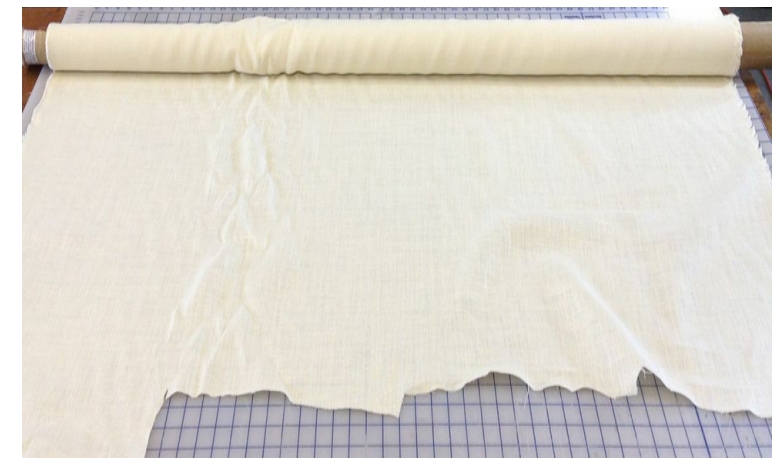
epoxy matrix impregnated in it already, ex-

Figure 2.6: Roll of dry hemp fabric in bulk tra manufacturing work was necessary to create the three ply facesheet laminates. This was beneficial because this fabric as well as the uncombined resin and hardener constituent materials of the composite could be stored at room temperature before use. The non-beneficial side of using dry fibers is that the fibers have to be impregnated with epoxy by hand. Without precision machinery to improve fiber volume ratios in the finished composite material, the hand layup method had to be used to construct hemp fiber composite sandwiches.

The first step of this process was to cut the hemp fabric into 12 inch by 12 inch squares similar to the prepreg material. The roll of hemp was a little less than five feet wide so only four squares could be cut out for every 12 inches cut down the length of the roll. The roll of hemp material can be seen in Figure 2.6. Once the six squares of dry hemp fabric were cut out, the hand layup method began. The first step in the hand layup method was to mix the correct amount of resin and hardener so that 864 square inches of hemp could be completely covered with epoxy. Earlier testing had been done to find out that the proper amount of resin necessary to cover one square foot of the B601 hemp easily was roughly 
0.25 grams. Knowing this ratio and that 864 square inches of hemp are needed for our composite sandwich plates, roughly 210 grams of Aeropoxy PR2032 resin was poured into

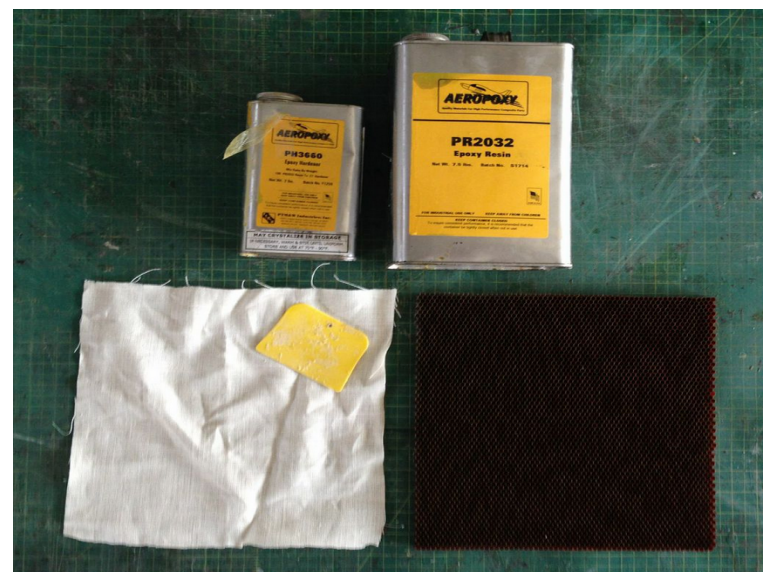

Figure 2.7: Aeropoxy resin and hardener (top), hemp dry sheet with epoxy spreader (left), honeycomb core (right)

a cup on the scale in the Cal Poly Aerospace structures lab. The Aeropoxy datasheets gave a resin-to-hardener ratio of 100 PR2032 to $27 \mathrm{PH} 3660$. Using this information, roughly 57 grams of hardener was added to the cup of resin and the resulting epoxy was stirred to evenly distribute the hardener throughout the resin. The newly formed epoxy was then evenly spread throughout each hemp square individually using the yellow epoxy spreader shown in Figure 2.7. After each hemp sheet was covered in epoxy, the next dry sheet of epoxy was then laid on top to soak up the excess epoxy and allow for conservation of epoxy. Once the three ply top and bottom facesheets were covered in epoxy and laid up together, the process of manufacturing the overall composite sandwich was identical to the prepreg layups. An adhesive layer was laid on both hemp composite laminates and then those laminates were laid on both sides of the core material, making sure that the adhesive was in contact with the core. Like the prepreg layup, every hand layup was done without the use of machinery; however, this could have resulted in slightly uneven distributions of epoxy throughout the composite laminates and different mechanical characteristics in each layer of the composite sandwich. The human error resulting from the hand layup of hemp was most likely larger than the error resulting from the prepreg tape layup of the other eight sandwich combinations.

\subsubsection{Curing and Test Setup Process}

After each composite sandwich plate was manufactured, they had to be cured using the 
heat press machine provided in the Cal Poly Aerospace structures lab. The fully manufactured, uncured composite sandwiches are shown in Figure 2.8. The heat press, shown in Figure 2.9, has two metal plates that are each 12 inch by 12 inch squares. The uncured composite sandwiches are stripped of any remaining protective film and then placed in-between the two metal

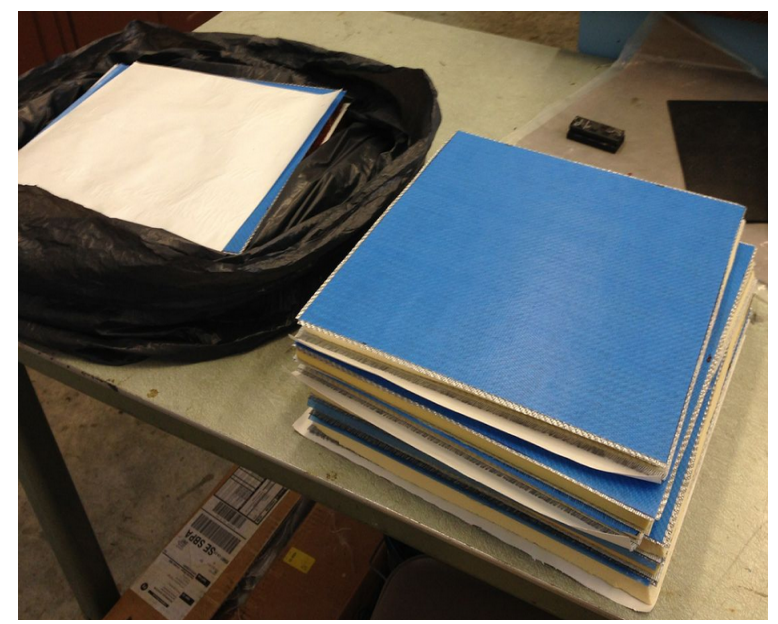

Figure 2.8: Uncured glass fiber composite sandwich plates with protective films on the outsides

plates with a sheet of nonporous material separating the sandwiches from the face of the metal plate. The nonporous material keeps the excess epoxy from seeping out onto the expensive metal plates and hardening on them after curing, ruining the plates. If two plates have the same facesheet cure schedule, then both of them can be put into the heat press with a metal plate separating them to allow simultaneous curing. The overall composite plate curing setup is shown in Figure 2.9.

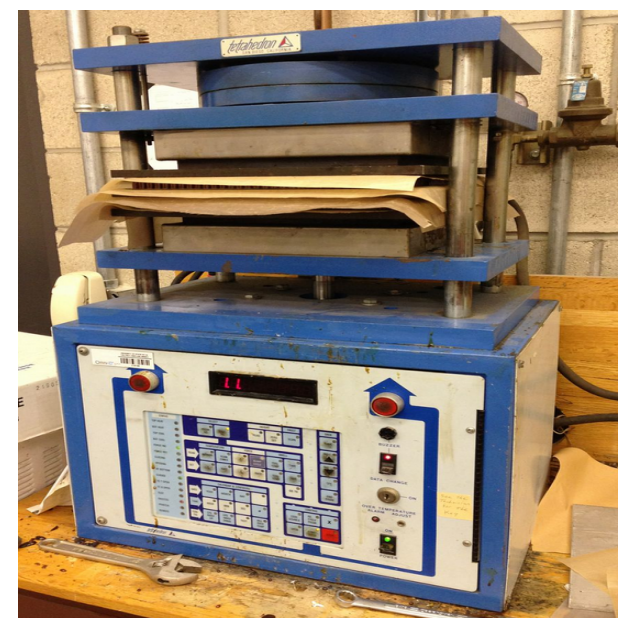

Figure 2.9: Cal Poly Aerospace structures lab heat press
Each cure cycle used in the heat press was based on the cure schedules of the epoxies used in each composite material. The Hexcel 8552 epoxy system in the carbon fiber prepreg facesheets had a suggested curing schedule on its datasheet.[28] This schedule consisted of an initial ramp up to $225^{\circ} \mathrm{F}$ where it held for an hour. Following that hour, the temperature ramped up again to $350^{\circ} \mathrm{F}$ and stayed there for two hours.[28] Finally, a cooling ramp down in temperature occurred to $145^{\circ} \mathrm{F}$ so that there was no shocking temperature drop for the sandwich. Large, rapid drops in temperature after a 
curing cycle create major thermal stresses on the sandwich that can deform the finished part and greatly decrease the structural integrity. A constant force of $300 \mathrm{lbf}$ was held on the carbon fiber sandwiches throughout the cure cycle as well. The hemp facesheet composite sandwiches cured based on the Aeropoxy cure schedule which was optimized at $120^{\circ} \mathrm{F}$ for 12 hours.[29] A constant force of $100 \mathrm{lbf}$ was held on the sandwiches throughout the process. The glass and aramid fiber composite materials were both generously donated by Quattro and they suggested a one hour cure time at $250^{\circ} \mathrm{F}$ for both of the materials. This cycle was applied to all glass and aramid fiber facesheet sandwiches with a 100 lbf constant force and resulted in acceptable finished parts. The carbon fiber, glass and aramid fiber, and hemp fiber cure schedules are shown in Figure 2.10a, 2.10b, and 2.10c, respectively.

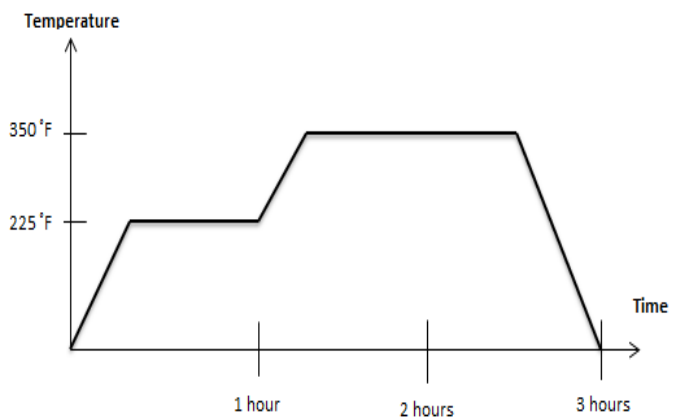

(a) Carbon fiber prepreg cure schedule [28]

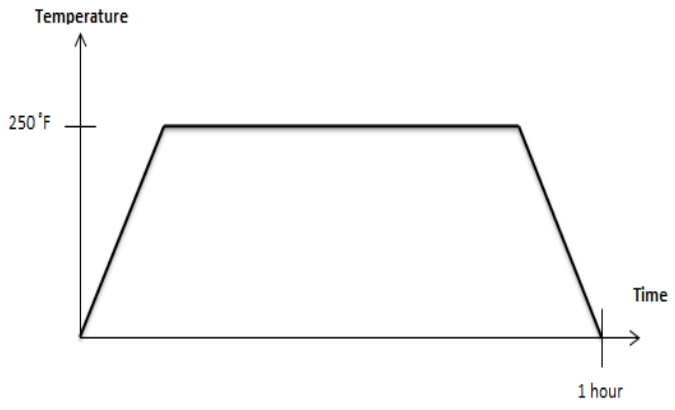

(b) Glass and aramid fiber prepreg cure schedule

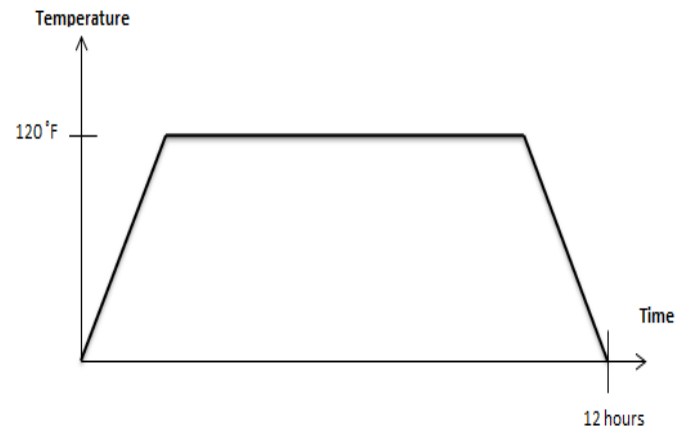

(c) Hemp facesheet cure schedule based on Aeropoxy epoxy [29]

Figure 2.10: Cure cycles of every composite sandwich facesheet material

Once the sandwich plates were finished curing, each one was allowed to cool before post-cure test preparations began. Each plate had to be cut down to the three 3 inch by 
10 inch test sandwich specimens after cooling. To accurately cut each specimen out of the plate, lines were drawn with straight edge tools on the cured plates to designate where each sandwich would be cut out of and each designated area was labeled with a specimen name and number. The lined and labeled plates are shown in Figure 2.11a. Once they were

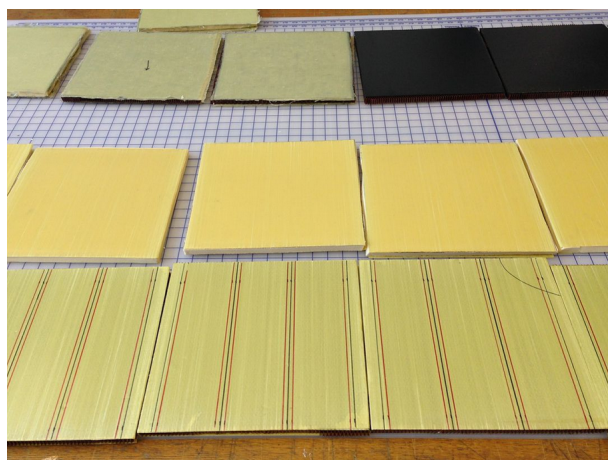

(a) Fully cured plates with cutting lines

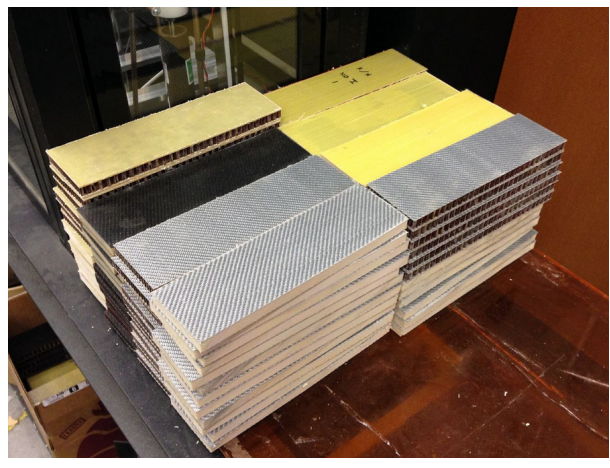

(b) Completely finished composite sandwich test specimen

Figure 2.11: Post-cure composite sandwiches

measured and lined, a diamond saw was used to cut out each specimen from the plates. The fully cut, finished, and labeled composite sandwich beams were cleaned up and organized for testing. These fully cut stacks of composite sandwich beams are shown in Figure $2.11 \mathrm{~b}$.

\subsubsection{Manufacturing and Testing of Hybrid Carbon and Aramid Fiber Facesheet Sandwiches with Honeycomb Cores}

Once all of the sandwiches were manufactured, two more hybrid sandwich designs were manufactured to improve the post-impact flexural strength of carbon fiber/honeycomb sandwiches. These sandwiches were only manufactured for the non-impact and impact damage on the compressive facesheet testing configurations because of the weakness in this sandwich design under the compressive bending post-impact loading condition. Hybrid carbon and aramid fiber facesheet structures were constructed using the same sandwich design that was used throughout this study of a half-inch thick core, 3 inch by 10 inch sandwich width and length dimensions, and three plies of composite materials on the top 
and bottom of the sandwiches. The idea behind this was that by replacing layers of carbon fiber on the exterior of a carbon fiber/honeycomb sandwich with layers of aramid fiber (proved in this study to have high impact damage resistance characteristics), the overall sandwich could improve its impact damage resistance and, thus, improve its post-impact compressive flexural strength characteristics. Two sandwich designs were manufactured and tested. One design was constructed with two carbon fiber plies connected to the core and one aramid fiber ply on the exterior of the sandwich. The other design had only one layer of carbon fiber connected to the core and two layers of aramid fiber composites on the exterior of the sandwich.

The manufacturing of these structures was done in a slightly different way than the rest of the sandwiches constructed for this study. Since the sandwiches are composed of two different types of facesheet materials that have two different curing cycles, they had to be manufactured and cured in two different steps. The first step was the construction of the carbon fiber laminates (one or two layers depending on the design) and the assembly of these laminates to the honeycomb core. This preliminary sandwich was cured using the carbon fiber prepreg's cure schedule. Once these sandwiches were fully cured, the single or double layer laminates of aramid fiber material was then laid on top of the carbon fiber facesheets. This new sandwich was then cured at the aramid fiber prepreg's cure schedule. This schedule was at a lower temperature and for a shorter length of time than the carbon fiber prepreg, which allowed the already cured carbon fiber parts of the sandwich to be unaffected by the second cure. Once this new sandwich had cured, it was then measured, cut, and tested like all of the other sandwich specimens.

For both of the sandwich designs, six specimens were manufactured, impacted, and then bent with the impact damage area under compressive bending loads and another six were manufactured and only tested under bending loads. The results of these tests were then compared to the non-impacted and post-impact bending with impact damage under 
compressive loads of the carbon fiber/honeycomb and aramid fiber/honeycomb sandwiches to understand the benefits of the hybrid sandwich design.

\subsubsection{Preparing Specimens for Mechanical Properties Testing}

The mechanical properties testing was done with strips of composite laminate materials so the manufacturing process of the composite laminates was exactly the same for each of the four composite facesheet materials as for the composite sandwiches. The manufacturing just ended before adhesive and core materials were used so the laminate plates were placed in the heat press and cured at the designated cure cycles shown in Figure 2.10a, 2.10b, and 2.10c. After curing the laminate plates were measured, lined, and cut into individual strips with the dimensions suggested by the ASTM standards. These measurements and test standards will be described in more detail in the next sections.

\subsection{Mechanical Properties Testing of Facesheet and Core Materials}

With all of the composite laminates cut to their correct dimensions for each test, the mechanical properties of each material were then found through three different tests on an Instron 8801 machine with wedge grip test fixtures: edgewise compressive, tensile, and strain gage assisted tensile tests. These tests all followed ASTM standards as closely as possible to obtain material properties data that was accurate and repeatable. The carbon fiber prepreg was the only material that had a datasheet with enough material properties data from the manufacturer to compare the accuracy of the testing findings to so carbon fiber was tested and analyzed first for each experiment to ensure results were acceptable.

\subsubsection{Preparing Facesheet Specimens for Material Properties Testing}

The fully cured, cut, and labeled test specimens were not completely prepared for test- 
ing after manufacturing. The wedge grip test fixtures, shown in Figure 2.12, clamp down on test specimens with a lot of pressure to ensure that each specimen does not slip out of the fixture during testing. An extra layer of material (typically a fiberglass or metal material) is added to the ends of each test specimen to increase the area in which the grips can clamp to minimize the slippage. This extra layer of material, called a tab, is also used to strengthen the part of the test strip in the clamped area which cre-

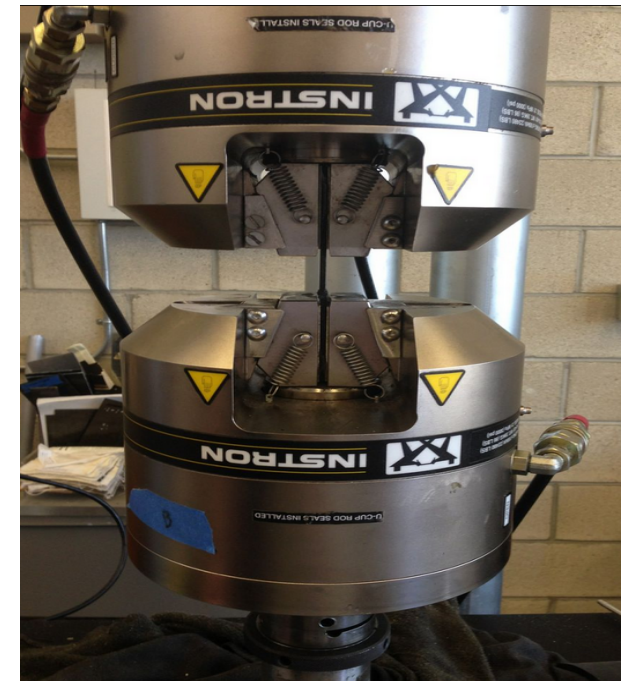

Figure 2.12: Instron 8801 tensile/compression test fixtures with clamped test specimen ates failures in the test strip between the clamping areas. Because of this, much better material properties values result from these tests. The compressive pressure from the clamps combined with the tensile/compressive longitudinal forces of the machine would create a failure where the test specimens are clamped without tabs; but, with tabs, the failure is only due to longitudinal forces, which is why the resulting values are more accurate. In this study, aluminum strips were bonded to each side of the fully cured and cut laminates on both ends. The strips were cut to the length and width suggested by the ASTM for each test. After being cut, a file was used to score the surface of each aluminum tab, allowing

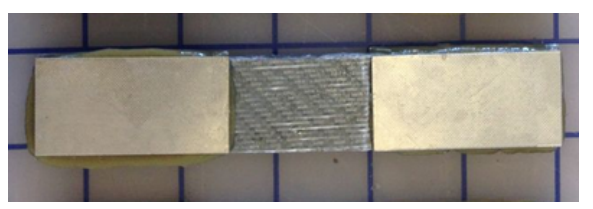

Figure 2.13: Compressive properties test strip with bonded aluminum tabs the surface to be rougher. This allowed for better bonding strength when the tabs were bonded to each specimen. For each tab, a $3 \mathrm{M}$ two part structural adhesive paste (1614A and 1614B) was used as the bonding material. By weight, the ratio of A-to-B used for the structural adhesive was one-to-one. Once all of the tabs were covered in adhesive and placed on the specimens, the adhesive was cured in the heat press with the same setup as when the laminate plates were cured. The adhesive cure schedule was $150^{\circ} \mathrm{F}$ for 1 hour with $100 \mathrm{lbf}$ of constant force. With the adhesive fully cured, the specimens 
were completely ready for testing. Figure 2.13 shows an example of a test strip with the aluminum tabs bonded on it. At least six of these test strips were made for each material for the compressive and tensile tests. One of the tensile strips was used as a Poisson's ratio test specimen and it had to undergo one more preparation step before testing.

\subsubsection{Compressive Testing Procedure (ASTM D3410)}

The test method used to find compressive characteristics of each facesheet material was ASTM D3410.[30] This test method suggested using test specimen that were 5.5 inches by 1.0 inch dimensions and roughly 0.1 inch thick. This dimensioning applied to glass, carbon, and hemp fiber materials as well as the 90 degree oriented aramid fiber material; however, for the 0 degree oriented aramid fiber test specimens, a half-inch width was recommended. The gage length (length of the section of specimen that is not clamped in the grips), see Figure 2.12, recommended by the ASTM for this test was 0.5-1.0 inch and the length of the aluminum tabs was recommended to be 2.5 inches. This meant that with a 5.5 inch long specimen and two 2.5 inch tabs, there was a 0.5 inch gage length for each compressive specimen. This worked out perfectly except for the fact that the Instron wedge grips were only 2 inches long. This meant that with a 5.5 inch specimen, the minimum gage length possible was 1.5 inches because of the two 2 inch grips. Because the

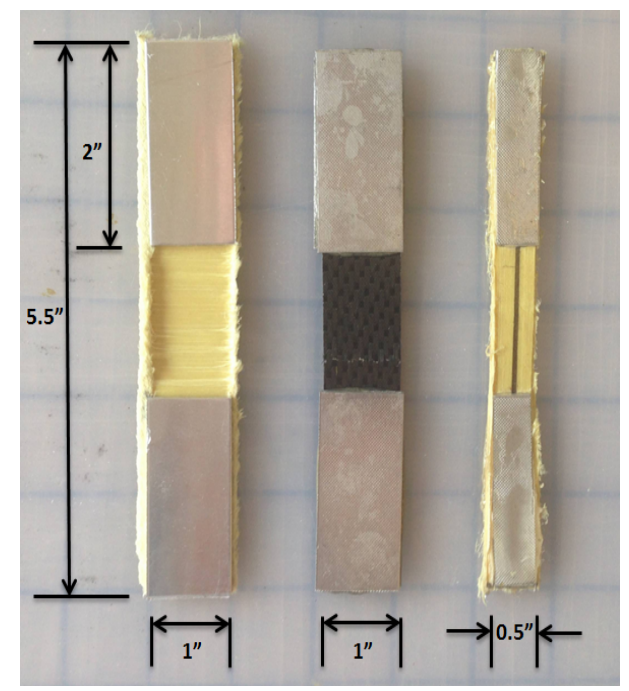

Figure 2.14: Compressive test specimens with dimensions Instron grips were the only ones available, the aluminum tabs were cut to be 2 inches long instead of 2.5 inches so as to not skew the mechanical properties results of each material. The fully manufactured compressive test specimens can be seen in Figure 2.14 with their dimensions. Once the tabs were on the specimens, they were individually placed into the wedge grips, as seen in Figure 2.12. When the test began, the bottom fixture began to move 
upward at the ASTM recommended rate of 0.05 inches per minute, creating a gradually increasing compressive load. The test ended when the strip fully failed and the load dropped to below $40 \%$ of the maximum load because of that failure. Plots of load vs. extension and stress vs. strain were outputted for each specimen's test along with raw load and extension data. Results for eight carbon fiber and seven aramid, glass, and hemp fiber specimens were analyzed to get updated structural characteristics of each material.

\subsubsection{Tensile Testing Procedure (ASTM D3039)}

The test method used to find tensile material characteristics was ASTM D3039.[31] The tensile test specimens had ASTM suggested dimensions of 1.0 inch by 10.0 inches with a thickness of 0.1 inch. These dimensions were for woven composite materials like the carbon, glass, and hemp fibers, however. The 0 degree aramid fiber direction test specimens were 0.5 inches by 10.0 inches and needed to be 0.04 inches thick; whereas, the 90 degree aramid fiber test specimens were 1.0 inch by 7.0 inches and had a thickness of 0.08 inches. The gage length for the tensile specimen was not as big of an issue as it was for the compressive specimen so a 2 inch tab length was used for every specimen, except the 90 degree aramid fiber specimens which were 1.0 inch long tabs per the ASTM. The ASTM did specify a tab length of 2.5 inches for the 0 degree aramid fiber direction specimens but 2 inch tabs

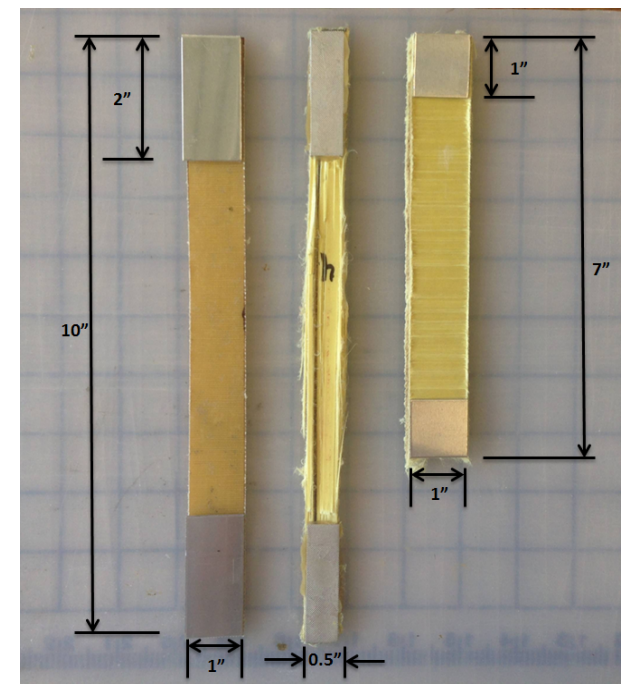

Figure 2.15: Tensile test specimens were used due to the size of the Instron wedge grips. with dimensions

Once the tabs were cut to the correct size and bonded to the test strips, the specimens were individually placed into the test fixture exactly like the compressive specimens. These finished specimens are shown in Figure 2.15 with their dimensions. The test was run exactly like the compressive test as well except that the bottom fixture moved downward when the 
test started at the ASTM specified rate of 0.05 inches per minute, gradually increasing the tensile load until the load dropped to $40 \%$ of its maximum because of ultimate failure. The same plots and raw data that were outputted for the compressive tests were also outputted for the tensile tests.

\subsubsection{Strain Gage Setup for Poisson's Ratio Test Specimens}

The last step for the tensile test specimen that was used for Poisson's ratio testing was the addition of lateral strain gages to get transverse strain readings for Poisson's ratio calculations. This step came after the aluminum tabs were bonded and cured to the test specimen. The first step in attaching the strain gages to the test strip was cleaning the specimen. Acetone was

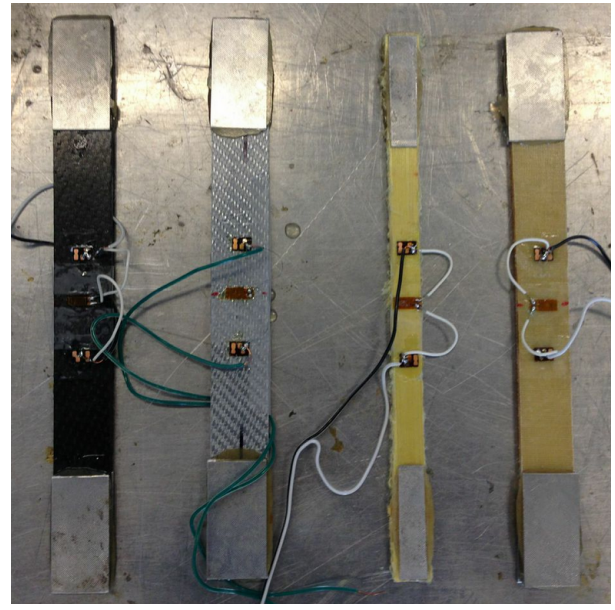

Figure 2.16: Poisson's ratio test specimens with strain gages and wiring attached used to wipe down the surface of the test strip that was going to have the strain gage on it so that the specimen was void of all dirt and debris. Along with that surface, another preparation surface was cleaned with acetone and the strain gage was placed on that surface after being taken out of the package. Once on that surface, a piece of Scotch tape was laid on top of the strain gage, making sure that the top surface of the strain gage was touching the tape. The tape, with the strain gage connected, was then laid down on the test specimen in the exact position and orientation that was necessary for the test. This position and orientation can be seen in Figure 2.16. With the orientation finalized, one end of the tape was lifted off of the test specimen, lifting the strain gage with it as well. While the bottom surface of the strain gage was exposed, a blue Vishay 200 Catalyst-C M-bond adhesive was brushed onto it. With the strain gage covered in the catalyst and still lifted up, the other part of the M-bond 200 adhesive is applied to the surface of the test specimen directly below the strain 
gage. Once both surfaces were covered, the tape was then reapplied to the surface of the specimen and the chemical reaction began, bonding the strain gage to the surface. After the curing had completed, the surface of the strain gage was clean by getting rid of any excess cured M-bond adhesive and wiping it with acetone. The wiring, shown in Figure 2.16, was then connected to the ports of the strain gages and grounds by soldering. Once each wire had been soldered to each strain gage port on the test specimen, an M-Line rosin solvent and then an M-Coat A air-drying polyurethane coating were brushed on top of the soldered areas of the strain gages to create a protective barrier on the wiring. The test specimen seen in Figure 2.16 are the completely finished test specimens that were used for Poisson's ratio testing.

\subsubsection{Poisson's Ratio Testing Procedure (ASTM E132)}

The test method used to find the Poisson's ratio of each facesheet material was ASTM E132.[32] The test specimens, as recommended by the ASTM, have a length that is at least five times larger than its width, a gage length that is at least seven times larger than its width, and a width that is larger than its thickness.[32] Each of these requirements were met with the tensile test strips manufactured so those strips were used for Poisson's ratio testing. Plus, the Poisson's ratio testing used the exact same test method on the Instron as the tensile test did so using the tensile test specimen dimensions was an easy decision. The rate of increase of the test fixture was 0.05 inches per minute like the tensile test but the test was stopped before failure for the purpose of keeping the strain gages from being broken. The only difference between

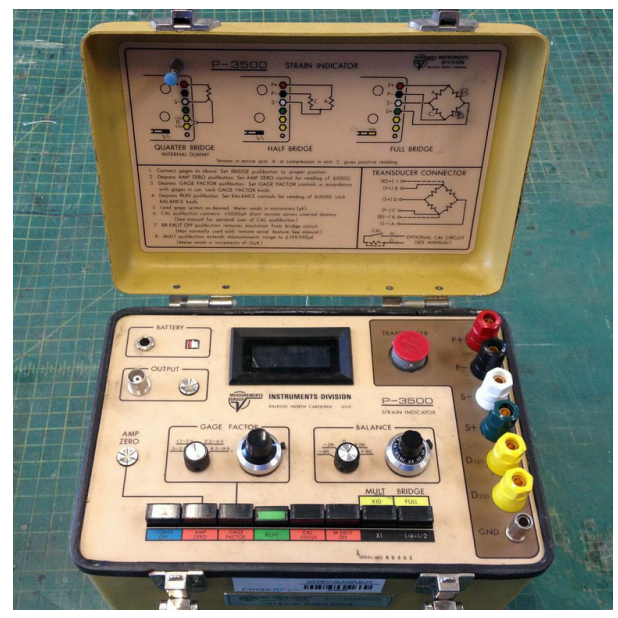

Figure 2.17: Strain indicator used with a quarter bridge circuit to collect strain data this test and the tensile tests was the collection of the transverse strain data from the attached 
strain gages. The collection of this data came from a combination of a Measurements Group strain indicator box, National Instruments USB-6229 DAQ device, and a LabView code written by a Cal Poly student named, Ross Gregoriev. The strain gage indicator can be seen in Figure 2.17. The wires extruding away from the strain gage setup on each test specimen run to the strain indicator box which is setup in a quarter bridge circuit with the USB DAQ device. These strain readings were then sent to the LabView code, shown in Figure 2.18, which converted the data into units of millistrain and outputted it to a .csv file with the load in units of pounds force.

All of the tests run in this study on the Instron machine were run using the Bluehill 2 program, which outputs longitudinal strain for each test specimen. Since the machine starts the test when prompted to from the Bluehill program, the Labview data collecting was started first, then the Bluehill test was started (allowing the test fixtures to start moving), then the Bluehill test was stopped after enough data was collected, and lastly,

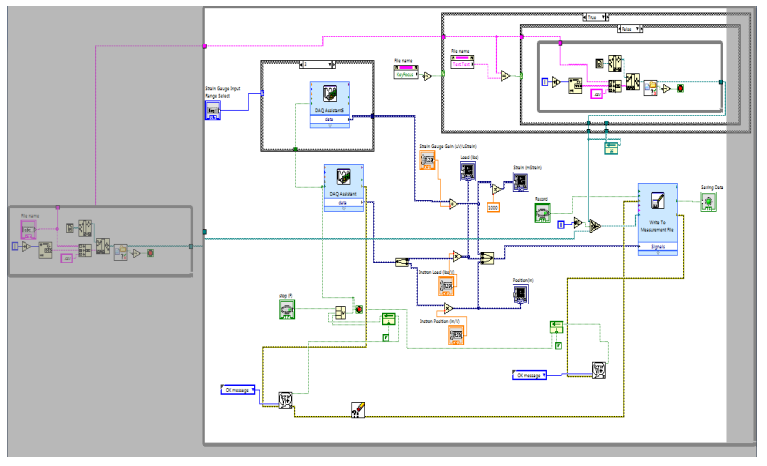
the Labview program was stopped. This Figure 2.18: LabView code used to collect created more data points in the Labview transverse strain gage data outputted data than it did for the Bluehill outputted data because the Labview was started before and ended after Bluehill was. The calculation of Poisson's ratio, according to the ASTM, is the slope of transverse strain vs. load (from LabView) divided by the slope of longitudinal strain vs. load (from Bluehill) so individual numbers were calculated from each set of data and divided by each other, resulting in no issue with the difference in number of data points from each data collecting program. The equation for Poisson's ratio of the facesheet materials, $v_{f}$, from the ASTM is shown below in Eq. ( 2.1).

$$
\mathrm{v}_{f}=\frac{\frac{d \varepsilon_{t}}{d P}}{\frac{d \varepsilon_{l}}{d P}}
$$


$\varepsilon_{t}$ and $\varepsilon_{l}$ are the strains in the transverse and longitudinal directions, respectively and $\mathrm{P}$ is the loading throughout the test.

\subsubsection{Poisson's Ratio Testing of Honeycomb Core (ASTM D6790)}

Since honeycomb does not have the same smooth, continuous structure that a composite laminate has, strain gages cannot be attached to it to get transverse strains so Poisson's ratio cannot be calculated using the methods described above. Also, if a strip of honeycomb was to be put into the wedge grip test fixture in the Instron machine, it would crush under the clamping force. Filling the open cells of the honeycomb with a solid homogeneous material with good compressive characteristics would allow for the clamped area to be uncrushed during testing but Poisson's ratio still can't be found using the Instron machine. Because of these issues, ASTM D6790 was used to as an alternative method to find the honeycomb's Poisson's ratio.[33] The method introduced in this testing procedure applies the theory of anticlastic curvature. When an anticlastic material is bent about one axis, bending will also occur about the perpendicular inplane axis. An example of this can be seen in Figure 2.19 where the honeycomb is bent down about the

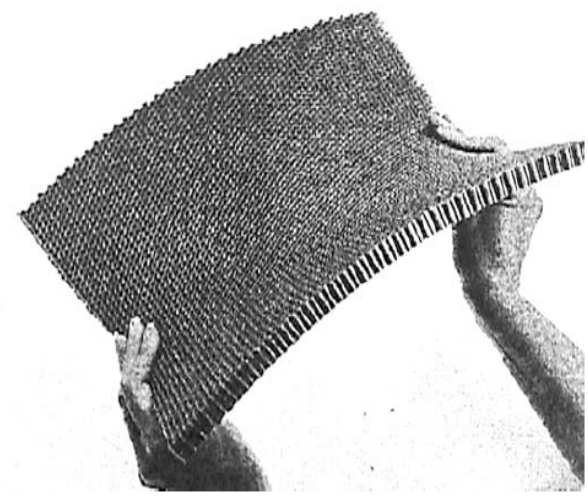

Figure 2.19: Example of anticlastic curvature with a honeycomb core longitudinal axis but upward bending occurs about the perpendicular, transverse in-plane axis (a line connecting the fingers on the left hand to the fingers on the right in Figure 2.19). Using the radii of anticlastic curvature, the Poisson's ratio can be calculated for the honeycomb core.

To find the radii necessary, the ASTM suggests bending a 12 inch by 12 inch half-inch thick honeycomb core around a recommended 24 inch diameter cylinder. The cylinder used for this study was a 25 inch cylinder but the honeycomb dimensions were used as 
suggested. When the honeycomb is bent around the outside of the cylinder, anticlastic curvature occurs and the sides of the honeycomb not being held down by fingers (like in

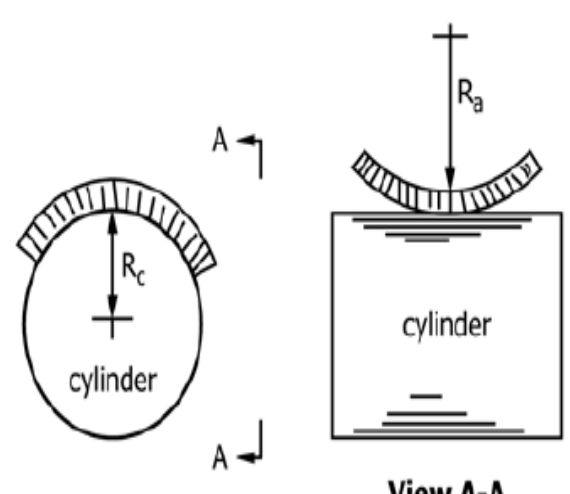

View A-A

$R_{C}=$ cylinder radius $\quad R_{a}=$ anticlastic radius

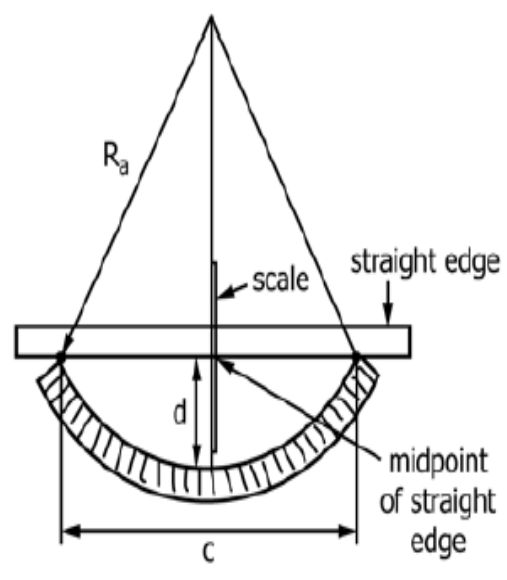

Measurements

Figure 2.20: Visual of how to calculate Poisson's ratio of honeycomb using anticlastic curvature

Figure 2.19) lift up. If a straight edge is placed on top of the lifted edges of the honeycomb, how high the sides of the honeycomb lift up as well as the distance between the two edges of the lifted up sides can be found. Figure 2.20 gives a visual representation of how to find these values. With these two values, the radius of anticlastic curvature can be found using Eq. ( 2.2). The Poisson's ratio of the honeycomb core, $v_{c}$, can then be found using this result and the radius of the cylinder using Eq. ( 2.3) below

$$
\begin{gathered}
R_{a}=\frac{4 d^{2}+c^{2}}{8 d} \\
v_{c}=\frac{R_{c}}{R_{a}}
\end{gathered}
$$


Where $d$ is the height of the anticlastic curvature, $c$ is the length between the raised edges, and $R_{a}$ and $R_{c}$ are the radii of anticlastic curvature and the cylinder, respectively.

\subsubsection{Tensile Testing of Honeycomb Core}

The honeycomb material that was used for testing in this study was transported in the back of an open bed truck to the Aerospace structures lab on the Cal Poly campus and stored outdoors under a tarp so the material naturally degraded overtime. Because of this, testing needed to be done to understand how much degradation there had been during the storage period. There are no guidelines that describe how to perform a tensile test

of honeycomb so a test was created to try to get the results necessary for theoretical and numerical analysis. This test began by cutting out a 5 inch by 10 inch piece of honeycomb with the longitudinal direction being 10 inches long and the transverse direction being 5 inches wide (this was a similar dimension to a test conducted for another study by Foo, Chai, and Seah[34]). Two aluminum plates were constructed with holes in them, as shown in Figure

(a) Honeycomb tensile test aluminum strips

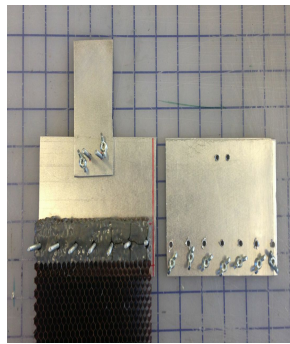
and screws through honeycomb cells

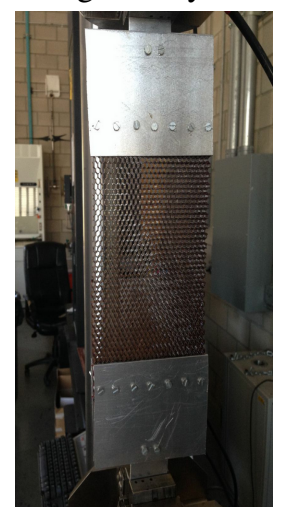

(b) Honeycomb tensile testing setup

Figure 2.21: Honeycomb core tensile test

2.21a, and screws were fed through these holes and the holes in the cells of the honeycomb. Another smaller plate was cut out and connected using two screws at the top of the two larger plates, as shown in Figure 2.21a. The plate on the right was the placed on top of the honeycomb, feeding the screws through its holes, enclose the honeycomb and top aluminum strip inside the large plates. To ensure that the screws wouldn't shred the cells of the honeycomb when the top aluminum strip pulled the honeycomb in the longitudinal during testing, structural adhesive, shown as the gray material in Figure 2.21a, was infused into 
the holes of the honeycomb around the holes that the screws were fed into. This made sure that the tensile failure was in the honeycomb and not in the fixture. The same setup was done on the other end of the honeycomb and the two thin aluminum strips were pulled in the Instron machine using the same testing procedure as the facesheet material tensile tests. This resulted in an elastic modulus value that more accurately represented the strength of the degraded honeycomb. The entire test fixture setup is shown in Figure 2.21b.

\subsubsection{Fiber Volume Fraction Calculations for Facesheet Materials}

Another beneficial method of determining the quality of a material is calculating that material's fiber volume percentage. This value describes how much of a material is composed of fibers and how much is matrix. Typically the datasheet for a prepreg material will give this value and then ignition loss calculations are done later to determine the loss of matrix material from the prepreg (degradation of the material overtime). This ignition loss is calculated by cutting out a small section of a specimen (in this study that specimen was 1 inch by 1 inch and had the same thickness as the tensile test specimens) and placing it in a furnace which is heated to the required temperature to burn off the matrix material but not burn the fibers. The specimen was left in the furnace, shown in Figure 2.22, until all of the epoxy was burned out of the material, leaving only the dry fibers. The specimen was weighed before being burned and then the dry fibers were weighed after the burning process was

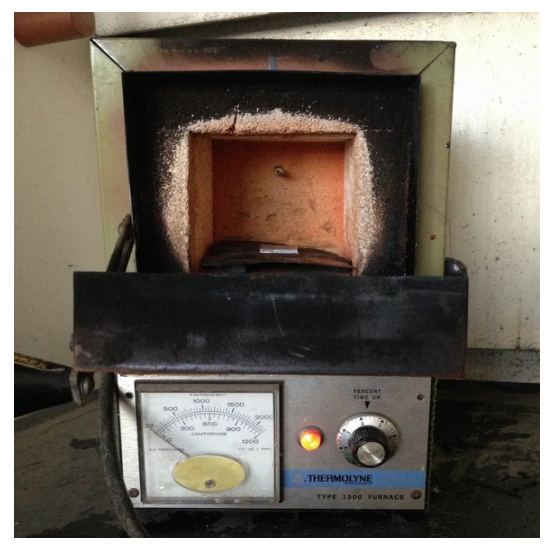

Figure 2.22: Furnace used to burn the epoxy out of fiber volume percentage specimens completed. The ignition mass loss was calculated using Eq. 2.4 from ASTM D2584.[35]

$$
\text { Ignitionloss, weight } \%=\left[\frac{W_{1}-W_{2}}{W_{1}}\right] * 100
$$


$W_{1}$ represents the initial weight of the specimen before burning and $W_{2}$ represents the weight of the dry fibers after burning. This mass percentage signifies that amount of epoxy that was in the specimen. If this number is subtracted from 100, the fiber mass percentage can be found. Typically, the material datasheet gives this value as a volume fraction instead of a mass fraction, however. So the density of the specimen was found by dividing its mass by the measured volume before burning. The density of the fibers (taken from the datasheet for carbon and glass fibers and calculated for hemp and aramid fibers) was then divided by the specimen density to get the fiber volume percentage.

\subsection{Composite Sandwich Experimental Impact and Four-Point Bend Testing}

Unlike the mechanical properties test specimens, the composite sandwich test specimens were ready to be tested after being cut to the 3 inch by 10 inch dimensions. As mentioned before, for each of the ten variations in sandwich design (two of the variations combine two different facesheet materials and the other eight use only one facesheet material for the entire sandwich), three different types of testing procedures were done. Six of the sandwiches were impacted and then the impacted surface was placed in compression (facing upward) when it was subjected to a four-point bending load. Another six specimens of the same composite sandwich design were impacted and then the impact was placed in tension during bending. And, lastly, a control sandwich was never impacted and was just subjected to a four-point bending load. These three test procedures allowed for the postimpact flexural strengths of each sandwich design to be analyzed. The rest of this chapter will describe how both the impact and four-point bending tests were performed. 


\subsubsection{Mechanical and LabView Rework on Dynatup 8250 Impact Machine}

Before any testing or analysis could be done, however, the Cal Poly Aerospace structures lab's Dynatup 8250 impact machine needed to be restored. Together with Dr. Eltahry Elghandour, a former Cal Poly Aerospace graduate student, Kodi Rider, assembled all software and hardware necessary to construct a fully operational and data collecting impact machine. Kodi wrote the LabView and Matlab codes necessary to allow for data to be collected from the impact machine and then be converted into user-friendly impact velocity and impact load plots and results. When this study began, however, the machine was not working the

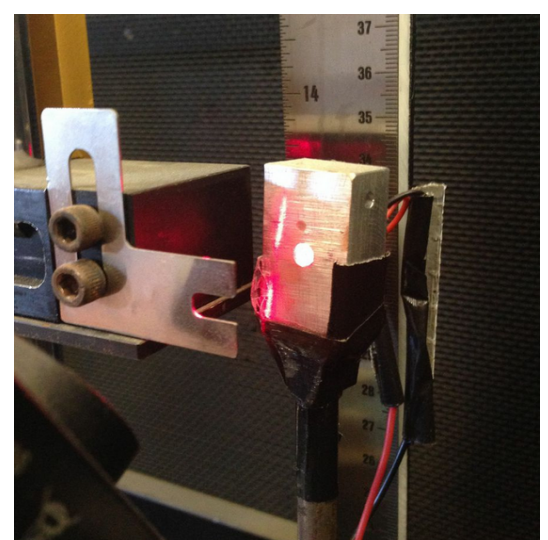

Figure 2.23: Red laser used to calculate veloctiy of impacts way that Kodi designed it to. The laser, shown in Figure 2.23, that is used to calculate the impact velocity would not turn on so an initial rewiring and reapplication of solder to the laser was done to make sure the wire wasn't the issue. It was not the issue but the wire that connects to the laser was traced back to the National Instruments SC-2345 signal conditioner where the wire also connects to an SCC-AO10 isolated analog output module, shown on the left of Figure 2.24 with a red line on it. This module was slightly displaced up from its connection port which meant that the unsecure connection was not allowing the computer to signal the laser to turn on. Rewiring the module and internally fixing its ability to connect with the signal conditioner resulted in a working laser.

The LabView code that Kodi had written was still not working, however. After attempts were made to adapt the code to improve the accuracy of the data being outputted, a new code was finally built using Kodi's code as a reference. This new code can be seen in Figure 2.25 and is very similar to the reference code but each DAQ assistant, which reads in the data from the signal conditioner, was recreated to ensure each port in the signal 


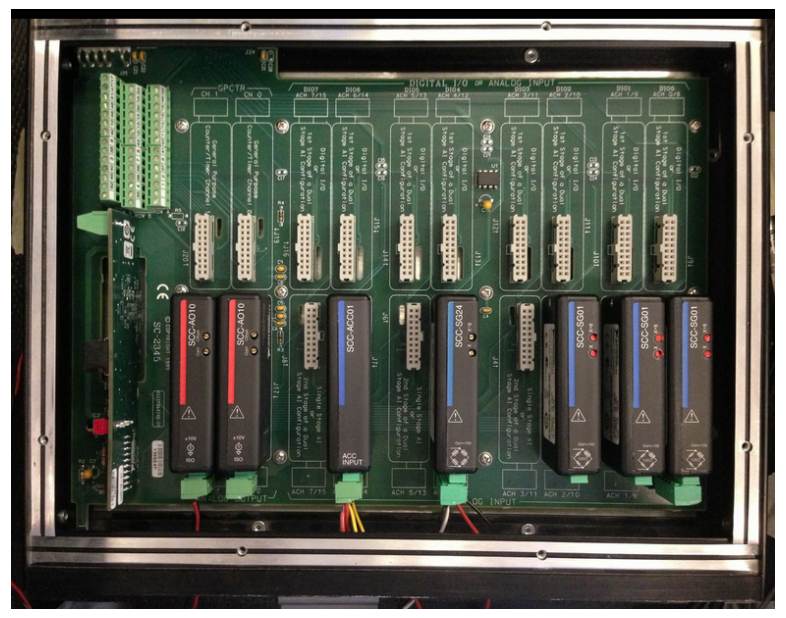

Figure 2.24: Signal conditioner with wires connecting to laser (left), accelerometer (middle), and load cell (right) modules

conditioner was reading the correct data. The next issue was that the Measurement and Automation Explorer scale, used to scale the incoming load cell data from volts to pounds force, used for Kodi's LabView code was nonexistent. A new scale was created using the 10 volt excitation voltage as a constant and the knowledge that the incoming data was in millivolts per volt. The outputted LabView data was compared to the raw data outputted by Kodi to ensure the new scale was accurate. The final data was close but not exact so another investigation of

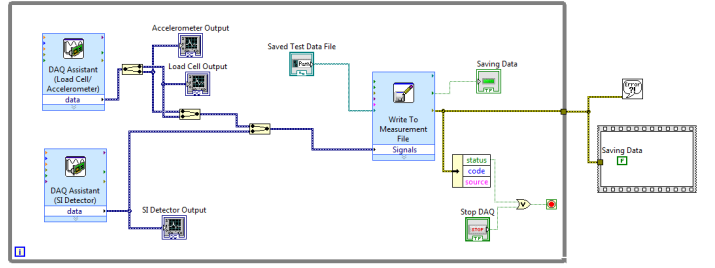
the signal conditioner lead to the conclu-

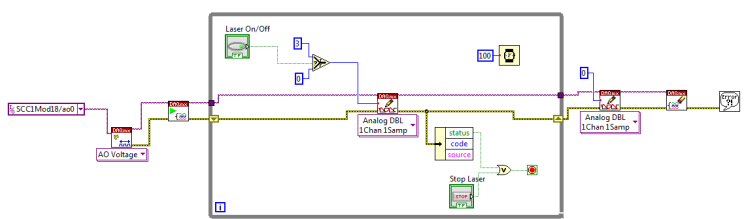

Figure 2.25: Dynatup 8250 impact machine LabView code created for data collection sion that the SCC-SG24 load cell module was not wired in the correct full-bridge setup. Rewiring this module per the manual to make sure each wire went to the correct ports on the module led to precise load cell raw data and allowed for the impact machine to be used experimentally. A complete description of how the Dynatup 8250 impact machine works will be presented in the next section. 


\subsubsection{Impact Machine and Testing Procedure}

To get a better idea of what part of the data collecting process those repairs were for and how the testing procedure worked for this study, an explanation of how the Dynatup 8250 impact machine works is necessary. The machine as a whole is shown in Figure 2.26. It is a drop-weight impact machine that drops a 7.56 lbf mass impactor (yellow crosshead mass plus silver load cell and rounded tip impact tup) down two control rails onto a test specimen that is clamped down by two 6 inch by 10 inch solid aluminum plates. Each plate has a 3 inch by 5 inch

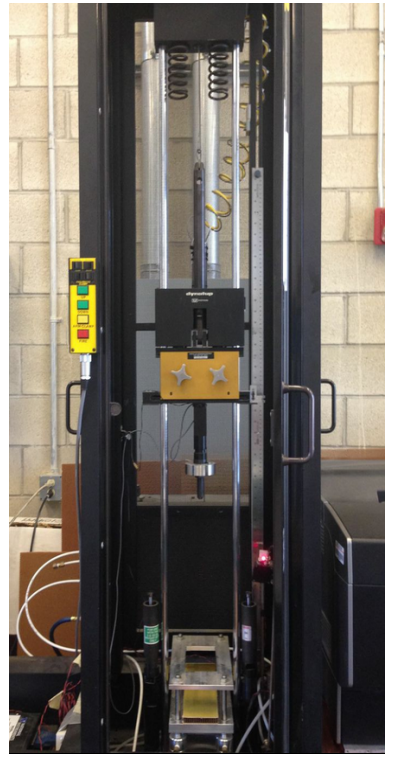

Figure 2.26: Dynatup 8250 impact machine cutout in it to allow the 0.625 inch diameter impact tup to contact the specimen without it getting any assistance from the plates. The system is pulled up and down along the rail to set impact height and then the crosshead is released from the black box above it to initiate the drop-weight impact. The springs at the top of the machine provide pneumatic, higher velocity impacts but this study strictly focuses on drop-weight impacts so that was never utilized.

When these impacts occur, three different sets of data are collected and sent through the signal conditioner to the LabView code. The three data set sources are the DET 10A Si biased detector which records the amount of light seen from the laser, the Transducer Techniques THD- 3K-W load cell which records loading throughout the impact, and the VIP Sensors accelerometer which sends a signal through a remote charge converter to the signal converter about accelerations during the impact. The accelerometer can be seen as the small silver part on top of the cylindrical silver load cell in Figure 2.27. The load cell 
records forces over the time of the impact and the accelerometer records acceleration over the same time so no extra work is needed to get maximum load results and accelerations after data conversion. The Si detector however, reads the amount of light received from the laser and then calculates the impact velocity using that information. It is able to do this because the impact crosshead and tup have a small metal sheet with a gap in it, shown in Figure 2.28, that juts out from the fixture. This gap passes through the beam of light from the laser, interrupting the signal that the Si detector witnesses. Knowing

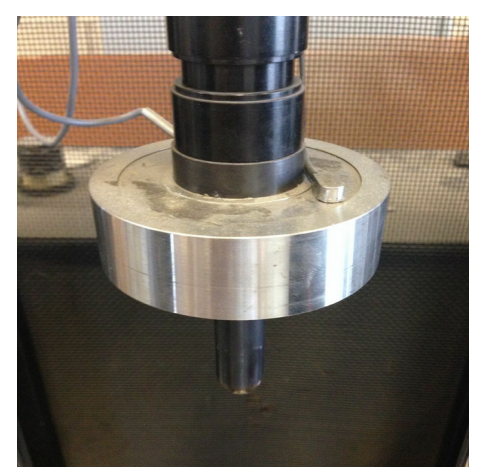

Figure 2.27: Cylindrical silver load cell with black impact tup below it and small accelerometer on top right the time it took for the light to disappear, appear, disappear, and then appear again as the impactor mass fell past the metal sheet, the velocity was calculated with a simple equation in the Matlab code. Altogether, these three data sets run through the signal conditioner and the LabView code and are outputted as impact load and velocity results in Matlab.

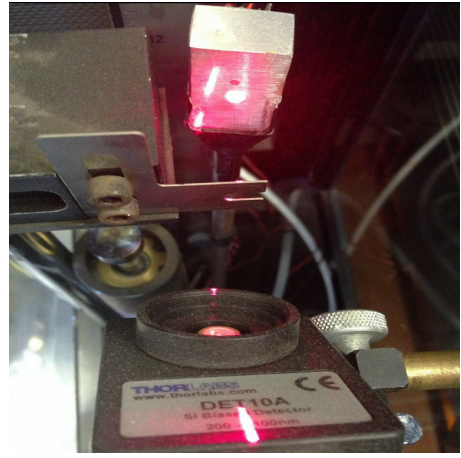

Figure 2.28: Metal sheet crossing the path of the red laser and disrupting $\mathrm{Si}$ detector data collection

Knowing the background of how the machine works, the overall testing method is pretty straightforward. The sandwich specimens were placed individually into the clamping fixture shown at the bottom of Figure 2.26 and when the test was ready to begin, the impactor mass system was raised to the top of the guide rail, roughly 38.15 inches above the top of the bottom aluminum plate, and the two aluminum plates clamped down on the sandwich to hold it in place. The LabView code was then prompted to run, the impactor mass was released, an impact occurred on the test specimen, the data being recorded on the raw data plots shown in Figure 2.29 were allowed to settle, and then the LabView code was prompted to stop running. The Matlab GUI code created by Kodi Rider was then opened 
and run. This opened the window shown in Figure 2.30 where the raw data file was selected and plots were created with the data from that file. Since there is not an actual ASTM standard for the dropweight impact on a composite sandwich, the maximum load and impact velocity were taken from these Matlab results and were used with ASTM D7136

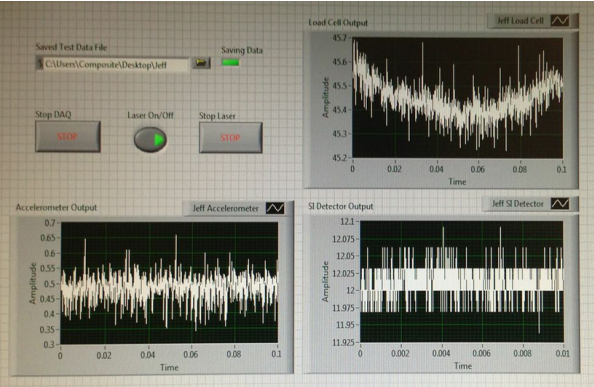

Figure 2.29: Accelerometer (bottom left), Si detector (bottom right), and load cell (top) raw data plots and ASTM D7766 to conclude the outcome of the tests. [32,33]

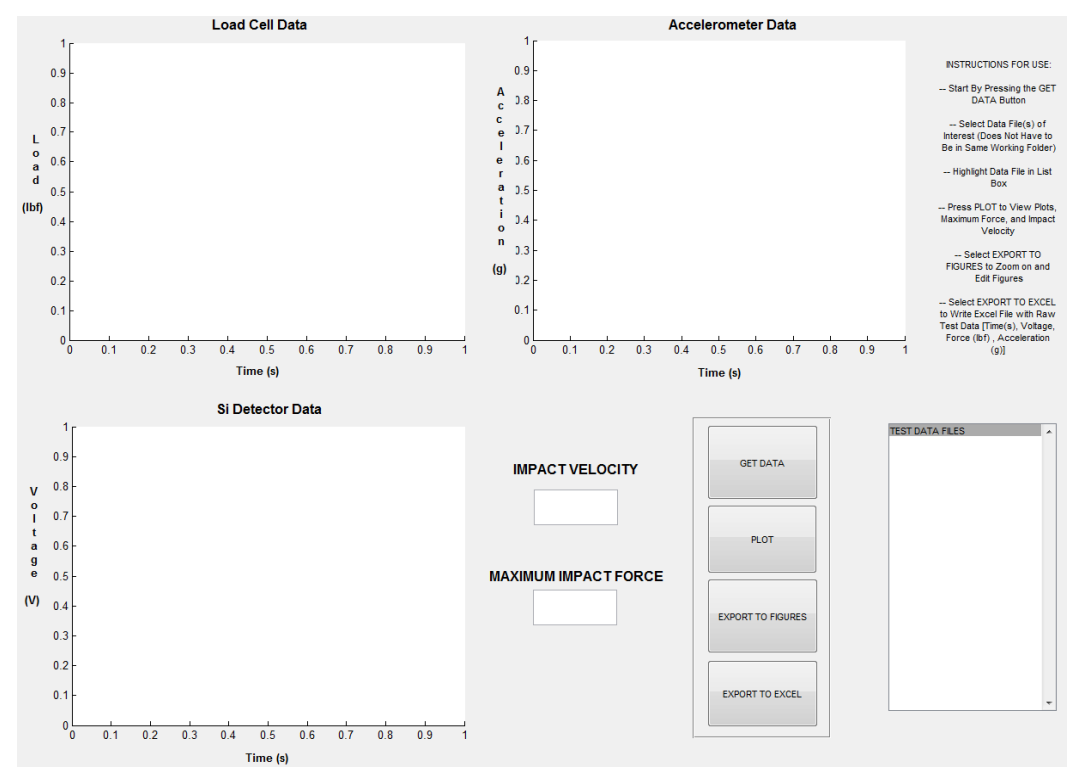

Figure 2.30: Matlab GUI prompt window for plotting LabView data

\subsubsection{Four-Point Bend Testing Procedure (ASTM D7250)}

The test method used to find the flexural strength and experimental mid-span deflections of the composite sandwich structures manufactured in this study was ASTM D7250.[36] This ASTM references and uses information from ASTM C393 and ASTM D7249 so these methods were used as well to get the experimental results necessary. [35,36] The majority of the testing procedure was based on ASTM D7250, though. This ASTM recommends using test specimens that have a width no less than twice the total thickness, no less than 
three times the dimension of a core cell, and no greater than half of the span length.[36] It also suggests that the length of each specimen be 2 inches greater than the support span length, which means that there will be an inch of overhang off the ends of the bottom test support fixtures. Because of the limitations on the impact machine clamping fixtures and the recommendations from this ASTM, the composite sandwiches tested in this study were manufactured with the dimensions mentioned earlier.

After the non-control sandwiches were impacted, all of the specimens were subjected to two four-point bend loadings. Per ASTM D7250, a minimum of two loading configurations must be used to minimize the error in the flexural and shear stiffness values, which led to mid-span deflection values. Because of this and the fact that a three-point bending load places stress concentrations on the centered impact damage, two four-point bend loading configurations were used. One quarter-point loading and one standard loading configuration were used. The general dimensions for these configurations are shown in Figure 2.31a next to the actual dimensions used for the sandwiches tested in this study in Figure 2.31b. The $\mathrm{S}$ in the general dimension loading configuration represents the support span length, the $\mathrm{L}$ represents the load span length, and $\mathrm{P}$ is the load on the sandwich. An 8 inch support span length was used for the 10 inch long sandwiches to allow the 1 inch overhang on each end, as mentioned earlier, and the load span varied for each loading configuration.
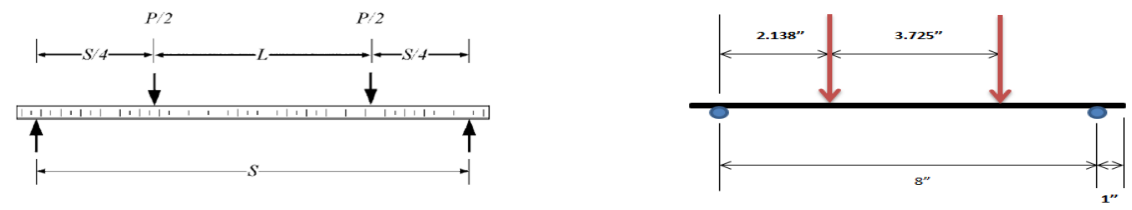

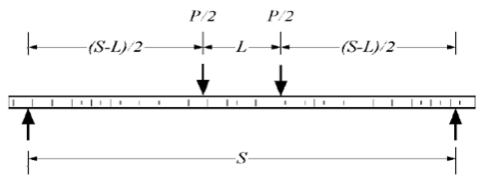

(a) ASTM D7250 four-point bend configurations

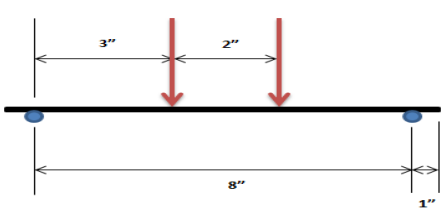

(b) Dimensions of four-point bend configurations used for testing

Figure 2.31: Quarter-point (top) and standard (bottom) four-point bend configurations for ASTM and actual testing 
The first loading that each specimen was subjected to was the quarter-point loading which made a 4 inch loading span between the top two loading pins; however, the top test fixture on the Instron 8801's four-point bend loading setup would not allow the two loading pins to be spread out any further than 3.725 inches so this was used as the loading span and the 8 inch support span was kept constant. The actual loading setup for the Instron 8801 is shown in Figure 2.32. Every test specimen was subjected to a 100 lbf load using this loading configuration so that the specimen would not be damaged by the test but data could still be collected about flexural and shear stiffness. Once all the specimens were tested using that loading configuration, the standard four-point bend configu-

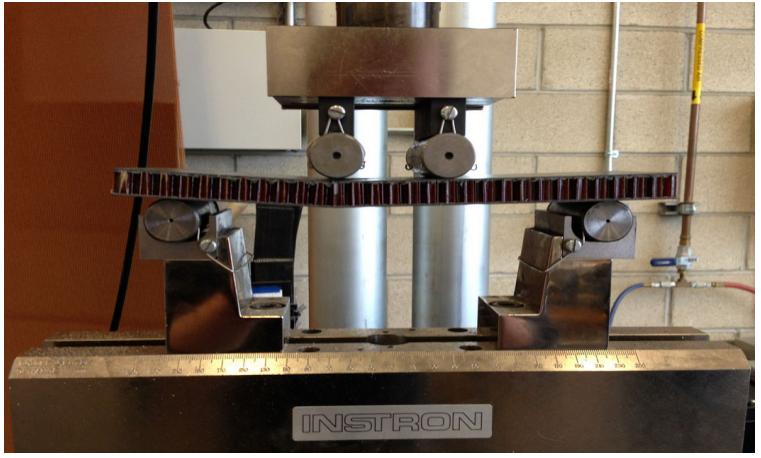

Figure 2.32: Carbon fiber/honeycomb composite sandwich under a standard four-point bend loading ration was then used with a 2 inch loading span. The load increased gradually on the specimens until they ultimately failed with this configuration. The load, support span length, and experimental extension values were taken from each testing configuration and used to calculate the transverse shear rigidity and flexural stiffness of the sandwich specimens. These values were then used to calculate the mid-span deflection of each sandwich at a 100 lbf loading. Maximum load values at failure were also taken from the standard four-point bending tests to use for analysis. 


\section{Chapter 3 \\ EXPERIMENTAL TESTING RESULTS AND DISCUSSION}

The results from the testing methods and procedures described in the previous chapter will be presented in this chapter. The compressive strengths and moduli and the tensile strengths and moduli, as well as the calculation of shear characteristics, of each facesheet and core material will be described. Experimental results from composite sandwich testing will then be presented for impact tests and then for four-point bend tests on sandwiches with and without impact damage. The description of experimental failure modes of each sandwich structure will be analyzed and the overall results will be summarized and compared.

\subsection{Facesheet and Core Material Properties Testing}

The overall purpose of performing the mechanical properties testing for this study was to get updated material characteristics for use in theoretical and numerical analysis. The values for compressive and tensile material properties given in the manufacturer's datasheets for prepreg materials doesn't always give an accurate representation of how that material performs experimentally because depending on the time since manufacture, the handling methods, and the storage of the material, the material characteristics can be greatly degraded. This is why updated numbers are necessary for these prepreg materials. Plus, since the glass and aramid fiber prepregs don't have datasheets, mechanical properties need to be collected from somewhere and testing the material laminates is the best way to get those. Lastly, since the hemp was not manufactured at a special facility, mechanical 
properties are nonexistent for this material without testing for them. These results help with the analysis of every experimental testing outcome as well as theoretical and numerical calculations.

Because the carbon, hemp, and glass fiber materials were weaves (shown in the tables as a "woven" material), the Poisson's ratio values, as well as the strengths and moduli, were considered to be the same in both the longitudinal and transverse directions. The aramid fiber material, however, was a unidirectional (in the tables unidirectional will be shortened as "uni") fibrous composite so its longitudinal and transverse properties were drastically different. For this reason, material properties for the 0 degree fiber orientation, as well as for the 90 degree fiber orientation, will be given for each aramid fiber material characteristic.

\subsubsection{Compressive Properties of Facesheet Materials from Testing}

The compressive strength of a composite material is an important property to know for any testing because composite materials, as mentioned in the introduction of this study, are typically poor in compression. This means that if a typical composite material has the option, it will fail in compression before tension. So knowing the compressive strength of a material can sometimes mean that the ultimate strength is known if that structure endures mostly compressive loadings. A composite sandwich structure under bending loads resists compres-
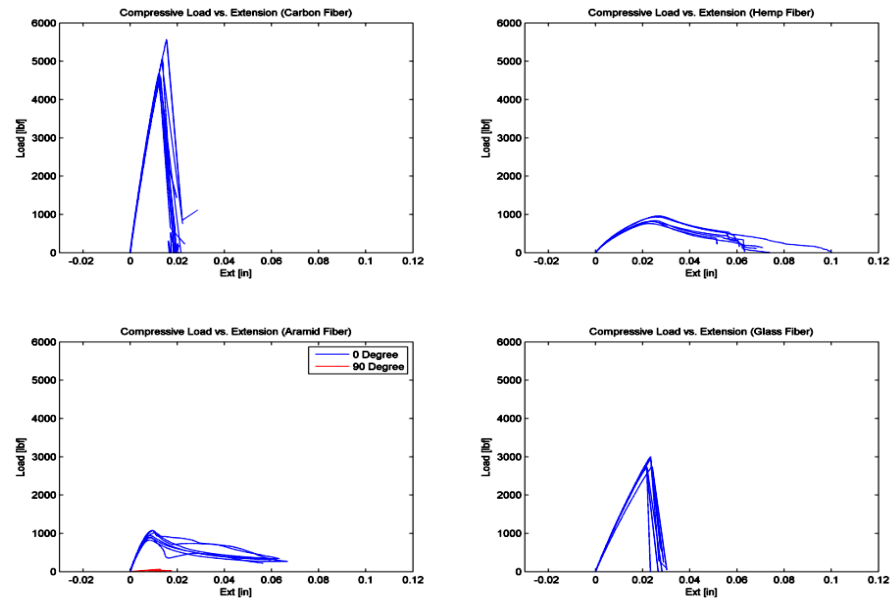

Figure 3.1: Raw data plots from compressive material properties testing sive forces on the top facesheet so the compressive strength of that top facesheet can describe when that structure might fail. 
This study tested carbon, hemp, aramid, and glass fiber composite materials for compressive strengths to gain an understanding of how and when the sandwiches using these facesheets might fail under bending loads. The findings of each compressive test are shown in Figure 3.1 and Table 3.1.

Table 3.1: Comparison of facesheet material compressive moduli and strengths

\begin{tabular}{|c|c|c|c|c|c|}
\hline & \multirow{2}{*}{$\begin{array}{c}\text { Carbon } \\
\text { Fiber }\end{array}$} & \multirow{2}{*}{$\begin{array}{c}\text { Hemp } \\
\text { Fiber }\end{array}$} & \multicolumn{2}{|c|}{ Aramid Fiber (Uni) } & \multirow{2}{*}{$\begin{array}{c}\text { Glass } \\
\text { Fiber }\end{array}$} \\
\cline { 4 - 5 } & (Woven) & (Woven) & 0 Degree & 90 Degree & (Woven) \\
\hline Compressive & $6.3 \mathrm{E} 6$ & $0.9 \mathrm{E} 6$ & $4.4 \mathrm{E} 6$ & $0.2 \mathrm{E} 6$ & $1.9 \mathrm{E} 6$ \\
Modulus [psi] & $+/-0.1 E 6$ & $+/-0.1 E 6$ & $+/-0.6 E 6$ & $+/-0.0 E 6$ & $+/-0.1 E 4$ \\
\hline Compressive & $4.3 \mathrm{E} 4$ & $0.7 \mathrm{E} 4$ & $1.7 \mathrm{E} 4$ & $0.1 \mathrm{E} 4$ & $2.3 \mathrm{E} 4$ \\
Strength [psi] & $+/-0.3 E 4$ & $+/-0.1 E 4$ & $+/-0.2 E 4$ & $+/-0.0 E 4$ & $+/-0.1 E 4$ \\
\hline
\end{tabular}

The most obvious conclusion that can be made about these facesheets under compression is that carbon fiber is definitely stiffer and stronger than any of the other materials and hemp fiber composites are definitely the weakest material in compression. The aramid and glass fibers are not better than hemp but not as effective as carbon fiber under compression. The odd result here is that the aramid fiber material has a higher compressive modulus so it is much stiffer than the glass fiber composite but the glass fibers are slightly strong than aramid. So if a structure needs to be able to carry a high compressive load, the Texalium would be the better material choice than the Twaron. The transverse strength and stiffness of the aramid fiber material was the least of any material so it must be loaded in the longitudinal direction to have any effectiveness. During testing, the aramid and hemp fiber composites failed more due to bending from buckling, as can be seen in Figure 3.2; whereas, the carbon and glass fiber composites failed due to stiff, brittle fibers fracturing. Global bending did not occur with these materials but instead, microbuckling of the individual fibers created fracture failure. The crushing of these individual fibers can be seen in Figure 3.2 . 


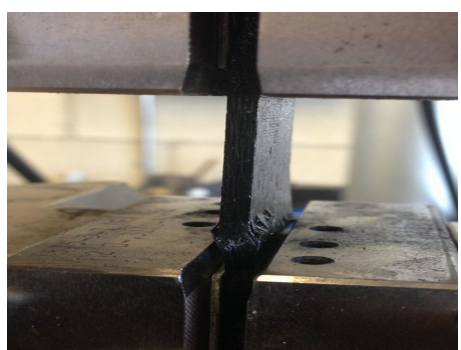

(a) Carbon fiber failure

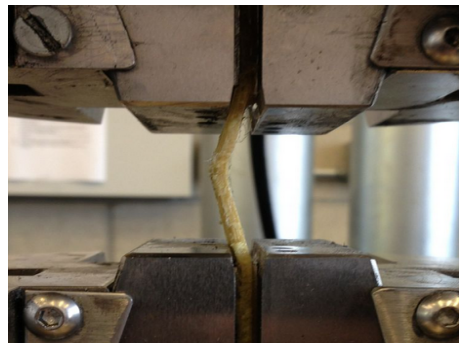

(c) Aramid fiber failure

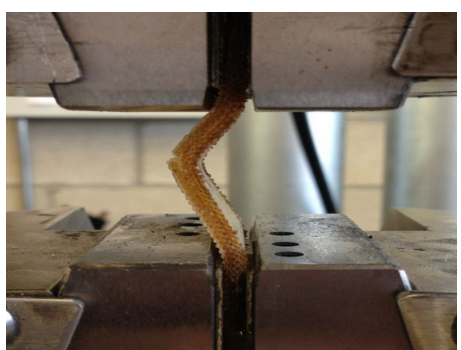

(b) Hemp fiber failure

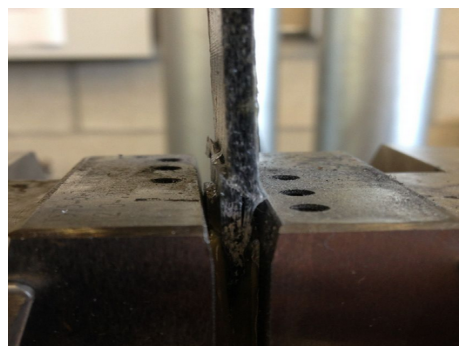

(d) Glass fiber failure

Figure 3.2: Compressive mechanical properties testing failure modes of facesheet materials

\subsubsection{Tensile Properties of Facesheet Materials from Testing}

When the fibers within a fibrous composite material are pulled along their longitudinal fiber axis, the material is at its strongest. Composite materials are meant to be put under ten-

sile loads because that's when the fibers within the material thrive. Some composite laminates have different orientations of their fibers in each layer so that certain fibers within the laminate will be in tension no matter which direction the load acts in. Because of this, the fibrous composite tensile material properties are extremely important. Fibers may typically fail in com-
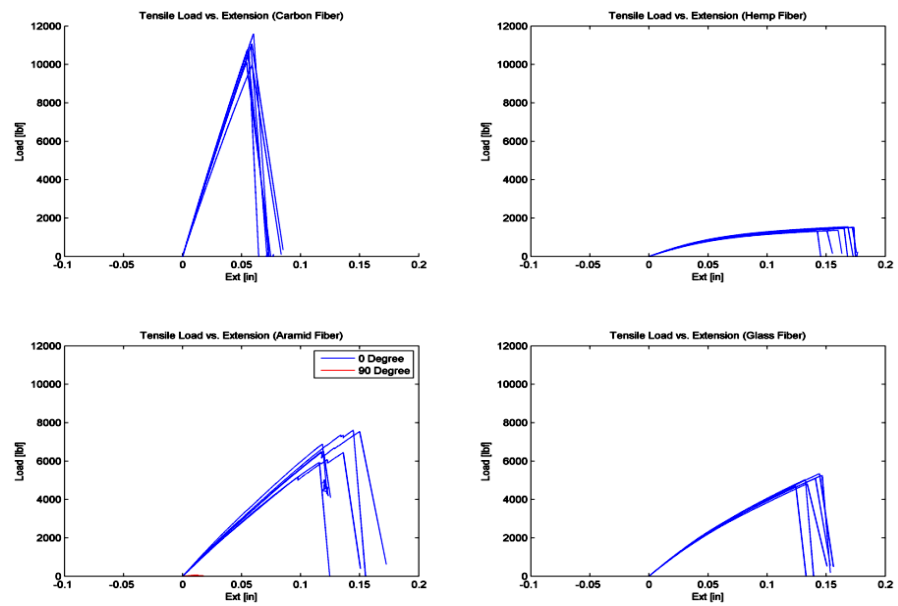

Figure 3.3: Raw data plots from tensile material properties testing pression but for most composite materials, the tensile strength decides how strong the overall material is. Tensile strength and modulus are the characteristics used to define the strength of the material. 
In this study, the investigation of impact damage on the tensile surface of the composite sandwich under bending loads is where this tensile characteristic is very important. The tensile strengths and moduli of each facesheet material are shown in Table 3.2 and the raw data plots for these tests are shown in Figure 3.3.

Table 3.2: Comparison of facesheet material tensile moduli and strengths

\begin{tabular}{|c|c|c|c|c|c|}
\hline & \multirow{2}{*}{$\begin{array}{c}\text { Carbon } \\
\text { Fiber }\end{array}$} & \multirow{2}{*}{$\begin{array}{c}\text { Hemp } \\
\text { Fiber }\end{array}$} & \multicolumn{2}{|c|}{ Aramid Fiber (Uni) } & \multirow{2}{*}{$\begin{array}{c}\text { Glass } \\
\text { Fiber }\end{array}$} \\
\cline { 4 - 5 } & (Woven) & (Woven) & 0 Degree & 90 Degree & (Woven) \\
\hline Tensile Modulus & $10.1 \mathrm{E} 6$ & $1.2 \mathrm{E} 6$ & $6.9 \mathrm{E} 6$ & $0.03 \mathrm{E} 6$ & $2.4 \mathrm{E} 6$ \\
[psi] & $+/-0.2 E 6$ & $+/-0.1 E 6$ & $+/-0.2 E 6$ & $+/-0.0 E 6$ & $+/-0.1 E 6$ \\
\hline Tensile Strength & $9.0 \mathrm{E} 4$ & $1.4 \mathrm{E} 4$ & $12.7 \mathrm{E} 4$ & $0.01 \mathrm{E} 4$ & $4.0 \mathrm{E} 4$ \\
[psi] & $+/-0.2 \mathrm{E} 4$ & $+/-0.1 E 4$ & $+/-1.1 E 4$ & $+/-0.0 E 4$ & $+/-0.2 E 4$ \\
\hline
\end{tabular}

The tensile results are, as expected, much higher than the compressive results in every category. The carbon fiber prepreg, like with the compressive results, was by far the best material for tensile loading situations and the hemp was the least. Carbon fiber is the stiffest material and hemp is the most ductile as well. The more interesting comparison is with the aramid and glass fibers again. The glass fibers were stronger than aramid fibers under compressive loads but had a lower modulus; however, aramid fibers are stronger and stiffer than glass fibers under tensile loads. Just like with the compressive testing, however, the 90 degree fiber direction resulted in severely lower strength and stiffness characteristics for the aramid fiber material so it may be stronger than glass fiber but if the orientation of the fibers changes at all, glass fibers may be the more favorable material under tensile loading.

Each of these materials failed in the same way with a uniform fracture of all fibers at a certain position except aramid fiber test specimens which had a matrix failure first and then individual fiber failures after that. These failures can all be seen in Figure 3.4. The hemp fiber material failed at a maximum load that was $1 / 7$ th the maximum load of carbon fiber but the extension of the hemp material was roughly three times as long as the carbon fiber. This is another example of hemp fiber's extreme ductility. The glass and aramid fiber 
materials had slightly lower extensions but maximum loads about half way between carbon and hemp fiber maximum loads.

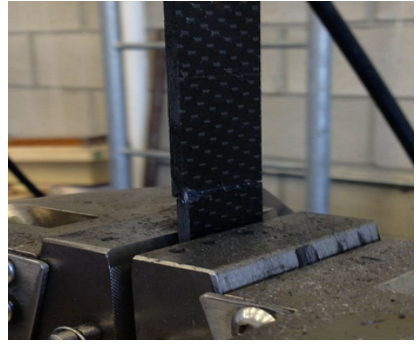

(a) Carbon fiber failure

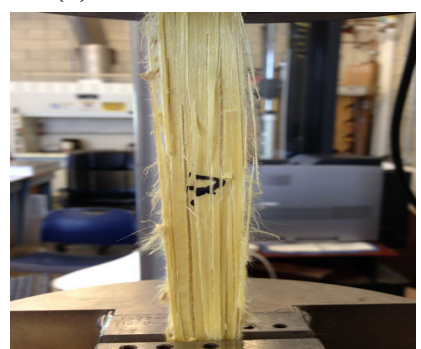

(c) Aramid fiber failure

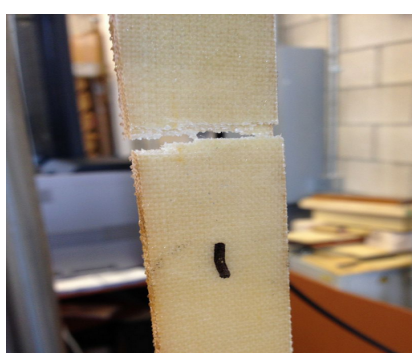

(b) Hemp fiber failure

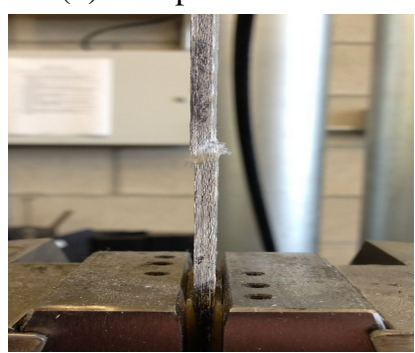

(d) Glass fiber failure

Figure 3.4: Tensile mechanical properties testing failure modes of facesheet materials

\subsubsection{Poisson's Ratio Values from Testing of Facesheet Materials}

The Poisson's ratio testing was not taken until failure like the compressive and tensile tests so the analysis of the results is not on the maximum loadings of each material but on the longitudinal and transverse strain relationships with the load instead. The transverse strains found using the LabView code were in units of millistrain so all of these values were converted to units of strain (inch per inch) to match the longitudinal data before analysis was done. As mentioned in the last chapter, Poisson's ratio for each material was calculated using the slopes of the transverse and longitudinal strain and load relationships, shown in Figure 3.5. These plots show that the longitudinal strains always had a higher slope when plotted against loads which leads to Poisson's ratio values less than one. The final Poisson's ratio values calculated from these plots for carbon, hemp, aramid, and glass fibers were $0.017,0.2,0.36$, and 0.12 , respectively. These values, like the tensile and compressive test, 
were considered to be the same in both the transverse and longitudinal directions for carbon,
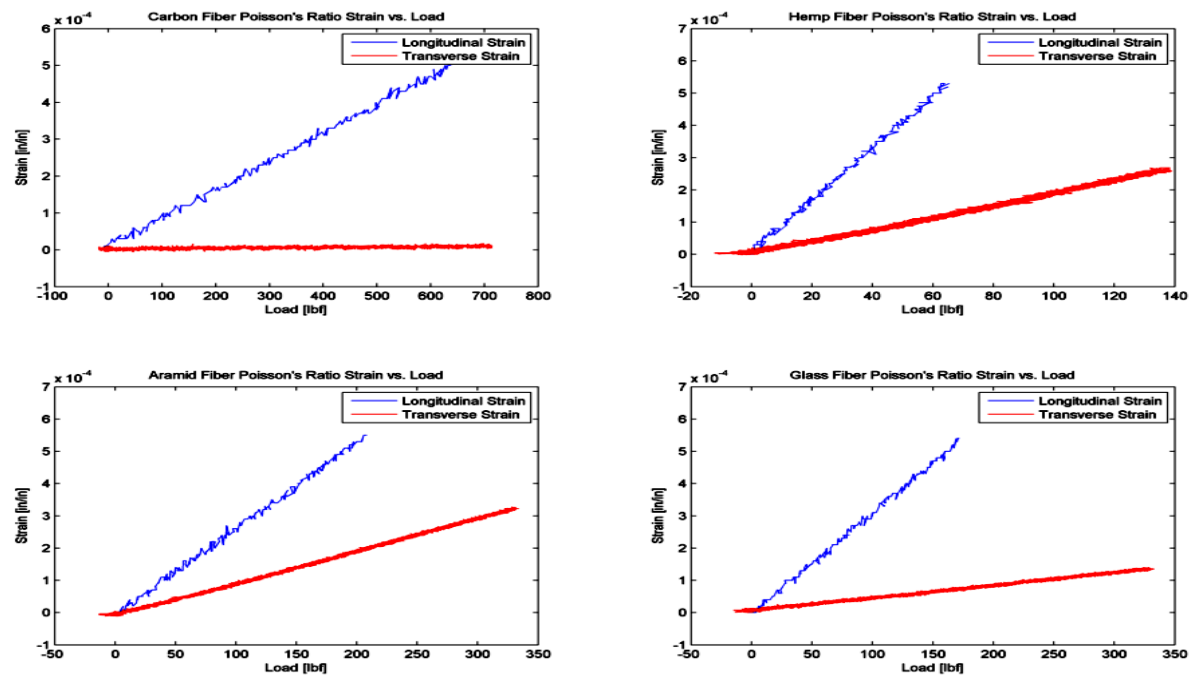

Figure 3.5: Longitudinal and transverse strain versus load plots for facesheet Poisson's ratio calculations

hemp, and glass fiber materials but the transverse Poisson's ratio was much different for aramid fiber materials. Poisson's ratio is basically a ratio of how far a material pinches in (transverse strain) when it is pulled in a perpendicular direction to the pinching versus how far it stretches (longitudinal strain) in the direction of the loading. So since the only thing keeping the 90 degree fiber oriented aramid material from stretching is the weak matrix (no fibers running in the load direction), then it stretches a lot more than it pinches. This leads to much higher longitudinal strain than the transverse strain and a much smaller Poisson's ratio value of around 0.01 .

\subsubsection{Honeycomb Poisson's Ratio Testing Method and Core Material Datasheet Properties}

Both the foam and honeycomb core materials had datasheets that gave all the necessary values for theoretical and numerical analysis of the composite sandwiches. Since the structural integrity of the honeycomb and foam cores didn't degrade overtime like the prepreg materials that needed special handling and storage, the datasheet values were considered 
to be accurate. The only value not given by the datasheets was the Poisson's ratio of the honeycomb material. This is why the ASTM D6790 test was done. The test was done for both the longitudinal and transverse Poisson's ratio values due to honeycomb's anisotropic behavior. The foam core material was a homogeneous, isotropic material which meant that it had the same material properties in every axis direction. The longitudinal direction of the honeycomb gave values for the height (d) of anticlastic curvature and the distance between raised edges (c) of 1.065 inches and 11.75 inches, respectively. These values led to a longitudinal Poisson's ratio value of 0.74 . The transverse $\mathrm{d}$ and c values for the 12 inch by 12 inch honeycomb square were 0.665 inches and 12.09 inches, respectively. These values gave a transverse Poisson's ratio value of 0.45 . The resulting Poisson's ratio values were then used to calculate the tensile modulus of the honeycomb core in the longitudinal and transverse directions. The foam datasheet did not give a value for tensile modulus so that was calculated using the given Poisson's ratio and shear modulus. All of the core material properties values as well as the datasheet values for the foam and honeycomb cores are shown in Table 3.3 .

Table 3.3: Comparison of core material properties

\begin{tabular}{|c|c|c|c|}
\hline & Foam & $\begin{array}{c}\text { Honeycomb } \\
\text { (Longitudinal) }\end{array}$ & $\begin{array}{c}\text { Honeycomb } \\
\text { (Transverse) }\end{array}$ \\
\hline Density [lbf/in ${ }^{3}$ ] & 0.0057 & 0.0046 & 0.0046 \\
\hline $\begin{array}{c}\text { Compressive } \\
\text { Modulus [psi] }\end{array}$ & $1.1 \mathrm{E} 4$ & $1.6 \mathrm{E} 5$ & $1.6 \mathrm{E} 5$ \\
\hline $\begin{array}{c}\text { Compressive } \\
\text { Strength [psi] }\end{array}$ & 352 & $1.53 \mathrm{E} 3$ & $1.53 \mathrm{E} 3$ \\
\hline $\begin{array}{c}\text { Tensile Modulus } \\
\text { [psi] }\end{array}$ & $7.3 \mathrm{E} 3$ & $1.15 \mathrm{E} 5$ & $5.5 \mathrm{E} 4$ \\
\hline Tensile Strength [psi] & 303 & 2 & 2 \\
\hline Poisson's Ratio & 0.3 & 0.74 & 0.45 \\
\hline Shear Modulus [psi] & $2.82 \mathrm{E} 3$ & $3.3 \mathrm{E} 4$ & $1.9 \mathrm{E} 4$ \\
\hline Shear Strength [psi] & 239 & 750 & 460 \\
\hline
\end{tabular}

From the datasheets and calculations, it's pretty clear that the honeycomb core is the lighter and stronger of the two core materials so its performance in the composite sandwich 
bending test should be better than the foam core. Tensile strength was not given in the datasheet for honeycomb and it is a tough value to calculate with the given information but it can be assumed that it was probably greater than the foam core tensile strength. The benefit of the foam core, however, is that there is more surface area to bond the facesheets to than honeycomb, resulting in improved delamination resistance. The honeycomb material used in this study, however, was not as strong as the datasheet says it was. Because of this, the tensile test of the honeycomb was performed to find materials properties that more accurately describe this core material. From this testing, an elastic modulus of 2.4E4 psi, shown in Table 3.4 was found for the honeycomb. This value was found by finding the slope of the stress vs. strain plot. The stress was calculated in an unorthodox way compared to typical $S=P / A$ calculations because the area that the force is acting on is different for the odd structure of a honeycomb material. Because of this, the area of the honeycomb was calculated using Eq. 3.1 below.

$$
A_{h c}=N * 2 t_{c e l l} * t_{c}
$$

Where $N$ is the number of cells across the honeycomb in the transverse direction, $t_{c e l l}$ is the thickness of one of the cell walls of the honeycomb, and $t_{c}$ is the thickness of the core structure as a whole. $t_{\text {cell }}$ is multiplied by two because for each cell, the cell wall is bonded to the cell wall next to it in the transverse direction to create the the honeycomb structure. The two cell walls together make a thickness of $2 t_{\text {cell }}$. Once the elastic modulus was found experimentally, the shear modulus could then be found with the longitudinal Poisson's ratio using Eq. ( 3.2 ) shown in the next section. This same equation was then used in the opposite direction with the transverse Poisson's ratio to solve for the transverse elastic modulus. Lastly, the updated compressive modulus of the honeycomb was scaled 
down from the datasheet using the experimentally measured elastic modulus, datasheet elastic modulus, and datasheet compressive modulus.

Table 3.4: Honeycomb experimental material properties found from tensile test on honeycomb structure

\begin{tabular}{|c|c|c|c|c|}
\hline & $\begin{array}{c}\text { Elastic } \\
\text { Modulus } \\
\text { (Long.) } \\
{[\mathbf{p s i}]}\end{array}$ & $\begin{array}{c}\text { Elastic } \\
\text { Modulus } \\
\text { (Trans.) } \\
{[\mathbf{p s i}]}\end{array}$ & $\begin{array}{c}\text { Shear } \\
\text { Modulus } \\
\text { [psi] }\end{array}$ & $\begin{array}{c}\text { Compressive } \\
\text { Modulus } \\
{[\mathrm{psi}]}\end{array}$ \\
\hline $\begin{array}{c}\text { Honeycomb } \\
\text { Experimental } \\
\text { Properties }\end{array}$ & $2.4 \mathrm{E} 4$ & $1.9 \mathrm{E} 4$ & $6.8 \mathrm{E} 3$ & $3.4 \mathrm{E} 4$ \\
\hline
\end{tabular}

\subsubsection{Calculation of Shear Moduli of Facesheet Materials}

One of the main reasons for finding the Poisson's ratio values of the facesheet materials was to be able to solve for the shear modulus of each material. Even though the core bares most of the shearing load under bending loads, the shearing modulus of the facesheet materials is still important for theoretical and numerical analysis. With the tensile modulus and Poisson's ratio values calculated from mechanical properties tests, a simple calculation can be done to find the shear modulus in any axis direction. Eq. ( 3.2) shows the relationship between the longitudinal shear modulus, $G_{12}$, and the longitudinal Poisson's ratio, $v_{12}$, and tensile modulus, $E_{12}$, of a material.

$$
G_{12}=\frac{E_{12}}{2\left(1+v_{12}\right)}
$$

Using this equation and the results from testing, the carbon, hemp, and glass fiber materials had the values for longitudinal and transverse shear moduli shown in Table 3.5. The aramid fiber material was different in the 0 and 90 degree direction, however, so two values had to be calculated. The 0 degree fiber orientation resulted in a shear modulus that 
was in the same range as the weaved composites but the 90 was significantly lower than any other material due to the lack of fibers oriented in the 90 degree direction.

Table 3.5: Comparison of facesheet material shear moduli

\begin{tabular}{|c|c|c|c|c|c|}
\hline & \multirow{2}{*}{$\begin{array}{c}\text { Carbon } \\
\text { Fiber }\end{array}$} & \multirow{2}{*}{$\begin{array}{c}\text { Hemp } \\
\text { Fiber }\end{array}$} & \multicolumn{2}{|c|}{ Aramid Fiber (Uni) } & \multirow{2}{*}{$\begin{array}{c}\text { Glass } \\
\text { Fiber }\end{array}$} \\
\cline { 4 - 5 } & (Woven) & (Woven) & 0 Degree & 90 Degree & (Woven) \\
\hline Shear Modulus & $5.0 \mathrm{E} 6$ & $0.48 \mathrm{E} 6$ & $2.5 \mathrm{E} 6$ & $0.02 \mathrm{E} 6$ & $1.1 \mathrm{E} 6$ \\
[psi] & $+/-0.1 E 6$ & $+/-0.0 E 6$ & $+/-0.1 E 6$ & $+/-0.0 E 6$ & $+/-0.0 E 6$ \\
\hline
\end{tabular}

\subsubsection{Comparison of Experimental and Datasheet Material Properties}

The carbon fiber prepreg material had a detailed datasheet so this material was used to explain the comparisons between the experimental values of facesheet material properties and the datasheet values. The reason for this comparison is to ensure that the testing results were correct and to gain an understanding of how much the structural integrity of the material has degraded overtime. The prepreg materials that were used for this study were generously donated by multiple different companies because the materials were expired according to their standards so by the time the Cal Poly Aerospace structures lab receives the material, the structural integrity may have already degraded slightly. The main reason why mechanical properties testing is so important in this study is because the materials used are not as strong as they were when they were manufactured so current values have to be found. The comparison of the current values from testing to the datasheet values is shown in Table 3.6.

The tensile strength and stiffness of the carbon fiber has degraded since being manufactured but not severely. The compressive strength and stiffness, however, have degraded significantly and this drop in structural integrity will be touched on again when theoretical failure analysis is presented in the next chapter. 
Table 3.6: Comparison of experimental and datasheet carbon fiber material properties

\begin{tabular}{|c|c|c|c|c|}
\hline & $\begin{array}{c}\text { Tensile } \\
\text { Modulus } \\
\text { [psi] }\end{array}$ & $\begin{array}{c}\text { Tensile } \\
\text { Strength } \\
\text { [psi] }\end{array}$ & $\begin{array}{c}\text { Compressive } \\
\text { Modulus } \\
\text { [psi] }\end{array}$ & $\begin{array}{c}\text { Compressive } \\
\text { Strength } \\
\text { [psi] }\end{array}$ \\
\hline $\begin{array}{c}\text { Carbon Fiber } \\
\text { Experimental }\end{array}$ & $\begin{array}{c}10.1 \mathrm{E} 6 \\
+/-0.2 E 6\end{array}$ & $\begin{array}{c}9.0 \mathrm{E} 4 \\
+/-0.2 E 4\end{array}$ & $\begin{array}{c}6.3 \mathrm{E} 6 \\
+/-0.1 E 6\end{array}$ & $\begin{array}{c}4.3 \mathrm{E} 4 \\
+/-0.3 E 4\end{array}$ \\
\hline $\begin{array}{c}\text { Carbon Fiber } \\
\text { Datasheet }\end{array}$ & $9.7 \mathrm{E} 6$ & $1.27 \mathrm{E} 5$ & $9.3 \mathrm{E} 6$ & $1.34 \mathrm{E} 5$ \\
\hline Error [\%] & $3.1 \%$ & $29.1 \%$ & $32.2 \%$ & $67.9 \%$ \\
\hline
\end{tabular}

\subsubsection{Summary of Constituent Material Properties Testing}

Overall, it is obvious from the mechanical properties that carbon fiber facesheets are significantly better than the other three facesheet materials so high strengths should be seen from the carbon fiber composite sandwiches. The hemp material is definitely the weakest but has a low compressive and tensile modulus so hemp sandwiches will probably have the highest mid-span deflections of any other sandwich. Aramid and glass fiber facesheets shouldn't have too much of a variation in their composite sandwich flexural performances due to the similarities in their material properties. If there is variation, aramid fiber composite sandwiches should have a slight advantage with a minor concern for matrix strength from the tensile tests. Strengths and deflections somewhere between carbon fiber and hemp sandwiches should be expected. In terms of the use of core materials, the honeycomb is clearly superior to the foam core in all areas and the benefit of increased core height for improved flexural strength and stiffness will not be a factor in this study so the flexural behavior of the sandwich materials with each core will probably be a good representation of each material's mechanical properties.

\subsubsection{Fiber Volume Fractions for Facesheet Materials}

To understand some of the reasons behind the decrease in material properties from the datasheet to the experimental results, the fiber volume percentage analysis was performed. 
According to the carbon fiber datasheet, the nominal fiber volume percentage was $55.29 \%$ when it was manufactured and the glass fiber prepreg was considered to have a similar percentage. Since the aramid fiber material was unidirectional, its fiber volume fraction was naturally less because it was composed of fewer fibers. In the Chapter 2 discussion on facesheet materials used in this study, the designation of the Twaron aramid fiber material was given and it described the material as having a $40 \%$ fiber volume fraction. The hemp fiber facesheet materials were manufactured for this study using a "wet" layup technique so they had a slightly different fiber volume for each layup.

With these theoretical fiber volume percentages in mind, the experimental volume fractions were calculated using the method described above. The results from these tests showed decent agreement with the datasheet values, as can be seen in Table 3.7, for the carbon and glass fiber materials with a slight increase in percentage which meant that there was some slight degradation in material quality over time. Not much epoxy was lost in these materials, though. The aramid fiber material, however, showed a significant increase in fiber volume percentage with meant there was a good amount of epoxy that was lost from the material over time. This explains some of the delamination issues that were occurring with these sandwich structures under impact and bending loads. The slightly higher percentage increase over carbon fiber for the glass fiber materials could be the reason for some of the small delamination issues with these sandwiches too. Since the hemp material never had a datasheet, there is no way of knowing what the optimal percentage was supposed to be but since delamination was never an issue with these materials, an educated guess would be that the fiber volume fraction was lower than optimal, meaning there was more epoxy in the specimens than necessary. Since the hemp fibers are natural materials, they are minimally porous which means that along with the epoxy matrix that surrounds the fibers, some epoxy seeps into the pores of the fibers. Because of this, the fiber volume percentage of this material is slightly less than a typically composite, which is another reason why the hemp percentages are lower than the other fiber volume percentages. 
Table 3.7: Comparison of fiber volume percentages from ignition loss calculations to theoretical values for facesheet materials

\begin{tabular}{|c|c|c|c|c|}
\hline & $\begin{array}{c}\text { Carbon } \\
\text { Fiber }\end{array}$ & Hemp Fiber & $\begin{array}{c}\text { Aramid } \\
\text { Fiber }\end{array}$ & Glass Fiber \\
\hline $\begin{array}{c}\text { Ignition Loss Fiber } \\
\text { Volume [\%] }\end{array}$ & $57.8 \%$ & $32.8 \%$ & $47.0 \%$ & $60.0 \%$ \\
\hline $\begin{array}{c}\text { Datasheet Fiber } \\
\text { Volume [\%] }\end{array}$ & $55.3 \%$ & - & $40.0 \%$ & $55.3 \%$ \\
\hline Error [\%] & $4.5 \%$ & - & $17.0 \%$ & $8.5 \%$ \\
\hline
\end{tabular}

\subsection{Impact Testing Results and Discussion}

The impact machine and testing procedure described in the previous chapter were able to produce values of impact velocity and impact force, shown in Figure 3.6 as the GUI output from the Matlab code, for every sandwich specimen subjected to a lowvelocity impact. As mentioned in the last chapter, the velocity was calculated using the time difference between the two disruptions of laser light hitting the Si detector.

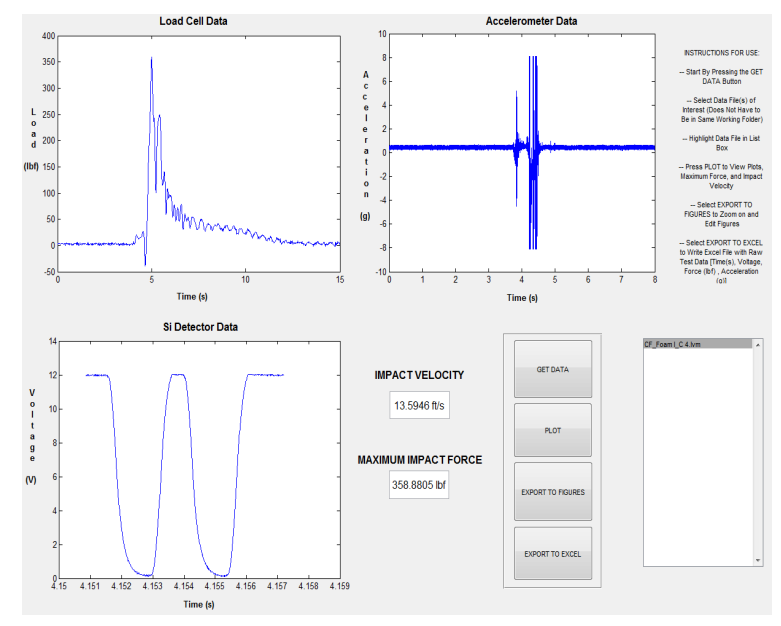
The disruption in signal as the metal sheet Figure 3.6: Example of impact testing results outputted on the Matlab GUI window passed by the laser during impact can be seen clearly in the Si Detector Data plot as the two troughs in the curve. The time between these two troughs and the knowledge of the distance between the top and bottom metal strips allowed for the calculation of the impact velocity shown in the Impact Velocity results box. The maximum load on the Load Cell Data plot was taken and outputted in the Maximum Impact Load results box. The damage that occurred following the impact was then measured using a caliper to get information on general impact size. The values measured for the impact damage size are not, however, precise and are not meant to be used for detailed analysis of impact prevention behaviors 
for each sandwich. These values have large errors involved with them due to the lack of more precise damage modeling tools so they are strictly used for general comparisons of impact damage between each sandwich design. Analysis was not able to be done on the indentation behavior of each test specimen over the time of the impact either, so residual impact energy and energy absorption data could not be collected from the tests. Energy at initial impact was calculated, however, using kinetic energy equations for each test specimen using Eq. 3.3

$$
K E=\frac{1}{2} m V^{2}
$$

This is the simple dynamic equation for kinetic energy of a drop weight impact using the mass of the impactor weight, $\mathrm{m}$, and the velocity at impact, $\mathrm{V}$, taken from the Matlab GUI output data. These results will be presented in tables and compared in the rest of this section. All of the tables in this section will use titles that describe the sandwich designs as shorter names. A carbon, hemp, aramid, or glass fiber facesheet sandwich will have the designation $\mathrm{CF}, \mathrm{HF}, \mathrm{AF}$, or GF in the title, respectively. The honeycomb and foam cores will be designated as $\mathrm{H}$ and $\mathrm{F}$, respectively. As an example, the results for a carbon fiber/honeycomb sandwich design will have the title $\mathrm{CF} / \mathrm{H}$ in the table heading. The two hybrid sandwich designs will be referred to as carbon(2)aramid(1)/honeycomb and carbon(1)aramid(2)/honeycomb throughout the rest of the study. The numbers in the parentheses represent the number of layers of each material used for one of the facesheets. The tables shown in this report will designate these two sandwiches as $\mathrm{CF}(2) \mathrm{AF}(1) / \mathrm{H}$ and $\mathrm{CF}(1) \mathrm{AF}(2) / \mathrm{H}$, respectively. Also, the results are presented as averages for all impacted sandwiches but half of those specimens for each sandwich design were then bent with the impact damage on the compressive side and half on the tensile side so different results may have occurred for the sandwiches that were subjected to different bending loads. 


\subsubsection{Carbon Fiber Facesheet Sandwiches}

From the mechanical properties testing, the results showed that carbon fiber has very high strength and stiffness characteristics; however, its ability to absorb impact forces in the perpendicular direction to its fiber weave plane is poor. It thrives with loads along the fiber longitudinal axis but outside of that, it is much weaker. Because of this, impact damages were quite large for the carbon fiber facesheet sandwiches. A typical impact on carbon fiber/honeycomb and carbon fiber/foam sandwiches produced complete local failure of the top facesheet and very large indentations (damages) in the top of the core. Table 3.8 shows the results of the impacts on carbon fiber facesheet sandwiches. From this table, the first conclusion that can be made is that the impact created a larger damage on the honeycomb core sandwiches than on the foam cores.

Figure 3.7: Comparison of foam and honeycomb core impact damages in carbon fiber facesheet sandwiches

The comparison of these two damages can be seen in

Figure 3.7. This is because the homogeneous structure of the foam allowed the instantaneous local force to be distributed throughout the core easier than the honeycomb which

Table 3.8: Impact testing results for composite sandwiches with carbon fiber facesheets

\begin{tabular}{|c|c|c|}
\hline & $\mathbf{C F} / \mathbf{F}$ & $\mathbf{C F} / \mathbf{H}$ \\
\hline \multirow{2}{*}{ Impact Velocity [ft/sec] } & 13.3 & 13.2 \\
& $+/-0.0$ & $+/-0.1$ \\
\hline \multirow{2}{*}{ Impact Force [lbf] } & $\mathbf{3 5 5 . 3}$ & $\mathbf{3 6 4 . 5}$ \\
& $+/-31.3$ & $+/-52.2$ \\
\hline Impact Energy & 667.3 & 656.9 \\
{$\left[l \mathrm{lbm}-f \mathrm{t}^{2} / \mathrm{sec}^{2}\right]$} & $+/-2.8$ & $+/-8.2$ \\
\hline Visible Damage & $\mathbf{0 . 5 9 7}$ & $\mathbf{0 . 6 0 8}$ \\
Diameter [in] & $+/-0.014$ & $+/-0.013$ \\
\hline Visible Damage Depth & $\mathbf{0 . 2 2 9}$ & $\mathbf{0 . 2 5 7}$ \\
[in] & $+/-0.014$ & $+/-0.023$ \\
\hline
\end{tabular}


resisted the impact with only a couple cell walls. Since the local indentation was slightly larger for the honeycomb, the force was slightly larger than the foam core sandwiches. The large error with these impact forces show that, in general, the impact forces resisted by both sandwiches were roughly the same. The velocity at impact for each sandwich depended on the height of impact which depended on thickness of the facesheets. Since all facesheets were carbon fiber, the impact velocities were similar and, thus, impact energy values were similar as well.

\subsubsection{Hemp Fiber Facesheet Sandwiches}

Because of the weak nature of the hemp facesheets, these sandwiches resulted in the largest impact damages. These damages were not too much larger than the carbon fiber facesheets, however. Because of this, the impact force values, shown in Table 3.9, were similar to the carbon fiber facesheets. The impact tup completely penetrated the top facesheet of each sandwich, as shown in Figure 3.8, and created a larger indentation on the honeycomb core than the foam core like the carbon fiber facesheet sandwiches. The velocity at impact for each sandwich was slightly smaller than carbon fiber, however, because the hemp facesheets were thicker. The carbon

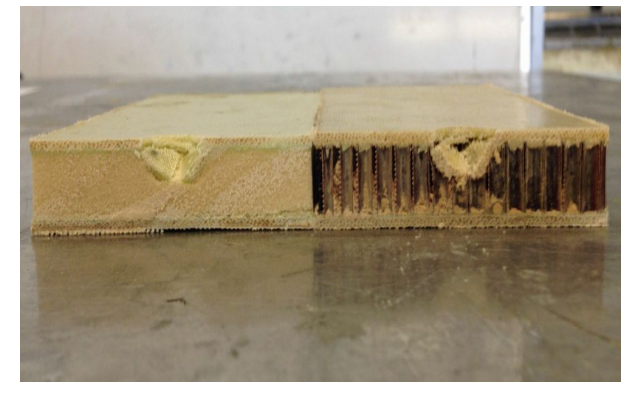

Figure 3.8: Comparison of foam and honeycomb core impact damages in hemp fiber facesheet sandwiches and hemp fiber facesheet sandwiches, in general, produced similar impact results with poor resistance to impact damage.

\subsubsection{Aramid Fiber (Twaron) Facesheet Sandwiches}

The aramid fiber facesheet sandwiches showed the best resistance to impact damage of any of the facesheets, which can be seen in Table 3.10. The impact damage size is clearly 
Table 3.9: Impact testing results for composite sandwiches with hemp fiber facesheets

\begin{tabular}{|c|c|c|}
\hline & HF/F & HF/H \\
\hline \multirow{2}{*}{ Impact Velocity [ft/sec] } & 13.1 & 13.1 \\
& $+/-0.1$ & $+/-0.1$ \\
\hline \multirow{2}{*}{ Impact Force [lbf] } & $\mathbf{3 5 1 . 9}$ & $\mathbf{3 7 4 . 7}$ \\
& $+/-9.2$ & $+/-21.6$ \\
\hline Impact Energy & 650.2 & 652.6 \\
{$\left[l b m-f t^{2} / \mathrm{sec}^{2}\right]$} & $+/-5.5$ & $+/-5.5$ \\
\hline Visible Damage & $\mathbf{0 . 6 5 1}$ & $\mathbf{0 . 6 7 6}$ \\
Diameter [in] & $+/-0.014$ & $+/-0.080$ \\
\hline Visible Damage Depth & $\mathbf{0 . 2 7 8}$ & $\mathbf{0 . 3 0 0}$ \\
[in] & $+/-0.031$ & $+/-0.012$ \\
\hline
\end{tabular}

smaller than carbon and hemp fiber sandwiches and, as shown in Figure 3.9, the impact tup never broke the facesheet of the sandwich which meant that the core didn't have to resist as much of the load because the load was spread out throughout the facesheets. This resulted in smaller damages within the core of the sandwich. The smaller impact damages and lack

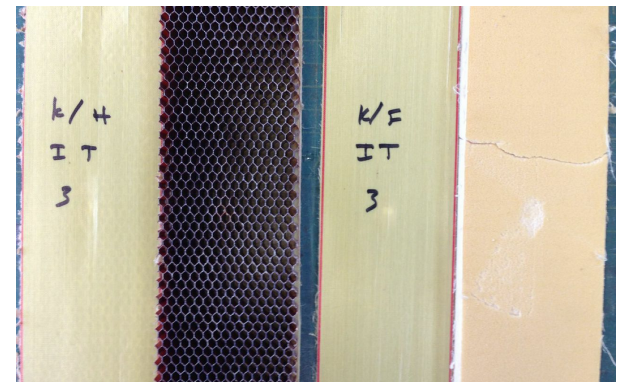

Figure 3.9: Comparison of foam and honeycomb core impact damages in aramid fiber facesheet sandwiches of penetration through the top facesheet, however, meant that the contact between the impact tup and the composite sandwich was much harder. Because of this, the load cell on the impact machine read much higher values of impact force. The lack of any indentation meant that none of the initial impact energy was dissipated during contact so almost all of the impact energy was transferred back to the impact tup, with the load cell attached, immediately. This is the reason for the higher resulting impact loads over the carbon and hemp fiber sandwiches. The size of the error for each average force value indicates that the forces felt by the sandwiches were similar for honeycomb and foam sandwiches. The aramid fiber facesheets were unidirectional and had a lower amount of epoxy content because of degradation over time, which meant that they were the thinnest sandwich. Because 
Table 3.10: Impact testing results for composite sandwiches with aramid fiber facesheets

\begin{tabular}{|c|c|c|}
\hline & $\mathbf{A F} / \mathbf{F}$ & $\mathbf{A F} / \mathbf{H}$ \\
\hline \multirow{2}{*}{ Impact Velocity [ft/sec] } & 13.6 & 13.3 \\
& $+/-0.5$ & $+/-0.1$ \\
\hline \multirow{2}{*}{ Impact Force [lbf] } & $\mathbf{4 3 7 . 8}$ & $\mathbf{4 2 7 . 0}$ \\
& $+/-7.6$ & $+/-30.4$ \\
\hline Impact Energy & 697.7 & 671.8 \\
{$\left[l b m-f t^{2} / \mathrm{sec}^{2}\right]$} & $+/-59.7$ & $+/-13.0$ \\
\hline Visible Damage & $\mathbf{0 . 3 3 8}$ & $\mathbf{0 . 2 8 8}$ \\
Diameter $[$ in] & $+/-0.030$ & $+/-0.002$ \\
\hline Visible Damage Depth & $\mathbf{0 . 0 4 8}$ & $\mathbf{0 . 0 5 3}$ \\
[in] & $+/-0.004$ & $+/-0.005$ \\
\hline
\end{tabular}

of this, the impact velocities and energies on these sandwiches were the highest. Overall, aramid fiber facesheets resisted impact damage incredibly well.

\subsubsection{Glass Fiber (Texalium) Facesheet Sandwiches}

Glass fiber sandwiches produced similar results to the aramid fiber sandwiches but had slightly larger damages. Similar to aramid fiber, the impact tup didn't penetrate the glass fiber facesheets which lead to very small damage depth and diameter dimensions but the impact energy reached the core more than aramid fiber facesheets. This led to higher damage depths within the core for both foam and honey-

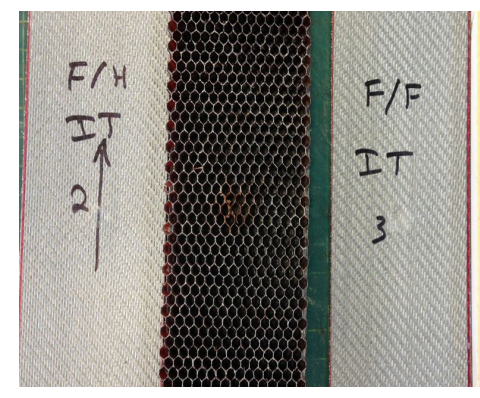

Figure 3.10: Comparison of foam and honeycomb core impact damages in glass fiber facesheet sandwiches comb core sandwiches but still much smaller damage sizes than carbon and hemp fiber facesheet sandwiches. The lack of penetration through the glass facesheets, shown in Figure 3.10 , led to impact force results that were similar to the aramid fiber sandwiches. There was more indention for these sandwiches, however, which meant more energy absorption from the sandwiches during testing. This is the reason for the slightly lower impact force values shown in Table 3.11. The glass fiber facesheets were roughly the same thickness as 
the carbon fiber facesheets which meant that the impact velocities and energies were similar between the two sandwiches. The glass fiber facesheet sandwiches, in general, resisted impact damages very well.

Table 3.11: Impact testing results for composite sandwiches with glass fiber facesheets

\begin{tabular}{|c|c|c|}
\hline & GF/F & GF/H \\
\hline \multirow{2}{*}{ Impact Velocity [ft/sec] } & 13.2 & 13.3 \\
& $+/-0.3$ & $+/-0.1$ \\
\hline \multirow{2}{*}{ Impact Force [lbf] } & $\mathbf{4 2 6 . 6}$ & $\mathbf{4 1 3 . 8}$ \\
& $+/-3.4$ & $+/-9.3$ \\
\hline Impact Energy & 655.0 & 666.2 \\
{$\left[l b m-f t^{2} / \mathrm{sec}^{2}\right]$} & $+/-25.1$ & $+/-14.8$ \\
\hline Visible Damage & $\mathbf{0 . 3 2 7}$ & $\mathbf{0 . 4 1 3}$ \\
Diameter [in] & $+/-0.015$ & $+/-0.053$ \\
\hline Visible Damage Depth & $\mathbf{0 . 0 5 8}$ & $\mathbf{0 . 0 9 2}$ \\
[in] & $+/-0.007$ & $+/-0.012$ \\
\hline
\end{tabular}

\subsubsection{Hybrid Carbon and Aramid Fiber Facesheet Sandwiches}

The impact results of the hybrid sandwich structures, shown in Table 3.12, display an odd drop in impact velocity, energy, and force for these two sandwich designs when compared to the three ply carbon fiber and three ply aramid fiber sandwiches. After analysis of the aramid and carbon fiber sandwich results, it was expected that these sandwiches would have higher impact loads and velocities than the carbon fiber sandwiches and lower values than the aramid fiber sandwiches. Errors in the machine combined with the odd nature of these sandwiches may have been the reason for this unexpected behavior but in terms of the damage caused to the sandwiches, the results were as expected. When more layers of carbon fiber material were replaced with aramid fiber material on the sandwich structure, the impact damage indentation size decreased because the added aramid fiber layers were able to resist the impact loads much better than the carbon fiber layers were able to. 
Table 3.12: Impact testing results for composite sandwiches with hybrid carbon and aramid fiber facesheets

\begin{tabular}{|c|c|c|c|c|}
\hline & AF/H & CF(1)AF(2)/H & CF(2)AF(1)/H & CF/H \\
\hline Impact Velocity & 13.6 & 12.8 & 13.0 & 13.2 \\
[ft/sec] & $+/-0.5$ & $+/-0.4$ & $+/-0.4$ & $+/-0.1$ \\
\hline Impact Force [lbf] & $\mathbf{4 3 7 . 8}$ & $\mathbf{3 1 3 . 9}$ & $\mathbf{3 3 2 . 1}$ & $\mathbf{3 6 4 . 5}$ \\
& $+/-7.6$ & $+/-19.6$ & $+/-15.7$ & $+/-52.2$ \\
\hline Impact Energy & 697.7 & 621.0 & 634.4 & 656.9 \\
{$\left[\mathrm{lbm}-\mathrm{ft}^{2} / \mathrm{sec}^{2}\right.$ ] } & $+/-59.7$ & $+/-41.5$ & $+/-37.4$ & $+/-8.2$ \\
\hline Visible Damage & $\mathbf{0 . 3 3 8}$ & $\mathbf{0 . 6 5 5}$ & $\mathbf{0 . 6 1 3}$ & $\mathbf{0 . 6 0 8}$ \\
Diameter [in] & $+/-0.030$ & $+/-0.027$ & $+/-0.012$ & $+/-0.013$ \\
\hline Visible Damage & $\mathbf{0 . 0 4 8}$ & $\mathbf{0 . 1 8 5}$ & $\mathbf{0 . 2 1 6}$ & $\mathbf{0 . 2 5 7}$ \\
Depth [in] & $+/-0.004$ & $+/-0.045$ & $+/-0.007$ & $+/-0.023$ \\
\hline
\end{tabular}

\subsubsection{Summary and Comparison of Impact Test Results}

Because of the nature of the aramid and glass fibers, it was pretty obvious that these sandwiches performed very well under impact loadings. The carbon and hemp fiber facesheets did not resist the impact damages nearly as well and needed support from the core material to completely stop the impact, which created very large and deep damages that allowed the impact tup to penetrate almost halfway through each of the sandwiches. The damages from the carbon and hemp fibers, while severe, were only local, though. Because the aramid and glass fiber facesheets prevented penetration so well, the instantaneous load was spread out over the entire sandwich. This meant that the impact damage was small locally and the force of the impact was dissipated throughout the sandwich, but the effect of the impact was noticeable in more regions of the sandwich. This meant that any regions of weakness in these sandwiches from manufacturing were exposed from the impact. The carbon and hemp fiber sandwiches only exposed weaknesses around the area of impact. The next section will describe how these local and global damages affected the flexural strengths of these sandwiches. 


\subsection{Four-Point Bend Testing Results and Discussion}

The four-point bend testing results are the focus of the majority of comparisons throughout this study. The mid-span deflection results are the focus of experimental, numerical, and theoretical comparisons and maximum bending loads are compared to every other experimental result. The useful data that was outputted from each four-point bend test was raw load and extension values. Stress, strain, maximum load, maximum extension, a calculated modulus, and numerous other values were outputted as well but any of these values that were needed for post-testing analysis were calculated using the load and extension values in Matlab codes. All of the bending results presented in this section were calculated using Matlab codes written strictly for this study.

\subsubsection{Toe Correction of Experimental Data}

One issue that was found with calculating these results from the load and extension data was that there was a small region at the beginning of each set of load and extension data that was not linear. When the four-point bending test fixture was setup for each test, a slight gap was left between the two loading pins and the top of the composite sandwich. This was done to ensure that no initial bending of the sandwiches was present when the testing began. The issue with this, however, was that the test fixture would increase the load very slowly at the beginning

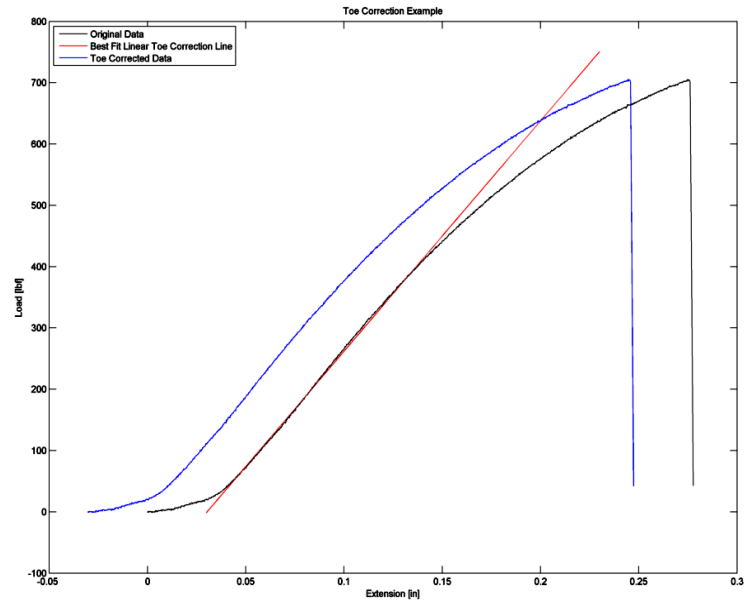

Figure 3.11: Example of load vs. extension plot being toe corrected

of the test until it contacted the sandwich. At that point the load began increasing closer to the desired ASTM suggested rate. This initial region, where the extension values increased much faster than the load values, is called the toe region of the load versus extension plot 
and it skews the final extension data. This toe region can be seen in Figure 3.11 as the slight curvature at the bottom of the original black data. If the maximum extension of the sandwich wanted to be calculated, for example, the value would be much higher than the actual experimental deflection value due to the initial increase in extension before contact with the sandwich.

To deal with this issue, a toe correction was done to each set of experimental data. This toe correction involved finding the slope of the linear section of the load versus extension plot, then drawing a line along that slope and calculating where it intersects the $\mathrm{x}$-axis of the plot. The distance from the origin of the plot to the $\mathrm{x}$-axis intersection point was the distance that the load versus extension curve was shifted back (toe corrected). This processes is shown in Figure 3.11 with the black curve being the load versus extension data taken straight from the Instron 8801 machine, the red line being the toe correction linear slope line, and the blue curve being the new toe corrected data that was used for the rest of the experimental analysis in this study. In the new toe corrected curve, all of the unwanted nonlinear data was now negative and the extension values calculated with this data were now more accurate. All of the plots and results shown in the rest of this study were calculated from toe corrected load versus extension data.

\subsubsection{Experimental Results Calculations}

The first step in the analysis of this new toe corrected data was the calculation of the mid-span deflection of each sandwich. As mentioned before, two tests needed to be done with two different four-point bending setups to minimize the error in the flexural stiffness and transverse shear rigidity calculations. These values use a combination of the mutual load felt by the sandwiches in both testing setups, the extension values for each setup, and the loading configuration dimensions. The equations for the relationship between these values and the flexural stiffness, D, and shear rigidity, U, are shown in Eq. ( 3.4) and Eq. 
(3.5).

$$
\begin{gathered}
D=\frac{3 P_{1} S_{1}^{3}\left(1128-1331 \frac{S_{2}{ }^{2}}{S_{1}{ }^{2}}\right)}{15488 \Delta_{1}\left(11-18 \frac{P_{1} S_{1} \Delta_{2}}{P_{2} S_{2} \Delta_{1}}\right)} \\
U=\frac{9 P_{1} S_{1}\left(1128 \frac{S_{1}{ }^{2}}{S_{2}{ }^{2}}-1331\right)}{4 \Delta_{1}\left(20304\left(\frac{P_{1} S_{1}{ }^{3} \Delta_{2}}{P_{2} S_{2}{ }^{3} \Delta_{1}}\right)-14641\right)}
\end{gathered}
$$

The $P_{1}$ and $P_{2}$ values are the $100 \mathrm{lbf}$ loadings that the first loading configuration was stopped at and that the second loading configuration is being compared to the first at. The $\Delta$ values are the extensions of the top two pins on the four-point bending machine under $100 \mathrm{lbf}$ for each test setup. The $\mathrm{S}$ values are the loading configuration dimensional values. Per ASTM D7250 Section 10.2.7 [36], the values for $S_{1}$ and $S_{2}$ are defined as $S_{1}=\frac{11 L_{1}}{2}$ and $S_{2}=2 L_{2}$. These values were used to calculate the $\mathrm{D}$ and $\mathrm{U}$ values above and then those values were used to calculate the overall mid-span deflections and core shear moduli for all composite sandwich specimens. The equations for experimental mid-span deflection and core shear modulus are shown in Eq. ( 3.6) and Eq. ( 3.7).

$$
\begin{gathered}
\delta=\frac{P\left(2 S^{3}-3 S L^{2}+L^{3}\right)}{96 D}+\frac{P(S-L)}{4 U} \\
G=\frac{U\left(t_{\text {sand }}-2 t_{f}\right)}{\left(t_{\text {sand }}-t_{f}\right)^{2} b}
\end{gathered}
$$

$\mathrm{P}$ is the total applied load (100 lbf was used for comparison), $\mathrm{S}$ is the support span length, $\mathrm{L}$ is the loading span length (standard four-point bend loading configuration), $t_{\text {sand }}$ is the sandwich thickness, $t_{f}$ is the facesheet thickness, and $\mathrm{b}$ is the sandwich width. These 
mid-span deflection values at $100 \mathrm{lbf}$ loads will be validated with numerical and theoretical deflection values in the next chapters.

Using the same values for sandwich dimensions, loading configuration dimensions, and loads that were used for the mid-span deflection calculations, the facesheet and core shear ultimate stresses were then calculated using equations from ASTM D7249 and ASTM C393, respectively. The equations for the ultimate stresses are shown in Eq. ( 3.8) for facesheets and in Eq. ( 3.9) for the core shear. The values for ultimate stress are only for a single facesheet laminate. If the facesheets of a sandwich are unsymmetrical, a different equation is used for the other facesheet but this study only focuses on symmetric composites sandwiches so only one equation is used. The equation for facesheet bending stress is also shown in Eq. ( 3.10).

$$
\begin{gathered}
F^{u l t}=\frac{P_{\text {max }} S\left(1-\frac{L}{S}\right)}{4\left(t_{\text {sand }}-t_{f}\right) b t} \\
F_{s}^{u l t}=\frac{P_{\text {max }}}{\left(t_{\text {sand }}+c\right) b} \\
\sigma_{\text {bend }}=\frac{P S}{2.6667 t_{f}\left(t_{\text {sand }}+c\right) b}
\end{gathered}
$$

All of the variables are described in the mid-span deflection equations except $\mathrm{c}$ which is a function of sandwich dimensions and is defined as $c=t_{\text {sand }}-2 t_{f}$. Since the facesheet materials bare almost all of the bending loads in a composite sandwich, the ultimate stresses calculated for the facesheets was almost identical to the bending stresses so the bending stress values will not be presented in this section. Altogether, these values describe the stresses throughout the composite sandwich during the four-point bend tests. 


\subsubsection{Carbon Fiber Facesheet Sandwiches}

The carbon fiber specimens, in general, greatly outperformed the other sandwich designs due to the facesheet's obvious structural advantages. In terms of the core materials, the honeycomb greatly outperformed the foam when combined with the carbon fiber facesheets. These sandwiches resisted loads that were roughly double what the foam was able to withstand, as can be seen in Figure 3.12. When impacted, however, the results were slightly different. The carbon fiber/foam sandwiches performed well after impact when the damage was bent in compression, losing only about $14 \%$ of their load carrying abilities from

the non-impacted sandwiches, as shown in Table 3.13. When the damage was bent in tension, however, the weak nature of the foam core resulted in the reason for failure. As mentioned earlier, carbon fiber composite materials (and fibrous composite in general) tend to perform better under tensile loads than compressive loads. Because of this, it was expected that when the impact damage was inflicted on the already naturally weak compressive facesheet, the load carrying ability of the sandwich would be much lower than when the impact was on the stronger tension-loaded facesheet. The foam core failed at very low loading values,
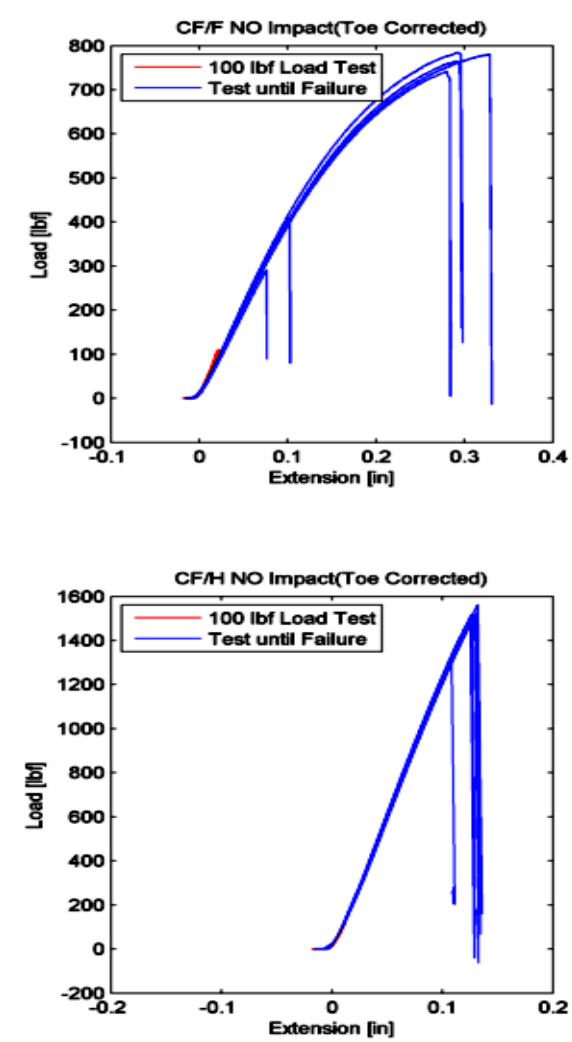

Figure 3.12: Raw data plots for carbon fiber sandwich structures under four-point bend loadings

however, due to shear failure before the carbon fiber facesheets could fail at their maximum values. The impact on these sandwiches may have caused some slight initial core damage 
that forced the sandwiches to fail in core shear at values that were roughly $20 \%$ of the non-impacted sandwich loads.

The carbon fiber/honeycomb sandwiches, on the other hand, performed exactly how carbon fiber was expected to perform. These sandwiches were able to withstand incredibly high bending loads compared to the other sandwich designs in this study but when impacted, the true nature of the carbon fiber facesheets was exposed. The honeycomb core was able to support the carbon fiber facesheets throughout every test, which meant that the sandwiches were able to fail at the carbon fibers weakest point. Because of this, carbon fiber/honeycomb sandwiches performed very well without impact and almost as well when the impact damage was bent in tension but saw a decrease of about $50 \%$ in load carrying ability when the damage was bent in compression. The sandwiches always failed at the carbon fiber facesheets weakest point, which was the compressive facesheet for all of the sandwiches except the damaged tensile surface sandwiches. These failed on the tensile surface of the sandwich at the impacted area because that was forced to be the weakest point on the sandwich by the impact.

Overall, the carbon fiber/honeycomb sandwiches performed much better than the foam core in load carrying abilities but, if the foam core doesn't fail first, the carbon fiber/foam sandwiches showed good post-impact strength characteristics. The carbon fiber/honeycomb sandwiches, however, were much lighter which led to a much higher strength-to-weight ratio for all of the sandwiches over the foam core alternatives. The carbon fiber/honeycomb sandwiches that had the impact damage on the compressive surface, while having poor post-impact strength compared to the non-impacted sandwiches, still had a higher strengthto-weight ratio than the non-impacted foam core sandwiches.

\subsubsection{Hemp Fiber Facesheet Sandwiches}

Hemp sandwich structures, pretty obviously based on the mechanical properties test results, showed a much lower ultimate load carrying ability when compared to the carbon 
Table 3.13: Four-point bend test results for carbon fiber facesheet sandwiches

\begin{tabular}{|c|c|c|c|c|c|c|}
\hline & \multicolumn{3}{|c|}{$\mathrm{CF} / \mathrm{F}$} & \multicolumn{3}{|c|}{ CF/H } \\
\hline & $\begin{array}{c}\text { No } \\
\text { Impact }\end{array}$ & $\begin{array}{l}\text { Impact } \\
\text { (Comp.) }\end{array}$ & $\begin{array}{c}\text { Impact } \\
\text { (Tens.) }\end{array}$ & $\begin{array}{c}\text { No } \\
\text { Impact }\end{array}$ & $\begin{array}{l}\text { Impact } \\
\text { (Comp.) }\end{array}$ & $\begin{array}{l}\text { Impact } \\
\text { (Tens.) }\end{array}$ \\
\hline $\begin{array}{c}\text { Weight } \\
\text { [lbm] }\end{array}$ & $\begin{array}{c}0.208 \\
+/- \\
0.003\end{array}$ & $\begin{array}{c}0.210 \\
+/- \\
0.002\end{array}$ & $\begin{array}{c}0.207 \\
+/- \\
0.001\end{array}$ & $\begin{array}{c}0.203 \\
+/- \\
0.002\end{array}$ & $\begin{array}{c}0.200 \\
+/- \\
0.002\end{array}$ & $\begin{array}{c}0.195 \\
+/- \\
0.001\end{array}$ \\
\hline $\begin{array}{c}\text { Facesheet } \\
\text { Ultimate } \\
\text { Stress [psi] }\end{array}$ & $\begin{array}{c}1.17 \mathrm{E} 4 \\
+/- \\
0.40 E 4\end{array}$ & $\begin{array}{c}1.21 \mathrm{E} 4 \\
+/- \\
0.07 E 4\end{array}$ & $\begin{array}{c}.39 \mathrm{E} 4 \\
+/- \\
0.08 E 4\end{array}$ & $\begin{array}{c}2.81 \mathrm{E} 4 \\
+/- \\
0.08 E 4\end{array}$ & $\begin{array}{c}1.52 \mathrm{E} 4 \\
+/- \\
0.19 E 4\end{array}$ & $\begin{array}{c}3.41 \mathrm{E} 4 \\
+/- \\
0.15 E 4\end{array}$ \\
\hline $\begin{array}{l}\text { Core Shear } \\
\text { Ultimate } \\
\text { Stress [psi] }\end{array}$ & $\begin{array}{c}195 \\
+/-68\end{array}$ & $\begin{array}{c}202 \\
+/-12\end{array}$ & $\begin{array}{c}46 \\
+/-10\end{array}$ & $\begin{array}{c}461 \\
+/-30\end{array}$ & $\begin{array}{l}234 \\
+/-9\end{array}$ & $\begin{array}{c}398 \\
+/-17\end{array}$ \\
\hline $\begin{array}{c}\text { Flexural } \\
\text { Stiffness (D) } \\
{\left[l b f-i n^{2}\right]}\end{array}$ & $\begin{array}{c}\text { 4.70E4 } \\
+/- \\
0.57 E 4\end{array}$ & $\begin{array}{c}4.43 \mathrm{E} 4 \\
+/- \\
0.35 E 4\end{array}$ & $\begin{array}{c}4.24 \mathrm{E} 4 \\
+/- \\
0.43 E 4\end{array}$ & $\begin{array}{c}8.70 \mathrm{E} 4 \\
+/- \\
0.72 E 4\end{array}$ & $\begin{array}{c}8.17 \mathrm{E} 4 \\
+/- \\
0.69 E 4\end{array}$ & 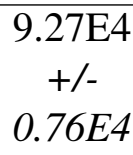 \\
\hline $\begin{array}{c}\text { Transverse } \\
\text { Shear } \\
\text { Rigidity (U) } \\
\text { [lbf] } \\
\end{array}$ & $\begin{array}{c}2.80 \mathrm{E} 3 \\
+/- \\
0.25 \mathrm{E3}\end{array}$ & $\begin{array}{c}2.66 \mathrm{E} 3 \\
+/- \\
0.16 E 3\end{array}$ & $\begin{array}{c}2.29 \mathrm{E} 3 \\
+/- \\
0.15 E 3\end{array}$ & $\begin{array}{c}5.68 \mathrm{E} 3 \\
+/- \\
0.41 E 3\end{array}$ & $\begin{array}{c}5.37 \mathrm{E} 3 \\
+/- \\
0.34 E 3\end{array}$ & $\begin{array}{c}5.93 \mathrm{E} 3 \\
+/- \\
0.36 E 3\end{array}$ \\
\hline $\begin{array}{c}\text { Mid-Span } \\
\text { Deflection } \\
\text { (100 lbf) [in] }\end{array}$ & $\begin{array}{c}0.033 \\
+/- \\
0.002\end{array}$ & $\begin{array}{c}0.034 \\
+/- \\
0.002\end{array}$ & $\begin{array}{c}0.043 \\
+/- \\
0.002 \\
\end{array}$ & $\begin{array}{c}0.015 \\
+/- \\
0.001\end{array}$ & $\begin{array}{c}0.016 \\
+/- \\
0.001\end{array}$ & $\begin{array}{c}0.015 \\
+/- \\
0.001\end{array}$ \\
\hline $\begin{array}{l}\text { Maximum } \\
\text { Load [lbf] }\end{array}$ & $\begin{array}{c}769 \\
+/-219\end{array}$ & $\begin{array}{c}\mathbf{6 6 0} \\
+/-41\end{array}$ & $\begin{array}{c}150 \\
+/-32\end{array}$ & $\begin{array}{l}1519 \\
+/-96\end{array}$ & $\begin{array}{c}744 \\
+/-24\end{array}$ & $\begin{array}{l}1298 \\
+/-58\end{array}$ \\
\hline $\begin{array}{c}\text { Strength-to- } \\
\text { Weight } \\
\text { Ratio } \\
\text { [lbf/lbm] }\end{array}$ & $\begin{array}{c}3.70 \mathrm{E} 3 \\
+/- \\
1.06 E 3\end{array}$ & $\begin{array}{c}3.14 \mathrm{E} 3 \\
+/- \\
0.20 E 3\end{array}$ & $\begin{array}{c}0.72 \mathrm{E} 3 \\
+/- \\
0.15 E 3\end{array}$ & $\begin{array}{c}7.50 \mathrm{E} 3 \\
+/- \\
0.48 E 3\end{array}$ & $\begin{array}{c}3.73 \mathrm{E} 3 \\
+/- \\
0.13 E 3\end{array}$ & $\begin{array}{c}6.67 \mathrm{E} 3 \\
+/- \\
0.30 \mathrm{E} 3\end{array}$ \\
\hline $\begin{array}{l}\text { Post-Impact } \\
\text { Load } \\
\text { Degradation } \\
{[\%]}\end{array}$ & $100 \%$ & $85.5 \%$ & $19.5 \%$ & $100 \%$ & $48.9 \%$ & $85.4 \%$ \\
\hline
\end{tabular}


fiber sandwiches. The raw data plots of the hemp sandwiches are shown in Figure 3.13. The results of the bending tests on these sandwiches, shown in Table 3.14, were similar to the carbon fiber sandwiches but at lower load values. The impact damaged compressive facesheet sandwiches didn't perform as well as the damaged tensile facesheet sandwiches just like carbon fiber structures. The main difference between the two facesheet materials, however, is that the hemp performed much better after impact than carbon fiber did. The post-impact strengths were about the same as the non-impacted sandwiches and in the case of the foam core structures, the load carrying ability was even higher after impact than without impact. Since the hand layup technique was used to manufacture the hemp facesheet sandwiches, the difference in strength between each specimen is more than the prepreg material facesheet sandwiches used for all other structures in this study. The higher postimpact strengths than non-impacted sandwich strengths for the foam core structures is a direct correlation to this manufacturing error but the important takeaway from these
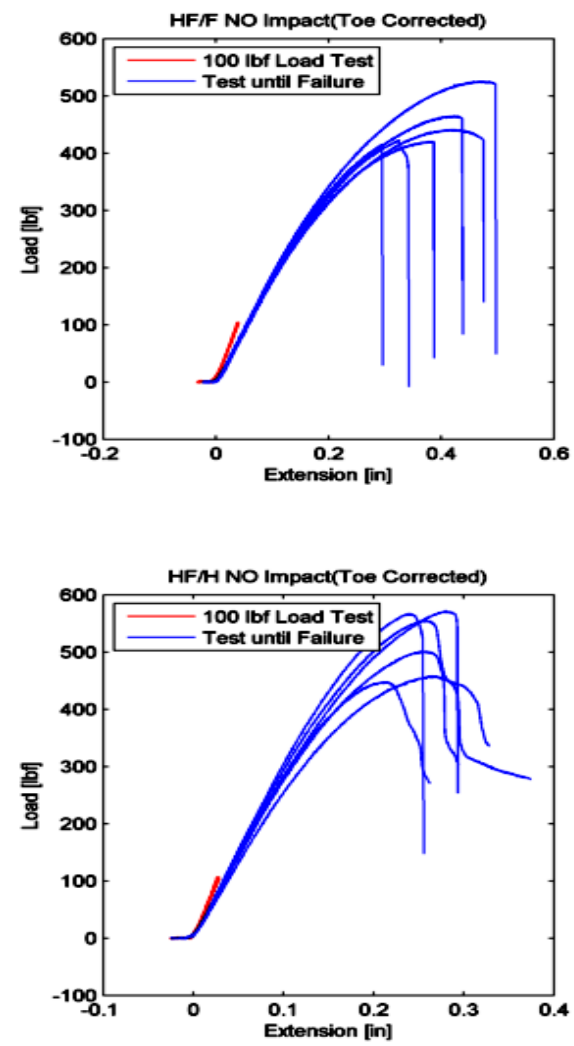

Figure 3.13: Raw data plots for hemp fiber sandwich structures under four-point bend loadings

results is the lack of load degradation after impact. The carbon fiber/foam sandwiches had much better post-impact strengths than the honeycomb core sandwiches did and the same result occurred for the hemp facesheet sandwiches.

The hemp/honeycomb sandwiches were able to, as expected, withstand generally higher loads than the foam core structures except for the impact damaged tensile facesheet sandwiches. The foam core sandwiches performed exceedingly well under these loading con- 
Table 3.14: Four-point bend test results for hemp fiber facesheet sandwiches

\begin{tabular}{|c|c|c|c|c|c|c|}
\hline & \multicolumn{3}{|c|}{ HF/F } & \multicolumn{3}{|c|}{ HF/H } \\
\hline & $\begin{array}{c}\text { No } \\
\text { Impact }\end{array}$ & $\begin{array}{l}\text { Impact } \\
\text { (Comp.) }\end{array}$ & $\begin{array}{c}\text { Impact } \\
\text { (Tens.) }\end{array}$ & $\begin{array}{c}\text { No } \\
\text { Impact }\end{array}$ & $\begin{array}{l}\text { Impact } \\
\text { (Comp.) }\end{array}$ & $\begin{array}{c}\text { Impact } \\
\text { (Tens.) }\end{array}$ \\
\hline $\begin{array}{c}\text { Weight } \\
{[\text { lbm] }}\end{array}$ & $\begin{array}{c}0.264 \\
+/- \\
0.003\end{array}$ & $\begin{array}{c}0.263 \\
+/- \\
0.004\end{array}$ & $\begin{array}{c}0.277 \\
+/- \\
0.003\end{array}$ & $\begin{array}{c}0.288 \\
+/- \\
0.003\end{array}$ & $\begin{array}{c}0.300 \\
+/- \\
0.004\end{array}$ & $\begin{array}{c}0.276 \\
+/- \\
0.003\end{array}$ \\
\hline $\begin{array}{l}\text { Facesheet } \\
\text { Ultimate } \\
\text { Stress [nsi] }\end{array}$ & $\begin{array}{c}0.51 \mathrm{E} 4 \\
+/- \\
0.04 E 4\end{array}$ & $\begin{array}{c}0.54 \mathrm{E} 4 \\
+/- \\
0.04 E 4\end{array}$ & $\begin{array}{c}0.62 \mathrm{E} 4 \\
+/- \\
0.02 E 4\end{array}$ & $\begin{array}{c}0.54 \mathrm{E} 4 \\
+/- \\
0.07 E 4\end{array}$ & $\begin{array}{c}0.46 \mathrm{E} 4 \\
+/- \\
0.10 E 4\end{array}$ & $\begin{array}{c}0.51 \mathrm{E} 4 \\
+/- \\
0.09 E 4\end{array}$ \\
\hline $\begin{array}{c}\text { Core Shear } \\
\text { Ultimate } \\
\text { Stress [psi] }\end{array}$ & $\begin{array}{c}137 \\
+/-12\end{array}$ & $\begin{array}{c}143 \\
+/-10\end{array}$ & $\begin{array}{l}154 \\
+/-6\end{array}$ & $\begin{array}{c}153 \\
+/-16\end{array}$ & $\begin{array}{c}132 \\
+/-29\end{array}$ & $\begin{array}{c}142 \\
+/-25\end{array}$ \\
\hline $\begin{array}{c}\text { Flexural } \\
\text { Stiffness (D) } \\
{\left[l b f-i n^{2}\right]}\end{array}$ & $\begin{array}{c}3.51 \mathrm{E} 4 \\
+/- \\
0.30 E 4\end{array}$ & $\begin{array}{c}3.51 \mathrm{E} 4 \\
+/- \\
0.87 E 4\end{array}$ & $\begin{array}{c}3.07 \mathrm{E} 4 \\
+/- \\
0.15 E 4\end{array}$ & $\begin{array}{c}\text { 4.37E4 } \\
+/- \\
0.35 E 4\end{array}$ & $\begin{array}{c}4.36 \mathrm{E} 4 \\
+/- \\
0.29 E 4\end{array}$ & $\begin{array}{c}4.66 \mathrm{E} 4 \\
+/- \\
0.61 E 4\end{array}$ \\
\hline $\begin{array}{c}\text { Transverse } \\
\text { Shear } \\
\text { Rigidity (U) } \\
\text { [lbf] }\end{array}$ & $\begin{array}{c}1.72 \mathrm{E} 3 \\
+/- \\
0.07 E 3\end{array}$ & $\begin{array}{c}1.59 \mathrm{E} 3 \\
+/- \\
0.18 E 3\end{array}$ & $\begin{array}{c}1.67 \mathrm{E} 3 \\
+/- \\
0.07 E 3\end{array}$ & $\begin{array}{c}2.36 \mathrm{E} 3 \\
+/- \\
0.12 \mathrm{E} 3\end{array}$ & $\begin{array}{c}2.26 \mathrm{E} 3 \\
+/- \\
0.19 E 3\end{array}$ & $\begin{array}{c}2.58 \mathrm{E} 3 \\
+/- \\
0.27 E 3\end{array}$ \\
\hline $\begin{array}{c}\text { Mid-Span } \\
\text { Deflection } \\
\text { (100 lbf) [in] }\end{array}$ & $\begin{array}{c}0.059 \\
+/- \\
0.001\end{array}$ & $\begin{array}{c}0.066 \\
+/- \\
0.004\end{array}$ & $\begin{array}{c}0.058 \\
+/- \\
0.002\end{array}$ & $\begin{array}{c}0.041 \\
+/- \\
0.002\end{array}$ & $\begin{array}{c}0.044 \\
+/- \\
0.004\end{array}$ & $\begin{array}{c}0.038 \\
+/- \\
0.004\end{array}$ \\
\hline $\begin{array}{l}\text { Maximum } \\
\text { Load [lbf] }\end{array}$ & $\begin{array}{c}449 \\
+/-42\end{array}$ & $\begin{array}{c}466 \\
+/-34\end{array}$ & $\begin{array}{c}530 \\
+/-23\end{array}$ & $\begin{array}{c}517 \\
+/-56\end{array}$ & $\begin{array}{c}461 \\
+/-96\end{array}$ & $\begin{array}{c}489 \\
+/-85\end{array}$ \\
\hline $\begin{array}{c}\text { Strength-to- } \\
\text { Weight } \\
\text { Ratio } \\
\text { [lbf/lbm] }\end{array}$ & $\begin{array}{c}1.70 \mathrm{E} 3 \\
+/- \\
0.16 E 3\end{array}$ & $\begin{array}{c}1.77 \mathrm{E} 3 \\
+/- \\
0.13 E 3\end{array}$ & $\begin{array}{c}1.91 \mathrm{E} 3 \\
+/- \\
0.08 E 3\end{array}$ & $\begin{array}{c}1.79 \mathrm{E} 3 \\
+/- \\
0.19 E 3\end{array}$ & $\begin{array}{c}1.54 \mathrm{E} 3 \\
+/- \\
0.32 \mathrm{E3}\end{array}$ & $\begin{array}{c}1.78 \mathrm{E} 3 \\
+/- \\
0.31 E 3\end{array}$ \\
\hline $\begin{array}{c}\text { Post-Impact } \\
\text { Load } \\
\text { Degradation } \\
{[\%]}\end{array}$ & $100 \%$ & $103.7 \%$ & $118.0 \%$ & $100 \%$ & $89.1 \%$ & $94.6 \%$ \\
\hline
\end{tabular}


ditions and outperformed the honeycomb core. Other than that, the honeycomb core structures showed the expected slight degradation in load carrying ability from the non-impacted sandwiches to the tension-loaded damaged facesheet sandwiches and the larger degradation in the sandwiches bent with the damaged surface in compression. In terms of the weight of these sandwiches, the honeycomb core was much lighter than the foam core which resulted in lighter sandwiches for the prepreg carbon fiber facesheet structures; however, when the hand layup technique was performed for the hemp specimens, the excess epoxy filled the holes of the honeycomb during curing instead of being drawn out of the sandwich, which is what happened when the foam core sandwiches were cured. Because of this, more epoxy in the honeycomb core sandwiches led to higher weights and since the load carrying abilities of each sandwich were similar, the strength-to-weight ratios were higher for the foam core sandwiches, except in the case of the non-impacted sandwiches. Overall, hemp/foam sandwiches and hemp/honeycomb sandwiches performed similarly under each loading condition and the hemp sandwiches showed great post-impact strength characteristics.

\subsubsection{Aramid Fiber (Twaron) Facesheet Sandwiches}

As shown in the fiber volume testing results, low epoxy content in the composites led to premature delaminations when impacted. This same low epoxy content also led to premature delaminations of the facesheets from the core material for both the foam and honeycomb core sandwiches when subjected to bending loads. This failure was the main reason for the low ultimate flexural strength values, shown in Figure 3.14, of the aramid fiber composite structure. From the mechanical properties testing results, it was expected that the aramid fiber sandwiches would be able to withstand higher bending loads than hemp and glass fiber but lower than carbon fiber. The results, however, showed that the aramid fiber sandwich was the weakest design in every testing category. Because of the initial impact delaminations on these sandwiches, some of the structures never even reached the $100 \mathrm{lbf}$ loading necessary for getting results from the first four-point bend test configuration. This 
created a major skew in the results of the testing so only the sandwiches that successfully finished both four-point bending tests were used to calculate the averages shown in Table 3.15. For the foam core sandwiches, these average values show low non-impacted ultimate load values in the low $200 \mathrm{lbf}$ range and a major decrease of load carrying ability after impact for both the compressive and tensile damage tested sandwiches.

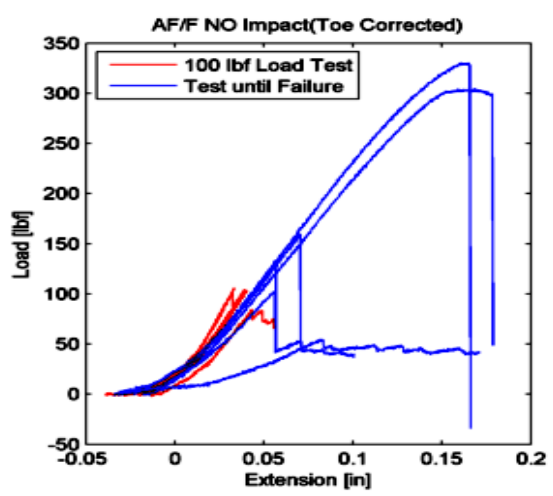

The aramid fiber/honeycomb sandwiches resulted in higher ultimate bending loads for the non-impacted specimens because of the honeycomb's superior characteristics over the foam core; however, when impacted, almost every structure resulted in immediate delamination because of the small surface area of the honeycomb and the low epoxy content of the aramid fiber

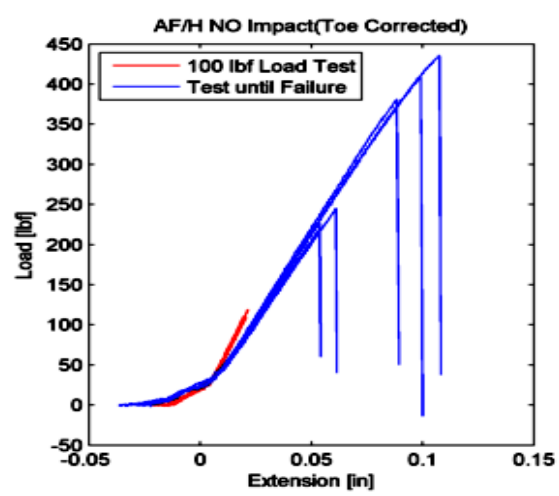

Figure 3.14: Raw data plots for aramid fiber sandwich structures under four-point bend loadings

laminates. These delaminations led to the largest drop in load carrying capabilities for any sandwich design in this study from low $300 \mathrm{lbf}$ ultimate load values for the non-impacted sandwiches to basically no load carrying ability for the impacted compressive and tensile damaged sandwiches. The only positive from the low epoxy content was the fact that these sandwiches were very light. Even with the very low ultimate load values, these sandwiches were still able to produce strength-to-weight values that were the second highest of all of the sandwich designs in this study (lower than carbon fiber sandwiches). Higher epoxy content aramid fiber materials may have been able to produce better bending test results but the high resistance to impact damage of the facesheets may have still been an issue for post-impact flexural strengths. 
Table 3.15: Useful four-point bend test results for aramid fiber facesheet sandwiches

\begin{tabular}{|c|c|c|c|c|c|c|}
\hline & \multicolumn{3}{|c|}{$\overline{\mathrm{AF} / \mathrm{F}}$} & \multicolumn{3}{|c|}{$\mathbf{A F} / \mathbf{H}$} \\
\hline & $\begin{array}{c}\text { No } \\
\text { Impact }\end{array}$ & $\begin{array}{l}\text { Impact } \\
\text { (Comp.) }\end{array}$ & $\begin{array}{l}\text { Impact } \\
\text { (Tens.) }\end{array}$ & $\begin{array}{c}\text { No } \\
\text { Impact }\end{array}$ & $\begin{array}{l}\text { Impact } \\
\text { (Comp.) }\end{array}$ & $\begin{array}{c}\text { Impact } \\
\text { (Tens.) }\end{array}$ \\
\hline $\begin{array}{c}\text { Weight } \\
{[\text { lbm] }}\end{array}$ & $\begin{array}{c}0.138 \\
+/- \\
0.001\end{array}$ & $\begin{array}{c}0.140 \\
+/- \\
0.001\end{array}$ & $\begin{array}{c}0.142 \\
+/- \\
0.002\end{array}$ & $\begin{array}{c}0.126 \\
+/- \\
0.002\end{array}$ & $\begin{array}{c}0.127 \\
+/- \\
0.001\end{array}$ & $\begin{array}{c}0.127 \\
+/- \\
0.002\end{array}$ \\
\hline $\begin{array}{c}\text { Facesheet } \\
\text { Ultimate } \\
\text { Stress [psi] }\end{array}$ & $\begin{array}{c}1.11 \mathrm{E} 4 \\
+/- \\
0.38 E 4\end{array}$ & $\begin{array}{c}0.50 \mathrm{E} 4 \\
+/- \\
0.01 E 4\end{array}$ & $\begin{array}{c}0.36 \mathrm{E} 4 \\
+/- \\
0.03 E 4\end{array}$ & $\begin{array}{c}1.51 \mathrm{E} 4 \\
+/- \\
0.47 E 4\end{array}$ & $\begin{array}{c}0.21 \mathrm{E} 4 \\
+/- \\
0.01 E 4\end{array}$ & $\begin{array}{c}0.19 \mathrm{E} 4 \\
+/- \\
0.02 E 4\end{array}$ \\
\hline $\begin{array}{c}\text { Core Shear } \\
\text { Ultimate } \\
\text { Stress [psi] }\end{array}$ & $\begin{array}{c}74 \\
+/-25\end{array}$ & $\begin{array}{c}33 \\
+/-1\end{array}$ & $\begin{array}{c}24 \\
+/-2\end{array}$ & $\begin{array}{c}101 \\
+/-32\end{array}$ & $\begin{array}{c}14 \\
+/-1\end{array}$ & $\begin{array}{c}13 \\
+/-1\end{array}$ \\
\hline $\begin{array}{c}\text { Flexural } \\
\text { Stiffness (D) } \\
{\left[l b f-i n^{2}\right]}\end{array}$ & $\begin{array}{c}2.87 \mathrm{E} 4 \\
+/- \\
0.04 E 4\end{array}$ & $\begin{array}{c}5.16 \mathrm{E} 4 \\
+/- \\
0.01 E 4\end{array}$ & $\begin{array}{c}0.44 \mathrm{E} 4 \\
+/- \\
0.09 E 4\end{array}$ & $\begin{array}{c}\begin{array}{c}6.08 \mathrm{E} 4 \\
+/- \\
0.16 E 4\end{array}\end{array}$ & $\begin{array}{c}0.99 \mathrm{E} 4 \\
+/- \\
0.13 E 4\end{array}$ & $\begin{array}{c}1.00 \mathrm{E} 4 \\
+/- \\
0.09 E 4\end{array}$ \\
\hline $\begin{array}{c}\text { Transverse } \\
\text { Shear } \\
\text { Rigidity (U) } \\
\text { [lbf] }\end{array}$ & $\begin{array}{c}1.64 \mathrm{E} 3 \\
+/- \\
0.16 E 3\end{array}$ & $\begin{array}{c}1.84 \mathrm{E} 3 \\
+/- \\
0.01 E 3\end{array}$ & $\begin{array}{c}0.52 \mathrm{E} 3 \\
+/- \\
0.10 E 3\end{array}$ & $\begin{array}{c}3.35 \mathrm{E} 3 \\
+/- \\
0.06 E 3\end{array}$ & $\begin{array}{c}1.18 \mathrm{E} 3 \\
+/- \\
0.16 E 3\end{array}$ & $\begin{array}{c}1.19 \mathrm{E} 3 \\
+/- \\
0.10 E 3\end{array}$ \\
\hline $\begin{array}{c}\text { Mid-Span } \\
\text { Deflection } \\
\text { (100 lbf) [in] }\end{array}$ & $\begin{array}{c}0.057 \\
+/- \\
0.004\end{array}$ & $\begin{array}{c}0.063 \\
+/- \\
0.001\end{array}$ & $\begin{array}{c}0.068 \\
+/- \\
0.015\end{array}$ & $\begin{array}{c}0.029 \\
+/- \\
0.001\end{array}$ & $\begin{array}{c}0.030 \\
+/- \\
0.004\end{array}$ & $\begin{array}{c}0.029 \\
+/- \\
0.003\end{array}$ \\
\hline $\begin{array}{l}\text { Maximum } \\
\text { Load [lbf] }\end{array}$ & $\begin{array}{c}232 \\
+/-77\end{array}$ & $\begin{array}{l}107 \\
+/-1\end{array}$ & $\begin{array}{c}\mathbf{7 8} \\
+/-7\end{array}$ & $\begin{array}{c}319 \\
+/-100\end{array}$ & $\begin{array}{c}46 \\
+/-1\end{array}$ & $\begin{array}{c}42 \\
+/-3\end{array}$ \\
\hline $\begin{array}{c}\text { Strength-to- } \\
\text { Weight } \\
\text { Ratio } \\
\text { [lbf/lbm] }\end{array}$ & $\begin{array}{c}1.68 \mathrm{E} 3 \\
+/- \\
0.56 E 3\end{array}$ & $\begin{array}{c}0.76 \mathrm{E} 3 \\
+/- \\
0.01 E 3\end{array}$ & $\begin{array}{c}0.55 \mathrm{E} 3 \\
+/- \\
0.05 E 3\end{array}$ & $\begin{array}{c}2.53 \mathrm{E} 3 \\
+/- \\
0.79 E 3\end{array}$ & $\begin{array}{c}0.36 \mathrm{E} 3 \\
+/- \\
0.01 E 3\end{array}$ & $\begin{array}{c}0.33 \mathrm{E} 3 \\
+/- \\
0.03 E 3\end{array}$ \\
\hline $\begin{array}{c}\text { Post-Impact } \\
\text { Load } \\
\text { Degradation } \\
{[\%]}\end{array}$ & $100 \%$ & $46.0 \%$ & $33.0 \%$ & $100 \%$ & $14.4 \%$ & $13.0 \%$ \\
\hline
\end{tabular}




\subsubsection{Glass Fiber (Texalium) Facesheet Sandwiches}

As has been seen throughout the analysis of the testing results in this study, glass and aramid fiber materials have been similar. The bending test results were no different. The ultimate bending loads held by the glass fiber sandwiches were higher than the aramid fiber specimens but still lower than expected. The premature delamination failure can be seen in the glass fiber/foam raw data plots in the top plot of Figure 3.15 as the much more plastic (ductile) failures. The glass fiber sandwiches had a high resistance to impact damage which was most likely the reason for the postimpact bending delamination failure, similar to the aramid fiber structures. The foam core sandwiches had poor adhesion
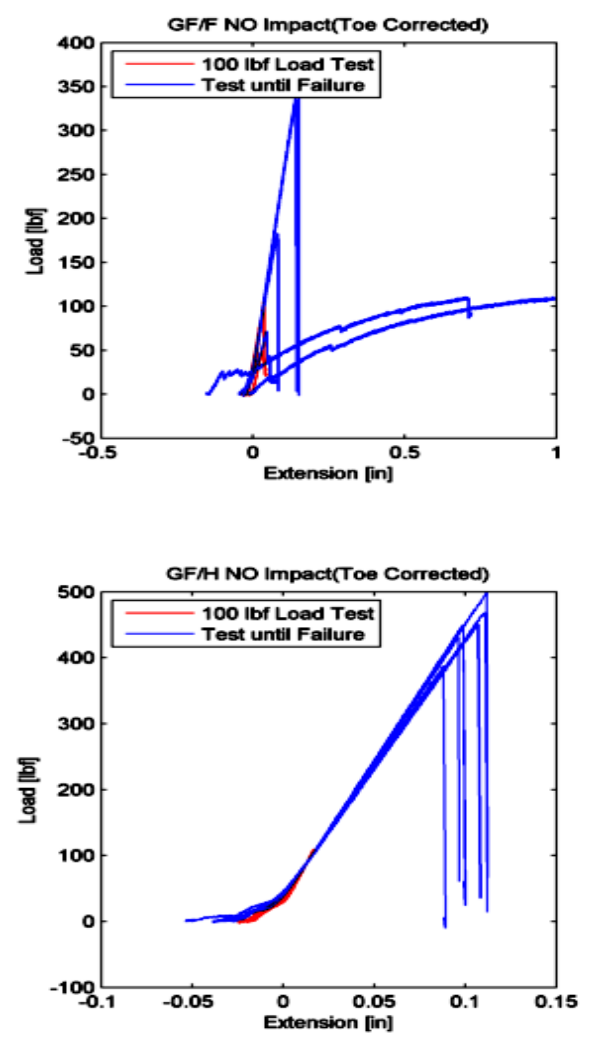
between the core and facesheets, resulting in delamination at low loading values for

Figure 3.15: Raw data plots for glass fiber sandwich structures under four-point bend loadings

the non-impacted sandwiches. Similar to the carbon fiber/foam sandwiches with the impact damage under tensile loading, the glass fiber/foam sandwiches all failed in core shear when bent with the damage in compression because of the weakened core from the impact damage, resulting in extreme drops in load carrying capabilities. The tension-loaded damaged facesheet sandwiches showed excellent post-impact characteristics, however, with a slightly higher average ultimate loading value than the non-impacted sandwiches (not including specimens that did not have legitimate results because they failed during the first $100 \mathrm{lbf}$ test configuration). 
Table 3.16: Useful four-point bend test results for glass fiber facesheet sandwiches

\begin{tabular}{|c|c|c|c|c|c|c|}
\hline & \multicolumn{3}{|c|}{ GF/F } & \multicolumn{3}{|c|}{$\overline{\text { GF/H }}$} \\
\hline & $\begin{array}{c}\text { No } \\
\text { Impact }\end{array}$ & $\begin{array}{l}\text { Impact } \\
\text { (Comp.) }\end{array}$ & $\begin{array}{c}\text { Impact } \\
\text { (Tens.) }\end{array}$ & $\begin{array}{c}\text { No } \\
\text { Impact }\end{array}$ & $\begin{array}{l}\text { Impact } \\
\text { (Comp.) }\end{array}$ & $\begin{array}{c}\text { Impact } \\
\text { (Tens.) }\end{array}$ \\
\hline $\begin{array}{c}\text { Weight } \\
\text { [lbm] }\end{array}$ & $\begin{array}{c}0.216 \\
+/- \\
0.003\end{array}$ & $\begin{array}{c}0.224 \\
+/- \\
0.001\end{array}$ & $\begin{array}{c}0.218 \\
+/- \\
0.003\end{array}$ & $\begin{array}{c}0.218 \\
+/- \\
0.003\end{array}$ & $\begin{array}{c}0.213 \\
+/- \\
0.004\end{array}$ & $\begin{array}{c}0.213 \\
+/- \\
0.002\end{array}$ \\
\hline $\begin{array}{c}\text { Facesheet } \\
\text { Ultimate } \\
\text { Stress [psi] }\end{array}$ & $\begin{array}{c}0.61 \mathrm{E} 4 \\
+/- \\
0.13 E 4\end{array}$ & $\begin{array}{c}0.23 \mathrm{E} 4 \\
+/- \\
0.01 E 4\end{array}$ & $\begin{array}{c}0.63 \mathrm{E} 4 \\
+/- \\
0.25 E 4\end{array}$ & $\begin{array}{c}0.91 \mathrm{E} 4 \\
+/- \\
0.08 E 4\end{array}$ & $\begin{array}{c}0.92 \mathrm{E} 4 \\
+/- \\
0.33 E 4\end{array}$ & $\begin{array}{c}0.82 \mathrm{E} 4 \\
+/- \\
0.34 E 4\end{array}$ \\
\hline $\begin{array}{c}\text { Core Shear } \\
\text { Ultimate } \\
\text { Stress [psi] }\end{array}$ & $\begin{array}{c}91 \\
+/-19\end{array}$ & $\begin{array}{c}34 \\
+/-1\end{array}$ & $\begin{array}{c}95 \\
+/-37\end{array}$ & $\begin{array}{c}137 \\
+/-13\end{array}$ & $\begin{array}{c}138 \\
+/-50\end{array}$ & $\begin{array}{c}123 \\
+/-51\end{array}$ \\
\hline $\begin{array}{c}\text { Flexural } \\
\text { Stiffness (D) } \\
{\left[l b f-i n^{2}\right]}\end{array}$ & $\begin{array}{c}2.70 \mathrm{E} 4 \\
+/- \\
0.06 E 4\end{array}$ & $\begin{array}{c}3.24 \mathrm{E} 4 \\
+/- \\
0.03 E 4\end{array}$ & $\begin{array}{c}2.54 \mathrm{E} 4 \\
+/- \\
0.05 E 4\end{array}$ & $\begin{array}{c}\text { 5.85E4 } \\
+/- \\
0.17 E 4\end{array}$ & $\begin{array}{c}\text { 5.44E4 } \\
+/- \\
0.20 E 4\end{array}$ & $\begin{array}{c}\text { 5.82E4 } \\
+/- \\
0.21 E 4\end{array}$ \\
\hline $\begin{array}{c}\text { Transverse } \\
\text { Shear } \\
\text { Rigidity (U) } \\
\text { [lbf] }\end{array}$ & $\begin{array}{c}1.71 \mathrm{E} 3 \\
+/- \\
0.02 \mathrm{E} 3\end{array}$ & $\begin{array}{c}1.78 \mathrm{E} 3 \\
+/- \\
0.01 E 3\end{array}$ & $\begin{array}{c}1.64 \mathrm{E} 3 \\
+/- \\
0.02 E 3\end{array}$ & $\begin{array}{c}3.70 \mathrm{E} 3 \\
+/- \\
0.07 E 3\end{array}$ & $\begin{array}{c}3.44 \mathrm{E} 3 \\
+/- \\
0.09 E 3\end{array}$ & $\begin{array}{c}3.66 \mathrm{E} 3 \\
+/- \\
0.09 E 3\end{array}$ \\
\hline $\begin{array}{c}\text { Mid-Span } \\
\text { Deflection } \\
\text { (100 lbf) [in] }\end{array}$ & $\begin{array}{c}0.051 \\
+/- \\
0.001\end{array}$ & $\begin{array}{c}0.054 \\
+/- \\
0.001\end{array}$ & $\begin{array}{c}0.053 \\
+/- \\
0.001\end{array}$ & $\begin{array}{c}0.024 \\
+/- \\
0.001\end{array}$ & $\begin{array}{c}0.026 \\
+/- \\
0.001\end{array}$ & $\begin{array}{c}0.024 \\
+/- \\
0.001\end{array}$ \\
\hline $\begin{array}{l}\text { Maximum } \\
\text { Load [lbf] }\end{array}$ & $\begin{array}{c}292 \\
+/-60\end{array}$ & $\begin{array}{l}112 \\
+/-5\end{array}$ & $\begin{array}{c}\mathbf{3 0 8} \\
+/-124\end{array}$ & $\begin{array}{c}448 \\
+/-37\end{array}$ & $\begin{array}{c}\mathbf{4 4 4} \\
+/-162\end{array}$ & $\begin{array}{c}397 \\
+/-163\end{array}$ \\
\hline $\begin{array}{c}\text { Strength-to- } \\
\text { Weight } \\
\text { Ratio } \\
\text { [lbf/lbm] }\end{array}$ & $\begin{array}{c}1.35 \mathrm{E} 3 \\
+/- \\
0.28 \mathrm{E} 3\end{array}$ & $\begin{array}{c}0.50 \mathrm{E} 3 \\
+/- \\
0.01 E 3\end{array}$ & $\begin{array}{c}1.41 \mathrm{E} 3 \\
+/- \\
0.57 E 3\end{array}$ & $\begin{array}{c}2.06 \mathrm{E} 3 \\
+/- \\
0.17 \mathrm{E} 3\end{array}$ & $\begin{array}{c}2.08 \mathrm{E} 3 \\
+/- \\
0.76 E 3\end{array}$ & $\begin{array}{c}1.87 \mathrm{E} 3 \\
+/- \\
0.77 \mathrm{E} 3\end{array}$ \\
\hline $\begin{array}{c}\text { Post-Impact } \\
\text { Load } \\
\text { Degradation } \\
{[\%]}\end{array}$ & $100 \%$ & $38.5 \%$ & $105.4 \%$ & $100 \%$ & $99.2 \%$ & $88.7 \%$ \\
\hline
\end{tabular}


The glass fiber/honeycomb sandwiches had similar results for each loading category to the carbon fiber/honeycomb sandwiches but at much lower ultimate load values; however, they were all higher than the foam core sandwiches, as can be seen in Table 3.16. The main difference between these sandwiches and the carbon fiber ones was the post-impact performance. The glass fiber/honeycomb sandwiches showed fantastic post-impact strengths for impact damages bent in both compression and tension. These sandwiches were the right balance between absorbing the impact energy with indentations (like the carbon and hemp fiber specimens) and completely resisting the impact (like the aramid fiber specimens), which meant that initial delaminations from the impact loadings were minimized compared to the aramid fibers and the core was protected better than the carbon and hemp fiber sandwich cores were. This is the reason for the small amount of degradation in load carrying abilities of these sandwiches after impact compared to the non-impacted specimens. Unfortunately for the foam core sandwiches, these structures weighed about the same as the carbon fiber sandwiches did, which meant that with small loads, the strength-to-weight values of them were the lowest of any sandwich analyzed in this study for the non-impacted specimens. The honeycomb core sandwiches, however, produced non-impacted strengthto-weight values slightly lower than the aramid and carbon fiber but impacted strength-toweight values that were second only to carbon fiber sandwiches. If the delamination issue can be controlled with the glass fiber/honeycomb structures, they could be a legitimate option for a sandwich design used in parts that are subjected to impact and bending loads.

\subsubsection{Hybrid Carbon and Aramid Fiber Facesheet Sandwiches}

Because the carbon fiber/honeycomb sandwich designs were greatly superior to all of the other designs in flexural strength, they were considered the overall best sandwich design for this loading condition; however, when the sandwich was damaged by a low-velocity impact and that damage occurred on the compressive surface of the sandwich, it was no longer superior to all of the other sandwich designs. For this reason, the hybrid sandwiches were 
constructed to try to improve the post-impact compressive strengths of these sandwiches by improving their impact damage resistance with aramid fiber composites. The raw data plots for these sandwiches are shown in Figure 3.16. When these hybrid sandwiches were tested, the impact damages affected the flexural characteristics of the hybrid sandwiches in the predicted ways. The non-impacted carbon(2)aramid(1)/honeycomb sandwich design dropped slightly in load carrying ability from the $1519 \mathrm{lbf}$ average of the three layer carbon fiber/honeycomb sandwich to $1076 \mathrm{lbf}$ because of the decrease in the number of carbon fiber layers. When another layer of carbon fiber was replaced with aramid fiber to create the carbon(1)aramid(2)/honeycomb sandwich, the ultimate load was dropped again to an average of $624 \mathrm{lbf}$, as shown in Table 3.17. Even with only
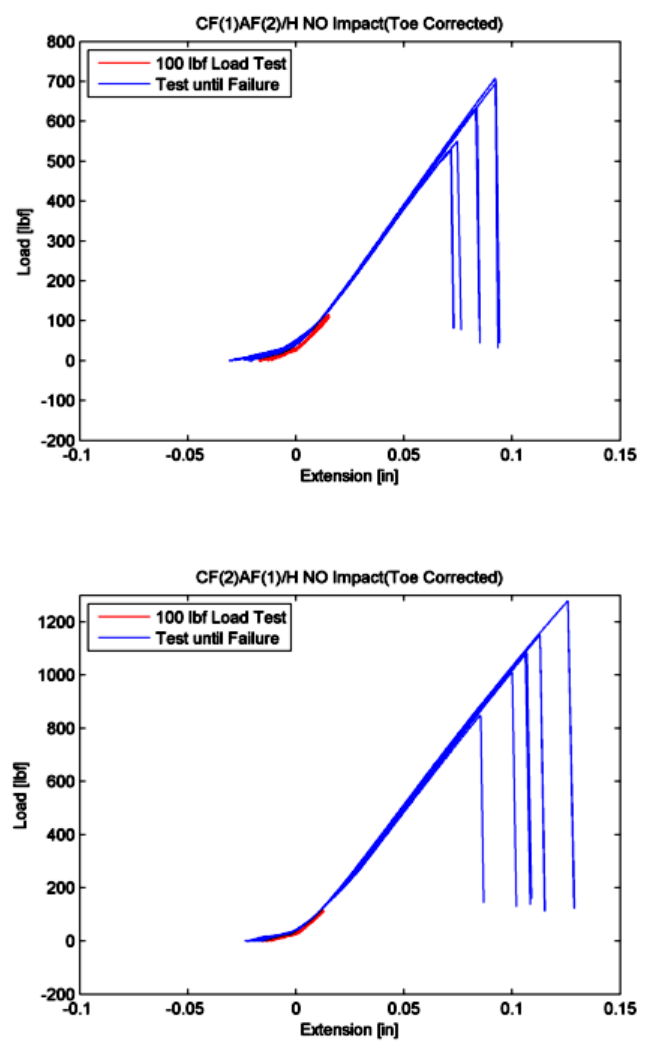

Figure 3.16: Raw data plots for hybrid carbon and aramid fiber sandwich structures under four-point bend loadings one layer of carbon fiber material on the top and bottom of these sandwiches, they were still able to withstand a higher loading than any other sandwich design that was subjected to bending loads without being impacted. The only sandwich that held a higher loading was the three layer carbon fiber/foam sandwiches which held roughly $150 \mathrm{lbf}$ more than the single layered carbon fiber hybrid sandwich. The two layered carbon fiber hybrid sandwich showed incredible flexural strength that was far superior to any other sandwich design but when impacted and bent with the impact under compressive loads, this sandwich resulted in poor post-impact flexural strengths. The drop in load carrying ability for the sandwiches was almost exactly the same as the three layer carbon fiber sandwiches. Both sandwich designs dropped over half of their load carrying ability after impact. The hybrid 
design reduced the impact damage size over the three layered carbon fiber sandwich so a load reduction percentage was expected but damage was still done to most of the carbon fiber facesheet and the core so the result is understandable. The reduction in load carrying ability after impact, however, was significantly lower with an increase of $13 \%$ over the two layered carbon fiber hybrid sandwich to a load carrying capability that was $62.8 \%$ of the non-impacted sandwich. This sandwich design, however, was only able to withstand and average ultimate load of $392 \mathrm{lbf}$ after impact which was one of the worst for average ultimate loads of any composite sandwich structure with impact damage under compressive loadings; only aramid fiber sandwiches were worse. The most beneficial part of these sandwiches was their strength-to-weight characteristics with and without being subjected to impact loads because of the addition of the light aramid fiber layers and combined with the high strength of the carbon fiber layers. The strength-to-weight ratios of each sandwich were significantly higher than any other sandwich except carbon fiber/foam with the damage under compressive loads. The non-impacted hybrid sandwiches had higher strengthto-weight ratios than the carbon fiber/foam non-impacted sandwiches, however.

Overall, the trend of these hybrid sandwiches was as expected. Replacing layers of carbon fiber with layers of aramid fiber increased the impact damage resistance of the sandwich, which decreased the magnitude of reduction in load carrying ability from the non-impacted specimens. The lightweight structures and high loads resulted in very high strength-to-weight ratios for each sandwich; however, large drops in ultimate bending loads were experienced for each replacement of a carbon fiber layer with an aramid fiber layer. Because of this, the three layer carbon fiber sandwich seems to still be the best design for parts that require high flexural strength, despite the large decrease in load carrying ability after impact. If a part is likely to experience more impact loadings than usual, however, and needs post-impact flexural strength, the single layer carbon fiber hybrid sandwich with a reduction of $62.8 \%$ in load carrying ability after impact may be a legitimate design consideration. The hemp sandwiches were the only other sandwich designs that were comparable 
Table 3.17: Four-point bend test results for carbon and aramid fiber hybrid facesheet sandwiches

\begin{tabular}{|c|c|c|c|c|c|c|c|c|}
\hline & \multicolumn{2}{|c|}{$\mathbf{A F} / \mathbf{H}$} & \multicolumn{2}{|c|}{$\overline{C F(1) A F(2) / H}$} & \multicolumn{2}{|c|}{$\mathrm{CF}(2) \mathrm{AF}(1) / \mathrm{H}$} & \multicolumn{2}{|c|}{$\overline{C F} / \mathrm{H}$} \\
\hline & $\begin{array}{l}\text { No } \\
\text { Im- } \\
\text { pact }\end{array}$ & $\begin{array}{l}\text { Impact } \\
\text { (Comp. }\end{array}$ & $\begin{array}{l}\text { No } \\
\text { Im- } \\
\text { pact }\end{array}$ & $\begin{array}{l}\text { Impact } \\
\text { (Comp. }\end{array}$ & $\begin{array}{l}\text { No } \\
\text { Im- } \\
\text { pact }\end{array}$ & $\begin{array}{l}\text { Impact } \\
\text { (Comp.) }\end{array}$ & $\begin{array}{l}\text { No } \\
\text { Im- } \\
\text { pact }\end{array}$ & $\begin{array}{l}\text { Impact } \\
\text { (Comp. }\end{array}$ \\
\hline $\begin{array}{l}\text { Weight } \\
\text { [lbm] }\end{array}$ & $\begin{array}{c}0.126 \\
+/- \\
0.002 \\
\end{array}$ & $\begin{array}{c}0.127 \\
+/- \\
0.001\end{array}$ & $\begin{array}{c}0.146 \\
+/- \\
0.001\end{array}$ & $\begin{array}{c}0.147 \\
+/- \\
0.000\end{array}$ & $\begin{array}{c}0.175 \\
+/- \\
0.001\end{array}$ & $\begin{array}{c}0.175 \\
+/- \\
0.003\end{array}$ & $\begin{array}{c}0.203 \\
+/- \\
0.002\end{array}$ & $\begin{array}{c}0.200 \\
+/- \\
0.002\end{array}$ \\
\hline $\begin{array}{c}\text { Facesheet } \\
\text { Ultimate } \\
\text { Stress } \\
\text { [psi] }\end{array}$ & $\begin{array}{c}1.51 \mathrm{E} 4 \\
+/- \\
0.47 E 4\end{array}$ & $\begin{array}{c}0.21 \mathrm{E} 4 \\
+/- \\
0.00 E 4\end{array}$ & $\begin{array}{c}2.38 \mathrm{E} 4 \\
+/- \\
0.28 E 4\end{array}$ & $\begin{array}{c}1.49 \mathrm{E} 4 \\
+/- \\
0.06 E 4\end{array}$ & $\begin{array}{c}3.35 \mathrm{E} 4 \\
+/- \\
0.45 E 4\end{array}$ & $\begin{array}{c}1.42 \mathrm{E} 4 \\
+/- \\
0.54 E 4\end{array}$ & $\begin{array}{c}2.81 \mathrm{E} 4 \\
+/- \\
0.08 E 4\end{array}$ & $\begin{array}{c}1.52 \mathrm{E} 4 \\
+/- \\
0.19 E 4\end{array}$ \\
\hline $\begin{array}{c}\text { Core } \\
\text { Shear } \\
\text { Ultimate } \\
\text { Stress } \\
\text { [psi] }\end{array}$ & $\begin{array}{c}101 \\
+/-32\end{array}$ & $\begin{array}{c}14 \\
+/-1\end{array}$ & $\begin{array}{c}198 \\
+/-23\end{array}$ & $\begin{array}{l}124 \\
+/-5\end{array}$ & $\begin{array}{c}335 \\
+/-45\end{array}$ & $\begin{array}{c}196 \\
+/-79\end{array}$ & $\begin{array}{c}461 \\
+/-30\end{array}$ & $\begin{array}{l}234 \\
+/-9\end{array}$ \\
\hline $\begin{array}{c}\text { Flexural } \\
\text { Stiffness } \\
\text { (D) } \\
{\left[l b f-i n^{2}\right]}\end{array}$ & $\begin{array}{c}6.08 \mathrm{E} 4 \\
+/- \\
0.16 E 4\end{array}$ & $\begin{array}{c}0.99 \mathrm{E} 4 \\
+/- \\
0.13 E 4\end{array}$ & $\begin{array}{c}6.13 \mathrm{E} 4 \\
+/- \\
0.80 E 4\end{array}$ & $\begin{array}{c}6.14 \mathrm{E} 4 \\
+/- \\
0.36 E 4\end{array}$ & $\begin{array}{c}7.45 \mathrm{E} 4 \\
+/- \\
0.81 E 4\end{array}$ & $\begin{array}{c}7.35 \mathrm{E} 4 \\
+/- \\
0.30 E 4\end{array}$ & $\begin{array}{c}8.70 \mathrm{E} 4 \\
+/- \\
0.72 E 4\end{array}$ & $\begin{array}{c}8.17 \mathrm{E} 4 \\
+/- \\
0.69 E 4\end{array}$ \\
\hline $\begin{array}{l}\text { Transverse } \\
\text { Shear } \\
\text { Rigidity } \\
\text { (U) [lbf] }\end{array}$ & $\begin{array}{c}3.35 \mathrm{E} 3 \\
+/- \\
0.06 E 3\end{array}$ & $\begin{array}{c}1.18 \mathrm{E} 3 \\
+/- \\
0.16 E 3\end{array}$ & $\begin{array}{c}4.15 \mathrm{E} 3 \\
+/- \\
0.42 E 3\end{array}$ & $\begin{array}{c}4.10 \mathrm{E} 3 \\
+/- \\
0.19 E 3\end{array}$ & $\begin{array}{c}5.00 \mathrm{E} 3 \\
+/- \\
0.41 E 3\end{array}$ & $\begin{array}{c}4.82 \mathrm{E} 3 \\
+/- \\
0.16 E 3\end{array}$ & $\begin{array}{c}5.68 \mathrm{E} 3 \\
+/- \\
0.41 E 3\end{array}$ & $\begin{array}{c}5.37 \mathrm{E} 3 \\
+/- \\
0.34 E 3\end{array}$ \\
\hline $\begin{array}{c}\text { Mid-Span } \\
\text { Deflection } \\
\text { (100 lbf) } \\
\text { [in] }\end{array}$ & $\begin{array}{c}0.029 \\
+/- \\
0.001\end{array}$ & $\begin{array}{c}0.030 \\
+/- \\
0.004\end{array}$ & $\begin{array}{c}0.020 \\
+/- \\
0.002\end{array}$ & $\begin{array}{c}0.021 \\
+/- \\
0.001\end{array}$ & $\begin{array}{c}0.017 \\
+/- \\
0.001\end{array}$ & $\begin{array}{c}0.018 \\
+/- \\
0.001\end{array}$ & $\begin{array}{c}0.015 \\
+/- \\
0.001\end{array}$ & $\begin{array}{c}0.016 \\
+/- \\
0.001\end{array}$ \\
\hline $\begin{array}{l}\text { Maximum } \\
\text { Load [lbf] }\end{array}$ & $\begin{array}{c}\mathbf{3 1 9} \\
+/-100\end{array}$ & $\begin{array}{c}46 \\
+/-1 \\
\end{array}$ & $\begin{array}{c}624 \\
+/-73 \\
\end{array}$ & $\begin{array}{c}392 \\
+/-15 \\
\end{array}$ & $\begin{array}{c}\mathbf{1 0 7 6} \\
+/-143 \\
\end{array}$ & $\begin{array}{c}532 \\
+/-29 \\
\end{array}$ & $\begin{array}{l}1519 \\
+/-96\end{array}$ & $\begin{array}{c}744 \\
+/-24 \\
\end{array}$ \\
\hline $\begin{array}{l}\text { Strength- } \\
\text { to-Weight } \\
\text { Ratio } \\
\text { [lbf/lbm] }\end{array}$ & $\begin{array}{c}2.53 \mathrm{E} 3 \\
+/- \\
0.79 E 3\end{array}$ & $\begin{array}{c}0.36 \mathrm{E} 3 \\
+/- \\
0.01 E 3\end{array}$ & $\begin{array}{c}4.28 \mathrm{E} 3 \\
+/- \\
0.50 E 3\end{array}$ & $\begin{array}{c}2.66 \mathrm{E} 3 \\
+/- \\
0.10 \mathrm{E} 3\end{array}$ & $\begin{array}{c}6.17 \mathrm{E} 3 \\
+/- \\
0.82 E 3\end{array}$ & $\begin{array}{c}3.04 \mathrm{E} 3 \\
+/- \\
0.17 \mathrm{E} 3\end{array}$ & $\begin{array}{c}7.50 \mathrm{E} 3 \\
+/- \\
0.48 E 3\end{array}$ & $\begin{array}{c}3.73 \mathrm{E} 3 \\
+/- \\
0.13 E 3\end{array}$ \\
\hline $\begin{array}{c}\text { Post- } \\
\text { Impact } \\
\text { Load } \\
\text { Degrada- } \\
\text { tion } \\
{[\%]}\end{array}$ & $100 \%$ & $14.4 \%$ & $100 \%$ & $62.8 \%$ & $100 \%$ & $49.4 \%$ & $100 \%$ & $48.9 \%$ \\
\hline
\end{tabular}


in load degradation characteristics after impact and ultimate load magnitudes. Depending on the design criteria, the hybrid sandwiches may be the better alternative because of the thinner and lighter sandwich design. Another layer of carbon fiber could be added to a sandwich design to create a four layer sandwich with two layers of carbon fiber and two of aramid fiber that would still be thinner and weigh less than the hemp sandwiches. It would, however, be much stronger and have comparable post-impact bending load degradation characteristics.

\subsubsection{Summary and Comparison of Four-Point Bending Test Results}

As expected, the carbon fiber sandwich designs outperformed every other specimen design experimentally in this study. Foam core sandwiches, even with carbon fiber facesheets, had issues with failing too early, which is cause for concern when designing sandwich structures with these cores. The foam core structures, however, did do well with post-impact strengths in general. While carbon fiber/honeycomb sandwiches did result in the highest loading values by far, the post-impact flexural strengths of these sandwiches when the impact damage was bent in compression were the worst of any honeycomb core sandwich except the already delaminated aramid fiber structures. The ultimate loads for these sandwiches were still higher than any other structure but this load degradation is definitely an area of concern. The hybrid sandwiches improved the post-impact load degradation percentages for these sandwiches by improving the impact damage resistance; however, by replacing the carbon fiber layers with the weaker tensile strength aramid fiber materials, the ultimate bending loads were not high enough to consider the hybrid sandwiches as beneficial alternatives to the entirely carbon fiber sandwiches. The use of different aramid fiber materials or a change in the design of the sandwich may make these hybrid sandwiches a more legitimate option, though. Even after being damaged from the impact more than any other sandwich, the hemp sandwiches had some of the best post-impact strengths

compared to the non-impacted specimens, especially when combined with the foam core 
which had good post-impact flexural characteristics as well. The glass and aramid fiber facesheet sandwiches were definitely the best at preventing impact damages. This benefit may have actually been harmful for them overall when they were used in composite sandwich structures, however, because the minimal facesheet damage ended up weakening the core-to-facesheet adhesion, resulting in low ultimate load delamination failures for these sandwiches when subjected to bending loads. If the aramid fiber facesheets were not expired prepreg materials, the post-impact strengths may have been similar to the glass fiber specimens but delamination issues after impact are still a major concern with these two facesheet sandwich designs.

\subsection{Experimental Failure Mode Analysis}

The failure behavior of a composite sandwich can be a good explanation of experimental results as well as give beneficial information about the weak areas of a structure for future design considerations. Depending on the type of material used for the facesheet and core, different regions of the sandwich can be weaker and stronger. The weaker regions are obviously the most failure prone and these regions are typically the facesheets under compressive or tensile loads due to bending, the core under shear loads, the core under compressive loads, and the adhesion region between the core and facesheets. When an impact occurs, there is damage in the facesheet and core at the impact location. The postimpact bending failures are the same as non-impacted sandwiches but the failures typically happening around the damage location or in regions that may have been affected by the impact. The mechanical properties testing showed that the compressive and tensile strengths of each facesheet material were different which is why the sandwiches were bent with the impact damages on the tensile surface for some specimen and on the compressive surface for the other half. Because the properties are different, the weak regions of the sandwich and, subsequently, the failures were different. 


\subsubsection{Carbon Fiber Facesheet Sandwiches}

As seen in Section 3.1, carbon fiber was by far the strongest and stiffest facesheet material used in this study. Because of this, it is able to resist very large bending loads without failing so the failure of the carbon fiber facesheet sandwiches depends on the strength of the core material. The core material datasheets as well as the material properties testing done showed that honeycomb was clearly the stronger core material in compression and in shear which are the main loads that the core of sandwich

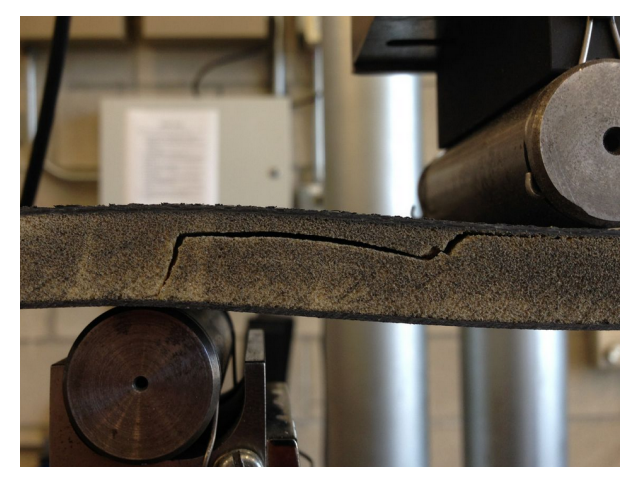

Figure 3.17: Core shear failure of carbon fiber/foam sandwich structures are subjected to under bending loads. The results of the bending test showed mainly brittle face fractures in the transverse direction across the face of the sandwich with no damage done to the core.

For non-impacted sandwiches with a foam core, the load versus extension plots in the last section showed that there were four sandwiches that reached maximum loads of around $700 \mathrm{lbf}$ but two sandwiches that barely made it to $300 \mathrm{lbf}$ and $400 \mathrm{lbf}$. The reason for the drastic difference in maximum loading values is that the face fractured for the four high loading specimens but the foam core was too weak to handle the high loads for two of the sandwiches so it failed due to shearing stresses, as seen in Figure 3.17. The impacted and then compression bent sandwiches reached high loads, similar to the non-impacted specimens, because every sandwich failed in face fracture. The failure loads were slightly lower than the non-impacted specimens, however, because they fractured at the impact damage area. The impacted sandwiches that were bent with the damage in tension failed prematurely due to shear loads on the foam core for each specimen which led to the very low maximum loads shown in the previous section. 
The carbon fiber/honeycomb sandwich structures, on the other hand, performed exactly how they were supposed to. The honeycomb is a very strong structure that is manufactured to withstand high bending loads so when it was combined with the high strength carbon fiber facesheet, one of the materials had to give out first and carbon fiber was that material. Each specimen failed in face fracture, shown in Figure 3.18, just like the foam core sandwiches but at over double the maximum load. Since carbon fiber is typically weak in compression and is mainly manufactured to withstand high tensile loads, the impacted specimens that were bent with the damage on the compressive surface failed in face fracture at much lower loads due to the weak-

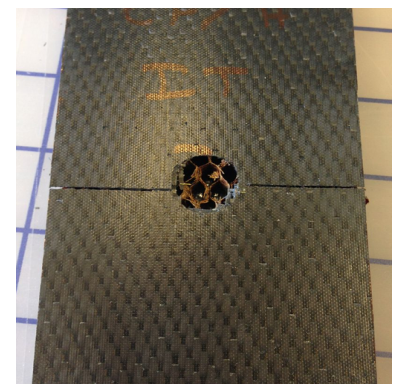

Figure 3.18: Face fracture at impact damage of carbon fiber facesheet sandwich

ness where the fibers had been broken. This weakness barely affected the sandwiches that were bent with the damage on the tensile surface, however. These sandwiches failed in face fracture like the compressive sandwiches but at loads that were $85 \%$ of the non-impacted specimens, showing that carbon fiber can withstand high tensile loads, even after being subjected to a low-velocity impact.

\subsubsection{Hemp Fiber Facesheet Sandwiches}

Hemp fiber composites were not nearly as strong or stiff as carbon fiber composites which resulted in much lower ultimate load values but the facesheets were not usually the reason for failure in these sandwiches. Foam core sandwiches failed due to core shear failure, which resulted in delamination, for every specimen except for the ones bent with the impact damage on the tensile surface. These specimens failed due to face fracture at the impact damage area which then immediately led to core shearing damage due to the lack of facesheet reinforcement. The core shearing failure is shown in Figure 3.19a and the face fracture failure is shown in Figure $3.19 \mathrm{~b}$. 
The honeycomb core sandwiches failed due to face fracture at the impacted area for the tensile loaded impact sandwiches but for compression and non-impacted sandwiches, the failure was slightly less clear. The core didn't fail in shear because honeycomb is designed to resist that loading well; it didn't fail from face fracture because the hemp facesheets were able to resist for most of the sandwiches; and the facesheet didn't delaminate from the core due to the excess resin added to the hemp dry fabric during manufacturing that added adhesion. When the sandwiches were analyzed in greater detail internally, delaminations were found between the longitudinal strands of glass fiber cell walls and slight breakage was found in each cell wall, indicating that the core had probably failed in compression by crushing, which occurred due to the large deflections that hemp sandwiches were able to withstand. The internal core failures were not large and not clear but no other failure was evident so this was the most logical failure location. The post-impact and post-bending core is shown in Figure 3.19c.

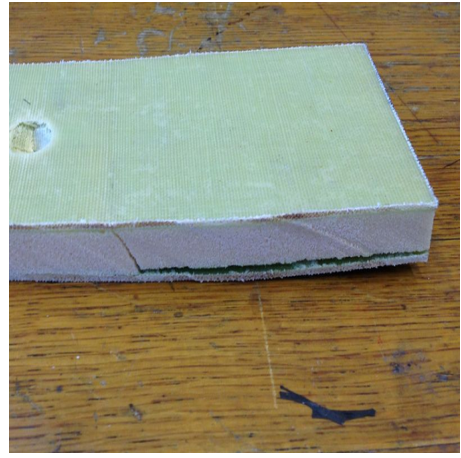

(a) Core shear failure of hemp fiber/foam sandwich

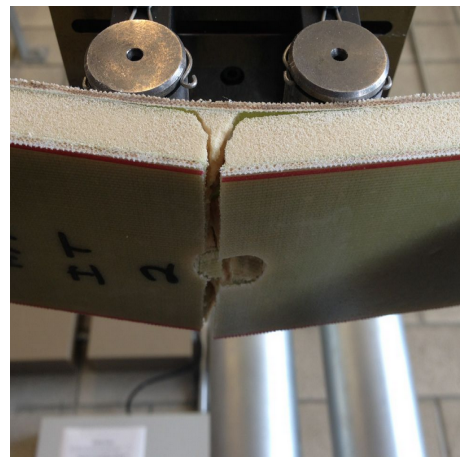

(b) Face fracture failure at impact damage of hemp fiber sandwich

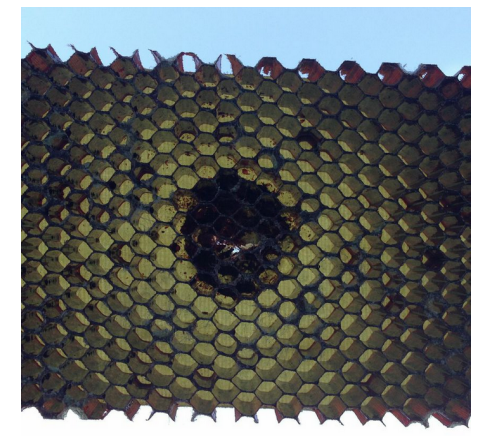

(c) Post-impact and postbending possible internal core failure of hemp fiber/honeycomb sandwich

Figure 3.19: Hemp fiber composite sandwich failures

\subsubsection{Aramid Fiber (Twaron) Facesheet Sandwiches}

The aramid fiber facesheet sandwiches had one very clear issue with every one of them that was the reason for the majority of failures with the sandwiches and was the reason for 
the severely low maximum load values. The aramid fiber available for this study was the prepreg material mentioned earlier but it was past its expiration date and the resin content was lower than what it was when the material was manufactured. Because of this, there was not much leftover epoxy to adhere the aramid fiber facesheets to the core material so the core-to-facesheet adhesion properties were clearly the weakest area of the structure. This lead to delaminations for almost every composite sandwich tested. The impacted foam core sandwiches were the only specimens that didn't fail entirely due to delaminations. The impacted and bent with damage in tension sandwiches all failed in core shear first which then led to delamination as shown in Figure 3.20a. Along with those, four of the six impacted and bent with damage in compression sandwiches also failed due to core shearing fractures. The aramid fibers, in general, have very high impact resistance characteristics so the damage was not large but the issue was that the impact load was spread out over the composite sandwich instead of just being local which subsequently created a delamination

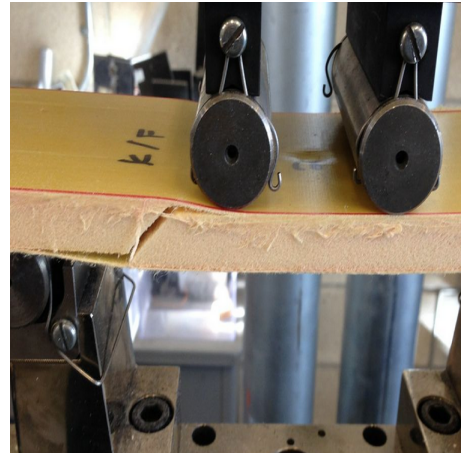

(a) Core shear failure of aramid fiber/foam sandwich

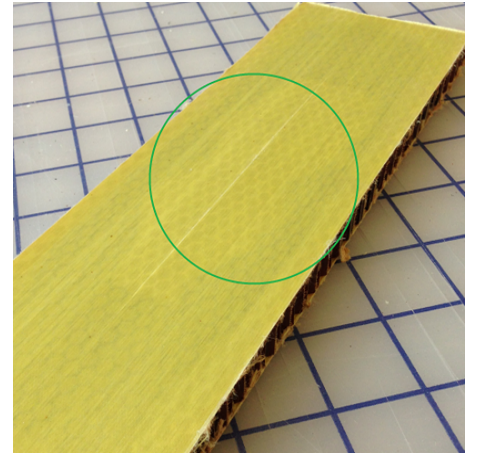

(b) Impact on top aramid fiber facesheet causes delamination of opposite facesheet from core

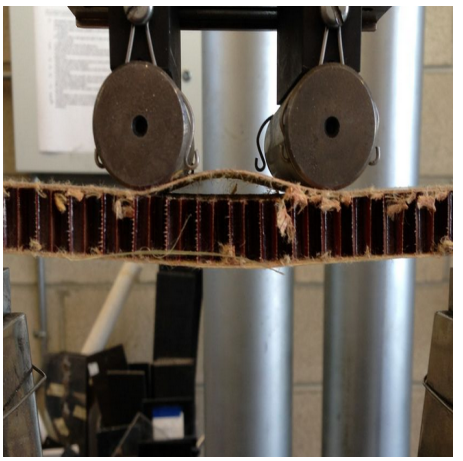

(c) Delamination failure of aramid fiber/honeycomb sandwich

Figure 3.20: Aramid fiber composite sandwich failures

on the other side of the sandwich. This delamination can be seen in Figure 3.20b. This meant that some of the sandwiches went into the bending tests already delaminated. This is why some of the load versus extension plots for aramid fiber sandwiches barely got above a maximum load of $5 \mathrm{lbf}$. Some of these sandwiches delaminated on the other side of the sandwich from the impact damage area and some delaminated on the impact damage side 
of the sandwich. These delaminations can be seen in Figure 3.20c. Either way, the low epoxy content in the aramid fiber prepreg material created mainly delamination failures during the bending tests and resulted in very low maximum load values.

\subsubsection{Glass Fiber (Texalium) Facesheet Sandwiches}

Glass fiber facesheet sandwiches had a similar issue to the aramid fiber sandwiches but on a smaller scale. The non-impacted glass fiber specimens mainly failed due to delaminations like aramid fiber did but half of the foam core non-impacted sandwiches failed in core shear which led to delamination. Every foam core impacted sandwich failed in core shear and subsequently delamination because of the core shear failure as shown in Figure 3.21a. The honeycomb core impacted sandwiches had slightly stronger adhesion properties than

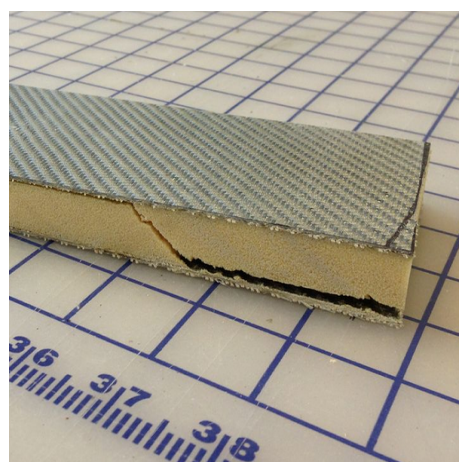

(a) Core shear failure of glass fiber/foam sandwich

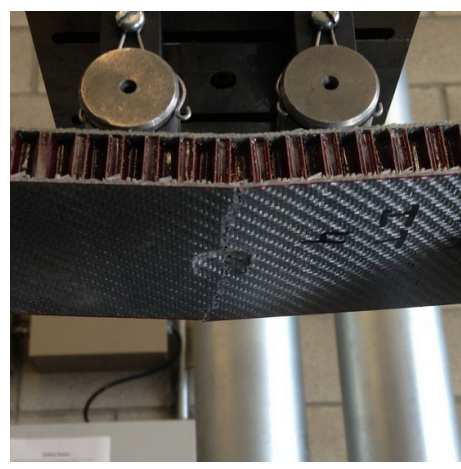

(b) Face fracture at impact damage of glass fiber/honeycomb sandwich with damage under tensile loading

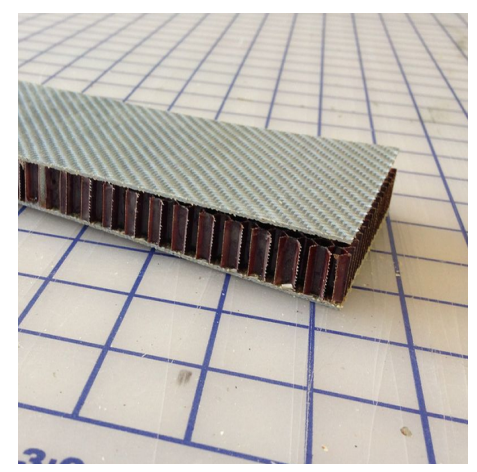

(c) Delamination failure of glass fiber/honeycomb sandwich

Figure 3.21: Glass fiber composite sandwich failures

the foam core specimens which led to a couple face fracture failures at the impact damage regions, which are shown in Figure $3.21 \mathrm{~b}$. Only two of the compressive and two of the tensile bent impact damage sandwiches failed due to face fracture, however. The rest failed due to very small delaminations as shown in Figure 3.21c. Overall, the impact damages were not very large on the glass fiber facesheet sandwiches and the effects of these impacts 
were not very large either. The only reason for low maximum bending load values was the weak core-to-facesheet adhesion properties of the sandwiches.

\subsubsection{Hybrid Carbon and Aramid Fiber Facesheet Sandwiches}

The hybrid sandwiches failed due to facesheet fracture within the carbon fiber facesheets underneath the aramid fiber layer which delaminated from the carbon fiber layers at this impact area and on the compressive surface of the sandwich for the non-impacted sandwiches. This facesheet delamination at the impacted area can be seen in Figure 3.22a for all sand-

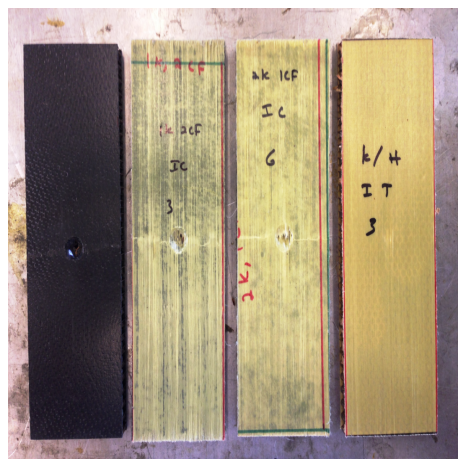

(a) Comparison of failures of the three layer carbon and aramid fiber sandwiches and the two hybrid sandwiches

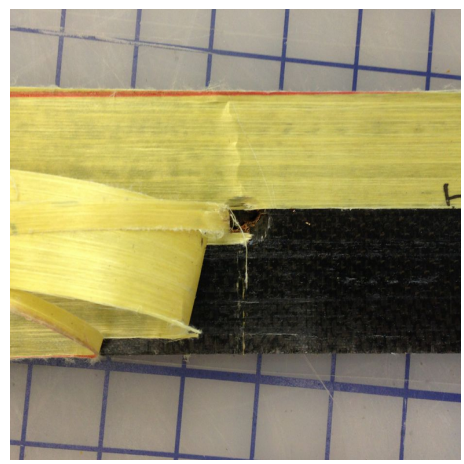

(b) Carbon fiber facesheet fracture under the delaminated aramid fiber facesheet

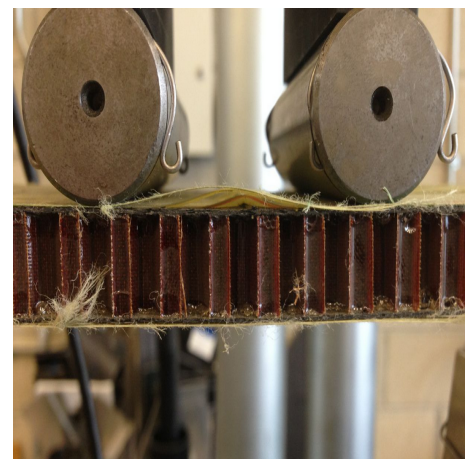

(c) Delamination of aramid fiber layers from carbon fiber layers

Figure 3.22: Hybrid carbon and aramid fiber composite sandwich failures

wiches compared. It can be seen in this figure that the impact damage size does noticeably decrease, however, as more layers of aramid fiber are added to the sandwich design which means that the aramid fiber layers did help resist the impact. The only reasons that the postimpact bending loads weren't as high as they could be were that the aramid fiber materials were not very strong under bending loads and the adhesion between the aramid and carbon fiber layers was poor. The delamination was still an issue for the aramid fiber facesheets as can be seen in Figure 3.22c. The carbon fiber facesheets did fail in face fracture, as shown in Figure 3.22b, but if the aramid fiber was a higher quality composite material, that delamination may have never happened and the failure of the sandwich could've been 
prolonged slightly. This may have helped for the sandwich design with one layer of carbon fiber and two layers of aramid fiber which dropped greatly in the overall ability to carry bending loads.

\subsubsection{Summary and Comparison of Experimental Failure Modes}

In general, when the core did not fail under the bending loads, the sandwich performed much better overall, with higher maximum loads. This meant that face fracture failures typically meant overall higher bending loads from the sandwich because the core did its job properly. Foam core sandwiches that failed due to core shearing typically had the lowest maximum bending loads because the core material was a poor support for the sandwich. The honeycomb core sandwiches never failed due to core shear because of the nature of the honeycomb but they did fail due to delamination more with the aramid and glass fibers due to the high fiber volume content in the expired prepreg materials and the significantly decreased bonding surface area on the honeycomb core versus the foam core. When carbon and aramid fiber hybrid sandwiches were tested, high ultimate bending loads resulted due to the face fracture failure in the carbon fiber laminates but delamination issues with the aramid fiber material led to lower maximum values than were expected. Overall, the carbon

fiber/honeycomb sandwich was the perfect example how a composite sandwich should work where a core supports the facesheet without failure until the facesheet finally fails from the high bending stresses.

All of the experimental failure modes discussed throughout this section are listed in Table 3.18 and shown in Figures 3.23a through 3.27c. 
Table 3.18: Failure Modes (FF: Face Fracture), (FFI: Face Fracture at Impact Damage), (CS: Core Shear), (D: Delamination), (CC: Core Compression), (DIL: Interlaminar Delamination), (DI: Delamination from Impact)

\begin{tabular}{|c|c|c|c|c|c|c|}
\hline & \multicolumn{3}{|c|}{$\mathrm{CF} / \mathrm{F}$} & \multicolumn{3}{|c|}{ CF/H } \\
\hline & $\begin{array}{c}\text { No } \\
\text { Impact }\end{array}$ & $\begin{array}{l}\text { Impact } \\
\text { (Comp.) }\end{array}$ & $\begin{array}{l}\text { Impact } \\
\text { (Tens.) }\end{array}$ & $\begin{array}{c}\text { No } \\
\text { Impact }\end{array}$ & $\begin{array}{c}\text { Impact } \\
\text { (Comp.) }\end{array}$ & $\begin{array}{l}\text { Impact } \\
\text { (Tens.) }\end{array}$ \\
\hline \multirow[t]{3}{*}{$\begin{array}{c}\text { Failure } \\
\text { Mode }\end{array}$} & $\mathrm{FF} / \mathrm{CS}$ & FFI & CS & $\mathrm{FF}$ & FFI & $\mathrm{FF} / \mathrm{FFI}$ \\
\hline & \multicolumn{3}{|c|}{ HF/F } & \multicolumn{3}{|c|}{ HF/H } \\
\hline & $\begin{array}{c}\text { No } \\
\text { Impact }\end{array}$ & $\begin{array}{l}\text { Impact } \\
\text { (Comp.) }\end{array}$ & $\begin{array}{l}\text { Impact } \\
\text { (Tens.) }\end{array}$ & $\begin{array}{c}\text { No } \\
\text { Impact }\end{array}$ & $\begin{array}{c}\text { Impact } \\
\text { (Comp.) }\end{array}$ & $\begin{array}{l}\text { Impact } \\
\text { (Tens.) }\end{array}$ \\
\hline \multirow[t]{3}{*}{$\begin{array}{c}\text { Failure } \\
\text { Mode }\end{array}$} & CS/D & CS/D & FFI/CS & $\mathrm{CC}$ & $\mathrm{CC}$ & FFI \\
\hline & \multicolumn{3}{|c|}{ AF/F } & \multicolumn{3}{|c|}{ AF/H } \\
\hline & $\begin{array}{c}\text { No } \\
\text { Impact }\end{array}$ & $\begin{array}{l}\text { Impact } \\
\text { (Comp.) }\end{array}$ & $\begin{array}{l}\text { Impact } \\
\text { (Tens.) }\end{array}$ & $\begin{array}{c}\text { No } \\
\text { Impact }\end{array}$ & $\begin{array}{c}\text { Impact } \\
\text { (Comp.) }\end{array}$ & $\begin{array}{l}\text { Impact } \\
\text { (Tens.) }\end{array}$ \\
\hline \multirow[t]{3}{*}{$\begin{array}{c}\text { Failure } \\
\text { Mode }\end{array}$} & $\mathrm{D}$ & CS/D/DI & $\mathrm{CS} / \mathrm{D} / \mathrm{DI}$ & $\mathrm{D}$ & $\mathrm{D} / \mathrm{DI}$ & D/DI \\
\hline & \multicolumn{3}{|c|}{ GF/F } & \multicolumn{3}{|c|}{ GF/H } \\
\hline & $\begin{array}{c}\text { No } \\
\text { Impact }\end{array}$ & $\begin{array}{l}\text { Impact } \\
\text { (Comp.) }\end{array}$ & $\begin{array}{l}\text { Impact } \\
\text { (Tens.) }\end{array}$ & $\begin{array}{c}\text { No } \\
\text { Impact }\end{array}$ & $\begin{array}{l}\text { Impact } \\
\text { (Comp.) }\end{array}$ & $\begin{array}{l}\text { Impact } \\
\text { (Tens.) }\end{array}$ \\
\hline \multirow[t]{3}{*}{$\begin{array}{c}\text { Failure } \\
\text { Mode }\end{array}$} & CS/D & CS/D & CS/D & $\mathrm{D}$ & FFI/D & FFI/D \\
\hline & \multicolumn{3}{|c|}{$\mathrm{CF}(1) \mathrm{AF}(2) / \mathrm{H}$} & \multicolumn{3}{|c|}{$\mathrm{CF}(2) \mathrm{AF}(1) / \mathrm{H}$} \\
\hline & $\begin{array}{c}\text { No } \\
\text { Impact }\end{array}$ & $\begin{array}{l}\text { Impact } \\
\text { (Comp.) }\end{array}$ & $\begin{array}{l}\text { Impact } \\
\text { (Tens.) }\end{array}$ & $\begin{array}{c}\text { No } \\
\text { Impact }\end{array}$ & $\begin{array}{l}\text { Impact } \\
\text { (Comp.) }\end{array}$ & $\begin{array}{l}\text { Impact } \\
\text { (Tens.) }\end{array}$ \\
\hline $\begin{array}{l}\text { Failure } \\
\text { Mode }\end{array}$ & $\begin{array}{c}\text { DIL/CF(1) } \\
\text { FF }\end{array}$ & $\begin{array}{c}\text { DIL/CF(1) } \\
\text { FFI }\end{array}$ & - & $\begin{array}{c}\text { DIL/CF(2) } \\
\text { FF }\end{array}$ & $\begin{array}{c}\text { DIL/CF(2) } \\
\text { FFI }\end{array}$ & - \\
\hline
\end{tabular}




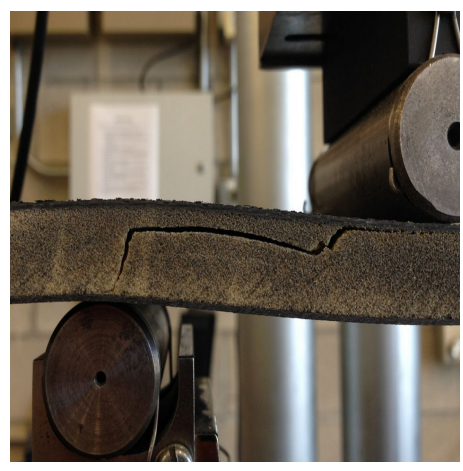

(a) Core shear failure $(\mathbf{C S})$

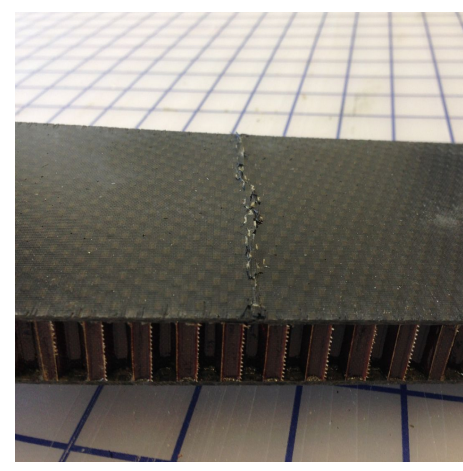

(b) Facesheet fracture failure (FF)

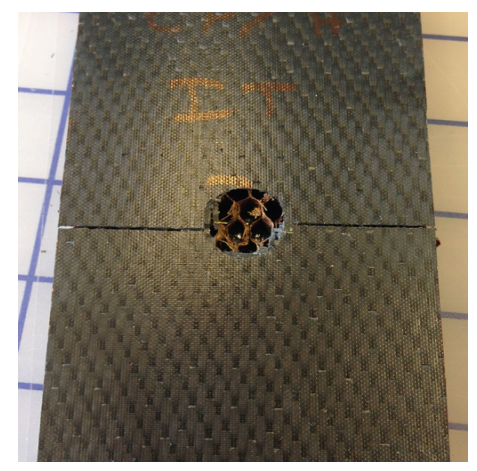

(c) Facesheet fracture failure at impact damage region (FFI)

Figure 3.23: All carbon fiber facesheet sandwich design failure modes

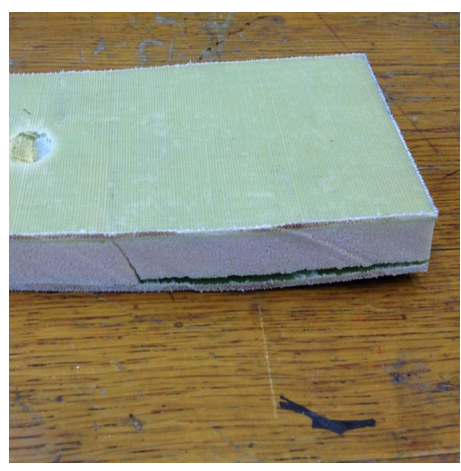

(a) Core shear and delamination failure $(\mathbf{C S} / \mathbf{D})$

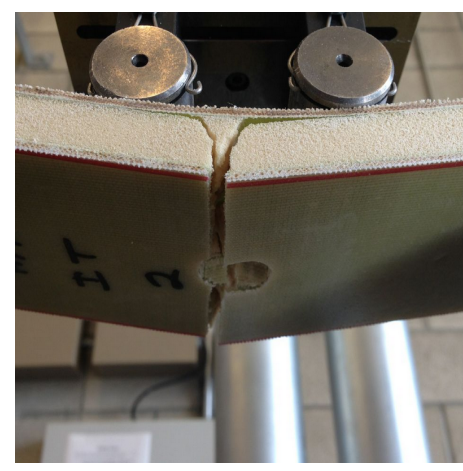

(b) Facesheet fracture failure at impact damage region for foam core (FFI)

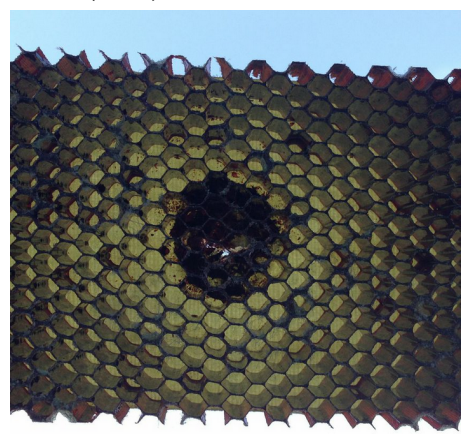

(d) Core compression failure (CC)

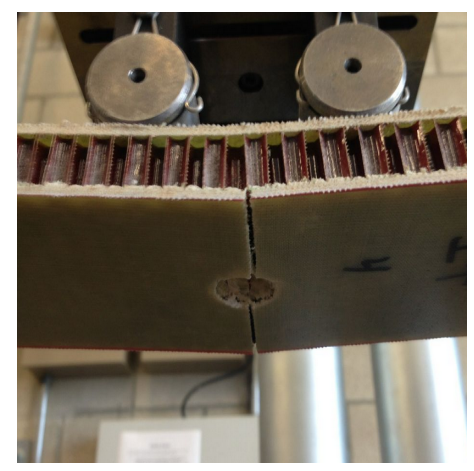

(c) Facesheet fracture failure at impact damage region for honeycomb core $(\mathbf{F F I})$

Figure 3.24: All hemp fiber facesheet sandwich design failure modes 


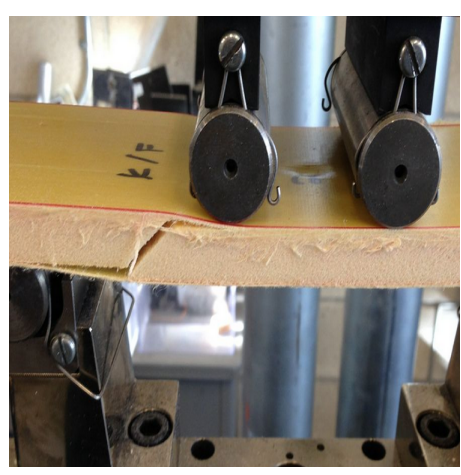

(a) Core shear and delamination failure (CS/D)

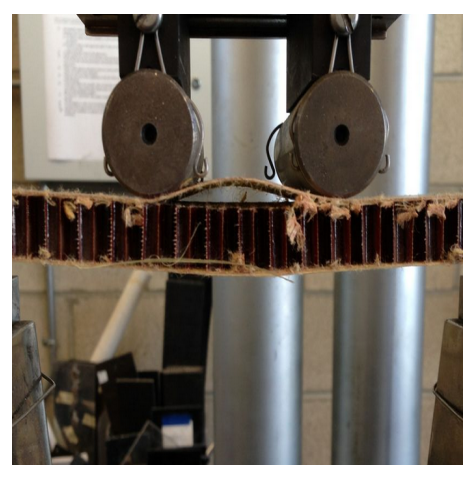

(b) Delamination failure (D)

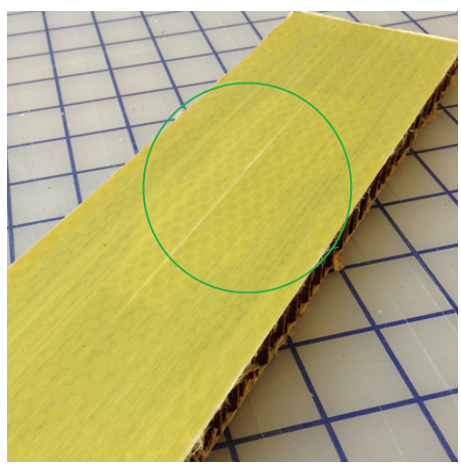

(c) Delamination failure from impact (DI)

Figure 3.25: All aramid fiber facesheet sandwich design failure modes

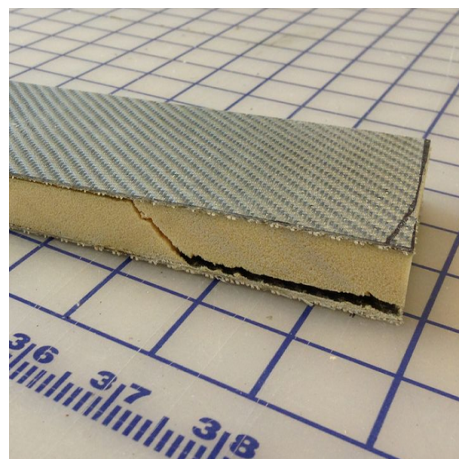

(a) Core shear and delamination failure $(\mathbf{C S} / \mathbf{D})$

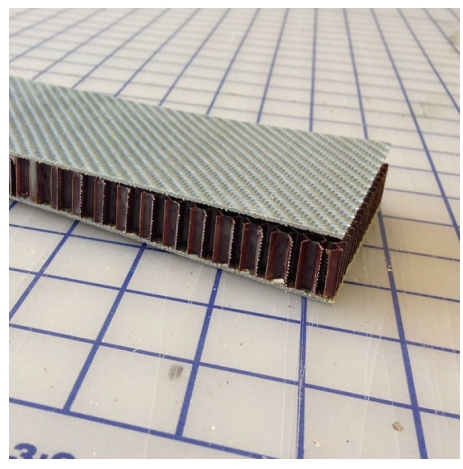

(b) Delamination failure (D)

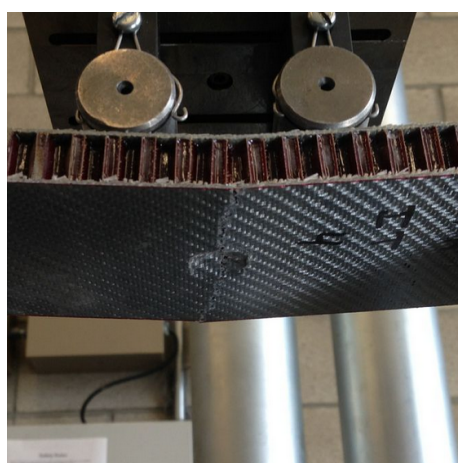

(c) Facesheet fracture failure at impact damage region (FFI)

Figure 3.26: All glass fiber facesheet sandwich design failure modes

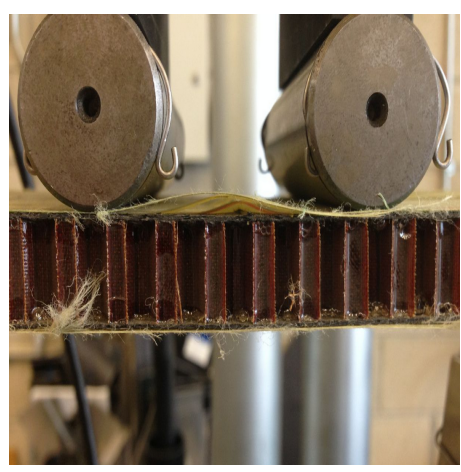

(a) Interlaminar delamination between the carbon and aramid fiber facesheets (DIL)

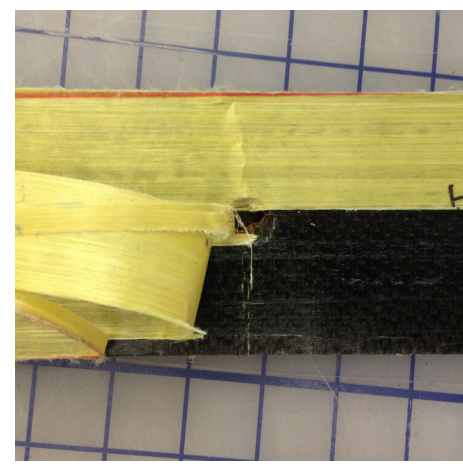

(b) Carbon fiber facesheet fracture under the delaminated aramid fiber layer (CF FF)

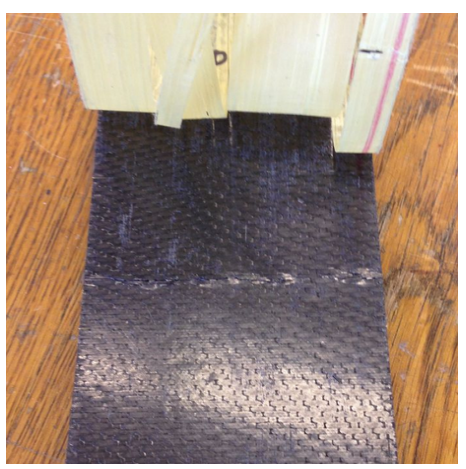

(c) Carbon fiber facesheet fracture at impact damage region under the delaminated aramid fiber layer (CF FFI)

Figure 3.27: All hybrid carbon and aramid fiber facesheet sandwich design failure modes 


\subsection{Summary and Comparison of Experimental Test Results}

To completely understand the benefits and negatives of each sandwich design subjected to impact and bending loads, comparisons must be done between all of the structures and the tests they were subjected to. The initial comparison was between the impact and bending tests to understand the correlations between the two results. The first plot created for this comparison was the plot of impact load versus maximum bending load, shown in Figure

3.28. The main takeaway from this comparison is that, in general, the sandwiches subjected to lower impact forces resulted in higher ultimate flexural strength values. This may seem obvious but considering that the magnitude of each impact force was based on energy absorption of the sandwich, this conclusion becomes interesting because the more damaged structures resulted in larger flexural strengths. The correlation between the visible impact damage depths and the maximum flexural loads is shown in Figure 3.29a. The flexural strengths of each sandwich depend on the flexural strength of the core and facesheet materials as well, as mentioned in the results described in the sections above, but, in general, the carbon and hemp fiber sandwiches were able to withstand higher bending loads after experiencing lower impact forces. The aramid and glass fiber sandwiches experienced higher impact forces which caused minimal damage to the facesheets and cores because of their high resistance to impact forces but, as mentioned earlier, these sandwiches delaminated prematurely and resulted in lower flexural 
strengths due to the impacts. When the weight of each sandwich is added to the discussion, the results change slightly because the glass fiber/honeycomb sandwiches had better flexural strength-to-weight characteristics with smaller impact damages than the heavy hemp fiber/foam sandwiches did with the largest damages, as shown in Figure 3.29b. This comparison gives a little more credit to the high impact resistance characteristics of the glass

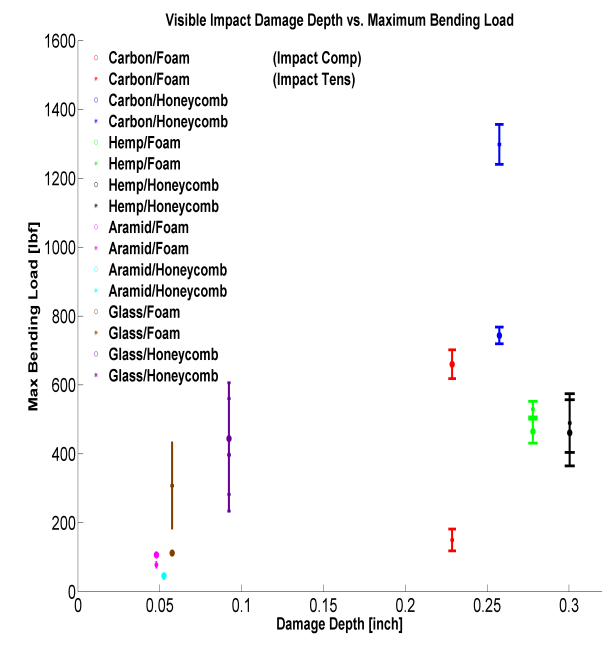

(a) Visible impact damage depth size versus the maximum bending loads

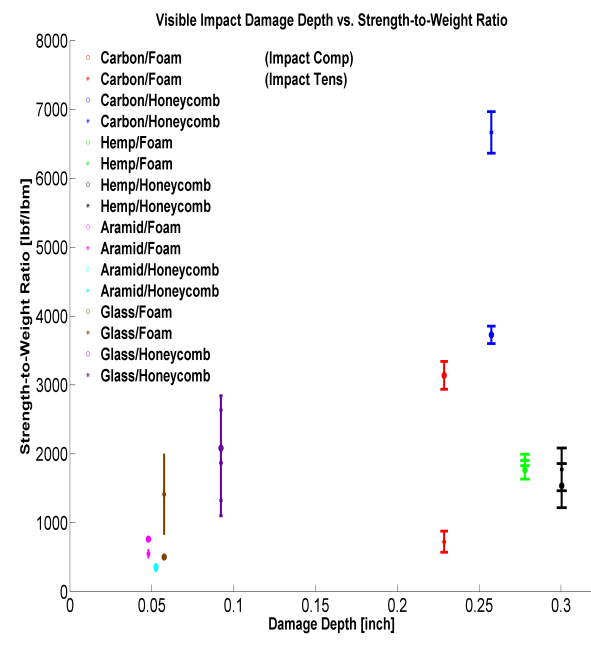

(b) Visible impact damage depth size versus strength-to-weight characteristics

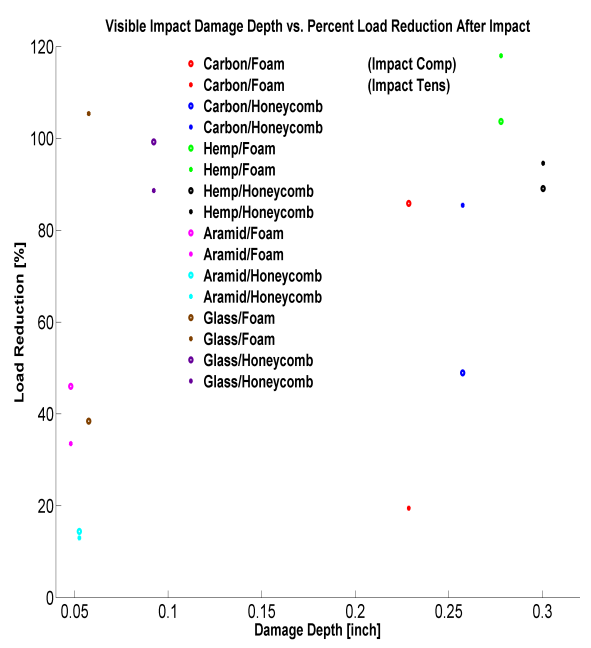

(c) Visible impact damage depth size versus the reduction in maxium bending load after impact

Figure 3.29: Plots of impact damage depth sizes versus bending test results for all composite sandwich structures 
fiber sandwiches because they performed better in this flexural category than the hemp fiber sandwiches while also performing better when subjected to the impact loads. The last impact and bending test comparison was between the impact damage size and the percent reduction in flexural strength after impact, shown in Figure 3.29c. This comparison shows that the flexural strengths of the glass and hemp fiber sandwiches were affected the least of any sandwich design by the impact damages. This again seems obvious for the glass fiber sandwiches because of the small impact damages inflicted on them but the hemp sandwiches were damaged severely from the impact loads and were still able to withstand, in general, the same bending loads that the non-impacted sandwiches were able to. The carbon fiber sandwiches performed decently in load reduction even after being greatly damaged by the impact but the compressive characteristics were exploited for the carbon fiber/honeycomb sandwiches and, like the glass fiber/foam sandwiches, carbon fiber/foam failed greatly before it was supposed to for one set of specimens because of the weak foam core material failing due to the shear loads. This plot shows that if these core shear failures weren't an issue, foam core sandwiches would be the more favorable sandwich design in terms of post-impact strength characteristics.

The other comparisons investigated were between the results of the bending tests. The objective of this study was to understand the effects of low-velocity impacts on the flexural strengths of these sandwiches so the post-impact bending load reduction percentages were a main focus for these comparisons. Figure 3.30a and Figure 3.30b show the comparisons between this percent maximum bending load reduction after impact and the ultimate load and strength-to-weight values, respectively. These two plots show that the hemp and glass fiber sandwich structures were very similar in post-impact strengths and load degradation characteristics and that the carbon and aramid fiber sandwiches stood out from the rest of the specimens in good and bad ways, respectively. The carbon fiber sandwiches clearly stand out as the favorite for highest strength sandwiches even after some of the generally larger reductions in strengths after impact. The aramid fiber sandwiches 
had the lowest ultimate loads and these values were much worse after impact but for the non-impacted specimens, the aramid fiber/honeycomb sandwich designs boasted the second highest strength-to-weight values due to their low weight facesheets; the carbon fiber sandwich designs were the only structures with higher strength-to-weight characteristics due to their incredibly high loading values. When the weight was accounted for, the glass fiber/honeycomb sandwiches improved their worth as well by having the best post-impact

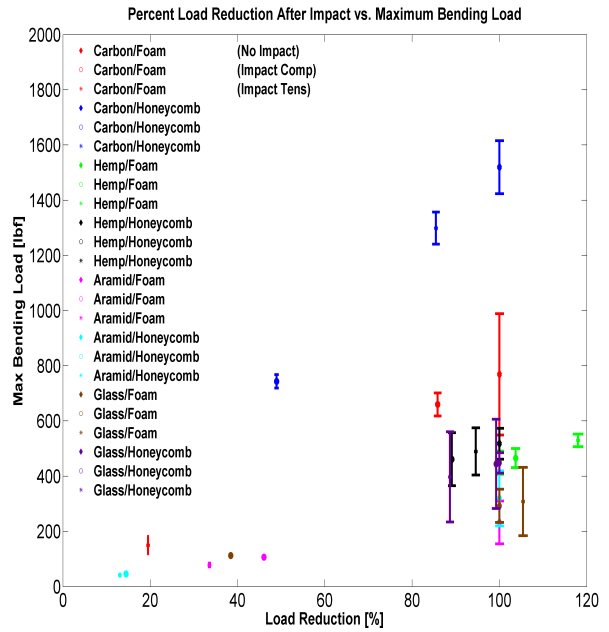

(a) Reduction in maxium bending load after impact versus maximum bending load

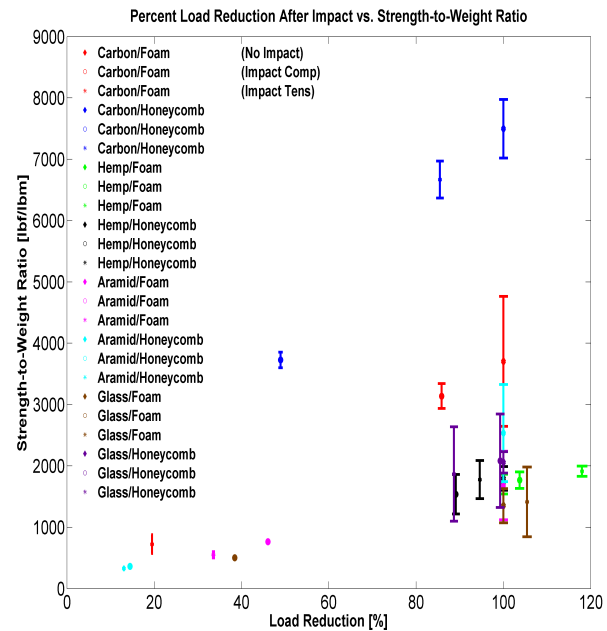

(b) Reduction in maxium bending load after impact versus strength-to-weight characteristics

Figure 3.30: Plots of the reduction in maxium bending load after impact versus other bending test results for all sandwich structures

load strengths and highest strength-to-weight values of any other sandwich, besides carbon fiber. So as long as the ultimate load is not as much of an issue as weight is in the design of a structure and the materials are used before their expiration, the aramid and glass fiber sandwich designs can be considered for parts subjected to impact and bending loads. The last important result that comes from these two plots is the dominance, expectedly, of the carbon fiber/honeycomb sandwich design under these loadings. The only flaw in this design is the strength after impact on the compressive surface of the sandwich. The carbon fiber/foam sandwiches are acceptable but the foam core shear failure issue is a major cause 
for concern in design and the flexural strengths aren't high enough for these sandwiches to ignore this issue. 


\section{Chapter 4 \\ COMPARISON OF EXPERIMENTAL RESULTS TO THEORETICAL AND NUMERI- CAL ANALYSIS}

This chapter will present the theoretical failure mode analysis and compare it to the experimental failure mode analysis. A description of the process used to build the numerical model of each sandwich design and testing configuration will be given. The mid-span deflection results of these numerical models will then be compared to experimental mid-span deflection values to better understand the results of each experiment.

\subsection{Theoretical Failure Mode Analysis}

To understand exactly why a material failed in the manner that it did, it is important to understand the way that it theoretically should have failed. A theoretical guess as to the failure mode of a sandwich structure can give insight into the success of that sandwich in testing. If the sandwich failed as expected, its ultimate loading values are probably accurate; however, if it fails in a manner that is different from the predicted, then there are probably underlying problems with the sandwich that caused it to fail prematurely. The sandwiches that failed correctly are not as much of an area of interest for analysis as the prematurely failing structures. Understanding why a sandwich design failed in an unexpected way can help pinpoint a region of the sandwich structure that is clearly the weakest and allow a designer to focus on improving this weak region for future testing and application of the design. 


\subsubsection{Methodology}

To create the theoretical failure mode model for these sandwich designs subjected to bending loads, a report from the Journal of Composite Materials by Lim, Lee, and Lee[37] was used. This report states that when a typical composite sandwich structure is subjected to a bending load, the main failure modes that result are face fracture, core shear yield, and core compressive yield. More failure modes are possible for a sandwich design depending on the size of the sandwich, materials used for the sandwich, and the test configuration used for the bending tests; however, the main failures that are noticed from composite sandwich structures that fail successfully are these. Because of this, the report delves into the creation of three equations that describe barrier regions between each of these failure modes. These equations, when plotted, form the three regions of failure that are used to theoretically describe how each sandwich should fail. The variables that makeup each of these transition equations are non-dimensional geometry and material properties values of the facesheet, core, and sandwich as a whole. The failure mode transition equation for face and core shear failure, face and core compressive failure, and core shear and compressive failure can be seen below in Eq. 4.1, Eq. 4.2, and Eq. 4.3.

$$
\begin{gathered}
\frac{L^{*}}{2 s^{*} \sigma^{*} t^{*}}+\frac{3\left(1+t^{*}\right)}{s^{*} \sigma^{*} t^{*}} \sqrt[4]{\frac{E^{*}}{3 t^{*}}}=1 \text { (Faceandcoreshear) } \\
\frac{L^{*}}{2 \sigma^{*}\left(1+t^{*}\right)} \sqrt[4]{\frac{E^{*}}{3 t^{*}}}+\frac{1}{\sigma^{*}} \sqrt{\frac{3 E^{*}}{t^{*}}}=1 \text { (Faceandcorecompressive) } \\
\frac{s^{*} t^{*}}{\left(1+t^{*}\right)} \sqrt[4]{\frac{E^{*}}{3 t^{*}}}=1 \text { (Coreshearandcorecompressive) }
\end{gathered}
$$


The non-dimensionalized variables $t^{*}, L^{*}, E^{*}, \sigma^{*}$, and $s^{*}$ are ratios of thickness, length, Young's modulus, compressive strength, and overall core strength, respectively, and can all be described by simple equations. These equations are $t^{*}=\frac{t_{f}}{t_{c}}, L^{*}=\frac{L}{t_{c}}, E^{*}=\frac{E_{f}}{E_{c}}, \sigma^{*}=\frac{X_{f}}{X_{c}}$, and $s^{*}=\frac{X_{c}}{S_{c}}$. The $t, L, E, X$, and $S$ values represent the thickness, length of structure, Young's modulus, compressive strength, and shear strength; the $f$ and $c$ subscripts correlate to the facesheet and core, respectively, and describe what the geometric or material property value is designated for. When these three equations are solved for in terms of $t^{*}$ with $L^{*}$ varying and plotted as $L^{*}$ vs. $t^{*}$, the failure mode maps that will be shown in the following sections are produced for each sandwich design. These plots will contain a solid horizontal line which represents the core shear and compressive failure transition region, a positive sloped diagonal dashed line which represents the face and core shear failure transition region, and an upward curving dashed line which designates the face and core compressive failure mode transition region. Every plot will have these three lines and the regions within these lines will be the failure modes. Two plots will be shown for each sandwich design with the same red dot plotted on each one. That red dot describes the geometric designation of each of those sandwiches in terms of $t^{*}$ and $L^{*}$. When the thicknesses of the facesheet and the core, as well as the length, of each sandwich was entered into the $t^{*}$ and $L^{*}$ equations, the coordinates of the red dots resulted. Because the material properties testing results for carbon fiber produced values for that were much lower than the datasheet values, a plot was created to show how the material properties testing values compared to the datasheet values in terms of failure mode analysis. The percent reduction in material properties values from the datasheet to the testing results for carbon fiber was implemented for the other three facesheet materials since their datasheets were not provided or did not exist. The first plot that will be shown in the following sections is the failure mode analysis using the material properties testing values and the second plot is a failure mode comparison of material properties testing results to datasheet values. Since analysis of post-impact bending failures is much less predictable, only a theoretical analysis of non-impacted sand- 
wiches will be described in the following sections; however, the effects of the impact on the location of the transition lines will be described for each sandwich design.

\subsubsection{Failure Mode Comparison for Carbon Fiber Facesheet Sandwiches}

The experimental failure mode results showed that carbon fiber sandwiches failed in facesheet fracture for almost every post-impact and non-impacted sandwich. Figure 4.1a shows exactly this. As can be seen in this Figure 4.1a, the three transition lines mentioned above are shown for the carbon fiber/foam (blue) and carbon fiber/honeycomb (maroon) sandwich. (Foam core sandwiches will be a blue colored plot and honeycomb cores will be a maroon colored plot for all plots shown throughout this theoretical failure mode section) The red dot, which designates the geometry of the sandwich design in this study, is shown to be very clearly in the face fracture failure mode region of both the foam and honeycomb core plots for carbon fiber facesheet sandwiches. This means that the majority of the carbon fiber sandwiches failed as predicted during the bending tests which gives a good indication that the ultimate loads that resulted from each test were accurate representations of the overall strength of these sandwiches. A couple of the foam cored carbon fiber sandwiches did experimentally fail in core shear, however, at much lower values than the face fractured sandwiches. For the plots using material properties testing results, this failure is very wrong which is why the ultimate load values were so much lower. When datasheet values are used, shown in Figure $4.1 \mathrm{~b}$ as the green lines, the foam cored sandwiches very clearly lie within the core shear failure mode region which means that core shear could have been a possible predicted failure mode.

The $\sigma^{*}$ and $s^{*}$ ratios from the transition equations describe the relationship between the

core shear, core compressive, and facesheet compressive strengths. When the compressive strength of the facesheet is much higher than the compressive strength of the core, the $\sigma^{*}$ value is much larger and the failure mode plot shifts to the right, resulting in a core failure prediction. When the core compressive strength is much higher than the core shear 


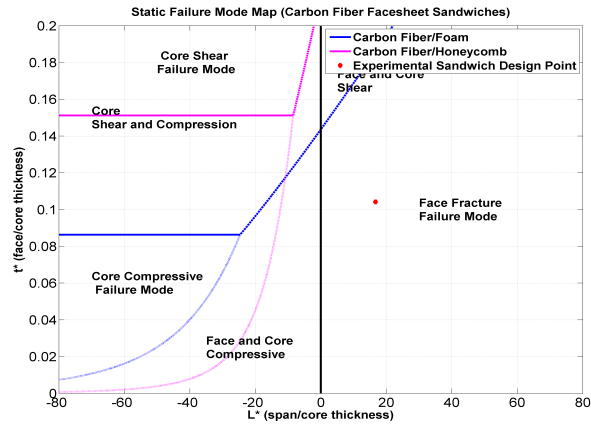

(a) Failure mode maps for foam and honeycomb core sandwiches using material properties testing values
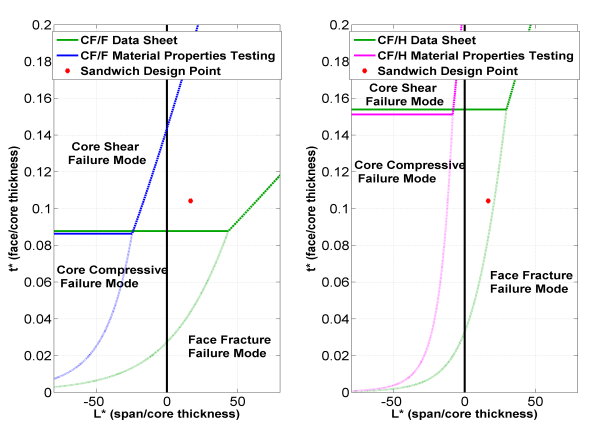

(b) Failure mode maps for foam and honeycomb core sandwiches comparing material properties values to datasheet values

Figure 4.1: Theoretical failure mode analysis plots for carbon fiber facesheet sandwiches

strength, the $s^{*}$ value is much larger and the plot shifts downward, resulting in core shear failure. Figure $4.1 \mathrm{~b}$ shows higher datasheet facesheet strength values for the carbon fiber facesheet sandwiches which is why the green plots are shifted to the right and core shear failure is the predicted failure mode. With more accurate material properties testing values, the red dot might actually be closer to the face and core shear transition line, allowing for both core shear and facesheet fracture failure types to be possible; however, if material degradation of the foam core was able to be measured and implemented in this analysis, the plot probably would have shifted towards a core shear failure. So depending on the quality of the foam used for each sandwich, the failure mode may have changed. This shows good agreement with the experimental failure mode analysis and confirms the concern for the use of foam cored carbon fiber sandwiches. The difference in ultimate loads for both failure modes was very drastic so the foam core should be tested and theoretical failure mode analysis should be done to make sure that the failure mode for this sandwich will be face fracture. If not, this sandwich type may fail catastrophically at a much lower loading value than desired.

When an impact damage was inflicted on carbon fiber facesheet sandwiches, the core and facesheet strengths changed, shifting the plots. Since the actual drop in strengths could not be calculated, the general plot shift is all that can be analyzed. The facesheet obviously 
drops in strength so the plot will shift greatly to the left, creating mainly facesheet fracture failures (at the weakened impact damage region). For the foam cored sandwiches tested with the impact damage in tension, the foam core was damaged was just as much as the compression impacted sandwiches but since the carbon fiber is so much stronger in tension, the damaged core failed before the facesheet could. The core was weakened much more than the facesheet was so the $\sigma^{*}$ ratio was much larger and the net movement of the plot was to the right. The strength of the honeycomb cores were not degraded as much after the impact so the larger facesheet strength degradation created a lower $\sigma^{*}$ value and strictly facesheet fracture failures.

\subsubsection{Failure Mode Comparison for Hemp Fiber Facesheet Sandwiches}

The theoretical failure mode analysis for hemp fiber facesheet sandwiches showed, in Figure $4.2 \mathrm{a}$, a very similar result to carbon fiber sandwiches of facesheet fracture failures for both foam and honeycomb core sandwiches. This is because of the lower strengths of the hemp fiber materials that resulted from the material properties testing results. Experimentally, these sandwiches failed in core compression for the honeycomb cores and core shear for the foam cores. When the percent increase from carbon fiber material properties testing results to datasheet results is implemented for the hemp facesheets, the failure mode plots shift to the right, as shown in Figure 4.2b, to the green plots due to the higher facesheet strengths and core failures become more of a theoretical possibility. Since the epoxy content of each hemp laminate varied due to the "wet" layup technique, the plots for both sandwich designs could vary more left or right depending on the sandwich. Because of this, core compressive failure seems to be the predicted failure mode for both sandwiches. When the possible degradation of the foam core material is taken into account, the plots may shift down to create an expected failure mode of hemp fiber/foam sandwich designs to be core shear failure, which would create an agreement between theoretical and experimental results. With more accurate material properties values for each hemp fiber 
facesheet used for each sandwich tested and for the degraded foam and honeycomb values, these plots will shift to predict core shear failure for foam cored sandwiches and core compressive failure for honeycomb sandwiches.

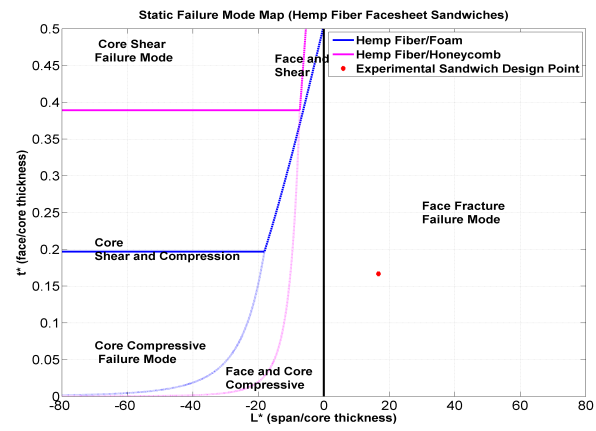

(a) Failure mode maps for foam and honeycomb core sandwiches using material properties testing values
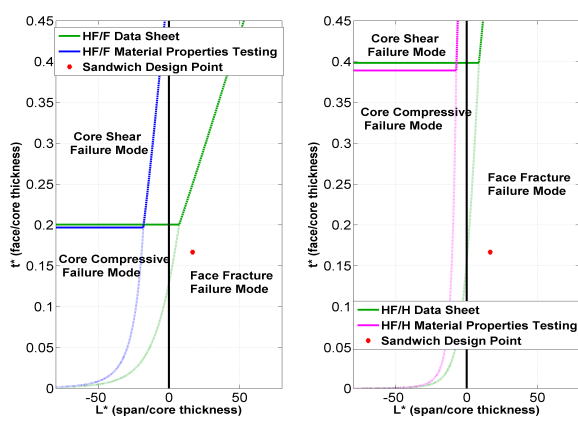

(b) Failure mode maps for foam and honeycomb core sandwiches comparing material properties values to datasheet values

Figure 4.2: Theoretical failure mode analysis plots for hemp fiber facesheet sandwiches

As mentioned in the last section, when an impact damages was inflicted on these sandwiches, the facesheet and core strengths were affected. Depending on the amount of degradation that resulted from the impact damage for the facesheet and core, these plots may have shifted more right or left. Using the experimental failure mode results for the impacted sandwiches as an indication of the degradation of strength for the facesheet and core materials, the theoretically foam core plots probably shifted greatly down and slightly left, resulting in a prediction of core shear failure for most of the sandwiches and possible facesheet fracture failure when the damage weakened the facesheet more than the core.

\subsubsection{Failure Mode Comparison for Aramid Fiber (Twaron) Facesheet Sandwiches}

The experimental failure mode results for aramid fiber facesheet sandwiches were, by knowledge of the material quality, predictable; however, using these theoretical failure mode analysis techniques, the experimental delamination failure mode was not predictable. The assumption of this analysis technique is that the sandwich structure was constructed correctly and material qualities were such that sandwiches fail due to the strength of the 
core and facesheet materials and not the adhesion of the facesheet to the core. With this in mind, assuming the quality of the aramid fiber material was improved and the sandwich was constructed correctly, Figure $4.3 \mathrm{a}$ and Figure $4.3 \mathrm{~b}$ show that these sandwiches should have failed in face fracture for both cores. Core shear strength was not the weakness of the foam

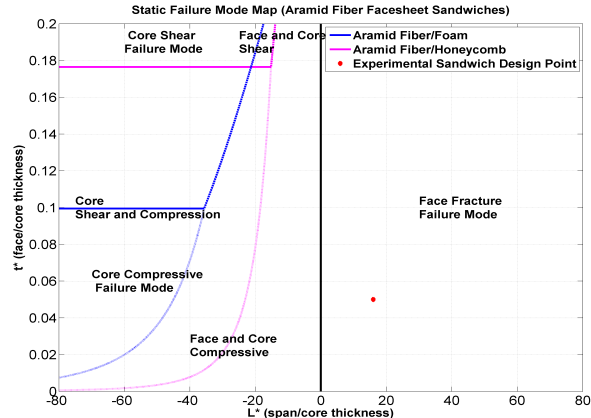

(a) Failure mode maps for foam and honeycomb core sandwiches using material properties testing values
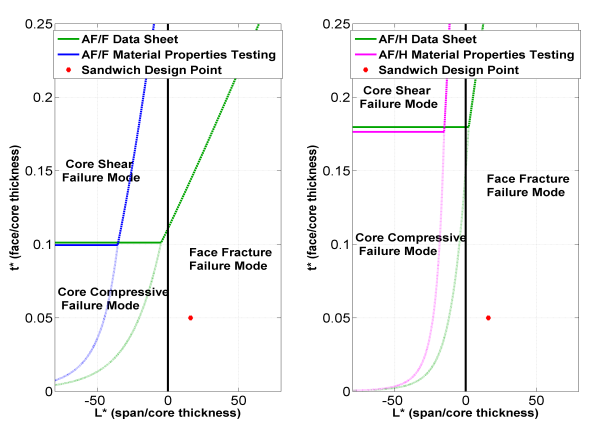

(b) Failure mode maps for foam and honeycomb core sandwiches comparing material properties values to datasheet values

Figure 4.3: Theoretical failure mode analysis plots for aramid fiber facesheet sandwiches

sandwich until impact damage was inflicted on the structure, decreasing the strength and shifting the plot down and to the right. As seen in Figure 4.3b, the compressive strength of the honeycomb was clearly weaker than the shear strength so a shift in the plot to the right would occur after being subjected to an impact load and core compressive failure would be expected with a higher quality sandwich structure. Since the aramid fiber material had the best impact resistance characteristics, the impact would do more damage to the core materials than the facesheet material, resulting in an increase in the $\sigma^{*}$ value. This is why the main shift in the plot would be to the right.

\subsubsection{Failure Mode Comparison for Glass Fiber (Texalium) Facesheet Sandwiches}

The experimental and theoretical failure mode results for the glass fiber facesheet sandwiches were very similar to the aramid fiber facesheet sandwiches. Experimentally, the glass fiber sandwiches failed mainly in delamination. Delamination combined with core shear failure occurred for the foam core sandwiches. The theoretical failure mode re- 
sults using material properties data in Figure 4.4a, like all the other facesheet materials, predicted strictly facesheet fracture failure for all sandwich designs; however, when the datasheet correction percentages were implemented for the glass fiber sandwiches, there was a drastic shift to the right for both of the plots resulting in strictly core compressive failure for the foam core sandwiches and a perfect split between core compressive and facesheet fracture failure for the honeycomb core sandwiches. The glass fiber/honeycomb, similar to aramid fiber/honeycomb, showed that the compressive strength of the core material was much weaker than the shear strength, so if the predicted failure was in the core, it would be a compressive failure for honeycomb cores no matter how much degradation there was in the actual material. The foam core material is shown in Figure $4.4 \mathrm{~b}$ as being clearly in the core compressive failure mode region of the plot but if foam core degradation is taken into account, the shear properties of the core may decrease and move the plot closer to a core shear predicted failure mode.

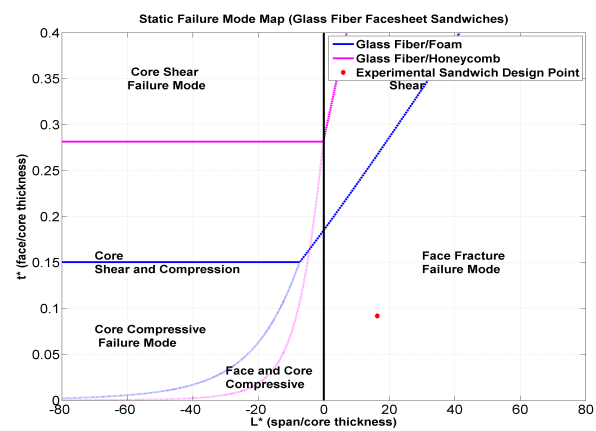

(a) Failure mode maps for foam and honeycomb core sandwiches using material properties testing values

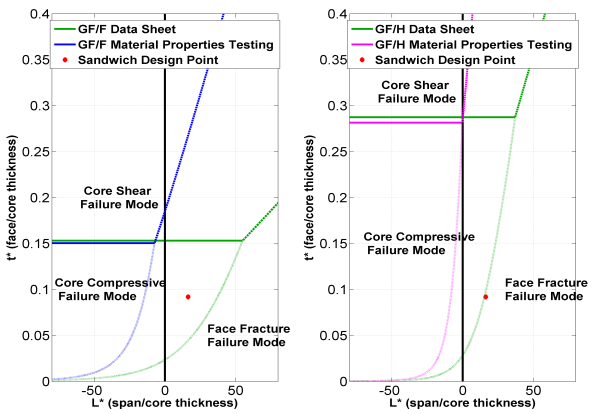

(b) Failure mode maps for foam and honeycomb core sandwiches comparing material properties values to datasheet values

Figure 4.4: Theoretical failure mode analysis plots for glass fiber facesheet sandwiches

The glass fiber sandwiches, like the aramid fiber sandwiches, showed very good impact resistance characteristics which meant that the core strengths were not affected as much by the impact as the hemp or carbon fiber sandwich cores were. The damage to the core was more than the aramid fiber sandwiches, however, so the degradation ratio of the core strength to the facesheet strengths was probably very similar, which means that the plot 
probably didn't shift too far left or right after the impact. This means that facesheet fracture or core compressive failure were both possible failure modes for the honeycomb core glass fiber sandwiches, which shows good agreement with the experimental failure modes. Experimentally, the honeycomb core sandwiches failed from delamination but also partial face fracture for the tensile loaded impact damaged facesheets and core compression for the compressive loaded impact damaged facesheets. The combination of the impact damage to the foam core and strength degradation of the foam over time would probably shift the core shear and compression transition line down, resulting in a core shear predicted flexural failure. The adjustment for material properties to the expected sandwich properties shows good agreement with the experimental results. This allows for decently accurate predictions to be made for these sandwiches as long as construction of the sandwiches is improved and more accurate material properties values are available.

\subsection{Numerical Four-Point Bending Model}

One of the best methods for analytically predicting the behaviors of composite sandwich structures under different loading conditions is the numerical modelling method. The numerical method of analysis implements the ideas of finite element analysis to solve for the necessary values of a testing procedure. This study uses the numerical modelling program Abaqus 6.10 to produce the predicted mid-span deflection results of the impacted and non-impacted four-point bending test procedures described in Chapter 3. This section will delve into the construction of the numerical model used to predict the results of the non-impacted four-point bending tested composite sandwich specimens.

\subsubsection{Geometric Definitions and Partitions}

Three parts were created for the general construction of the composite sandwich structure. These three parts included two 3D, deformable shells to model the facesheet materials 
with thicknesses matching the facesheets and a 3D, deformable solid model to act as the core structure. All three parts were partitioned with a line running along its y-axis that split the part into two equal halves and a similar line that ran along the $\mathrm{x}$-axis of the part. These partitions were created to be used for boundary conditions, which will be described later. The bottom shell part was partitioned with two lines that ran along the $\mathrm{x}$-axis of the part 1 inch in from each end of the facesheet. These partitions were created to allow boundary conditions to be imposed on them that would recreate the support pins used during experimental bending tests. The top facesheet part was partitioned with two lines that were 1.5 inches and two that were 0.5 inches away from and parallel to the center x-direction partition line. These four lines created two areas on the surface of the facesheet that were 3 inches wide by 1 inch long and provided the loading regions that were used to mimic the standard four-point bend loading condition used per the ASTM for experimental testing. The top facesheet, core, and bottom facesheet parts and their partitions are shown in Figure $4.5 \mathrm{a}, 4.5 \mathrm{~b}$, and $4.5 \mathrm{c}$, respectively. For the hybrid carbon and aramid fiber sandwiches, two parts had to be created for the top facesheet and two for the bottom facesheet with their respected thicknesses to be able to accurately model the material properties and behavior of theses sandwiches. All of the parts for the hybrid sandwiches were modelled with the central $\mathrm{x}$-axis and $\mathrm{y}$-axis partitions but only the outside aramid fiber parts were modelled with the extra top and bottom facesheet partitions to mimic the loading conditions as seen in Figure 4.5a and 4.5c. 


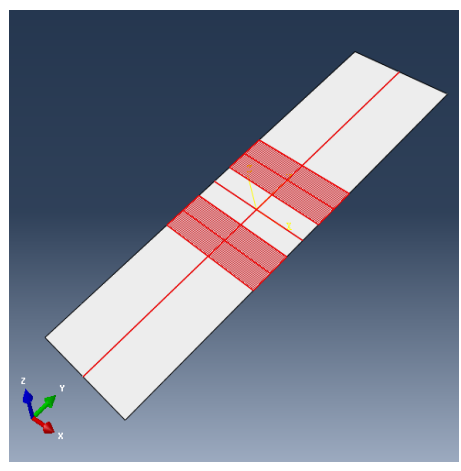

(a) Top facesheet part

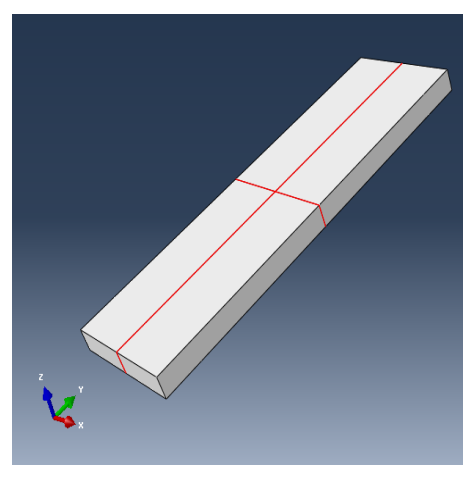

(b) Core part

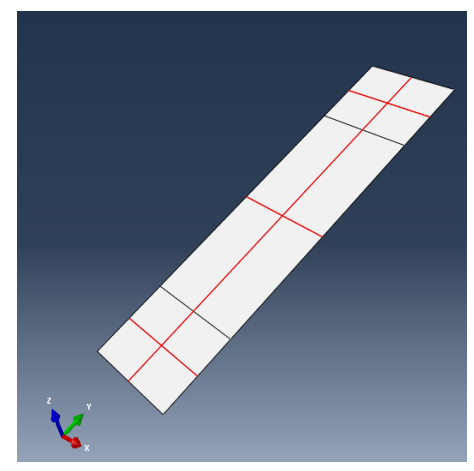

(c) Bottom facesheet part

Figure 4.5: Top facesheet, core, and bottom facesheet numerical model part with red partitions

\subsubsection{Material Creation and Section Assignments}

Each facesheet material was created using elastic engineering constants to describe their material properties. For the carbon, hemp, and glass fiber woven composite materials, the E1 and E2 elastic moduli were considered to be the same and the compressive modulus was used to describe the E3 value. For the aramid fiber unidirectional material, the E2 value was different from the E1 and was taken from the 90 degree elastic modulus value shown in Chapter 3. $v_{12}$ was the value calculated from the Poisson's ratio testing described in the past two chapters and $v_{13}$ and $v_{23}$ were considered to be typical Poisson's ratio values of 0.3 because it was not possible to measure this value. The shear value calculated for each material using the equation from Chapter 2 was used to describe all three shear variables in the model because the z-direction shear variables could not be measured or calculated. Each material was given a density from datasheet and weight calculations in units of $l b f * s^{2} / i n^{4}$ to keep units consistent with the Abaqus US inch units system. The honeycomb core material was modelled using the same elastic engineering constants used for the facesheet materials. The longitudinal modulus was used for the E1 value and the transverse modulus was used for E2 for the material; the compressive modulus was used to describe the E3 value. Since there was no $v_{21}$ variable on the Abaqus material creation window, only $v_{12}$ was entered for the honeycomb. The shear moduli were all entered as 
the longitudinal shear modulus. The foam core was considered to be isotropic and only a single Young's modulus and Poisson's ratio value were entered.

With all of the materials created, two sections were produced for the core and facesheets to assign the materials to. The core section was a solid, homogeneous section and the facesheet section was a composite shell section with three layers that were each $1 / 3$ of the total shell thickness. The orientation angle was 0 and 3 integration points were used for each layer of the composite section. This section was used for both the top and bottom facesheets and in the case of the hybrid sandwiches, two sections had to be created for the facesheets. Both of the sections had only two or one layer of material depending on how many layers of aramid and carbon fiber were used and which shell the section was being assigned to.

\subsubsection{Assembly and Steps}

Each part was given a dependent instance to allow meshing to change between the facesheets and core. Once one instance was created for each part, position constraints were then applied each to construct the composite sandwich structure. Face-to-face constraints were used to move the top and bottom facesheets to the same $\mathrm{z}$-coordinate as the top and bottom surfaces of the core part. From there, edge-to-edge constraints lined up the $\mathrm{x}$ direction and y-direction edges of the facesheets and

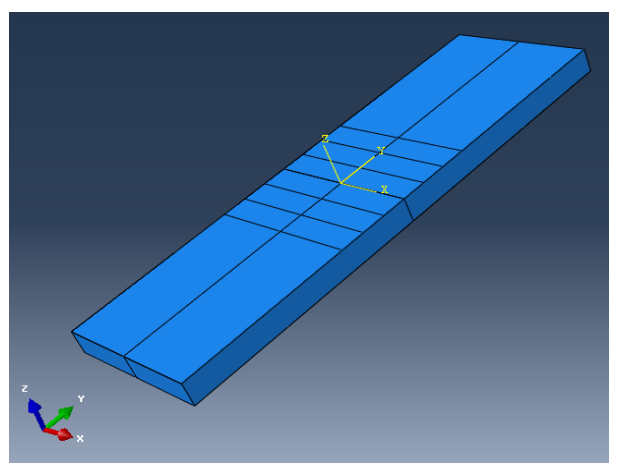

Figure 4.6: Fully assembled numerical composite sandwich model their corresponding core surfaces to fully construct the sandwich. The fully constructed composite sandwich can be seen in Figure 4.6.

Once the composite sandwich was constructed, a static, general step was created after the initial step to be used for loading the sandwich model and collecting mid-span deflection 
data. A time period of 1, maximum number of increments of 100, maximum increment size of 0.1 , and minimum increment size of $1 \mathrm{E}-005$ was used to describe this loading step.

\subsubsection{Constraints, Boundary Conditions, and Loads}

To describe the relationship between the facesheets and the core, tie constraints were created. These tie constraints connected the bottom of the top facesheet to the top surface of the core and the bottom surface of the core to the top surface of the bottom facesheet. These constraints are shown in Figure 4.7a as the small yellow circles on the sandwich. With the sandwich constrained, boundary conditions and loads were then imposed on the structure for the new step created. A mechanical displacement/rotation boundary condition was imposed on the $y$-direction and x-direction partitions of all three parts. The boundary condition on the y-direction partition lines restricted movement of these lines in the $\mathrm{x}$-direction and the boundary condition on the $\mathrm{x}$-direction lines restricted movement in the y-direction, keeping the sandwich from sliding during the test. These boundary conditions can be seen in Figure 4.7b. The two partition lines running in the x-direction that were located 1 inch in from each end of the sandwich were then given a mechanical displacement/rotation boundary condition that restricted their movement in the z-direction, mimicking the pin boundary condition experienced by the experimentally tested sandwiches. With all of the boundary conditions in place, two mechanical pressure loads where applied to the two red partitioned regions shown in Figure 4.7c for the step created earlier. The overall load that was trying to be modelled was the $100 \mathrm{lbf}$ load, which would allow for a comparison of mid-span deflection values with the experimental test results. Since that was an overall loading value from the Instron machine, the $6 \mathrm{in}^{2}$ area of the two regions combined had to be used to calculate the pressure loading magnitude used for the Abaqus model. A simple calculation using the equation $P=\frac{\text { Load }}{\text { Area }}$ was done to find the value of 17 psi that was entered into Abaqus as the pressure load magnitude. 


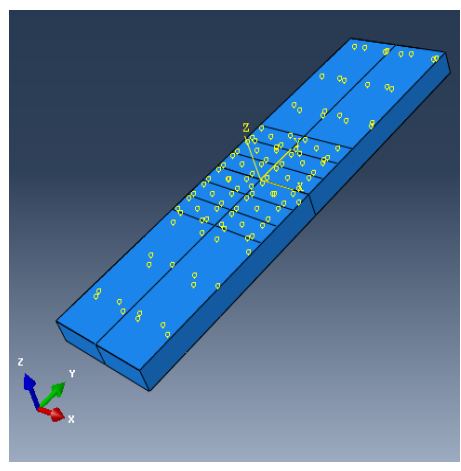

(a) Tie constraints to constrain facesheets to core

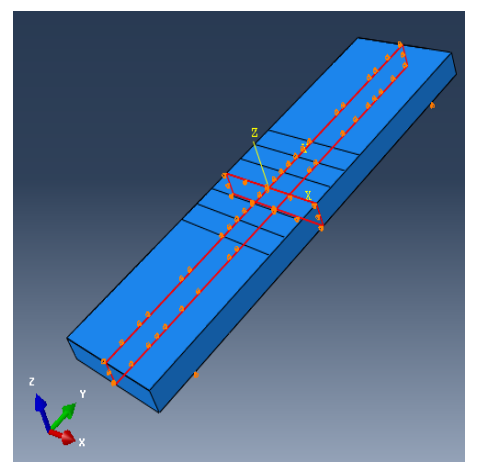

(b) Boundary conditions for partitions in the $\mathrm{x}$-direction and $\mathrm{y}$ direction

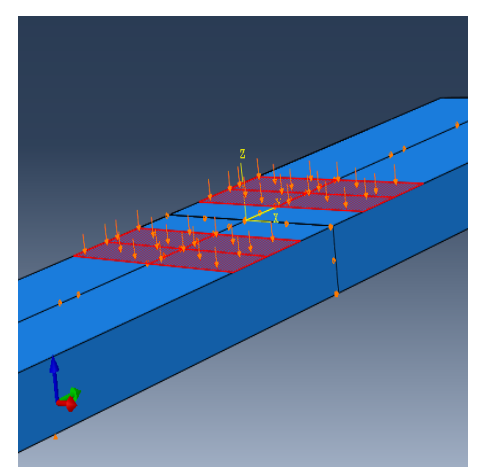

(c) Pressure load of 17 psi imposed on composite sandwich

Figure 4.7: Constraints, boundary conditions, and bending load on composite sandwich

\subsubsection{Meshing}

Creating dependent instances allowed for both the facesheet parts and the core part to be meshed separately. The facesheet parts were meshed with standard, structured quadratic shell elements with 8-nodes and reduced integration was used for the calculation of results throughout the facesheet. The core structure was modelled using standard, linear hexagonal brick elements with 8-nodes and reduced integration was used for these structures as well. All three parts were meshed with a seed size of 0.18 . This value was determined to produce the most accurate bending results for mid-span deflection from a mesh convergence analysis described in the subsection below. The meshes for the top facesheet, core, and bottom facesheet are shown in Figure 4.8a, 4.8b, and 4.8c, respectively. 


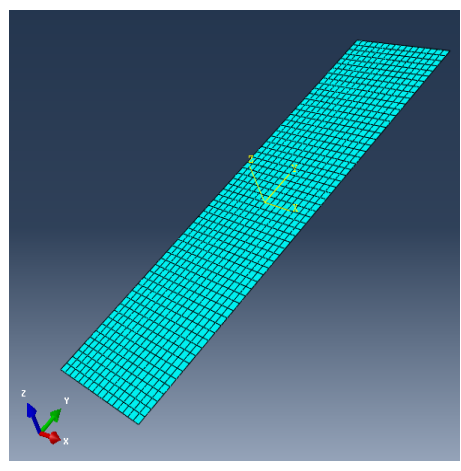

(a) Top facesheet meshed

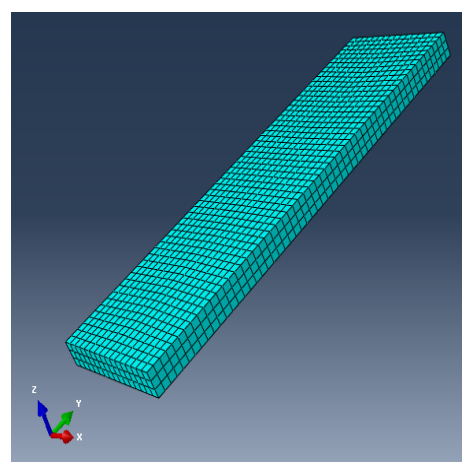

(b) Core meshed

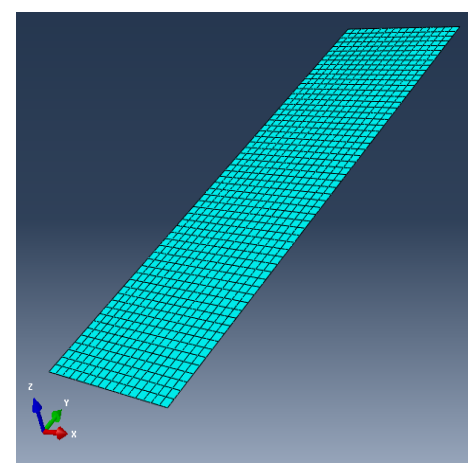

(c) Bottom facesheet meshed

Figure 4.8: Top facesheet, core, and bottom facesheet meshes

\subsection{Additions to Four-Point Bend Numerical Model to Implement Impact Loadings}

To implement a pre-bending impact load to the four-point bending numerical model, a couple additions had to be made to it. To start, an impact tup (impactor) had to be created to create the impact loading condition. From there that part had to be assembled with the rest of the model, impact testing steps had to be created, interactions between the impact tup and the sandwich had to be developed, and the boundary conditions for the impact step had to be imposed on the tup and sandwich. Also the initial velocity field for the impact tup was generated to simulate the experimental tup impacting the sandwich at a velocity of $13 \mathrm{ft} / \mathrm{sec}$. These model additions are described in the sections below.

\subsubsection{Impact Tup Part Creation, Assembly, and Steps}

The impact tup model created to simulate the impact load was a $3 \mathrm{D}$, discrete rigid shell part that was built by revolving a half circle of diameter 0.625 inches (diameter of experimental impact tup) 360 degrees. The part was discrete rigid because no analysis was necessary on the actual tup, so run times could be improved as well as numerical accuracy. The tup was then assembled with the rest of the sandwich, shown in Figure 4.9, so that it was located slightly above the top facesheet for the impact loading on the compressive 
surface and slightly above the bottom facesheet for the impact on the tensile surface. It was oriented so that it was centered above the sandwich in both the $\mathrm{x}$ - and $\mathrm{y}$-directions.

To allow two different loading conditions (with one being a dynamic loading) to run consecutively during an analysis of a single sandwich, multiple dynamic, explicit steps had to be created for each type of test. The first step (after the initial step) was the impact loading step. Since the tup was located just above the surface of the sandwich and the impact step consisted of the tup hitting the surface of the sandwich and bouncing away, the step time didn't have to be very long to capture the results of this loading condition; the time step was 0.05 for the impact step because of this. After the impact loading, there was a settling period where the oscillation from the im-

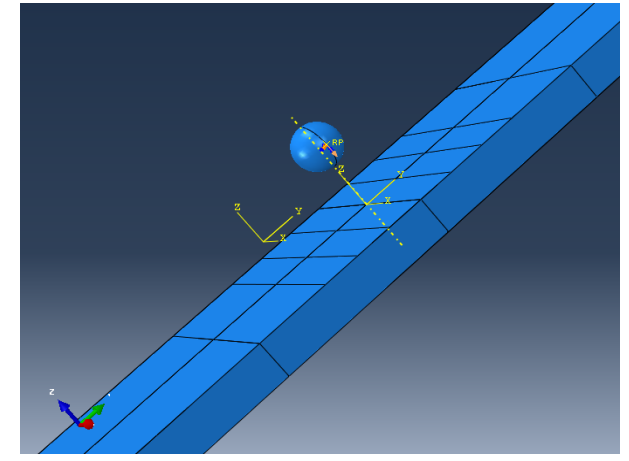

Figure 4.9: Fully assembled numerical composite sandwich model with impact tup pact loading was allowed to disperse. This step time varied from 0.001 to 2.0 to ensure full damping occurred. The bending test used a step time of 1.0 to 2.0 because a longer step time forced the pressure loading to act more like the static ramp load that was used for the non-impacted model. Since the first step was a dynamic, explicit step, the two steps following had to be dynamic, explicit as well so the static load case used for the non-impacted bending models was not possible for this model.

\subsubsection{Interactions, Loads, Boundary Conditions, and Predefined Fields}

To simulate the contact force that the impact tup made on the sandwich facesheets throughout the loading, an interaction was created between the face of the tup and the facesheet of the sandwich. The interaction was a general contact interaction and "All* with self" was chosen to describe the same interaction for every surface in the model. This interaction used and interaction property that was described as having normal behavior that created "hard" contact between the surfaces and allowed separation after the impact for the 
tup. This interaction was only applied for the impact step. To create the impact loading that would use this contact interaction, a predefined field, shown as the orange downward arrow on the impact tup part in Figure 4.9, was created on the reference point of the impact tup. This predefined field was defined in the initial step as a velocity field for the impact tup reference point with a magnitude of -156 for the impact on the compressive surface of the sandwich (-z-direction) and 156 for the tensile impact loading (+z-direction). This field gave the impact tup an initial velocity of $13 \mathrm{ft} / \mathrm{sec}(156 \mathrm{inch} / \mathrm{sec})$ which created the impact loading seen during experimental testing. To mimic the plates used to hold the experimental test specimens in place during the impact test, each part of the sandwich was partitioned with lines along the $\mathrm{x}$-axis of the sandwich that were 2.5 inches from the center of the part. This created the 5 inch area on the sandwich that was open to the impact, similar to the 5 inch opening that the aluminum clamping plates allowed in the experimental tests. The areas outside of this, as well as the edges of the sandwich model, were restrained from movement in any direction as well as rotation about the z-axis.

For the bending analysis, the same pressure load of $17 \mathrm{psi}$ was applied to the same area as the static loading case used for the non-impacted models; however, a smooth step amplitude had to be used for the dynamic bending load case to force this load to act like it was static. The smooth step described the load as having a magnitude of 0 at 0 time and 1 at the final step time which matched the total step time value. This, along with the longer step time, assisted with making the dynamic loading act like a static load. All of the analysis that was done with these models was linear for simplicity. The sandwich was restrained for the bending step with the same boundary conditions as the non-impact sandwich model was. 


\subsection{Comparison of Experimental and Numerical Mid-Span Deflection Results}

All of the modeling described above was done for each sandwich design described in this study and for each loading condition that the sandwiches were subjected to. The results of these models led to the mid-span deflection values that will be presented in this section.

The values of mid-span deflection for each numerical model matched the experimental values with an acceptable and predicted amount of error. Some sandwich models showed much more agreement with the experimental values than others. The carbon fiber/foam sandwich design that was impacted on the tensile surface of the sandwich showed a much higher error than expected, however. This is because the carbon fiber/foam didn't fail due to face fracture like all of the other carbon fiber sandwiches. The unexpected weak core shear failure gave the overall sandwich much more ductility than it was predicted to have with the numerical model which is why this experimental value is so much higher than the Table 4.1: Experimental and numerical comparison of mid-span deflections for carbon fiber facesheet sandwiches

\begin{tabular}{|c|c|c|c|c|}
\hline \multicolumn{1}{|c|}{} & $\begin{array}{c}\text { Experimental } \\
\text { Mid-span } \\
\text { Deflection (100 lbf) } \\
{[\text { [in] }}\end{array}$ & $\begin{array}{c}\text { Numerical } \\
\text { Mid-span } \\
\text { Deflection (100 lbf) } \\
{[\text { in] }}\end{array}$ & Error \\
{$[\%]$}
\end{tabular}

predicted numerical value. Since the hemp fiber sandwiches were all manufactured with different amounts of epoxy due to the "wet" layup, the ductility of these sandwiches were 
unpredictable. More epoxy content made the sandwiches more ductile, thus resulting in higher mid-span deflection values. This is why some of the hemp sandwiches saw larger disagreement between numerical and experimental values and some saw less. The low epoxy content that led to delamination failures for the aramid and glass fiber sandwiches

Table 4.2: Experimental and numerical comparison of mid-span deflections for hemp fiber facesheet sandwiches

\begin{tabular}{|c|c|c|c|c|}
\hline & & $\begin{array}{c}\text { Experimental } \\
\text { Mid-span } \\
\text { Deflection (100 lbf) } \\
\text { [in] }\end{array}$ & $\begin{array}{c}\text { Numerical } \\
\text { Mid-span } \\
\text { Deflection }(100 \mathrm{lbf}) \\
\text { [in] }\end{array}$ & $\begin{array}{c}\text { Error } \\
{[\%]}\end{array}$ \\
\hline \multirow{3}{*}{ HF/F } & $\begin{array}{c}\text { No } \\
\text { Impact }\end{array}$ & $\begin{array}{c}0.059 \\
+/-0.001\end{array}$ & 0.055 & $7.7 \%$ \\
\hline & $\begin{array}{l}\text { Impact } \\
\text { (Comp.) }\end{array}$ & $\begin{array}{c}0.066 \\
+/-0.004\end{array}$ & 0.057 & $16.9 \%$ \\
\hline & $\begin{array}{l}\text { Impact } \\
\text { (Tens.) }\end{array}$ & $\begin{array}{c}0.058 \\
+/-0.002\end{array}$ & 0.056 & $4.2 \%$ \\
\hline \multirow{3}{*}{ HF/H } & $\begin{array}{c}\text { No } \\
\text { Impact }\end{array}$ & $\begin{array}{c}0.041 \\
+/-0.002\end{array}$ & 0.035 & $17.8 \%$ \\
\hline & $\begin{array}{l}\text { Impact } \\
\text { (Comp.) }\end{array}$ & $\begin{array}{c}0.044 \\
+/-0.004\end{array}$ & 0.036 & $22.8 \%$ \\
\hline & $\begin{array}{l}\text { Impact } \\
\text { (Tens.) }\end{array}$ & $\begin{array}{c}0.038 \\
+/-0.004\end{array}$ & 0.036 & $4.2 \%$ \\
\hline
\end{tabular}

was unpredictable using this numerical model so and the error between numerical and experimental for these sandwiches changes depending on how the experimental sandwiches failed. The aramid fiber/foam sandwiches all delaminated immediately, and some delaminated during impact loading, which created a much more ductile overall structure and explains the high experimental deflections. These sandwiches were predicted to be close to the experimental values by the numerical analysis but the aramid fiber experimental material properties may have suggested a stronger material than the prepreg actual was. This is why the numerical mid-span deflections are higher than experimental for the honeycomb core sandwiches. If the aramid fiber/foam structures displayed a more accurate experimental stiffness, the errors would probably have been higher than $2 \%$ and the numerical 
Table 4.3: Experimental and numerical comparison of mid-span deflections for aramid fiber facesheet sandwiches

\begin{tabular}{|c|c|c|c|c|}
\hline & & $\begin{array}{c}\text { Experimental } \\
\text { Mid-span } \\
\text { Deflection }(100 \mathrm{lbf}) \\
\text { [in] }\end{array}$ & $\begin{array}{c}\text { Numerical } \\
\text { Mid-span } \\
\text { Deflection (100 lbf) } \\
\text { [in] }\end{array}$ & $\begin{array}{c}\text { Error } \\
{[\%]}\end{array}$ \\
\hline & $\begin{array}{c}\text { No } \\
\text { Impact }\end{array}$ & $\begin{array}{c}0.057 \\
+/-0.004\end{array}$ & 0.059 & $2.8 \%$ \\
\hline $\mathbf{A F} / \mathbf{F}$ & $\begin{array}{l}\text { Impact } \\
\text { (Comp.) }\end{array}$ & $\begin{array}{c}0.063 \\
+/-0.001\end{array}$ & 0.061 & $2.4 \%$ \\
\hline & $\begin{array}{l}\text { Impact } \\
\text { (Tens.) }\end{array}$ & $\begin{array}{c}0.068 \\
+/-0.015\end{array}$ & 0.058 & $17.7 \%$ \\
\hline & $\begin{array}{c}\text { No } \\
\text { Impact }\end{array}$ & $\begin{array}{c}0.029 \\
+/-0.001\end{array}$ & 0.038 & $24.4 \%$ \\
\hline $\mathbf{A F} / \mathbf{H}$ & $\begin{array}{l}\text { Impact } \\
\text { (Comp.) }\end{array}$ & $\begin{array}{c}0.030 \\
+/-0.004\end{array}$ & 0.041 & $27.8 \%$ \\
\hline & $\begin{array}{l}\text { Impact } \\
\text { (Tens.) }\end{array}$ & $\begin{array}{c}0.029 \\
+/-0.003\end{array}$ & 0.040 & $26.9 \%$ \\
\hline
\end{tabular}

Table 4.4: Experimental and numerical comparison of mid-span deflections for glass fiber facesheet sandwiches

\begin{tabular}{|c|c|c|c|c|}
\hline & & $\begin{array}{c}\text { Experimental } \\
\text { Mid-span } \\
\text { Deflection }(100 \mathrm{lbf}) \\
\text { [in] }\end{array}$ & $\begin{array}{c}\text { Numerical } \\
\text { Mid-span } \\
\text { Deflection (100 lbf) } \\
\text { [in] }\end{array}$ & $\begin{array}{c}\text { Error } \\
{[\%]}\end{array}$ \\
\hline \multirow{3}{*}{ GF/F } & $\begin{array}{c}\text { No } \\
\text { Impact }\end{array}$ & $\begin{array}{c}0.051 \\
+/-0.001\end{array}$ & 0.042 & $21.6 \%$ \\
\hline & $\begin{array}{l}\text { Impact } \\
\text { (Comp.) }\end{array}$ & $\begin{array}{c}0.054 \\
+/-0.001\end{array}$ & 0.043 & $25.5 \%$ \\
\hline & $\begin{array}{l}\text { Impact } \\
\text { (Tens.) }\end{array}$ & $\begin{array}{c}0.053 \\
+/-0.001\end{array}$ & 0.043 & $23.8 \%$ \\
\hline \multirow{3}{*}{ GF/H } & $\begin{array}{c}\text { No } \\
\text { Impact }\end{array}$ & $\begin{array}{c}0.024 \\
+/-0.001\end{array}$ & 0.023 & $3.9 \%$ \\
\hline & $\begin{array}{l}\text { Impact } \\
\text { (Comp.) }\end{array}$ & $\begin{array}{c}0.026 \\
+/-0.001\end{array}$ & 0.024 & $7.1 \%$ \\
\hline & $\begin{array}{l}\text { Impact } \\
\text { (Tens.) }\end{array}$ & $\begin{array}{c}0.024 \\
+/-0.001\end{array}$ & 0.023 & $5.3 \%$ \\
\hline
\end{tabular}


values would have been higher than the experimental. The glass fiber sandwiches showed a similar trend as the aramid fiber sandwiches but the experimental material properties used for the numerical model were much more accurate. The glass fiber/foam designs had much higher ductility because the delamination failure was worse for the foam core sandwiches than honeycomb. This resulted in higher errors for these sandwiches when compared to numerical. The glass fiber/honeycomb sandwiches behaved almost as expected experimental which is why these numerical values are much closer. Since the carbon fiber facesheets in the hybrid aramid and carbon fiber sandwich were the stiffest part of the sandwich, these Table 4.5: Experimental and numerical comparison of mid-span deflections for carbon and aramid fiber hybrid facesheet sandwiches

\begin{tabular}{|l|c|c|c|c|}
\hline & $\begin{array}{c}\text { Experimental } \\
\text { Mid-span } \\
\text { Deflection (100 lbf) } \\
{[\mathrm{in}]}\end{array}$ & $\begin{array}{c}\text { Numerical } \\
\text { Mid-span } \\
\text { Deflection (100 lbf) } \\
{[\mathrm{in}]}\end{array}$ & $\begin{array}{c}\text { Error } \\
{[\%]}\end{array}$ \\
\hline $\mathbf{C F}(\mathbf{1})$ & $\begin{array}{c}\text { No } \\
\text { Impact }\end{array}$ & $\begin{array}{c}0.020 \\
+/-0.002\end{array}$ & 0.018 & $12.7 \%$ \\
\cline { 2 - 5 }$/ \mathbf{H}$ & $\begin{array}{c}\text { Impact } \\
\text { (Comp.) }\end{array}$ & $\begin{array}{c}0.021 \\
+/-0.001\end{array}$ & 0.019 & $9.3 \%$ \\
\hline $\mathbf{C F}(\mathbf{2})$ & $\begin{array}{c}\text { No } \\
\text { Impact }\end{array}$ & $\begin{array}{c}0.017 \\
+/-0.001\end{array}$ & 0.015 & $12.9 \%$ \\
\cline { 2 - 5 }$/ \mathbf{H}$ & $\begin{array}{c}\text { Impact } \\
(\text { Comp. })\end{array}$ & $\begin{array}{c}0.018 \\
+/-0.001\end{array}$ & 0.016 & $11.6 \%$ \\
\hline
\end{tabular}

layers of the facesheet defined the stiffness of the sandwich. Because of this, the errors between experimental and numerical values for these sandwiches were similar to the carbon fiber/honeycomb sandwiches. The aramid fiber layers of the sandwich followed what the carbon fiber layers did and only delaminated from the carbon fiber when those facesheets fractured at failure.

Overall, there was good agreement between experimental and numerical mid-span deflection values, which allows for a good prediction of experimental behavior for these sandwiches. Focus on the limitation of delamination failures for experimental sandwiches and 
improved material quality and material characteristics, however, is necessary for more accurate comparisons with numerical models. 


\section{Chapter 5 \\ DISCUSSION OF RESULTS}

Composite sandwich structures have significantly increased bending strength-to-weight and stiffness-to-weight characteristics over metal and composite laminate structures; however, they have been disregarded in many areas of aircraft design due to the poor impact resistance characteristics that they display. This study has shown that the impact loads on these structures can cause localized damages that propagate easily when the structures are subjected to bending loads, causing severely low post-impact ultimate flexural strengths in some cases. The behavior of each core and facesheet material combination used for the design of the sandwiches in this study varied under these loading conditions. These behaviors led to the derived general conclusions about each sandwich design, which are described below.

- Carbon fiber sandwich designs outperformed all other sandwiches under bending loads

- Honeycomb Core: the flexural strengths were the highest of any sandwich but when impacted on the compressive facesheet, post impact strengths were much lower

- Foam Core: ultimate flexural strengths were lower but load degradation percentages were much better despite a weak batch of foam that hindered the flexural strengths when impacted on the tensile surface 
- Application:Great for structures that need high flexural strength-to-weight and stiffness-to-weight

* If impact loads are prevalent and high flexural strength isn't crucial, foam cores should be used to improve post impact flexural strengths because impact loads can cause severe degradations in load carrying ability with carbon fiber facesheet sandwiches

- Hemp fiber sandwiches were damaged the most by impact loadings but were still able to produce the highest post-impact load degradation percentages

- Maximum load was less than half of the maximum load for carbon fiber facesheet sandwiches

- Application:Areas where very high ultimate flexural strengths aren't necessary, high ductility is necessary, and small impacts may be customary

* If flexural strengths cannot be compromised from impact damage, this sandwich design will be the most optimal and with generally lower costs and better recyclability

- Aramid fiber sandwich designs suffered from low epoxy content in this study which led to extremely low ultimate flexural strength for both non-impacted and postimpact sandwiches

- These sandwiches were able to resist impact damage better than any other sandwich but the lack of penetration of the impact tup through the facesheets, along with low epoxy content, created delaminations in the sandwich that propagated when subjected to bending loads

- Application:With improved material quality and increased attention to delamination resistance, these structures may be the best combination of ultimate 
flexural strength, post-impact load degradation, and impact resistance so use in high impact loading areas would be beneficial

- Glass fiber sandwich designs showed similar results to the aramid fiber sandwiches with high impact resistance but low flexural strengths due to minor delamination issues from low epoxy content

- Impact resistance was not as good as the aramid fiber sandwiches but postimpact load degradation was very high because the impact damage was more localized

- Application:With a little more emphasis on delamination resistance, these sandwiches may be the preferred option for structures that require good impact resistance and flexural strength

- Hybrid aramid and carbon fiber sandwiches improved the impact resistance characteristics over carbon fiber sandwiches which improved the post-impact load degradation percentages as well

- The ultimate bending loads were lower than the impacted carbon fiber sandwiches though so these sandwiches would need at least a fourth layer on them to make them legitimate alternatives for the carbon fiber sandwiches

- Application:Areas where high ultimate bending strength is necessary and impact damage needs to be minimized (increase number of layers for more optimal performance)

- Foam core sandwiches, overall, showed better impact resistance and post-impact load degradation characteristics but at lower ultimate flexural strengths

- Core fails due to core shear which is a catastrophic failure so extreme caution needs to be taken when considering these cores for major structures 
- Application:Structures that require decent impact resistance but not high flexural strengths

- Honeycomb cores displayed high flexural strengths but post-impact strengths were an issue with some of the facesheets

- Application:Structures that require high flexural strengths

- Numerical mid-span deflections agreed with experimental but improved material characteristics and more focus on controlling experimental failure is necessary for better agreement

When a composite sandwich is constructed using the optimal combination of materials, structures can see improved flexural characteristics with minimal weight penalties. The impact resistance of sandwich designs is still an issue but this study has shed light on the benefits and areas of improvement for these structures, which will hopefully act as an aid for structural designers in their material selection processes. The composite sandwich has many applications in the aerospace industry and continued research and development of these structures, and their impact resistance characteristics, will lead to an increased use of them throughout the airframe of aircraft. 


\section{Chapter 6 \\ CONCLUSION}

As a designer, knowing the correct material to use for a certain design is crucial for the success of that structure. For a designer looking to have high strength-to-weight and stiffnessto-weight structures, carbon fiber/honeycomb sandwiches are the best option. For high ductility but lower flexural strength, hemp fiber structures are the best. A structure that requires higher impact resistance and average flexural strength, aramid and glass fiber sandwiches are the optimal materials. In general, foam core sandwiches have better post-impact flexural strength degredation characteristics than honeycomb core sandwiches but at lower ultimate strengths. In terms of theoretical and numerical predictions, material characteristics for each material must be improved over the findings in this study to produce more accurate comparisons with experimental results. Overall, the findings in this study can improve the design consideration processes for structures subjected to both impact and bending loads by analyzing the experimental conclusions.

\subsection{Future Considerations}

In an experimental study, error found between theoretical predictions and experimental results suggests a need for improvement with the study. In the case of this study, these experiments and the errors that resulted are a basis for future analysis to be done. The improvement of composite sandwiches is an ongoing study that takes past research and builds on it. To build on this study, the following improvements and studies could be done. 
- More precise machinery can be used to improve layup techniques, which would result in better material properties values for theoretical and numerical analysis and more predictable flexural failure modes

- More research can be done into the use of the hybrid sandwich design to improve resistance characteristics of carbon fiber sandwiches

- There are many structures that could benefit from the use of hemp fiber sandwich structures so research into better layup techniques and stronger fiber weaves can be done to improve the performance of these sandwiches

- The understanding of impact loading effects on sandwich structures subjected to vibrational, buckling, fatigue, and other loadings is just as crucial as bending loads so research into these loading conditions would be beneficial for the improvement of sandwich structures as well

- A study that focuses on the minimization of delamination issues that come from high impact resistant facesheet materials being subjected to impact loads may greatly increase the legitimacy of using aramid and glass fiber sandwich structures 


\section{BIBLIOGRAPHY}

[1] Introduction to Composites. URL: http: / / nptel .ac. in/courses/101104010/ lecture1/1_3.htm.

[2] Autar Kaw. Mechanics of Composite Materials. Taylor Francis Group, 2006.

[3] "Putting It Together - Science and Technology of Composite Materials". In: NOVA: Science in the News (Nov. 2000).

[4] Introduction. Net Composites. URL: http: / / www . netcomposites.com/guide/ introduction/1.

[5] Thermoset vs. Thermoplastics. Modor Plastics. 2014. URL: http: //www. modorplastics . com/thermoset-vs-thermoplastics.

[6] Thermoset vs. Thermoplastic Materials. RL Hudson. 2011. URL: http : / / www . rlhudson.com/publications/techfiles/thermo.htm.

[7] Reinforcement Types. Smithers Rapra. 2014. URL: http : / / www . rapra . net / composites/material-selection/reinforcement-types.asp.

[8] Particulate Reinforced Composites. Enlighten. 2014. URL: http: / / altairenlighten. com/2011/12/thermoplastics/.

[9] Bimetal Technology. Delta Concept. URL: http://www.delta-concept.fr/en/ bimetal-technology/.

[10] P.C. Pandey. Composite Materials. URL: http://nptel.iitk.ac.in/courses/ Webcourse - contents / IISc-BANG / Composite \\%20Materials / Learning \ $\div 20$ material \\%20- \\%20composite $\div 20$ material.pdf. 
[11] Fabrication Methods. Composites World. January 1st, 2014. URL: http: / / www . compositesworld.com/articles/fabrication-methods.

[12] “Architectural Cladding Panel Fiber-X Aluminum Honeycomb Panel”. In: Talford (31 Jan. 2014).

[13] DIAB Guide to Core and Sandwich. DIAB. December 2012.

[14] URL: http: / / www . hexcel . com/Resources / DataSheets / Brochure-DataSheets/Honeycomb_Sandwich_Design_Technology.pdf.

[15] HexWeb Honeycomb Sandwich Design Technology. Hexcel. URL: http://altairenlighten. com/2012/07/sandwich-structures/.

[16] Hexcel Honeycomb Sandwich Bending Advantage Reference. Hexcel.

[17] Lawrence J. Broutman. Impact Strength and Toughness of Fiber Compsosite Materials. Illinois Institute of Technology. November 1972. URL: http://www . dtic . $\mathrm{mil} / \mathrm{dtic} / \mathrm{tr} /$ fulltext/u2/753101.pdf.

[18] Joris Leijten. "Experimental study of the low-velocity impact behavior of primary sandwich structures in aircraft". In: Science Direct ().

[19] Patrick M Schubel. "Impact and post impact behavior of composite sandwich panels". In: Science Direct ().

[20] Alan T Nettles. "Compression after impact testing of sandwich structures using a four point bend test”. In: Science Direct ().

[21] Michael Klaus. "Numerical investigation of different strength after impact test procedures". In: Science Direct ().

[22] Wilfried Gottner. "Bending strength of sandwich panels with different cores after impact". In: Science Direct ().

[23] M Klaus. "Residual strength simulations of sandwich panels after impact". In: Science Direct (). 
[24] Jilin Yu. "Static and low-velocity impact behavior of sandwich beams with closedcell aluminum-foam core in three-point bending”. In: Science Direct ().

[25] Dave P. What is Texalium? Carbon Fiber Gear. March 18, 2009. URL: http: / / www . carbonfibergear.com/colored-carbon-fiber-is-usually-texalium-butwhat-is-texalium/.

[26] Hexcel HRP US Units PDF. Hexcel.

[27] 3M Structural Adhesive PDF. 3M.

[28] Hexcel 8552 (Highlighted). Hexcel.

[29] Aeropoxy Cure Cycle (Hemp). Aeropoxy.

[30] D3410: Standard Test Method for Compressive Properties of Polymer Matrix Composite Materials with Unsupported Gage Section by Shear Loading. ASTM.

[31] D3039: Standard Test Method for Tensile Properties of Polymer Matrix Composite Materials. ASTM.

[32] E132: Standard Test Method for Poisson's Ratio at Room Temperature. ASTM.

[33] D7136: Impact. ASTM.

[34] Leong Keey Seah Choon Chiang Foo Gin Boay Chai. "Mechanical properties of Nomex material and Nomex honeycomb structure”. In: Science Direct ().

[35] D2584: Standard Test Method for Ignition Loss of Cured Reinforced Resins. ASTM.

[36] D7250: Standard Practice for Determining Sandwich Beam Flexural and Shear Stiffness. ASTM.

[37] Chang Sup Lee Tae Seong Lim and Dai Gil Lee. "Failure Modes of Foam Core Sandwich Beams under Static and Impact Loads". In: Journal of Composite Materials (Aug 27, 2004). 


\section{APPENDIX}

\section{A.1 Impact Testing Figures}

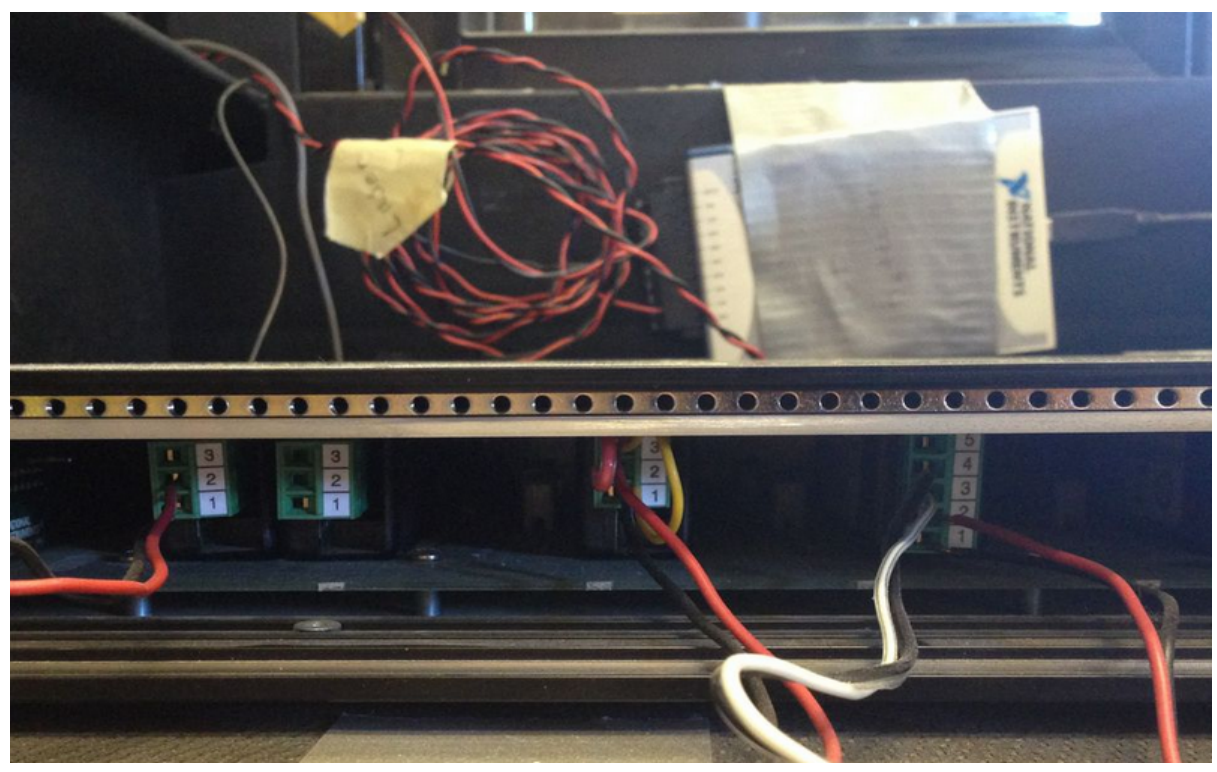

Figure A.1: Signal conditioner wiring for laser module (left), accelerometer module (center), and load cell module (right) 


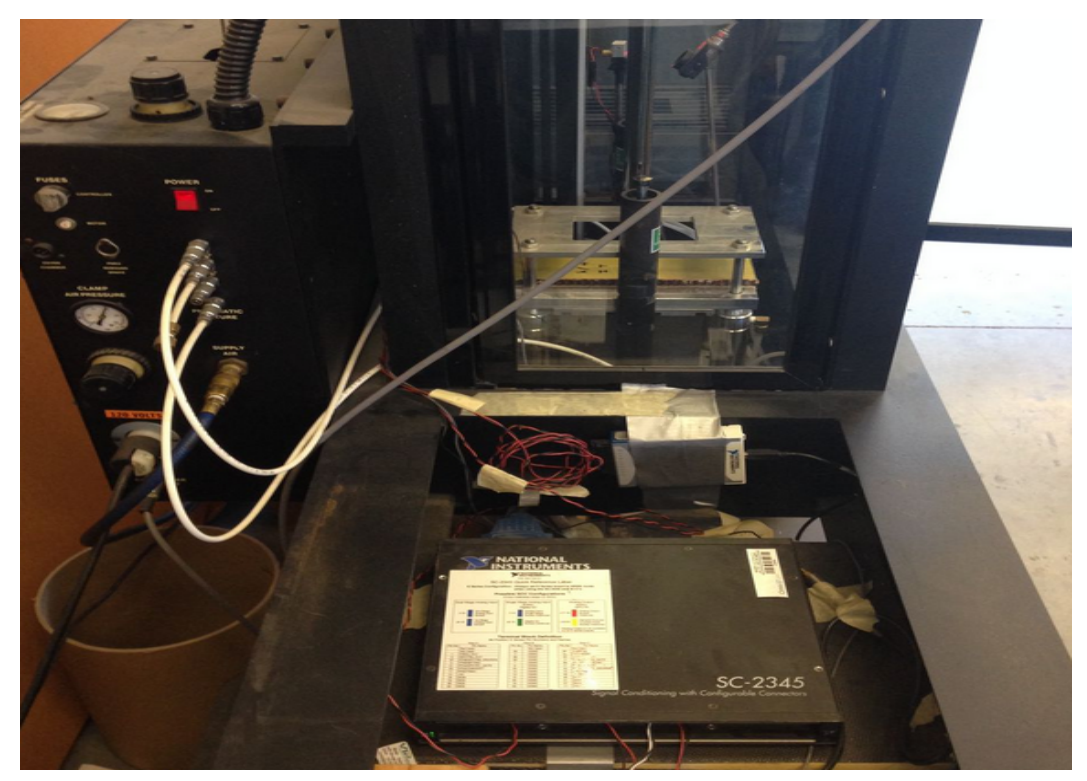

Figure A.2: Impact machine setup with signal conditioning box (bottom), power and control box (left), and testing area (center)

\section{A.2 Four-Point Bending}

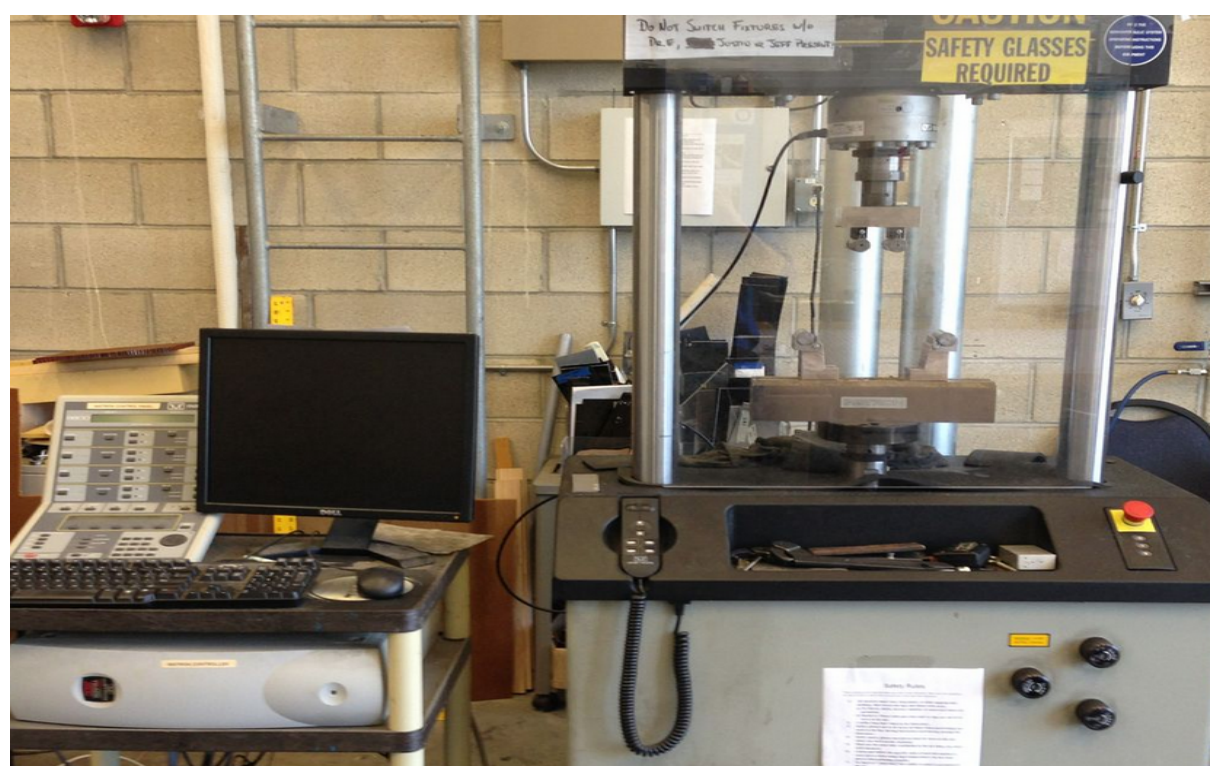

Figure A.3: Four-point bending test setup with control panel (left), computer control (center), and testing machine and fixtures (right) 


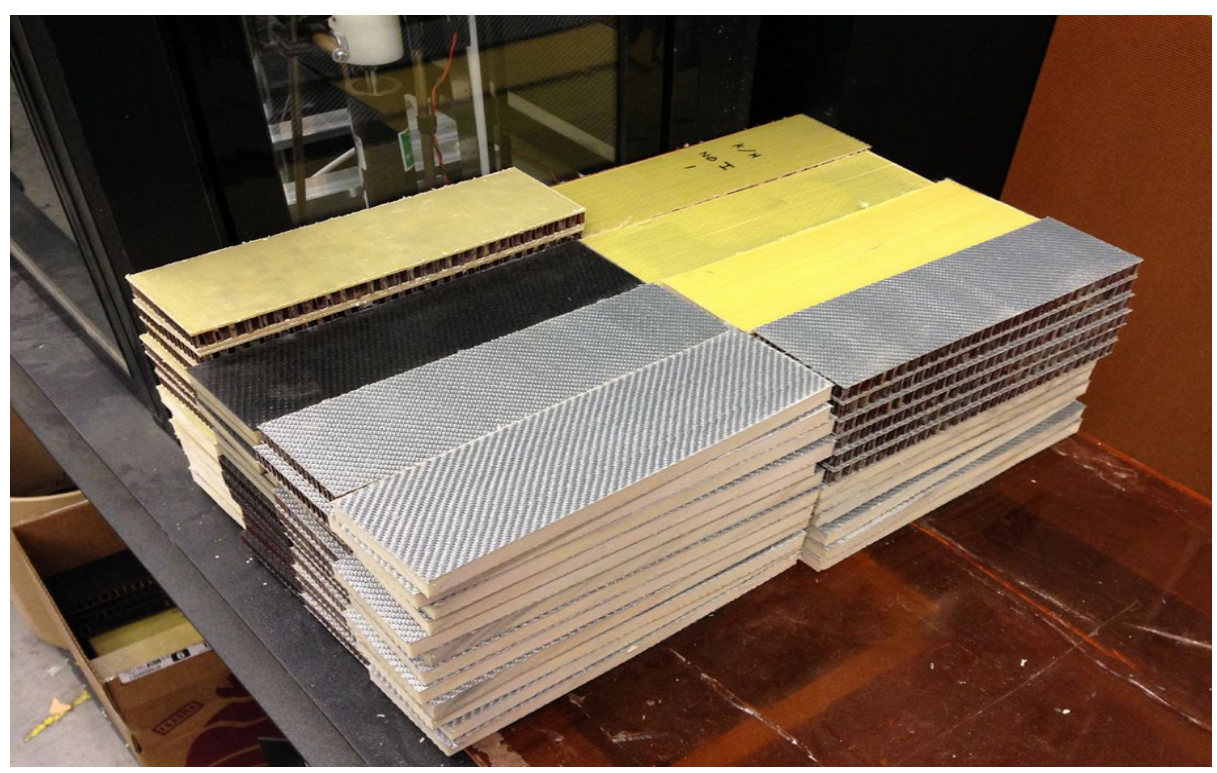

Figure A.4: Stack of composite sandwich test specimens before testing

\section{A.3 Hybrid Sandwich Experimental Results Plots}

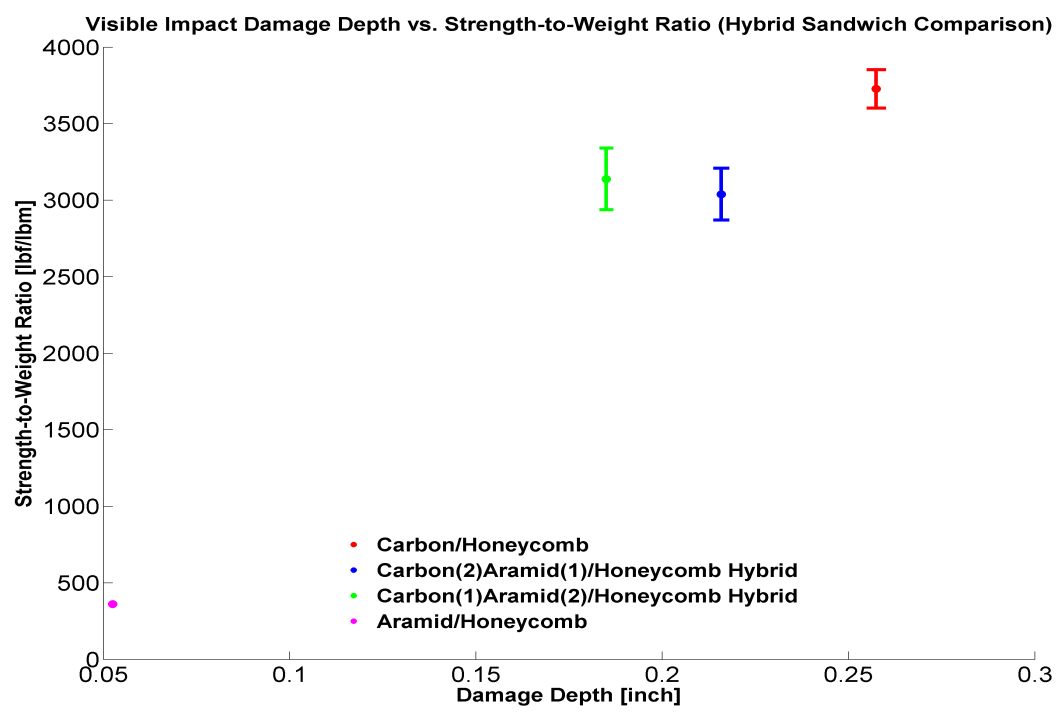

Figure A.5: Hybrid carbon and aramid fiber sandwich impact damage size vs. flexural strength-to-weight 




Figure A.6: Hybrid carbon and aramid fiber sandwich post impact flexural strength reduction percentage vs. flexural strength-to-weight

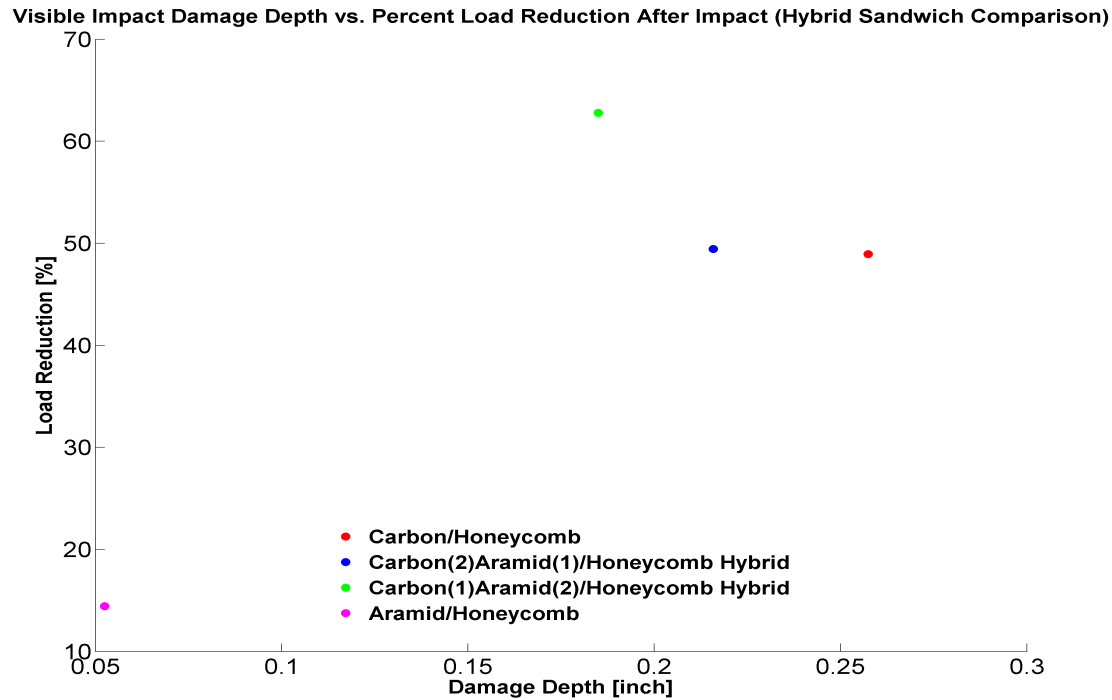

Figure A.7: Hybrid carbon and aramid fiber sandwich impact damage size vs. post impact flexural strength reduction percentage 


\section{A.4 Failure Mode Plots using Experimental Honeycomb Material Properties}

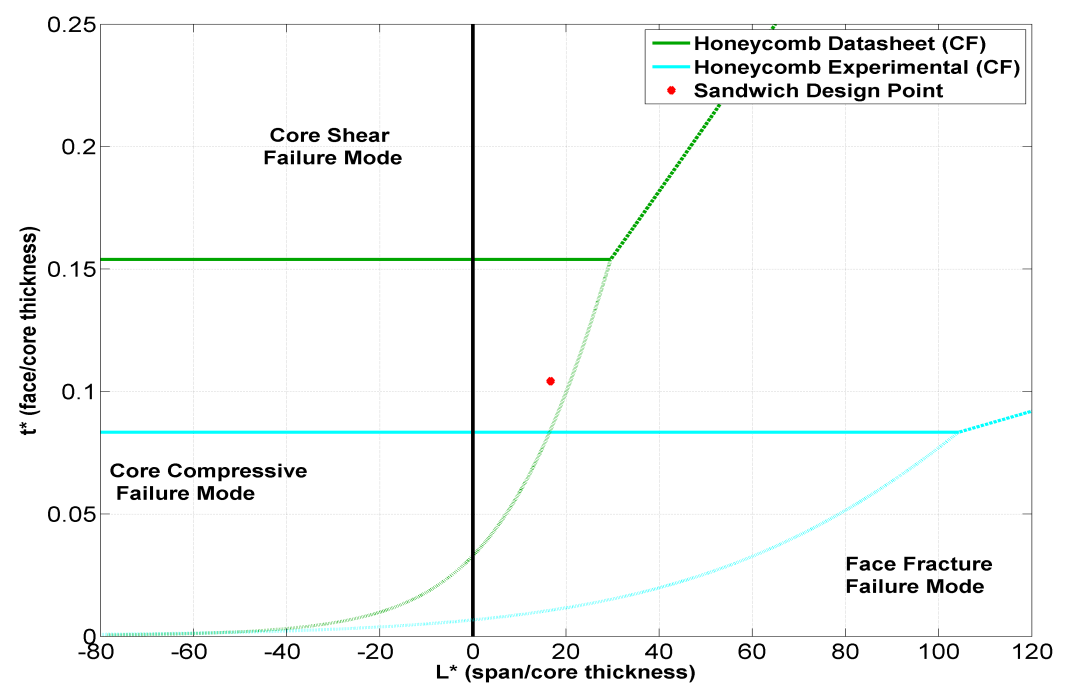

Figure A.8: Carbon fiber/honeycomb sandwich failure mode plots with datasheet and experimental honeycomb material properties

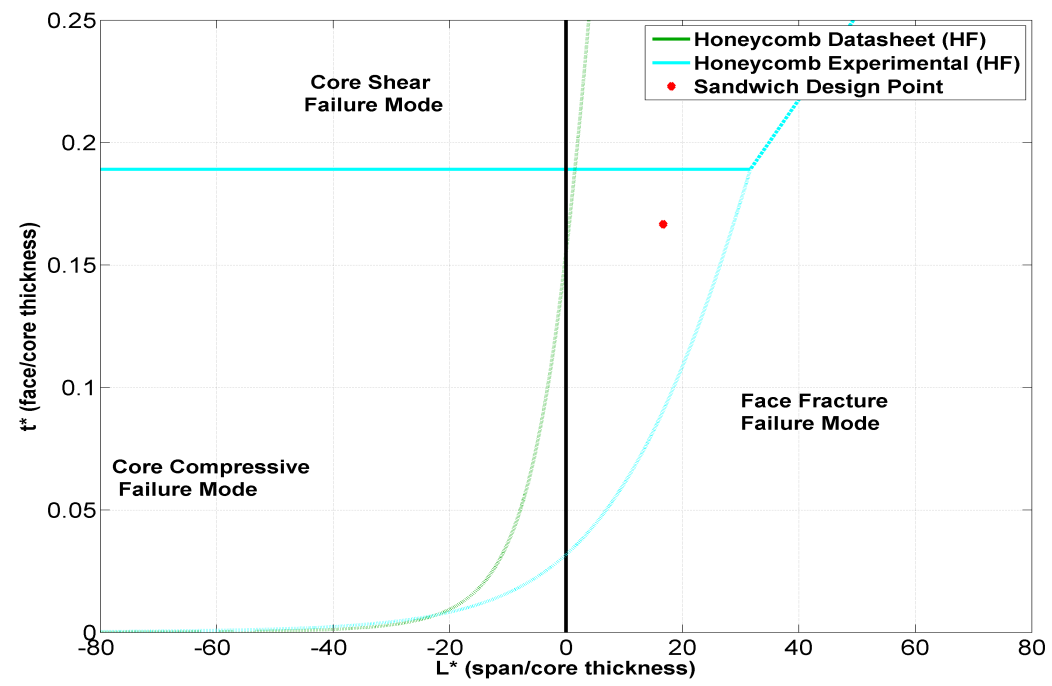

Figure A.9: Hemp fiber/honeycomb sandwich failure mode plots with datasheet and experimental honeycomb material properties 


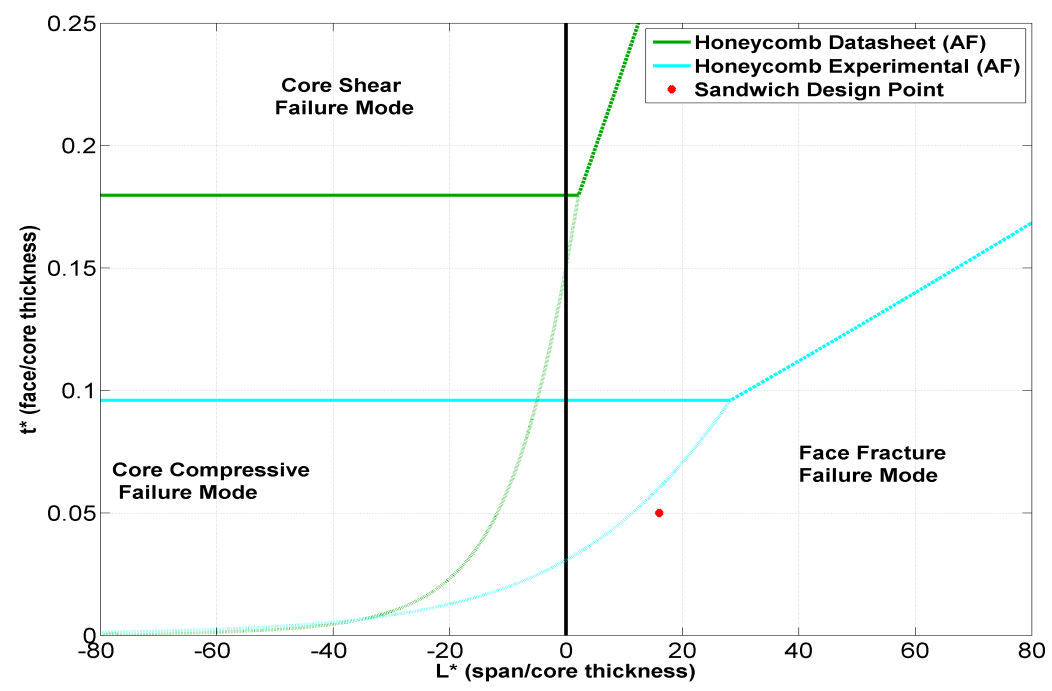

Figure A.10: Aramid fiber/honeycomb sandwich failure mode plots with datasheet and experimental honeycomb material properties

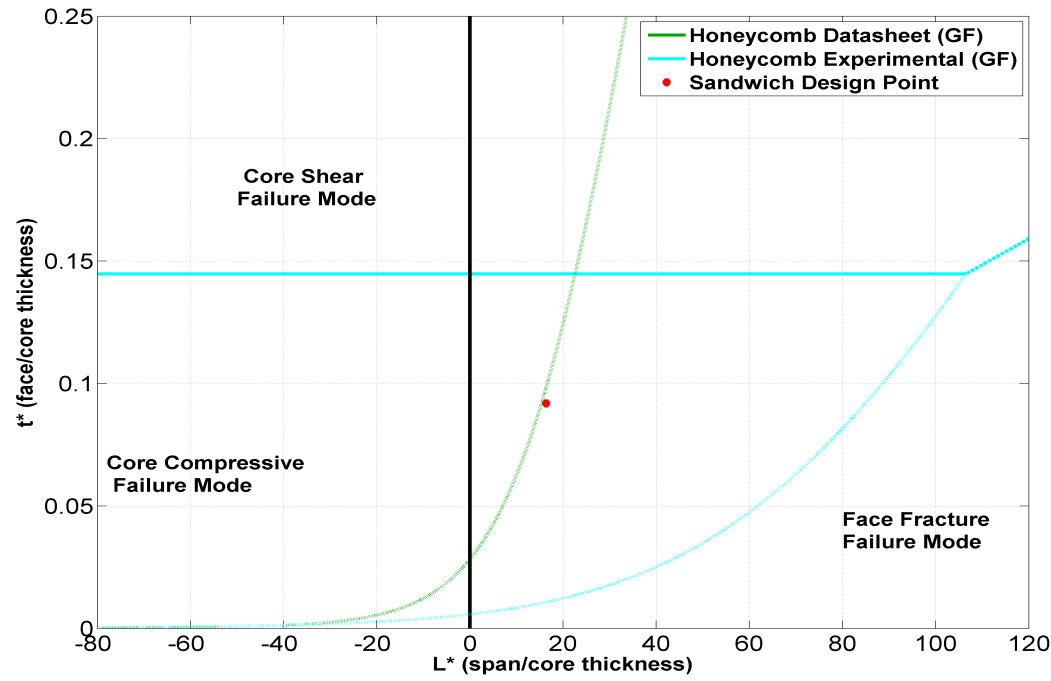

Figure A.11: Glass fiber/honeycomb sandwich failure mode plots with datasheet and experimental honeycomb material properties 


\section{A.5 Numerical Model Mesh Convergence Plot}

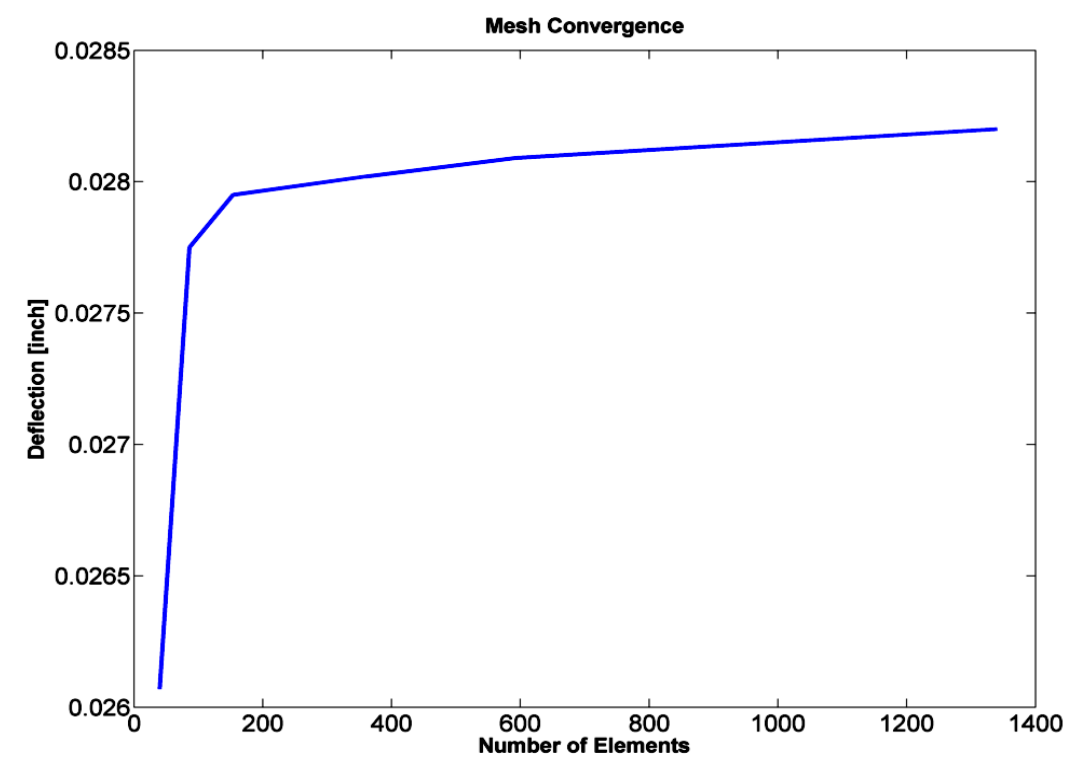

Figure A.12: Mesh convergence plot

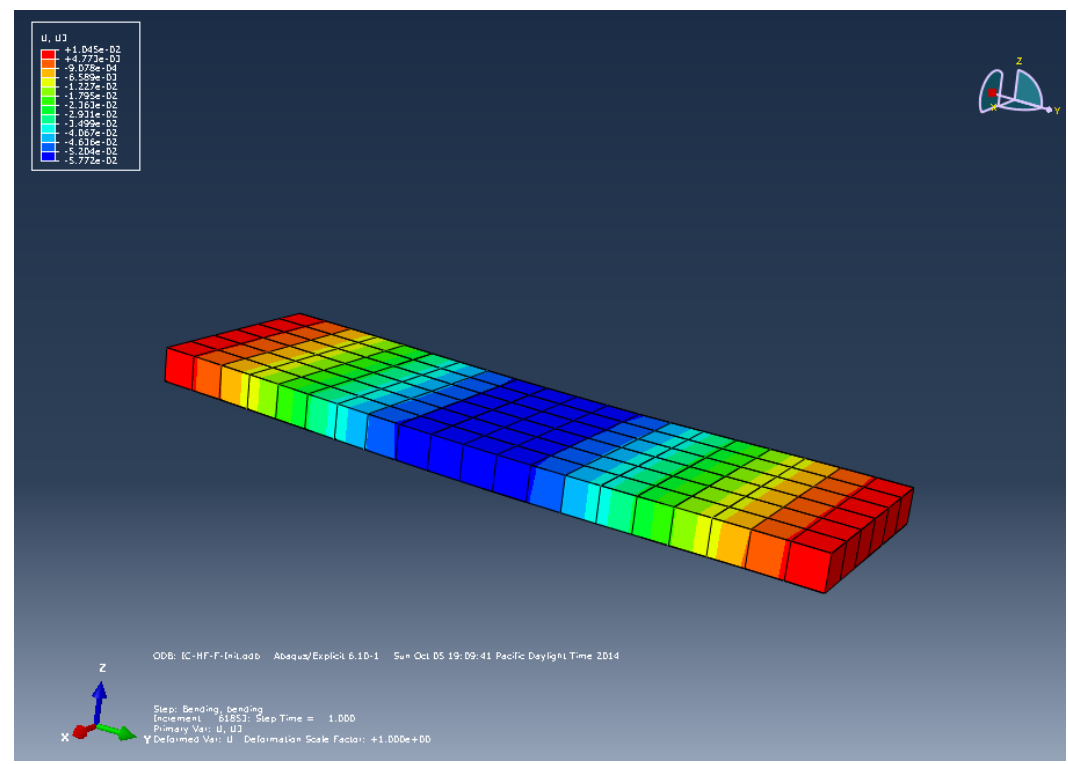

Figure A.13: Numerical results for deflection in the z-axis 